Coastal and Marine Hazards and Resources Program and Ecosystems Mission Area

Prepared in cooperation with the U.S. Fish and Wildlife Service

\title{
Impacts of Sediment Removal from and Placement in Coastal Barrier Island Systems
}

Open-File Report 2021-1062 



\section{Impacts of Sediment Removal from and Placement in Coastal Barrier Island Systems}

By Jennifer L. Miselis, James G. Flocks, Sara Zeigler, Davina Passeri, David R. Smith, Jill Bourque, Christopher R. Sherwood, Christopher G. Smith, Daniel J. Ciarletta, Kathryn Smith, Kristen Hart, David Kazyak, Alicia Berlin, Bianca Prohaska, Teresa Calleson, and Kristi Yanchis

Coastal and Marine Hazards and Resources Program and Ecosystems Mission Area

Prepared in cooperation with the U.S. Fish and Wildlife Service

Open-File Report 2021-1062 


\section{U.S. Geological Survey, Reston, Virginia: 2021}

For more information on the USGS - the Federal source for science about the Earth, its natural and living resources, natural hazards, and the environment—visit https://www.usgs.gov or call 1-888-ASK-USGS.

For an overview of USGS information products, including maps, imagery, and publications, visit https://store.usgs.gov/.

Any use of trade, firm, or product names is for descriptive purposes only and does not imply endorsement by the U.S. Government.

Although this information product, for the most part, is in the public domain, it also may contain copyrighted materials as noted in the text. Permission to reproduce copyrighted items must be secured from the copyright owner.

Suggested citation:

Miselis, J.L., Flocks, J.G., Zeigler, S., Passeri, D., Smith, D.R., Bourque, J., Sherwood, C.R., Smith, C.G., Ciarletta, D.J., Smith, K., Hart, K., Kazyak, D., Berlin, A., Prohaska, B., Calleson, T., and Yanchis, K., 2021, Impacts of sediment removal from and placement in coastal barrier island systems: U.S. Geological Survey Open-File Report 2021-1062, 94 p., https://doi.org/10.3133/ofr20211062.

ISSN 2331-1258 (online) 


\section{Acknowledgments}

This project was funded through U.S. Fish and Wildlife Service Agreement M0 4500144447. The authors would like to acknowledge Nathaniel Plant, E. Robert Thieler, and Lianne Ball for their leadership and contributions to this effort. Peer reviews greatly improved the quality of the manuscript.

Support to produce this report was provided by Betsy Boynton, Heather Schreppel, Breanna Williams, Noreen Buster, and Joe Carroll. 



\section{Contents}

Acknowledgments .......................................................................................................................ii

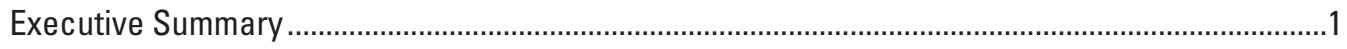

Physical Impacts of Sediment Removal and Placement on Coastal Sediment Supplies .........2

Impacts of Sediment Removal and Placement on Benthic Habitats and Their

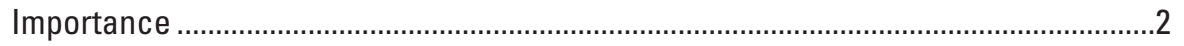

Impacts of Sediment Removal and Placement on Fish and Other Marine Species ...................

Impacts of Sediment Removal and Placement on Subaerial Beach Habitats ...........................4

Impacts of Sediment Removal and Placement on Coastal Resiliency .....................................5

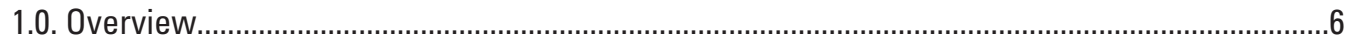

2.0. Introduction to Barrier Island Sediment Dynamics ...........................................................6

3.0. Physical Impacts of Sediment Removal and Placement on Coastal Sediment Supplies ...........8

3.1. Impacts of Sediment Removal on Barrier Islands .........................................................

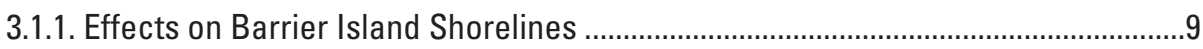

Shoreline Changes from Sediment Removal from Inlet-Associated Shoals ...........9

Shoreline Changes from Shoreface Sediment Removal...........................................11

Shoreline Changes from Inner Continental Shelf Sediment Removal ......................11

3.1.2. Effects on Barrier Island Sediment Supply ……….............................................12

Effects of Sediment Removal from Within the Active Barrier Island System.........12

Effects of Sediment Removal from Outside the Active Barrier System...................13

Remote Sources or Upland Sources .......................................................................

3.2. Impacts of Sediment Placement on Barrier Islands ....................................................14

3.2.1. Sediment Placement Effects During Construction.................................................14

3.2.2. Placement Effects on Barrier Island Morphology.................................................14

Shoreface Nourishment ..................................................................................14

Beach Nourishment-Beach Profile and Planform Effects and Sedimentological Changes ...........................................................................15

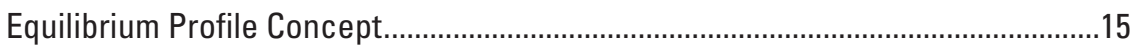

Beach Profile Changes Resulting from Beach Nourishment ...................................16

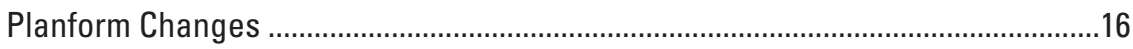

Changes in Beach Sediment Size, Composition, and Texture...................................17

Dune Construction and Nourishment...................................................................18

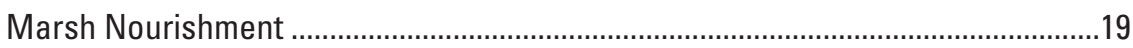

Nourishment of Estuarine Beaches.................................................................19

3.2.3. Effects Beyond the Placement Area ……………................................................19

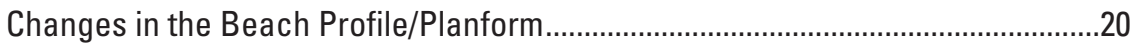

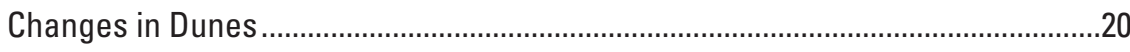

Changes in Marsh and Other Back-Barrier Environments ......................................21

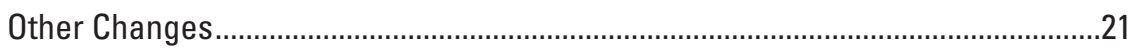

3.3. Other Impacts, Opportunities for Further Research, and Recommendations ..................22

3.3.1. Other Physical Processes for Consideration ..........................................................22

Biogeochemical Effects Resulting from Sediment Removal and Placement.........22

3.3.2. Opportunities for Future Research ................................................................22

3.3.3. Recommendations for Impact Monitoring and Evaluation .....................................23

4.0. Impacts to Benthic Habitats and Their Importance..............................................................23 
4.1. Physical Changes Resulting from Sediment Removal .....................................................24

4.1.1. Surficial Seabed Changes Resulting from Sediment Removal .............................24

4.1.2. Potential Effects to Sediment and Porewater Biogeochemical Framework .........25

4.1.3. Water Column Changes from Sediment Removal ...................................................26

4.2. Benthic Community Changes Resulting from Sediment Removal ....................................26

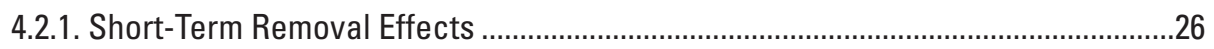

4.2.2. Long-Term Removal Effects ..............................................................................27

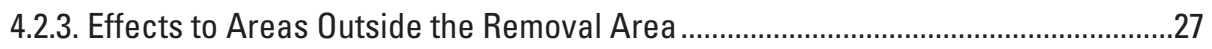

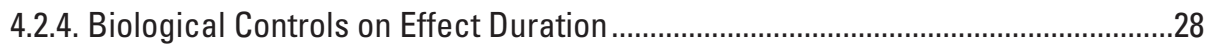

4.3. Benthic Community Changes Resulting from Sediment Placement .................................28

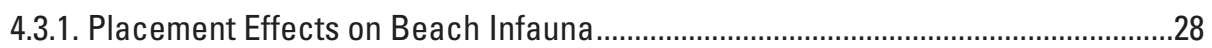

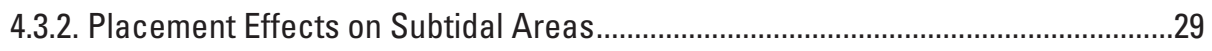

4.3.3. Placement Effects on Coastal Marsh Benthic Ecosystems .................................30

4.3.4. Placement Effects on Adjacent Habitats ...........................................................30

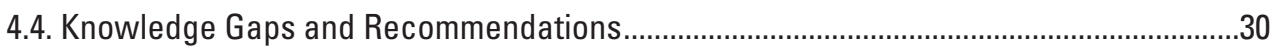

4.5. Another Consideration ..............................................................................................

5.0. Impacts of Sediment Removal and Placement on Fish and Other Marine Species..................31

5.1. Impacts Due to Entrainment and Entanglement...........................................................33

5.2. Impacts Related to Suspended, Settled, and Contaminated Sediments...........................34

5.2.1. Behavioral Changes Caused by Suspended Sediment ..............................................34

5.2.2. Physiological Effects of Suspended Sediment ........................................................

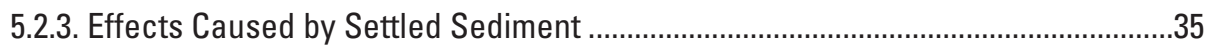

5.2.4. Effects Caused by Contaminated Sediment ........................................................35

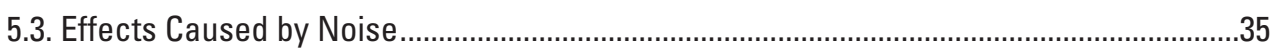

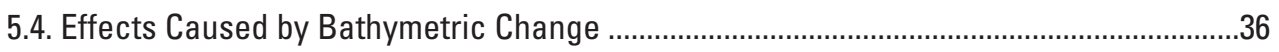

5.5. Effects Caused by Sediment Placement on Estuarine Beaches .......................................37

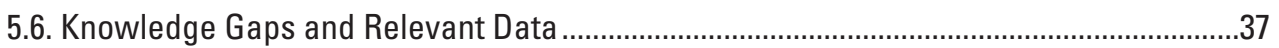

6.0. Impacts of Sediment Removal and Placement on Subaerial Beach Habitats ..........................38

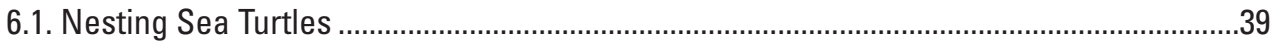

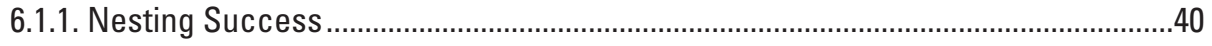

6.1.2. Hatching Success............................................................................................... 41

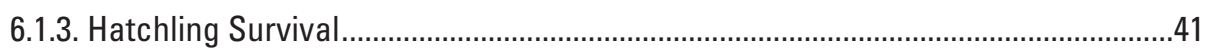

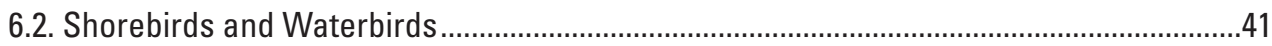

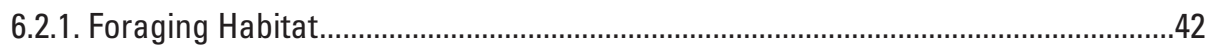

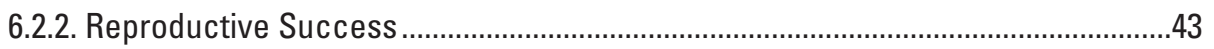

6.3. Impacts on Other Taxa, Opportunities for Further Research, and Recommendations ....44



6.3.2. Opportunities for Further Research, Impact Monitoring, and Evaluation ...............45

7.0. Impacts of Sediment Removal and Placement on Coastal Resiliency .....................................45

7.1. Impacts of Sediment Placement and Removal on Short-Term Coastal Resilience ..........46

7.1.1. Sediment Placement and Short-Term Resiliency................................................46

7.1.2. Sediment Removal and Short-Term Resiliency....................................................47

7.2. Impacts of Sediment Placement and Removal on Long-Term Coastal Resiliency ...........47

7.2.1. Sediment Placement and Long-Term Resiliency.................................................47

7.2.2. Sediment Removal and Long-Term Resiliency....................................................48 
7.3. Impacts of Sediment Removal and Placement on Coastal-Ecosystem Connectivity.......49

7.3.1. Coastal Ecosystem Resiliency

7.3.2. Short- and Long-Term Effects of Sediment Placement and Removal on Ecosystem Resilience.........................................................................................50

7.4. Knowledge Gaps and Recommendations.....................................................................51

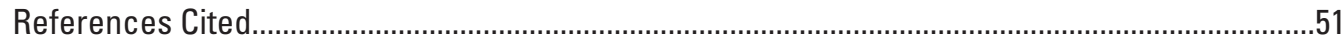

Appendix 1. Sediment Management Impact Monitoring Data and Availability............................90

\section{Figures}

1. Map and cross section showing barrier island geomorphic environments.....................7

2. Map showing inlet geomorphic environments with sediment transport pathways..........8

3. Map showing bathymetry offshore of Fire Island, New York, showing a series of shoreface-attached sand ridges and the locations of several borrow areas..................11

4. Diagrams showing geologic features on the shelf that may serve as sources of

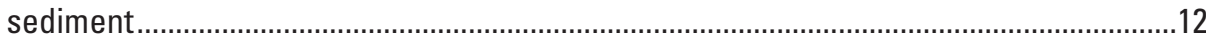

5. Cross sections showing changes in beach profile after nourishment............................16

6. Graph and diagram showing changes after beach nourishment......................................17

7. Diagram showing a conceptual model linking sediment dredging processes, ecological factors, and individual-, population-, and species-level responses

\section{Conversion Factors}

International System of Units to U.S. customary units

\begin{tabular}{lcl}
\hline \multicolumn{1}{c}{ Multiply } & By & \multicolumn{1}{c}{ To obtain } \\
\hline centimeter $(\mathrm{cm})$ & Length & \\
meter $(\mathrm{m})$ & 0.3937 & inch (in.) \\
kilometer $(\mathrm{km})$ & 3.281 & foot $(\mathrm{ft})$ \\
kilometer $(\mathrm{km})$ & 0.6214 & mile (mi) \\
meter $(\mathrm{m})$ & 0.5400 & mile, nautical (nmi) \\
\hline & 1.094 & yard (yd) \\
\hline cubic meter $\left(\mathrm{m}^{3}\right)$ & Area & \\
cubic meter $\left(\mathrm{m}^{3}\right)$ & 6.290 & barrel (petroleum, 1 barrel = 42 gal) \\
cubic meter $\left(\mathrm{m}^{3}\right)$ & 264.2 & gallon (gal) \\
cubic meter $\left(\mathrm{m}^{3}\right)$ & 0.0002642 & million gallons $(\mathrm{Mgal})$ \\
cubic meter $\left(\mathrm{m}^{3}\right)$ & 35.31 & cubic foot $\left(\mathrm{ft}^{3}\right)$ \\
cubic meter $\left(\mathrm{m}^{3}\right)$ & 1.308 & cubic yard $\left(\mathrm{yd}^{3}\right)$ \\
\hline
\end{tabular}




\title{
Datum
}

Vertical coordinate information is referenced to the North American Vertical Datum of 1988 (NAVD 88).

Tolerance for sedimentation is given in milligrams per centimeter per day.

\section{Supplemental Information}

\author{
Abbreviations \\ ASMFC Atlantic States Marine Fisheries Commission \\ CBRA Coastal Barrier Resources Act \\ EFH essential fish habitat \\ NMFS National Marine Fisheries Service \\ NRCS Natural Resources Conservation Service \\ SLR sea-level rise \\ TLD thin-layer deposition \\ USACE U.S. Army Corps of Engineers \\ USFWS U.S. Fish and Wildlife Service
}




\title{
Impacts of Sediment Removal from and Placement in Coastal Barrier Island Systems
}

\author{
By Jennifer L. Miselis, ${ }^{1}$ James G. Flocks, ${ }^{1}$ Sara Zeigler, ${ }^{1}$ Davina Passeri,, David R. Smith, ${ }^{1}$ Jill Bourque, ${ }^{1}$ \\ Christopher R. Sherwood, ${ }^{1}$ Christopher G. Smith, ${ }^{1}$ Daniel J. Ciarletta, ${ }^{1}$ Kathryn Smith, ${ }^{1}$ Kristen Hart, ${ }^{1}$ David \\ Kazyak, ${ }^{1}$ Alicia Berlin, ${ }^{1}$ Bianca Prohaska, ${ }^{2}$ Teresa Calleson, ${ }^{3}$ and Kristi Yanchis ${ }^{3}$
}

\section{Executive Summary}

On June 24, 2019, Congressman Raul Grijalva of Arizona, Chair of the House Committee on Natural Resources, sent a letter to the directors of the U.S. Fish and Wildlife Service and the U.S. Geological Survey to request their assistance in answering questions regarding coastal sediment resource management within the Coastal Barrier Resources System as defined by the Coastal Barrier Resources Act (Public Law 97-348; 96 Stat. 1653; 16 U.S.C. 3501 et seq.). For the purposes of this response, coastal sediment resource management refers to the removal of sediment from one part of a barrier island system for placement in another part of the coastal system, for either hazard mitigation (for example, erosion or flood control) or coastal restoration (for example, expansion or restoration of beach, dune, and [or] marsh habitats). The specific topics of concern are as follows (paraphrased from Congressman Grijalva's letter):

1. Disruption of coastal sediment supply resulting from sediment removal and placement, including the replenishment rate of removed sediments and impacts to other components of the barrier island system (discussed in sec. 3).

2. Physical and biological impacts of sediment removal and placement on benthic habitats (discussed in sec. 4).

3. Impacts of sediment removal and placement on fish and other marine species (discussed in sec. 5).

4. Changes in migratory bird nesting and foraging habitats resulting from sediment removal and placement (discussed in sec. 6).

5. Long-term impacts of sediment removal and placement on physical coastal resiliency (discussed in sec. 7).

\footnotetext{
${ }^{1}$ U.S. Geological Survey.

${ }^{2}$ Formerly with the U.S. Fish and Wildlife Service. Currently (2021) with the National Oceanic and Atmospheric Administration.

${ }^{3}$ U.S. Fish and Wildlife Service.
}

To address these five topics, it is essential to begin with some background information about the terrestrial and submerged geomorphic components of coastal barrier island systems and the dominant physical processes that shape and connect them. Barrier islands and spits (referred to as barrier islands throughout the text) are wave-constructed landforms, typically parallel to the coast with a high-energy shoreline facing the open coast and a lowenergy shoreline along the lagoon or estuary. Barrier islands are dynamic and can change in size, shape, and behavior over time. Size and shape are mainly changed by the predominance of wave and (or) tidal processes and the balance between sediment supply and sea-level change. Given static sea level, a decrease in sediment supply might cause island narrowing, segmentation, and (or) rotation of the barrier island's orientation, whereas an increase in sediment supply might cause increases in island height and width or in alongshore growth. If sediment supply is constant, increases in sea level will result in erosion and landward migration of the island (called "transgression"), whereas decreases in sea level will result in increases in barrier height and seaward movement of the shoreline (aggradation and progradation, respectively). Variations on these principal behaviors occur when sea level and sediment supplies are changing.

Barrier island sediment dynamics today (2021) are largely sustained by natural and anthropogenic processes. Seasonal and storm-driven changes in wave and current energy and short- and long-term changes in water level and inlet dynamics result in natural sediment exchanges among barrier island environments (namely, the inner continental shelf, shoreface, beach, dunes, marsh, and estuary). Coastal sediments are moved within and among these environments by alongshore and cross-shore sediment transport processes. Sediment removal and placement activities contribute to these naturally occurring processes.

The following subsections contain summaries of the consensus findings and research gaps that this report identifies as relevant to the five topics addressing sediment removal and placement impacts. It should be noted that, in addition to the physical and ecological focus of Congressman Grijalva's inquiry, sediment removal and placement could also have economic, cultural, and recreational impacts, which, though beyond the scope of this review, could be important to consider in some locations within the Coastal Barrier Resources System. 


\section{Physical Impacts of Sediment Removal and Placement on Coastal Sediment Supplies}

Barrier islands reflect a balance of the dynamic physical processes that shape them. Intentional alterations to the coastal barrier island system through sediment removal and (or) placement reshape barrier islands and their habitats by altering (1) wave and current energy at the shoreline, (2) the volume of sediment exchanged via inlets, (3) alongshore sediment transport, and (or) (4) the frequency of sediment exchanges between beaches and back-barrier environments. A review of the state of the science on the subject revealed the following considerations:

- Removing sediment from any part of the submerged barrier island system may alter the position of barrier island shorelines. However, removal-adjacent shoreline erosion is more likely if sediment is removed from within the active system.

- Typically, sediment removal affects barrier island sediment supplies through the sequestration of sediment in the borrow area. Instead of contributing to the coastal sediment budget, sediment that is actively transported in the system is trapped in the borrow area. The largest decreases in sediment supply will result from shoreface and inlet removal actions and will occur downdrift of the borrow area, sometimes cascading to other barrier islands.

- Sediment can be placed on the shoreface, beach, dunes, or marsh, or along estuarine shorelines, but it is usually placed on the beach as part of a beach nourishment project. Regardless of environment, immediate changes in elevation, extent, and often sediment characteristics will occur in the placement area.

- Over time, placed sediment may be dispersed to other barrier island environments and may cause physical and ecological benefits, such as increased sediment supply to downdrift beaches and habitat extent. Placement may also result in adverse effects, such as altered natural sediment exchanges between barrier island environments and reduced habitat suitability.

- Various numerical models, from simple empirical models to complex deterministic models, are used to predict the success and longevity of sediment removal and placement activities. Recent work highlights the importance of considering large scales that go beyond that of the removal and placement area itself and include physical and ecological feedbacks to understand the system-wide effects of removal and placement activities on barrier islands and their associated ecosystems. Our review suggests that process-based, regional-scale models can sufficiently represent the important physical and ecological interactions that occur in coastal barrier island systems. Probabilistic models may provide the most actionable forecasts of beneficial or adverse effects because they predict impact likelihood rather than specific outcomes.

- To preserve the physical and ecological integrity of barrier island environments, sediment placement designs can be developed that maximize or restore natural sediment transport pathways.

There are some uncertainties because of lack of information related to either data or fundamental understanding, including the following:

- Before sediment removal, it is important to establish the range of natural shoreline variability so that postremoval variability in shoreline position can be determined to be normal or abnormal, possibly requiring remediation.

- How long removal reduces barrier island sediment supply is related to how quickly a borrow area fills up, or the "rate of infilling." However, infilling rates depend on several local factors, making it difficult to determine when downdrift impacts, such as shoreline erosion, will occur and how long they will last.

- Regardless of model type, substantial uncertainty surrounds forecasts of the impacts of sediment removal and placement activities, mostly because of the episodic nature of the storms that drive many of the changes and the difficulty in predicting exact magnitudes of storm-related sediment transport.

- Compared to the volume of literature on open-coast sediment management impacts, little documentation exists regarding the practice of placing sediment on estuarine or back-barrier shorelines.

- Existing models that predict the natural response to sediment-placement activities are often focused on physical (for example, storm defense) and economic gains and often neglect effects on coastal barrier island ecosystems.

\section{Impacts of Sediment Removal and Placement on Benthic Habitats and Their Importance}

Benthic habitats are regions of specific physical, hydrodynamic, and sedimentologic characteristics that promote the colonization of organisms that live in and on the seabed and are directly and immediately affected by sediment removal and placement. Impacts include the following:

- Sediment removal can change three principle physical factors: water depth, sediment composition, and the hydrodynamic conditions at the seafloor. These changes can affect habitat quality for benthic organisms. 
- Changes in benthic habitat type and subsequent recolonization by organisms more amenable to the new bottom characteristics may occur when the borrow site is infilled with sediments that are a different size than the sediments that were removed.

- Immediate sediment-removal impacts in benthic communities are mortality and reduced abundances and are related to the physical removal of sediments. Over the short term, effects are typically characterized by temporary increased abundances of opportunistic taxa and low diversity in taxa. Longer-term impacts to benthic communities are typically related to persistent changes in physical sediment characteristics, such that the more conditions differ before and after removal, the longer the benthos will be affected.

- Recovery of benthic communities depends on multiple physical and biological factors, including location and depth of sediment removal, the removal footprint, differences in sediment characteristics before and after removal, local hydrodynamics, and the composition of the benthic community. In general, benthic communities recover to preremoval conditions faster when sediment characteristics before and after removal closely match.

- In addition to localized changes, sediment removal can also affect nearby sensitive habitats, including seagrasses, corals, and other hard bottoms when sediment plumes and subsequent sediment deposition smothers these environments and associated sessile taxa. Studies have determined these effects are, in general, short lived and of limited extent.

- Sediment placement impacts on benthic communities are related to placement location. Beach placement results in initial mortality through burial and persistent reduced abundances of such taxa as polychaetes, mollusks, and crustaceans, which are important prey to foraging shorebirds and surf fish. The impact duration is related to changes in physical characteristics on the beach such as beach slope and timing of placement. Subtidal placement of sediments results in burial and mortality of sediment fauna and in increased turbidity and nutrient particulates that can affect nearby sensitive sessile fauna such as corals. Thin-layer sediment placement in degraded marshes may have a positive effect by increasing vegetation cover and infaunal abundance.

Uncertainties in understanding benthic impacts also exist:

- The primary knowledge gap for benthic communities is how sediment removal and placement affect benthic ecosystem functioning. Because the infaunal community can completely differ before and after removal despite similar abundance, biomass, and diversity, the trophic value of the new community to higher organisms as prey items and foraging grounds is still not known.

- How efficiently and quickly resident taxa repopulate affected areas, and how less-mobile members of the benthic community repopulate affected areas, is poorly understood. Additional information is needed on long-term effects of sediment removal and placement because most environmental impact studies cease 2 years after construction.

- Although impacts to benthic communities from physical processes such as burial or changes in oceanographic conditions are well documented in the literature, effects caused by other processes such as changes in mineralogy or organic content are not as well studied and could compound habitat alterations with unknown beneficial or adverse effects.

- Additional research and monitoring efforts may be needed to evaluate sediment removal and placement effects where detrimental microbes, harmful algae, or toxic metals have already been identified.

\section{Impacts of Sediment Removal and Placement on Fish and Other Marine Species}

The effects of sediment removal and (or) placement on fish and other marine species can be evaluated via a threat-assessment approach that considers the entire dredging process:

- Vulnerability to direct entrainment or indirect impacts of dredging depends, in large part, on an organism's mobility relative to the spatial footprint of sediment removal, which includes equipment and vessels in addition to changes to the physical environment. Thus, early life stages (for example, eggs and larvae) or dormant stages that are more sessile (for example, burrowing to overwinter by Callinectes sapidus [M. J. Rathbun, 1896] [blue crabs] and Limulus polyphemus [Linnaeus, 1758)] [horseshoe crabs]) are generally more vulnerable than adults or mobile juveniles. Similarly, demersal species are typically more vulnerable than pelagic species.

- Direct dredging impacts include species entanglement in buoys or lines that mark projects and physical injury if struck by transiting vessels working on a project. Sea turtles, Trichechus spp. (Linnaeus, 1758) (manatee), and sturgeon are susceptible to vessel collisions, propeller strikes, and (or) crushing because they may spend a considerable amount of time at or near the water surface. 
- Impacts due to dredging noises and suspended sediments vary widely among species and life stages. In some instances, suspended sediments can have beneficial effects, but higher concentrations are generally associated with increased adverse effects. Noise levels associated with sediment dredging are generally not strong enough to cause direct mortality or serious injury, but many sublethal effects, such as alterations to feeding patterns and predator avoidance, have been reported in the literature.

- Many adverse impacts to fish from contaminants are known, but contaminants are generally more prevalent in finer sediments than in sand and coarser sediments. Thus, contaminants are likely not a major risk factor for removal and placement activities in most coastal marine waters.

- The scale of dredging and placement impact is a function of the likelihood that the threats from sediment management operations overlap with occupied habitat and the degree that the activity affects behavior, physiology, or survival. Thus, potential for impact is particularly acute when sediment removal and increased suspended sediment overlaps spatially or temporally with sensitive habitats (for example, coral reefs), with migration paths or foraging areas in which species congregate, or with spawning, nursery, or overwintering habitats.

Uncertainties stem from knowledge gaps related to species population information and the interaction of those populations with the dredging process:

- Given the wide variation in known responses among fish species and life stages, prevalence of laboratory studies versus field studies, and existing knowledge gaps, additional research is necessary to characterize population-, species-, and community-level effects of sand mining in situ.

- With a well-planned experimental design, studies of fine-scale movements in areas where dredge operations occur could identify taxa that avoid dredging operations versus those that exhibit no avoidance response (or taxis) to dredging operations. These studies could rely on a variety of techniques such as satellite telemetry, three-dimensional acoustic telemetry arrays, hydroacoustics, or environmental deoxyribonucleic acid.

- Assessing contaminants in marine sediment deposits would help ensure that disturbed sediments do not release toxins into the environment and food chain.
- More on-site research focusing on the actual responses of a variety of taxa to active sand mining operations is needed. New tools such as popoff accelerometers allow researchers to quantify fine-scale activity patterns on free-ranging animals.

- More research is needed to comprehensively determine the importance of marine sand deposits and sandbar morphology as key habitats for all life stages of fish and other marine species, throughout all seasons.

- Presently (2021), little is known about the extent of connectivity among sandy habitats for fishes. We have a limited understanding of how habitat changes at specific sites may affect populations at the regional level.

- The net population effect of sediment removal operations is not well assessed, and there is a research need to determine how project-scale effects translate to effects on population growth, distribution, and abundance. Generalizing to multiple species will be difficult because vulnerability depends on life history and habitat requirements.

- Many species of sharks, skates, and rays rely on shallow nearshore coastal habitats as nursery grounds, and information regarding the effects of sediment removal and placement on these species is generally lacking. Direct investigation of the effects of sediment removal and placement on these species is necessary.

- Effective mitigation of adverse effects at removal and placement sites is a key knowledge gap that limits the ability to predict impact and define area closures.

\section{Impacts of Sediment Removal and Placement on Subaerial Beach Habitats}

Sandy beaches provide many important ecosystem services, including habitat for federally and State-listed plants and animals, which may be directly or indirectly affected by sand placement on beaches:

- Beach nourishment can lead to improved sea turtle and shore/waterbird use by widening severely eroded beaches.

- Reduced sea turtle nest success is associated with beach nourishment; on nourished beaches, female emergences, in which no nest is started or in which a nest is abandoned mid-dig, tend to increase. Effects are attributed to the presence of steep slopes or wider beaches, and higher sediment compactness on nourished beaches. Effects tend to disappear after 1-2 years as the sediments and profiles of nourished beaches equilibrate. 
- Some studies suggest that beach nourishment can reduce sea turtle hatching success by increasing the likelihood that a nest will be washed out on nourished beaches with artificially low slopes. Nourished beaches also can cause low hatching success if sand placement alters the mineral content, gas exchange, temperature, and moisture of the nest environment during embryonic development.

- Extracting materials from shoals, mudflats, and sandbars can remove habitats that are vital to overwintering and migrating shore/waterbirds.

- Losses in the abundance and diversity of seagrass, macroinvertebrate, and benthic species during the removal and placement phases of renourishment projects can propagate up through the food web to shore/ waterbirds, resulting in reduced shore/waterbird populations on nourished beaches throughout the annual cycle. Detrimental effects to shore/waterbirds through the food web can persist for months to several years. However, the placement of dredged materials can also provide entirely new foraging grounds for these birds where such habitats were lacking because of shoreline erosion.

- Sediment placement can benefit shore/waterbird communities by creating beach and backshore nesting habitats on eroding shorelines, minimizing vegetation growth and succession, and providing shell-hash that camouflages eggs.

- Sediment placement during the shore/waterbird breeding season can harm reproductive success by increasing human disturbance, crushing or burying eggs or unfledged chicks, reducing prey species, and impeding access to back-barrier foraging habitats. Many of these effects can be avoided if nourishment activities occur outside of the breeding season.

For this review, we found only a few studies that evaluated the direct effects of beach nourishment on coastal taxa, and most of these studies focused on sea turtles and shorebirds. The following additional areas of research and monitoring may be warranted:

- There are few studies on the topic of sea turtle hatchling survival, and the results are mixed; most studies determined beach nourishment did not affect hatchling success. However, one study determined hatchling survival was reduced on nourished beaches, though the relation was not statistically significant. More thorough research is needed to verify whether hatchling survival is or is not affected by beach nourishment.

- The impacts of beach nourishment on taxa other than sea turtles and shore/waterbirds is not well represented in the literature. A variety of other federally and Statelisted species rely on these sandy habitats, and the effects of beach nourishment on plants, insects, and other species should be evaluated if broader species diversity is to be considered in future sediment placement and removal assessments.

- Statistically rigorous before-and-after monitoring studies on species' population dynamics are needed that examine species use, survival, and reproductive success and productivity throughout the species' annual life cycle.

- To understand the cumulative effects of multiple sediment removal and placement actions, the impacts of repeated nourishment cycles should be evaluated. Most of the studies we reviewed examined the effects of a single beach nourishment application on the population dynamics of sea turtles and shore/waterbird prey species.

- Evaluating the biological effects of construction, disturbance, and other related practices has not been studied to address the reproductive success of sea turtles and shore/waterbirds.

- Additional research may be needed to more definitively understand how beach nourishment affects sea turtle and shore/waterbird reproductive success because existing studies have presented conflicting results.

\section{Impacts of Sediment Removal and Placement on Coastal Resiliency}

Coastal resiliency is defined as the ability of a coastal system to withstand and adapt to perturbations, natural or otherwise. Sediment removal and placement can affect short- and long-term coastal resiliency, including the following:

- Sediment placement either through nourishment or emergency sand berms is a short-term strategy that can help protect coastal infrastructure and critical habitats from storm inundation.

- Sediment removal, such as channel dredging, may increase tide and storm-surge inundation in coastal embayments, which can adversely affect infrastructure and habitats.

- A few studies suggest that nourishment may be helpful in reducing erosion under future sea-level rise; however, artificially high, nourished dunes may reduce overwash and deprive back-barrier environments of deposition needed to keep pace with sea-level rise.

- The effects of sediment removal, such as downdrift shoreline erosion and reduced sediment supply, may be worsened by sea-level rise. 
- To assess long-term coastal resiliency, physics-based and ecological models can be used to predict impacts of sediment removal and placement, particularly under scenarios of future storms and sea-level rise.

Uncertainties result from observational and fundamental research limitations and could be addressed as follows:

- Studies to assess how past and present nourishment of the beach, dune, and shoreface can improve long-term barrier island resiliency, especially under future sealevel rise considerations, would address the question of whether beach nourishment can help improve longerterm coastal resiliency through increased overwash deposition on back-barrier shorelines to aid in barrier island migration and (or) stability.

- Studies that evaluate the effects of shoreface nourishment in the context of storm protection and short-term coastal resiliency can improve understanding of storm impacts caused by downdrift shoreline erosion from sediment removal.

- Evaluating the long-term effects of sediment removal from ebb-tidal deltas or channel dredging would benefit from identifying primary sediment pathways, which would improve understanding of erosion and deposition patterns along adjacent shorelines.

- Analysis of beach nourishment and frequent complementary activities such as berm construction and sand fencing on ecosystem connectivity over short and long timescales requires multiyear monitoring to evaluate ecosystem health and function in situations where sediment pathways and connectivity may have been disrupted.

- In order to assess longer-term coastal resilience impacts to human and ecological communities, it is important for monitoring and modeling studies of existing and future sand removal and placement activities to consider time scales spanning more than 1 year after construction.

\subsection{Overview}

On June 24, 2019, Congressman Raul Grijalva of Arizona, Chair of the House Committee on Natural Resources, sent a letter to the directors of the U.S. Fish and Wildlife Service and the U.S. Geological Survey to request their assistance in answering some questions about coastal sediment resource management within the Coastal Barrier Resources System as defined by the Coastal Barrier Resources Act (CBRA; Public Law 97-348; 96 Stat. 1653; 16 U.S.C. 3501 et seq.). For the purposes of this response, sediment resource management refers to the removal of sediment from one part of a coastal barrier island system for placement in another part of the system, for either hazard mitigation (for example, erosion or flood control) or coastal restoration (for example, expansion or restoration of beach, dune, and [or] marsh habitats). The specific topics of concern are as follows (paraphrased from Congressman Grijalva's letter):

1. Disruption of coastal sediment supply resulting from sediment removal and placement, including the replenishment rate of removed sediments and impacts to other components of the coastal barrier island system (discussed in sec. 3)

2. Physical and biological impacts of sediment removal and placement on benthic habitats (discussed in sec. 4)

3. Impacts of sediment removal and placement on fish and other marine species (discussed in sec. 5)

4. Changes in migratory bird nesting and foraging habitats resulting from sediment removal and placement (discussed in sec. 6)

5. Long-term impacts of sediment removal and placement on physical coastal resiliency (discussed in sec. 7)

Section 2 of this report provides essential background information about the terrestrial and submerged geomorphic components of coastal barrier island systems and the dominant physical processes that shape and connect them. Sections 3-7 address the topics outlined above by addressing primary physical and (or) biological/ecological processes pertinent to each topic, as well as other relevant processes that may require consideration in certain coastal settings. Each of these five sections begins with a summary of the consensus findings and (or) research gaps relevant to the topic addressed. Finally, appendix 1 reviews the physical and biological data and information required for assessing and monitoring impacts of sediment resource management practices on coastal barrier island systems and provides tables of existing U.S. Geological Survey resources for five Coastal Barrier Resources System areas of interest (appendix tables 1.1-1.5).

\subsection{Introduction to Barrier Island Sediment Dynamics}

Barrier islands and spits (referred to as barrier islands throughout the text) are wave-constructed landforms, typically parallel to the coast (McBride and others, 2013; Otvos, 2018), that have a high-energy shoreline (for example, gulf- or oceanfacing) and a low-energy shoreline (for example, lagoon- or estuary-facing) (fig. 1). They form by different mechanisms (Hoyt, 1967, 1968; Fisher, 1968; Schwartz, 1971), such as delta-lobe degradation (Penland and others, 1985), shoal aggradation (Otvos, 1981), or sand spit growth and segmentation (Leatherman, 1985; Otvos, 1985; Blum and others, 2003; Rodriguez and Meyer, 2006), and are often perched atop highs 

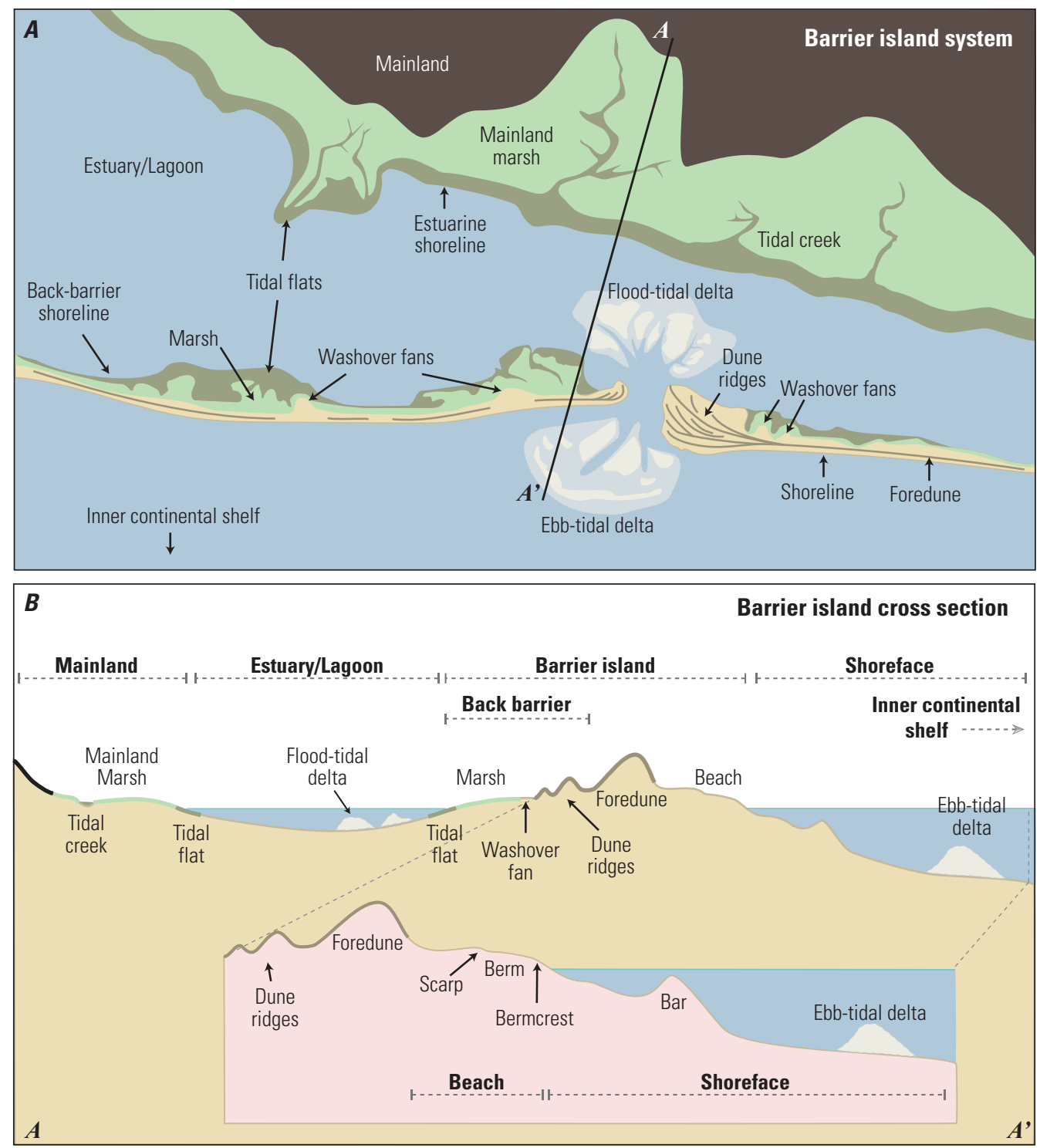

Figure 1. Barrier island geomorphic environments. Illustration credits: Noreen Buster, U.S. Geological Survey. $A$, plan view. $B$, profile view. in antecedent topography (Rampino and Sanders, 1981; Otvos, 1981; Belknap and Kraft, 1985; Locker and others, 2003; Raff and others, 2018; Shawler and others, 2021). Barrier islands are dynamic and can change in size, shape, and behavior over time. Size and shape are mainly changed by the predominance of wave and (or) tidal processes (Hayes, 1979, 1994; Davis and Hayes, 1984), and first-order behavior is affected by a balance between sediment supply and sea-level change (McBride and others, 2013). Given static sea level, a decrease in sediment supply might result in barrier island narrowing, segmentation, and (or) rotation, whereas an increase in sediment supply might result in increases in island height and width or in alongshore growth (McBride and Byrnes, 1995). If sediment supply is constant, increases in sea level will result in erosion and landward migration of the island (for example, transgression), whereas decreases in sea level will result in increases in barrier height and seaward movement of the shoreline (for example, aggradation and progradation, respectively). Variations on these principal behaviors occur when sea level and sediment supplies are changing.

Most barrier islands were formed by natural processes; however, sediment dynamics today (2021) are largely sustained by natural and anthropogenic processes. Seasonal and storm-driven changes in wave and current energy and shortand long-term changes in water level and inlet dynamics result in natural sediment exchanges among barrier island environments (namely, the inner continental shelf, shoreface, beach, dunes, marsh, and lagoon/estuary; fig. 1). Coastal sediments are moved within and among these environments by alongshore and cross-shore sediment transport processes. In general, alongshore transport magnitudes are driven by breaking wave height and the angle of the waves relative to the coast. Though cross-shore transport occurs continuously, increases in wave 
energy (for example, during storms) drive larger exchanges of sediment among the shoreface, beach, dunes, marsh, and lagoon/estuary.

Inlets often separate barrier islands in series and provide a direct pathway of sediment exchange between shoreface and back-barrier environments. Tidal flows through inlets interrupt alongshore transport of sediments, which are then stored in tidal deltas. Ebb-tidal deltas form on the seaward side of the inlet, and flood-tidal deltas form on the estuarine or bay side (fig. 2). Tide-dominated inlets tend to have larger ebb-tidal delta deposits, whereas inlets exposed to an energetic wave climate tend to have larger flood-tidal delta deposits (Hayes, 1980). Tidal deltas are very dynamic and change in volume depending on magnitude of water flows through the inlet, on storm intensity, and on migration of the primary tidal channel. Ebb-tidal deltas can often sequester more sediment than the adjacent barrier island shoreface and can release this sediment either episodically during storms or through long-term supply (Flocks and others, 2020), referred to as sediment bypassing. Wave- and tidal current-driven changes in ebb-tidal delta morphology can also alter wave refraction patterns that dictate the position and depth of the primary inlet channel, the width of adjacent beaches, the exchange of water between the coast and estuary, and sediment supply magnitudes to downdrift barrier islands. Flood-tidal deltas can also act as long-term sinks of sediment and, in some cases, act in combination with ebb-tidal deltas to starve downdrift barrier islands of alongshore sediment delivery over decadal timescales (Nienhuis and Ashton, 2016), a process that can be exacerbated by inlet dredging and stabilization (for example, Chincoteague Inlet, Hardaway and others, 2015; and Ocean City Inlet, Leatherman, 1979). However, over multidecade to centennial timescales, sediments stored in flood-tidal deltas can be released to the shoreface during landward barrier migration, helping maintain resiliency in the face of long-term drivers of change such as sea-level rise (SLR) (Nienhuis and Lorenzo-Trueba, 2019).
Finally, humans modify sediment dynamics on coasts through the use of coastal engineering structures, such as groins along beaches and jetties at inlets. These practices alter existing sediment-supply pathways, create new pathways, or both. Humans also alter barrier island sediment transport through sediment resource management (for example, removal and placement), commonly for shoreline restoration, or navigation channel maintenance. Sections 3-7 address the impacts of sediment removal and placement as they relate to the initial questions posed by Congressman Grijalva.

\subsection{Physical Impacts of Sediment Removal and Placement on Coastal Sediment Supplies}

By Jennifer L. Miselis, Christopher R. Sherwood, James G. Flocks, Daniel J. Ciarletta, and Christopher G. Smith

Barrier islands reflect a balance of the dynamic physical processes that shape them. As wave energy and water levels change, natural barrier island systems adjust their shape (for example, morphology) through sediment erosion and deposition, allowing them to mitigate wave energy at the shoreline during storms, rebuild after storms, and maintain certain heights and widths that allow the landforms to keep up with sea level. As such, intentional alterations to the barrier island system through sediment removal and (or) placement result in corresponding adjustments throughout the coastal system as the entire system establishes new balance or equilibrium. Depending on the magnitude and nature of the changes, short- and long-term impacts to barrier island resiliency and ecological function may occur. Terrestrial and (or) submerged changes in morphology cause changes in wave characteristics (for example, wave height, angle, and energy) that, in turn,

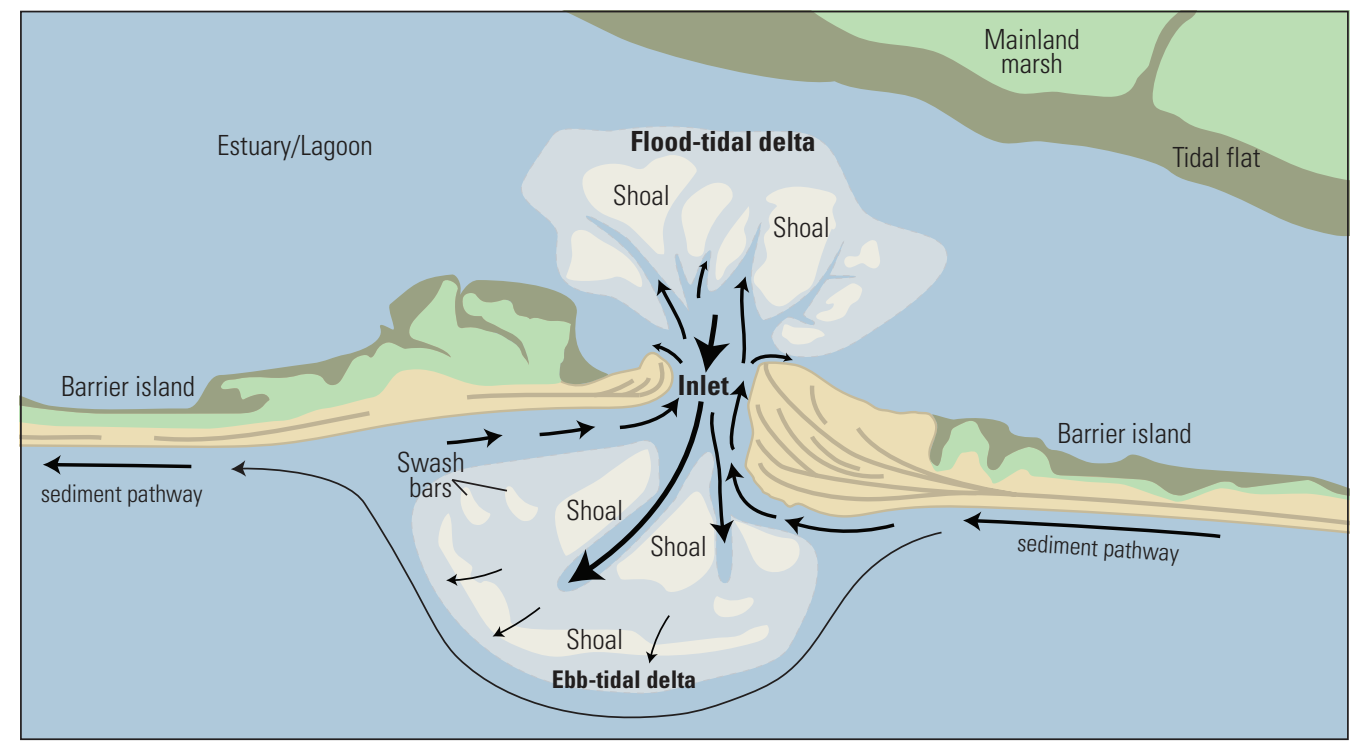

Figure 2. Inlet geomorphic environments with sediment transport pathways indicated by black arrows. Illustration credit: Noreen Buster, U.S. Geological Survey. 
reshape barrier islands and their habitats by altering (1) wave and current conditions at the shoreline, (2) the volume of sediment exchanged via inlets, (3) alongshore sediment transport, and (or) (4) the frequency of sediment exchanges between beaches and back-barrier environments. This section reviews the physical impacts to barrier island systems resulting from sediment removal (sec. 3.1) and placement (sec. 3.2).

The main points from this section are as follows:

- Removal of sediment from the submerged barrier system, regardless of where it might occur (for example, from offshore, the shoreface, or an inlet), may alter the position of barrier island shorelines. However, removal-adjacent shoreline erosion is more likely if sediment is removed from within the active coastal system, defined here as the region in which waves interact with the seabed frequently over a given period of time. Before sediment removal, it is important to quantify the range of natural shoreline variability so that variability in shoreline position after removal can be determined to be natural or in excess of natural variability, possibly requiring remediation.

- Sediment removal affects barrier island sediment supplies most often through the subsequent sequestration of sediment in the borrow area. Instead of contributing to the coastal sediment budget, sediment that is actively transported in the system is trapped in the borrow area. The largest decreases in sediment supply result from shoreface and inlet sediment removal actions and occur downdrift of the borrow area, sometimes cascading to other barrier islands.

- How long sediment removal reduces barrier island sediment supply is related to how quickly a borrow area fills up, or the "rate of infilling." However, infilling rates depend on several local factors, making it difficult to determine when downdrift effects, such as shoreline erosion, will occur and how long they will last.

- Sediment can be placed on the shoreface, beach, dunes, or marsh, or along estuarine shorelines, though the most common practice is placement on the beach (for example, beach nourishment). Regardless of environment, immediate changes in elevation, extent, and often sediment characteristics will occur in the placement area.

- Over time, placed sediment may be dispersed to other barrier island environments having physical and ecological benefits, such as increased sediment supply to downdrift beaches and increasing habitat extent. Placement may also result in adverse effects, such as the alteration of natural sediment exchanges between barrier island environments and reductions in habitat suitability. To preserve the physical and ecological integrity of barrier island environments, sediment placement designs that maximize or restore natural sediment transport pathways should be prioritized.

- A variety of numerical models, from simple empirical models to complex deterministic models, are used to predict the success and longevity of sediment removal and placement activities. Recent work highlights the importance of considering large scales (for example, beyond that of the removal and placement area itself) and physical and ecological feedbacks to understand the system-wide impacts of removal and placement activities on barrier islands and their associated ecosystems. Our review suggests that process-based, regional-scale models can sufficiently represent the important physical and ecological interactions that occur in barrier island systems. However, probabilistic models may provide the most actionable forecasts of beneficial or adverse effects because they predict impact likelihood rather than specific outcomes. Regardless of model type, substantial uncertainty surrounds forecasts of the impacts of sediment removal and placement activities, mostly because of the episodic nature of the storms that drive many of the changes.

\subsection{Impacts of Sediment Removal on Barrier Islands}

The nature and scale of physical impacts of sediment removal on barrier islands are controlled by (1) the relative location of the place from which sediment is removed (for example, borrow area) to the barrier island system, (2) the effect of the borrow area geometry on wave and current characteristics at the borrow site and shoreface, and (3) the rate and type of infilling of the borrow area. The next section addresses shoreline changes immediately onshore or adjacent to the sediment removal site. Section 3.1.2 addresses effects of removal on barrier island sediment supplies, which extend farther afield of the removal area and can affect barrier islands downdrift.

\subsubsection{Effects on Barrier Island Shorelines}

\section{Shoreline Changes from Sediment Removal from Inlet-Associated Shoals}

Sediment in inlet-associated shoals, particularly those within ebb-tidal deltas (fig. 2), are increasingly being considered for beach nourishment and restoration because they are economically desirable, are compatible with barrier island sediment, and are thought to be sediment sinks in the overall coastal sediment budget (Beck and Wang, 2019). Their proximity to barrier islands makes them easier to access than shelf deposits (fig. 2). In addition, ebb-tidal shoals are generated 
from barrier island sediment and are exposed to similar wave energy as beaches and are therefore generally compatible with beach sediment (Finkl and others, 2007). However, the effects of ebb-tidal shoal excavation on barrier island shoreline change are more complex than excavation from offshore or nearshore sources because they may cascade to more than one barrier island (discussed in sec. 3.1.2) and can alter the balance between shoal morphology and adjacent inlet shoreline behavior (discussed next).

Removal impacts on inlet shorelines are difficult to generalize or predict. Even without sediment removal, the greatest changes in barrier island shoreline position occur near inlets (Davis and FitzGerald, 2004). This is because of the dynamic feedbacks between waves and tides, ebb shoal shape, and inlet shoreline position. Inlet environments are dominated by swash bars (fig. 2), and every adjustment to wave energy or tidal current velocities results in changes to the shape of the bars and, in turn, changes in the magnitude of waves and currents at the shoreline resulting in almost constant shoreline adjustments. Therefore, removal of sediment from ebb-tidal deltas can alter those feedbacks, leading to increases in dynamic behavior of inlet-adjacent shorelines. It has been suggested that there may be optimal removal designs that would limit impacts to adjacent shorelines (Fontolan and others, 2007) just as for shoreface removal designs (Benedet and others, 2013), but unfortunately, the magnitude of inlet shoreline changes resulting from ebb-shoal sediment removal is largely unknown and, therefore, challenging to predict. In their evaluation of eight ebb shoal mining projects along the Gulf and Atlantic coasts of the United States, Cialone and Stauble (1998, p. 538) stated, "The opportunity to understand the effects of shoal mining by evaluating ebb shoal mining projects has been hampered by limited monitoring data documenting pre-project conditions and post-project system response. This lack of data has limited improvement of the engineering design process and assessment of project performance. Regulatory concerns and design practices cannot be addressed until we have sufficient understanding of the impacts of shoal mining on the inlet system."

It is clear from Cialone and Stauble (1998) that monitoring of the dynamics of the inlet system before and after removal is needed before the benefits and drawbacks of ebb shoal mining can be determined. Monitoring before removal captures the range of natural variability, whereas monitoring after removal can help to determine whether sediment removal actions result in inlet shoreline changes in excess of established natural variability. Recently, shoreline changes adjacent to Little Egg Inlet, New Jersey, were monitored after removal of sediment from the ebb shoal in December 2017. The analysis showed substantial erosion of the downdrift inlet shoreline between 2016 and 2018 and continued erosion from 2018 to 2020 (Stockton University Coastal Research Center, 2019, 2020). However, it is unclear if the erosion was outside of the range of natural variability. Further, erosion of the downdrift inlet shoreline might be expected if the removal area was infilling and preventing sediment from being transported downdrift. But initial monitoring of the removal area indicated no infilling occurred as of 2019 (Stockton University Coastal Research Center, 2019). It is possible that wave energy to the downdrift inlet shoreline has increased since the shoal morphology was altered. But it is also possible that the shoreline elevation dataset used to quantify erosion, based on 2016 and 2018 surveys, did not resolve shoreline conditions coincident with removal that occurred in 2017. Subsequent bathymetric surveys have shown that 80 percent of the removed volume has been infilled and, yet, similar magnitudes of downdrift inlet shoreline erosion continued to occur (Stockton University Coastal Research Center, 2020). This decoupling of borrow area infilling and inlet shoreline response suggests the shoreline is sensitive to changes in some other part of the ebb-tidal delta morphology and not solely the infilling of the borrow area. The Cialone and Stauble (1998) analysis, the somewhat mixed results from Little Egg Inlet, and the general paucity of scientific and engineering literature that addresses ebb shoal sediment removal effects on inlets and adjacent shorelines suggests that more research and monitoring is required to understand the feedbacks between changing ebb shoal morphology and inlet shoreline dynamics.

In addition to impacts associated with ebb-tidal delta modifications, some effects may result from removing sediment from flood-tidal deltas (fig. 2). Material dredged from either navigation channels that dissect the flood-tidal delta or from its associated shoals may be used as nourishment material (for example, de Lange and Healy, 1990). However, because these sediments are generally finer grained than those found in ebb-tidal deltas, they may be more appropriate for placement on estuarine shorelines rather than on open-coast beaches (de Lange and Healy, 1990). Removal of sediment from flood shoals may result in channel migration and (or) changes in the position of adjacent estuarine shorelines (de Lange and Moon, 2017). Likewise, estuarine shoreline changes (for example, estuarine spit accretion) may result in changes to tidal delta channels, necessitating dredging to maintain navigation channels (Velasquez-Montoya and others, 2020). There is comparatively less literature on the impacts to barrier island environments from sediment removal from flood-tidal deltas than for ebb-tidal deltas, suggesting floodtidal delta removal actions might require more research and monitoring.

In addition to altering the morphologic feedbacks between tidal delta shoals and estuarine or barrier island shorelines, removing sediment from either or both flood- and ebb-tidal deltas may also lead to changes in water levels along estuarine and mainland shorelines because of increased exchange of water between the ocean and estuary (Orton and others, 2015; Familkhalili and Talke, 2016; Aretxabaleta and others, 2017; Ralston and others, 2019). This may be particularly pronounced during storms when increased storm-surge heights and greater landward incursion of surge have been reported (Familkhalili and Talke, 2016; Ralston and others, 2019). Though increases in estuarine and mainland water levels have been associated with maintaining inlet channels, wholly new inlets created during storms do not necessarily 
cause the same response (Aretxabaleta and others, 2017), though this may highly depend on location and regional inlet spacing.

\section{Shoreline Changes from Shoreface Sediment Removal}

Sediment that is close to the coast, such as in shorefaceattached sand ridges or the shoreface itself, is less expensive to remove and transport for placement within the coastal system than offshore deposits (Finkl and others, 2007; figs. 1 and 3). Therefore, this material has commonly been targeted as a supply for beach nourishment and coastal restoration. Furthermore, shoreface sands are considered more compatible with beach sand, which is important for maintaining the natural conditions on the barrier and in its associated habitats.

Though economically desirable, extracting sediment from an active part of a coastal barrier island system often results in changes to nearby shorelines and beaches, sometimes reducing the effectiveness of nourishment (Kennedy and others, 2010). Nearshore sediment-removal effects on barrier island shorelines are related to changes in the local wave climate resulting from the borrow area itself. Changes in seabed elevation alter wave characteristics and, when these changes extend to the surf zone, they modify longshore and cross-shore coastal currents, resulting in shoreline changes along the coast onshore of and adjacent to the sediment removal area (Demir and others, 2004). Depending on the wave climate and borrow area characteristics (for example, depth and shape), the shoreline onshore of and adjacent to a shoreface borrow area can respond in a variety of ways. Shorelines have moved seaward (shoreline accretion; Combe and Soileau, 1987; Bender and Dean, 2003) and landward (shoreline erosion; Wang and Dean, 2007; Bender and Dean, 2003; Demir and others, 2004; Benedet and List, 2008) because of sediment removal. The opposite response (erosion or accretion, respectively) often occurs along the shoreline on either side of the borrow area. This coupled shoreline erosion-accretion response results occurs (Demir and others, 2004) because the accumulation of sediment along one part of the shoreline starves another stretch of shoreline and vice versa.

The exact locations of removal-related shoreline changes can be difficult to predict because they can translate up or down the coast relative to the borrow area location, depending on the angle of the waves relative to the shoreline (Benedet and List, 2008), the offshore distance of the borrow area (Benedet and others, 2013), or the morphologic stability of the borrow area itself (Desprez, 2000). Furthermore, storm waves, which often come from a different angle and are far more energetic than fair-weather waves (Michalsen and others, 2008), increase the magnitude of beach volume change (Benedet and others, 2013) and may translate zones of erosion and accretion to parts of the shoreline that were previously stable. Numerical model simulations suggest that, to reduce impacts to beaches, shoreface borrow areas should have a shallow excavation depth (Demir and others, 2004) and a shore-parallel dimension that is at least four times greater than the cross-shore dimension (Benedet and others, 2013). However, shoreface sediment sources are not often uniformly distributed (for example, shore-oblique sand ridges); thus, it is not always possible to implement this optimal design in practice (fig. 3).

\section{Shoreline Changes from Inner Continental Shelf Sediment Removal}

Sediment from inner continental shelf sources (fig. 4) has often been used for coastal sediment management because the sediment is often considered to be separate from the modern coastal system. It is thought that nourishment from these sources represents an increase in sediment supply because the sediment is derived from features that were deposited over geologic timescales and subsequently drowned over the last several thousand years as sea levels rose (Dame, 1990; Anderson and others, 1992; Kulp and others, 2001; Flocks and others, 2009; Rogers and others, 2009).

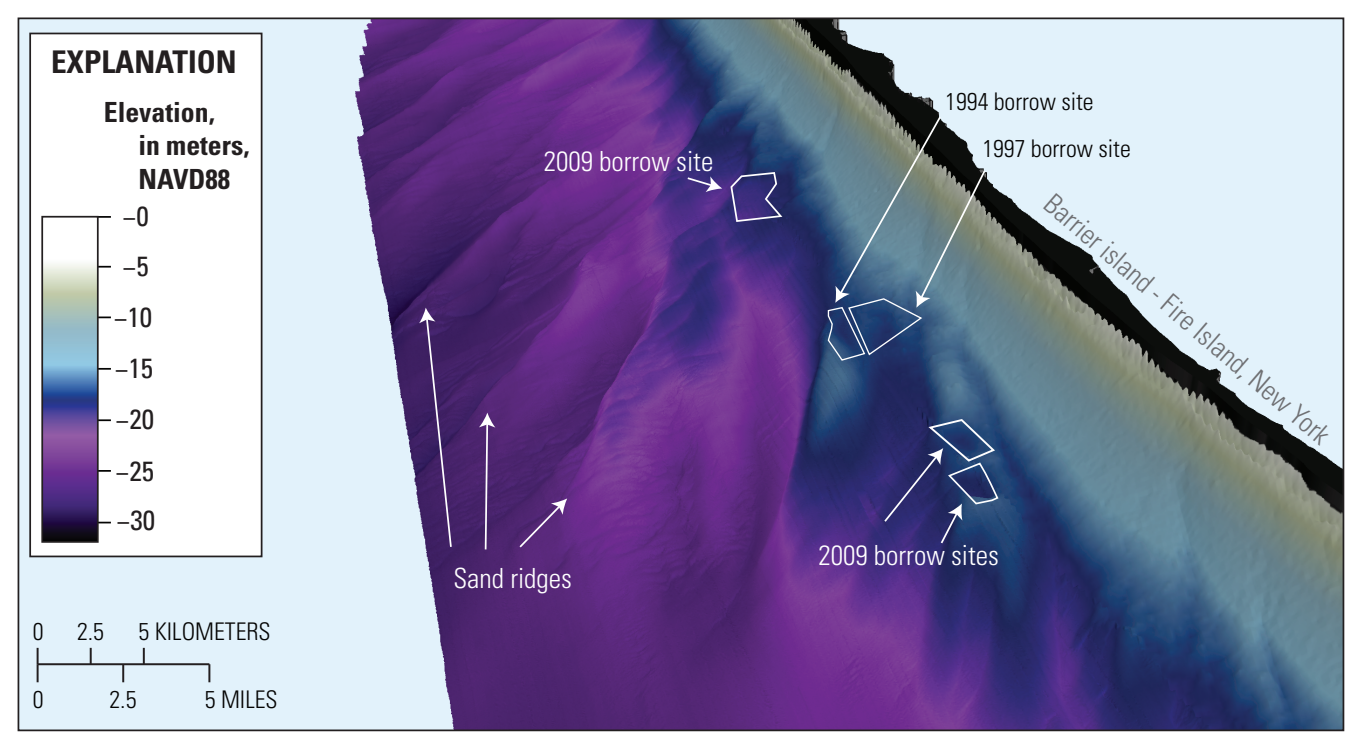

Figure 3. Bathymetry offshore of Fire Island, New York, showing a series of shoreface-attached sand ridges and the locations of several borrow areas. Modified from Schwab and others (2013). Reproduced with permission from the Coastal Education and Research Foundation, Inc. [m, meter; NAVD88, North American Vertical Datum of 1988] 


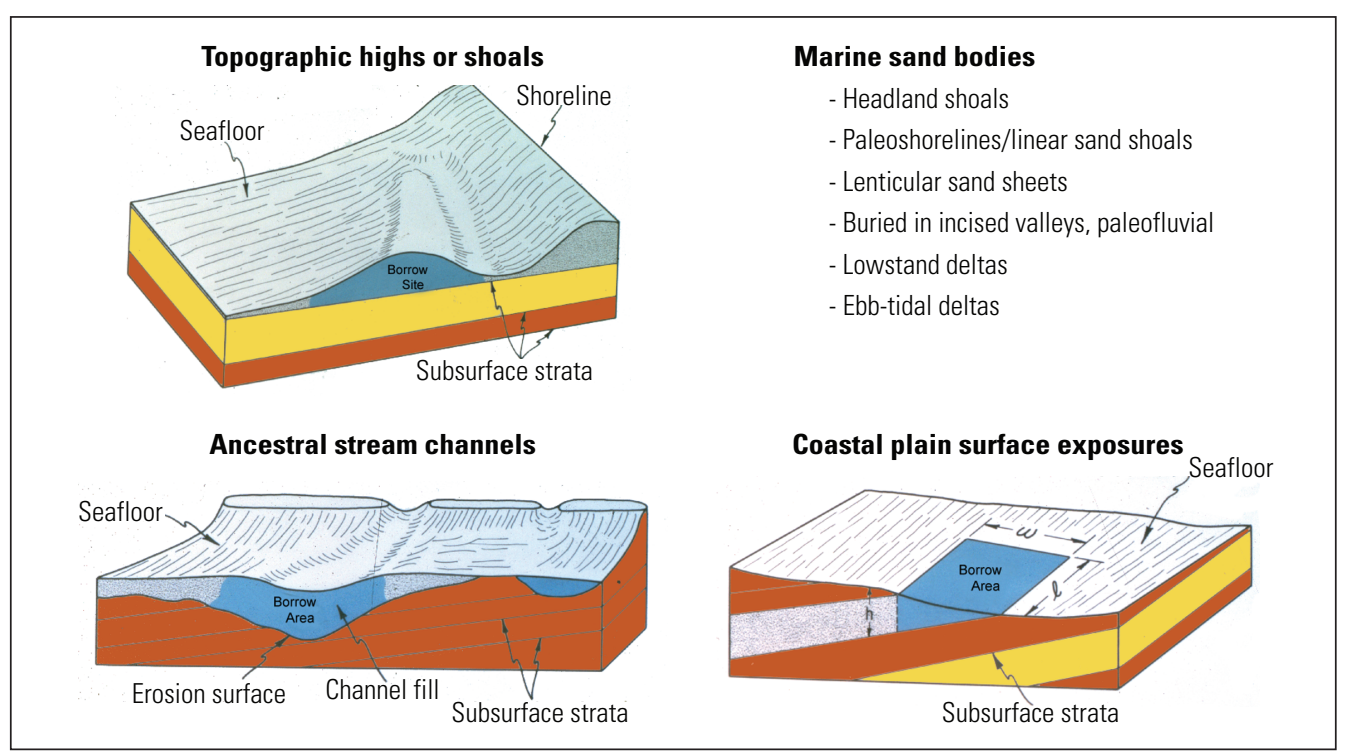

Figure 4. Geologic features on the inner continental shelf that may serve as sources of sediment. Modified from Williams and others (2012). Reproduced with permission from the Coastal Education and Research Foundation, Inc.
Because these deposits are often in deeper water where waves do not interact with the seabed frequently, the shoreline impacts of inner continental shelf sediment removal are diminished. Modeling efforts have repeatedly shown that effects on nearby shorelines are negligible or within the range of natural variability (Maa and Hobbs, 1998; Zarillo and others, 2009; Byrnes and others, 2004b; Dalyander and others, 2015). For example, Stone and others (2004) modeled the effects of mining Ship Shoal in Louisiana and, although they found substantial increases in wave height after mining (20-100 percent), they concluded that this would not lead to increased erosion along the Isles Dernieres. Although shelf borrow sites are often in Federal waters and, therefore, outside of the jurisdiction of the CBRA, it should be noted that, in some cases, interactions between multiple inner continental shelf borrow areas have been predicted to result in shoreline erosion (Byrnes and others, 2004a; Maa and others, 2004).

In addition to causing shoreline changes, sediment removal also has local impacts at the borrow sites. Dredging removes material (along with any biota), increasing water depths and exposing previously buried material that may have different grain size and geochemical properties (Newell and others, 1998). Additionally, the borrow site may trap sediment and refill at varying rates (van Dalfsen and others, 2000; Kobashi and Jose, 2018). In some cases, borrow sites refill with similar material (van Dalfsen and others, 2000; Byrnes and others, 2004b, 2010; Simonini and others, 2007), but many refill with sediment finer than the pre-removal material (van der Veer and others, 1985; van Dalfsen and others, 2000; Graca and others, 2004; Fraser and others, 2006). This has important implications for benthic geochemistry (Graca and others, 2004) and communities (Simonini and others (2007), which are fully explored in section 4.

\subsubsection{Effects on Barrier Island Sediment Supply}

\section{Effects of Sediment Removal from Within the Active Barrier Island System}

Borrow sites within the normally active zone of coastal sediment transport will become sediment sinks due to equilibration of the site itself with waves and currents. Therefore, infilling of the void left from sediment removal may reduce the sediment budget available for downdrift beaches resulting in downdrift shoreline erosion (Dalyander and others, 2015) further afield than the shoreline changes discussed in section 3.1.1. The longer a removal area remains a sink, the longer impacts to downdrift sediment supplies can be expected to persist, so it can be argued that the rate of borrow area infilling is important for regulating downdrift effects. Borrow areas proximal to sediment sources such as rivers infill faster (Obelcz and others, 2018) than those that rely on longshore sediment transport alone (Byrnes and others, 2004a, 2004b). Longshore transport itself is neither consistent nor constant. Storms, periods of increased storm frequency lasting decades, disruption in updrift sediment supply through inlet channel maintenance, or simply a diminishing source of sediment affect the rate and volume of longshore sediment transport over time (van Dalfsen and others, 2000; Flocks and others, 2017; Kobashi and Jose, 2018). Therefore, the rate of infilling is difficult to predict because of uncertainty surrounding the magnitude and variability in longshore sediment supply. This is demonstrated by the persistence of shoreface borrow area morphology for more than 20 years at a location thought to have relatively high sediment transport rates (Schwab and others, 2014, 2017). Uncertainty surrounding infilling rates is higher where past sediment sources have been exhausted, such that transport rates based on geologic or historical data may overestimate modern rates (Miselis and others, 2015). These complexities undoubtedly result in weak correlations between removed volume and infilling rate and the wide span 
of replenishment rates that can range from 5 years for smaller volumes to hundreds of years for larger volumes (Obelcz and others, 2018).

For inlet-associated shoals, sediment supply impacts may simply depend on the dominance of waves or tides at a particular inlet. Tide-dominated inlets that are not substantially affected by waves are not efficient at passing sediment downdrift. Their large ebb-tidal shoals generally serve as sinks for coastal sediment (Finkl and others, 2007); therefore, their excavation is thought to have little effect on downdrift barriers. On the other hand, wave-dominated inlets, which often have smaller ebb-tidal shoals, are more efficient at passing sediment around the shoals, thereby supplying sediment to adjacent barrier islands. For example, it is broadly accepted that sediment removal from ebb-tidal delta channels often leads to downdrift beach erosion because sediment that might otherwise bypass the inlet becomes trapped in the excavation (Dean and Walton, 1973; Dean, 1991; Montague, 2008; Finkl, 2012), though Byrnes and others (2010) suggested that sediment removal from locations other than the channel may result in less adverse effects. Excavating material from wavedominated ebb-tidal shoals for beach nourishment updrift from the inlet could disrupt sediment bypassing and lead to beach erosion on barrier islands downdrift, complicating coastal sediment management, particularly if downdrift barrier islands are in a different jurisdiction. In addition, if the normal wave climate is punctuated by high-energy events such as storms, wave action may periodically activate sand transport from the ebb-tidal shoal downdrift, providing episodic sand supply to neighboring barrier islands.

Despite the broadly accepted understanding that ebbtidal shoal sediment removal results in downdrift impacts, there is uncertainty surrounding how long these effects might persist and how far afield they might occur due to lack of temporally and spatially relevant monitoring data (Cialone and Stauble, 1998). In fact, observations from a few locations have demonstrated a variety of responses. For example, millions of cubic meters of sand have been extracted from the flood-tidal deltas, tidal flats, and tidal channels of the Dutch Wadden Sea. Assessments indicated that infilling rates of borrow sites on tidal flats were extremely slow and, though infilling of the borrow site itself was likely faster, the benthic community did not recover after 15 years (van der Veer and others, 1985). However, tidal channels recovered in 1-3 years (van der Veer and others, 1985) suggesting that, in this case, downdrift effects may not have persisted for very long at this site. In contrast, postremoval inlet monitoring was conducted at Little Egg Inlet, N.J., in the United States, where sediment was removed from an ebb-tidal shoal in December 2017. Despite expectations that the removal area would gain 90 percent of its pre-removal volume in 5 years, monitoring data showed continued erosion in the removal area almost 1 year later rather than any accumulation (Stockton University Coastal Research Center, 2019). Given that the location of the sediment removal site has increased water flow through the inlet channel (Stockton University Coastal Research Center, 2019), it is unclear if, or when, infilling of the borrow area may occur or if, or for how long, downdrift effects from the excavation will persist. This is important because more recent observations show that, since 2019 , the borrow site has recovered 80 percent of its pre-removal volume and yet downdrift erosion is still occurring. Continued monitoring will provide insight as to how this change in the balance between tidal currents and ebb-tidal shoal morphology will affect future shoal morphology and sediment bypassing efficiency that will alter sediment supply to downdrift barriers. Based on the scarce information available, borrow area infilling rates may have to be assessed on a location-by-location basis. Further, the downdrift effects of sediment removal from ebb and flood tidal deltas, shoals, and flats could be better quantified to understand the spatial extent and persistence of removal impacts.

\section{Effects of Sediment Removal from Outside the Active Barrier System}

In comparison to other environments discussed, continental shelf environments are relatively quiescent and are outside the zone of active coastal sediment transport. However, higher-than-normal wave energy associated with seasonal or tropical storms can mobilize sediment there and potentially affect barrier island sediment supplies. For example, Schwab and others (2017) found that along the Atlantic coast, storm-induced sediment erosion and deposition on shorefaceattached sand ridges occurred in water depths as deep as 30 meters $(\mathrm{m})$, which is substantially outside what is normally thought of as the littoral zone. The storm processes resulted in movement of sediment onshore, and this flux was necessary to balance the coastal sediment budget there (for example, outputs equal inputs), implying that in establishing offshore limits of sediment transport at a given location, storm frequency and intensity should be considered. Furthermore, infilling of offshore borrow areas on those sand ridges (fig. 3) could disrupt this episodic, storm-related sediment supply to the barriers inshore, resulting in a deficit in the sediment budget. Even without sand ridges, rapid infilling of continental shelf borrow areas during storms is common (Kennedy and others, 2010; Gonçalves and others, 2014). In one case, a volume of sediment equal to 4 years of longshore sediment transport was deposited in a borrow site (Kennedy and others, 2010) during one storm. Because it is likely that any sediment deposited in a shelf borrow area will be retained (Kennedy and others, 2010), the result is a permanent loss of sediment from the barrier island supplies.

\section{Remote Sources or Upland Sources}

Though not the focus of this inquiry, sediment from well outside the barrier system could be used for nourishment. There are no removal impacts to the coastal system from this practice since no sediment is removed. Any local effects resulting from mining upland sources is beyond the scope of this report. Furthermore, sediment supplied from remote or upland sources will always act to increase the 
inventory of sediment in the system, which is generally considered beneficial, particularly in sediment-starved locations. Other advantages to external sources may include lower cost, less-restrictive permitting, and high-quality material. Disadvantages may include high transportation costs and effects associated with transportation (traffic congestion and road damage).

\subsection{Impacts of Sediment Placement on Barrier Islands}

Once removed from a borrow area, sediment is placed within coastal barrier island systems to mitigate hazards and (or) to restore coastal environments or ecosystem function. Depending on the placement objective, sediment may be placed on the shoreface, beach, foredune, marsh/back-barrier flats, or along estuarine shorelines. The goal of sediment placement designs is to support the intended goal without negative consequences for other parts of the coastal system (for example, neighboring shorelines, back-barrier regions, and so on). This section focuses on placement of sediment in ocean-facing barrier island environments (for example, shoreface, beach, and dune), the resulting changes in morphology immediately near placement (discussed in sec. 3.2.2), and subsequent alterations of sediment transport pathways between barrier island environments (discussed in sec. 3.2.3). Back-barrier, marsh, and estuarine shores are relatively undisturbed during sediment placement on or along the open-coast shoreline but may experience similar impacts if nourished themselves (discussed briefly in sec. 3.2.2).

\subsubsection{Sediment Placement Effects During Construction}

Temporary impacts to open-coast barrier environments occur during construction and depend on the construction method. Typically, construction adversely affects recreational use of the beach because beaches are typically closed during construction (for example, Frazier, 2020; ABC7 Staff, 2020). The use of heavy equipment contributes to noise and air pollution at the construction site. Construction activities are often conducted on a 24-hour, 7-days-per-week schedule, but at some projects, construction progresses down the beach, so activity in front of any single property lasts only a few days (for example, Manatee County, Florida, 2020; Delmarva Now Staff Reports, 2019). Heavy equipment may also increase beach sediment compaction, potentially degrading beach and nearshore habitats (reviewed in Greene, 2002). Suspended fine sediment can temporarily decrease water clarity at the borrow and placement sites, interfering with food-web dynamics in beach and intertidal habitats (Manning and others, 2014). In some cases, placement activities and disruptions may be prolonged if storms induce changes in beach width and shoreface profile during construction, as described by Edge and others (1995) for Folly Beach, South Carolina. Regardless of the environment in which sediment is placed, the most immediate effects are changes to the morphology, generally followed by changes in the location of the placed sediment as it is distributed to other barrier island environments. All these changes have the potential to either improve or degrade beach and nearshore habitats, and these topics are discussed in sections 5 and 6.

\subsubsection{Placement Effects on Barrier Island Morphology}

The objectives of placing sediment within coastal systems are to reduce storm damage, increase recreational or other economic benefits, and (or) restore lost or damaged habitat (Dean, 1988, 2002; Dallas and others, 2012). These objectives are achieved by strategically placing sediment so that it increases the elevation and extent of the nourished or restored environment (National Research Council, 1995; Dean, 2002) or, in the case of shoreface nourishment, provides a source of sand and protection from waves (van Duin and others, 2004). Therefore, any given sediment placement activity will increase the local sediment budget and can be expected to elevate and expand the area in which the sediment is placed. The most common changes in a nourished region are higher and wider beaches, extended foreshore regions, and, if part of the design, higher dunes. This section discusses typical opencoast sediment placement practices and how they change the morphological and geological characteristics of the placement site, starting offshore with the shoreface and continuing across the barrier island to marshes and estuaries.

\section{Shoreface Nourishment}

Material placed underwater on the lower shoreface is termed shoreface nourishment (van Duin and others, 2004) and can be implemented with or without beach nourishment. Shoreface nourishments can be divided into stable berms or feeder berms (van Rijn, 2012). Stable berms are placed in deep water (greater than 10-15 m) and (or) are constructed of nearly immobile material and are intended to alter the waves and currents impinging on the beach. Feeder berms are intended to act as a supply of sand for adjacent beaches and tend to migrate onshore, though some remain stable (van Rijn, 2012). Shoreface nourishment projects add sand to the lower shoreface (outer bars and bar troughs) and are intended to add to the regional sediment budget, feed sand to the upper shoreface, and increase wave dissipation (Grasso and others, 2011).

In general, shoreface nourishment has two effects: (1) a feeder effect, whereby sand is supplied to the upper shoreface and beach via natural hydrodynamic processes; and (2) a lee effect, in which the nourishment site itself reduces landwarddirected wave energy, encouraging reductions in sediment transport away from the target site and ultimately sediment accumulation (van Duin and others, 2004; Grunnet and others, 2005); however, in some places, reductions in wave energy have not resulted in shoreline accretion (Barnard and 
others, 2009). The primary physical changes associated with shoreface placement are increased volumes and thickness of material in the lower shoreface (resulting in shallower depths) and potential changes in grain sizes (Brutsché and others, 2014) and cobble or shell content (for example, Huisman and others, 2018). Studies of effects of major nourishment projects in the Netherlands show substantial, multiyear changes to lower shoreface profiles, including the location, size, shape, and mobility of nearshore bars (van Duin and others, 2004; Grunnet and Ruessink, 2005; Ojeda and others, 2008). These profiles eventually returned to their original configuration, though that recovery took anywhere from 8 months to 7 years (Grunnet and Ruessink, 2005; Ojeda and others, 2008; Brutsché and others, 2014, 2015, 2017), suggesting that the benefits of this style of nourishment may be fleeting depending on local physical conditions. Some field and laboratory studies suggest that shoreface nourishment projects are successful at feeding sand to the beach (for example, Brutsché and others, 2014, 2015, 2017; Bryant and McFall, 2016; Smith and others, 2017) and are more persistent than beach nourishment projects (Hoekstra and others, 1997; van Duin and others, 2004; Grunnet and Ruessink, 2005; Huisman and others, 2019).

In a recent report from the U.S. Army Corps of Engineers (USACE) that addresses the state of the science on shoreface nourishment based on results from assessments of shoreface nourishment success, five topics for further research are identified (Krafft and others, 2020): (1) winnowing of fines from placed materials; (2) sediment transport predictions for nearshore placement projects; (3) turbidity generated by nearshore placement; (4) combined effects of nearshore and beach placements; and (5) equipment and costs associated with nearshore placement. This list, coupled with the development of several modeling tools that have been used to evaluate nearshore placements and ecological effects (Demirbilek and Rosati, 2011; Johnson and others, 2012; Brutsché and others, 2017), highlight that the physical and ecosystem impacts of shoreface nourishment depend on local conditions and mode of placement, and any implementation of such activities in CBRA environments should be carefully monitored to optimize the benefits of this relatively new approach.

\section{Beach Nourishment—Beach Profile and Planform Effects and Sedimentological Changes}

Beach nourishment is the most common type of sediment placement activity in coastal systems. It has become a widely accepted method for coastal protection in the United States (Nelson, 1993; Stauble and Kraus, 1993; National Research Council, 1995; Finkl and Walker, 2002), Europe (Delft Hydraulics Laboratory, 1987; Hamm and others, 2002; Hanson and others, 2002), Australia (Cooke and others, 2012), and China (Luo and others, 2016) in part because it is a method of "soft" engineering that avoids some of the adverse impacts to coastal amenities and ecosystems associated with hard structures. Davison and others (1992) state that beach nourishment is the preferred alternative for a variety of reasons. First, the resulting widened beach extends the foreshore and dissipates wave energy, is esthetically pleasing compared to hard structures, provides room for recreation, and resets the timescale for long-term erosion. Also, the placed sand adds to the coastal sediment budget and benefits downdrift beaches. Finally, sediment placement projects are flexible and can adjust to varying water levels and are often lower in cost, which are spread over a longer time, relative to hard structures (Davison and others, 1992). In this section, we introduce the concept of the equilibrium profile, which is the conceptual basis of most beach nourishment projects and then discuss how nourishment changes that profile and the planform shape of the beach. A discussion of sedimentological changes resulting from beach sediment placement completes this section. The review shows that although beach nourishment has many benefits, it is possible to minimize effects to barrier island ecosystems, which is critical for maintaining the physical and ecological integrity of the coastal barrier island system.

\section{Equilibrium Profile Concept}

The concept of an equilibrium beach profile (Keulegan and Krumbein, 1949; Brunn, 1954; Dean, 1991; USACE, 2008 ) is central to the design of nourishment projects (Dean, 2002). The concept is based on an interest in predicting shoreline position. Wright and others (1985) suggested that there is an equilibrium shoreline position related to grain size and wave characteristics, such that when conditions change (for example, grain size or waves), erosion or accretion will occur and move the shoreline toward the new equilibrium condition (fig. 5). In the context of sand placement on a beach, this theory suggests that increases in grain size or decreases in wave energy will cause the equilibrium shoreline to extend seaward, whereas decreases in grain size or increased wave energy will cause the shoreline to move landward. Furthermore, the shape of the equilibrium beach profile can be related to grain size (coarser sediment results in steeper slopes; Moore, 1982, cited in Dean, 2002; Dean, 1991; USACE, 2008), which has been noted as a characteristic of nourished beaches (Pilkey, 1990), as discussed in more detail below. Despite the widespread use of the equilibrium beach profile concept for the design of many beach nourishment projects, it is continually being expanded and reevaluated (Miller and Dean, 2004; Yates and others, 2009, 2011; Davidson and others, 2013; Castelle and others, 2014; Splinter and others, 2014; Montaño and others, 2020). Some authors have argued that adjustments to the profile are much more complex and that changes in grain size, subseafloor/beach geology, nearshore currents, and sediment transport beyond the seaward extent of the equilibrium profile are important to consider when predicting shoreline position and beach morphology (for example, Pilkey and others, 1993; Thieler and others, 1995). Some of these complexities can be addressed through thorough and robust pre-placement hydrodynamic and geomorphologic assessments. Appropriate assessment of shoreface grain size and the wave climate for a given timescale of interest could reduce the possibility that 




After a beach nourishment project is constructed, coastal engineers expect the beach to change gradually over time and assume a more natural form.

Figure 5. Changes in beach profile after nourishment. Illustration credit: U.S. Army Corps of Engineers (Fioto and Ward, 2015).

sediment transport would occur beyond the offshore limit of the equilibrium profile (Ortiz and Ashton, 2016). Also, geomorphologic assessments could identify the presence of seafloor (for example, hard bottoms) or subseafloor variability (for example, changes in sediment erodibility) that might limit profile adjustments resulting in actual profile behavior that differs from predictions (Kinsela and others, 2020). Appropriately constraining some of the sources of uncertainty surrounding the equilibrium profile will result in improved understanding of nourishment project efficacy and longevity.

\section{Beach Profile Changes Resulting from Beach Nourishment}

The primary changes in response to sand placement are wider, flatter, higher beaches (berms) (Ernest and Martin, 1999; Dean, 2002) with foreshores extending farther offshore. This artificial increase in the elevation and width of the beach often results in a beach profile that is not in equilibrium with prevailing oceanographic conditions. Therefore, the placement area will begin to adjust to wave, water-level, and current conditions, sometimes even before the project is complete and often very quickly thereafter (Pilkey, 1990; Willson and others, 2017), which may result in a steeper beach configuration (Pilkey, 1990). In some cases, this steeper shape increased beach erosion because of increased wave energy reaching the shoreline (Dolan and others, 1973). In other examples, steepened foreshore profiles caused by mechanical flattening and widening of the beach may have caused an offshore loss of material (gravel), resulting in permanent removal of material from the sediment budget (Anthony and others, 2011). Similar redistribution of sandy sediment beyond the shoreface and onto the inner continental shelf was also demonstrated at Folly Beach, S.C., and Wrightsville Beach, North Carolina (Thieler and others, 1999). Finally, as the nourished profile adjusts toward its new equilibrium slope, beach or dune scarps can form, which might create hazards or annoyances for beachgoers (de Alegria-Arzaburu and others, 2013) and obstacles for nesting turtles (Grain and others, 1995; Rivas and others, 2016) and for foraging shore/waterbirds (McLachlan, 1996; Rakocinski and others, 1996; Peterson and others, 2000a, 2006; Colosio and others, 2007). For any nourishment activities that occur within CBRA boundaries, designs should be evaluated thoroughly to ensure their predicted adjustments will not induce increased shoreline erosion, offshore sediment loss, or obstacles to human/animal access.

\section{Planform Changes}

One of the goals of beach nourishment is to create a wider beach, so most nourishment projects initially result in wider beaches over the length of the project per the design goals (for example, Dean, 2002). But this planform shape changes over time as placed sand erodes and spreads laterally along the adjacent shoreline. Coastal engineers have developed models to represent the retreat and spreading of placed material, some using simple linear or exponential retreat of the shoreline (Verhagen, 1993, 1996) and others using slightly more complicated approaches that account for the angle of waves relative to the new shoreline and resulting changes in longshore sediment transport (Pelnard-Considère, 1956). Dean (2002) provided an analytical solution for an initially rectangular planform and an infinite shoreline, which shows that the material spreads laterally over time (fig. 6). The modeled symmetrical shape is a result of an equal balance in the direction and magnitude of longshore transport rates (fig. 6A). Realworld changes can be more difficult to predict. First, longshore transport rates are often dominant in one direction, which skews the planform adjustment in that direction (Luijendijk and others, 2017), potentially resulting in uneven impacts to adjacent shorelines. Second, the longevity of the nourishment is linked to the spreading rate, or the rate at which sediment is spread laterally alongshore (Dean and Yoo, 1992). The spreading rate is episodic because it is driven mostly by storms, the frequency and intensity of which are difficult to predict now and may be complicated in the long term by climate change (Emanuel, 2013). The presence of seawalls, groins, jetties, or inlets will also affect the planform distribution (Dean and Yoo, 1992; Dean, 2002), as seen by Elko and others (2005) at a 


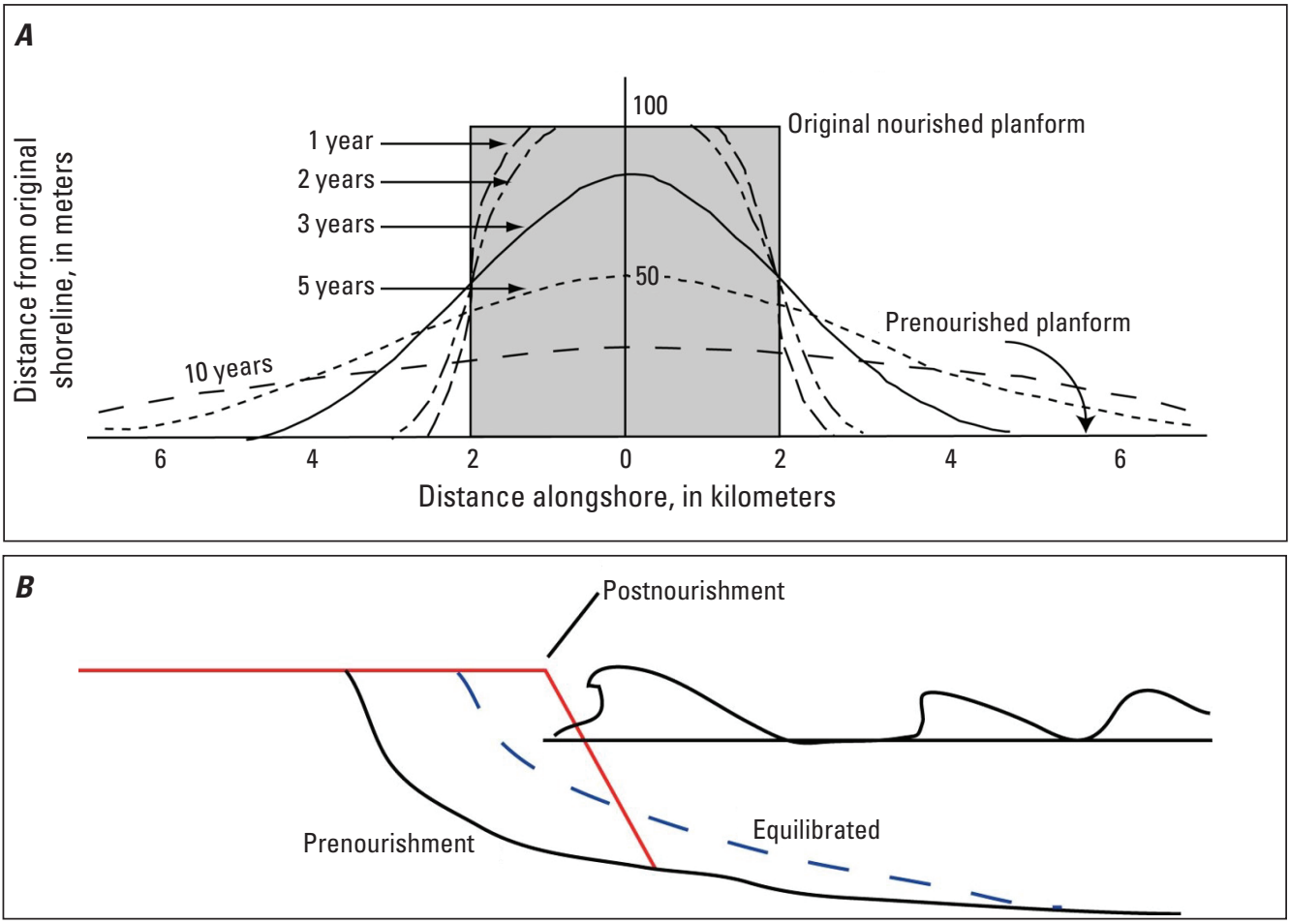

Figure 6. Changes after beach nourishment. Modified From Elko and Wang (2007) after Dean (2002). Reproduced with permission from Elsevier. $A$, planform shape. $B$, profile.

small (about 193,000 cubic meters) nourishment project on the west coast of Florida. Therefore, to understand the magnitude and nature of planform changes associated with a nourishment project, important factors to consider are the dominant direction and variability of longshore transport, storminess over the life of the project, and the location of existing coastal engineering structures and inlets.

Building on the insights gained from earlier, simpler models, many other numerical models have been developed to plan and evaluate the success of beach nourishment projects, including shoreline-change models like GENESIS (Hanson and Kraus, 1989, 2011) and more process-based multidimensional models such as Delft3D (Lesser and others, 2004; Grunnet and others, 2004; van Duin and others, 2004; List and others, 2007) and XBeach (Roelvink and others, 2009; Zimmermann and others, 2015), the latter of which have been validated against measured planform evolution of nourishment projects (for example, Bolle and others, 2011; Zimmermann and others, 2015; Bart, 2017; Luijendijk and others, 2017; Kroon and others, 2019). In the United States, coastal engineers often use the Coastal Modeling System (Demirbilek and Rosati, 2011). Recent studies have advocated for consideration of systems at a large scale to evaluate the effects of dredging, inlet modifications, or mining ebb shoals (Dabees and Moore, 2011; Roberts and Wang, 2012), which may be important for evaluating far-field and longer-term effects. It should be noted that many models simplify coastal systems (Young and others, 1995; Thieler and others, 2000). This may be more problematic for locations or environments where physical and ecological feedbacks are complex because biological habitat characteristics, such as vegetation density and height, are not typically included in even the more advanced models cited above. Though there have been many advances in the prediction of the physical evolution of sediment placement on beaches, it is clear that, to predict impacts to both the physical environment and coastal habitats, models that can be tuned to the specific physical and ecological characteristics of the placement location are needed.

\section{Changes in Beach Sediment Size, Composition, and Texture}

Sediment size and sorting (texture) are important to the design of nourishment projects because the use of compatible sediment will help to prevent drastic postplacement changes in beach elevation and width and will improve the accuracy of predictions of project performance (Stauble and others, 1985; Leonard and others, 1990; USACE, 2008). Grain size controls the mobility of sediment and, as discussed above, affects the equilibrium beach profile (Dean, 2002), affects the potential spread rate, and can be used to assess the compatibility of fill material. The grain-size distribution of placed material will initially reflect the borrow material but will change over time as the finer fraction is winnowed from higher-energy regions (for example, the beach) and transported to lowerenergy regions (for example, the lower shoreface). Guillén and Hoekstra (1997) found only temporary changes in postnourishment grain-size distribution, whereas modeling of a Dutch nourishment project, which introduced substantially coarser sand to the system, indicated that storms reduced the median grain size by mixing in finer sand from farther offshore or from underlying substrate (Huisman and others, 2018). The 
extent of changes in postnourishment sediment size will ultimately depend on how different the placed material is from the sediment found on the beach naturally. To assess the suitability of borrowed sediment for placement on the beach, a parameter called the fill factor is calculated. The fill factor is the ratio of the volume of sediment required to the volume of sediment that remains after a new equilibrium state has been achieved and is a function of the grain-size distributions of the native and placed sediment (Stauble and others, 1985). However, the methods by which the distributions are calculated and whether the placed sediment has substantial amounts of finer-grained sediment or shell can affect the accuracy of the fill factor, potentially resulting in erroneous estimates of how long the benefits of nourishment may persist (Stauble and others, 1985). Furthermore, the idea that grain size controls the longevity of a nourishment project and that coarser material will last longer is ingrained in the engineering literature (for example, Berg and Duane, [1969]; Dean, 1983), but Leonard and others (1990) found no evidence for this in a review of beach nourishment projects on the U.S. east coast. Consistent determinations of grain-size distributions between native beach sediment and nourishment sediment and the fine and shell fractions of the borrowed material are needed before placement to ensure the best predictions of nourishment longevity.

In addition to changes in grain size and sorting, beach nourishment may also result in beach sediment compaction, or a reduction in the void space between sand grains, in two important ways. First, heavy construction equipment used during nourishment or subsequent use by recreational vehicles can increase beach sediment compaction. Tilling is sometimes used to reduce these effects upon project completion. Second, some barrier islands, such as those on the Mississippi Delta and the Virginia coast, are underlain by poorly consolidated (for example, relatively loose) sediment. Rosati and others (2006) caution that placing sediment to nourish islands with similar geology, such as those in New Jersey and parts of North and South Carolina, could cause compaction of the underlying strata and subsidence, or loss of land elevation. Rosati and others (2006) used a model to forecast nourishment-related subsidence, and the results suggested that single, large nourishment placements are more effective at reducing land elevation loss than those that place an equal amount of sediment incrementally over time. Though tilling may be effective at reducing surface sediment compaction, only knowledge of the subsurface geology of a barrier island will provide insight about the likelihood of nourishmentinduced land elevation loss.

In addition to the physical impacts discussed above, changes in the texture, composition, and compaction of beach sediment resulting from nourishment can also affect the suitability or quality of beach habitat. For example, Ernest and Martin (1999) note that, in addition to a different texture, placed sand can have a different color and mineral composition, which can affect temperature and moisture content, both potentially important for turtle nest incubation. They found that nourished beaches in Florida, which had sharp changes in beach slope and darker, coarser sediment richer in calcium carbonate (and thus higher moisture content and temperature) were less suitable as Caretta caretta (Linnaeus, 1758) (loggerhead sea turtle) habitat than an adjacent unnourished control beach. Though this is just one example, more detail about impacts to habitat resulting from sediment placement on beaches is discussed in section 6 .

\section{Dune Construction and Nourishment}

Constructing artificial dunes or enhancing existing dunes may be the primary form of coastal nourishment and restoration or a part of a larger project. Psuty and Silveira (2013) classify a wide range of foredune construction approaches, and stress that morphologic and functional variability is a vital part of foredune restoration. In natural systems, foredunes typically form with a characteristic setback from the shoreline, determined by local wind and wave conditions and by vegetation. For scenarios in which artificial or rehabilitated dunes are intended to mimic natural features, sediment may be placed amongst rows of existing dunes. This may include sand augmentation from beach scraping, where heavy machinery is used to move sediment to the base of the dune line (Psuty and Silveira, 2013). Alternatively, intentionally planted vegetation or placement of sand fencing may encourage sediment to accumulate in the backshore (Psuty and Silveira, 2013). In developed systems, dunes may be constructed seaward of where natural dunes would occur because fixed infrastructure often reflects coastal conditions as they existed decades earlier. In such cases, the primary purpose for a dune is likely to be a defense against storm-related increases in water level; therefore, construction of a high dune seaward of the natural dune line may be necessary despite the potential for beach sediment loss caused by increased wave reflection during storms (Dolan and others, 1973; Psuty and Silveira, 2013; Elko and others, 2016).

Dune nourishment may include modifications to support habitat restoration (Elko and others, 2016). For example, constructing or modifying a dune line could include purposeful notching along the crest line or installation of nonlinear dune forms to permit storm-driven overwash, allowing the transfer of beach and dune sediment into the back-barrier environment. At Assateague Island, Maryland, dune notching was used to provide habitat for Charadrius melodus (Ord, 1824) (piping plovers), a species that relies on overwash for habitat creation and quality (Schupp and others, 2013). Other considerations in dune sand placement can involve constructing or restoring dune slacks or intradune wetlands, which often provide habitat for rare and endangered coastal species (Grootjans and others, 2002). In the long term (decades or more), construction or modifications that promote natural processes, such as overwash, can help maintain the morphological integrity of barrier islands. Rapidly rebuilding dunes without considering natural processes can disrupt the transfer of sediment throughout the barrier system, which is critical for maintaining not 
only beaches but also marshes. Ultimately, this disruption may drive increasingly deleterious morphological and ecological effects, including enhanced erosion and chronic flooding (Elko and others, 2016). Our review of the available literature suggests that dune-building and restoration practices that maintain the coupling between physical and ecological processes in barrier island environments can support storm -defense, habitat creation and restoration, and the long-term resilience of barrier islands simultaneously.

\section{Marsh Nourishment}

Diverting sediment-rich river water (for example, Allison and Meselhe, 2010) or mechanically adding thin (a few centimeters to $0.5 \mathrm{~m}$ ) layers of sediment to marsh surfaces (thinlayer deposition [TLD] or thin-layer placement; Berkowitz and others, 2019) is intended to restore marsh-surface elevation (Cahoon and Cowan, 1988; DeLaune and others, 1990; Ford and others, 1999; Slocum and others, 2005; USACE, 2020). The TLD process involves spraying a sediment slurry on the marsh surface such that elevation relative to the tidal range is optimized for vegetative growth. Sediment used in marsh restoration is usually fine material suspended in the water column of adjacent rivers or estuaries or dredged from nearby channels, sediment that would not be suitable for nourishing high-energy, open-coast beaches. For example, marsh restoration projects on the Mississippi River Delta use suspended sediment from the channel of the Mississippi River (Allison and Meselhe, 2010; Krauss and others, 2017); most of the sediment filling the restored South San Francisco Bay salt flats is derived from sediment suspended in the bay (Shellenbarger and others, 2013); and the sediment filling previously diked regions in northern San Francisco Bay is suspended sediment derived from the estuarine turbidity maxima of the Petaluma River (Ganju and others, 2004). Thin-layer placement is one of the beneficial uses of dredged material from navigation channels in most coastal States; examples in New Jersey, Texas, and the Gulf coast are provided by Lunemann and others (2017), Randall and others (2000), and Parson and Swafford (2012), respectively. As of 2012, about 20-30 percent of the greater than 100 million cubic yards of material dredged from Gulf coast navigation channels was used to restore marsh habitat (Parson and Swafford, 2012).

Studies of TLD projects in Mississippi, North Carolina, and New Jersey suggest that the technique is capable of elevating marsh surfaces, changing soil chemistry by reducing hydrogen sulfide, temporarily increasing nutrients, and sometimes encouraging the growth of intertidal marsh vegetation (Cahoon and Cowan, 1988; Croft and others, 2006; La Peyre and others, 2009; VanZomeren and others, 2018). La Peyre and others (2009) found that above-ground vegetation decreased in areas that were vegetated before TLD but that vegetation approached biomass levels of the surrounding marsh in interior ponds where TLD raised their elevations. Slocum and others (2005) concluded that the long-term effects (7 years) of TLD were positive: elevations and above-ground biomass of Spartina alterniflora (Loisel) (saltmarsh cordgrass) were increased compared to adjacent untreated marsh. As in other systems where there is a dynamic balance in sediment budgets, there is a risk that dredging sediment from nearby channels to supply sediment for marsh restoration can lead to increased sediment loss on adjacent tidal flats or marsh edges (Redfield, 1972; Ganju, 2019), and flow diversion can cause a loss of river power, leading to shoaling downstream (Meselhe and others, 2016). Other methods of supplying sediment to marshes include disposal of dredged material into shallow tidal channels that feed mud to adjacent marshes or tidal flats (Baptist and others, 2019). Ganju (2019) cautions that sediment-transport measurements and models should be considered to determine if marsh restoration will be successful. It is clear from the literature that the addition of sediment to marshes can increase their elevation and promote vegetation growth, but that monitoring before and after the project can help clarify whether natural sediment supplies to marshes are adversely affected by the removal and placement of sediment.

\section{Nourishment of Estuarine Beaches}

Estuaries and back-barrier environments generally have lower wave energy than ocean beaches, but nourishment projects are still susceptible to spreading and loss by wave action (for example, DeLange and Healy, 1990). Nourishment projects in lower-energy estuarine environments can create wider and higher beaches, possibly with different sediment characteristics, than would occur naturally (Jackson and others, 2010). Higher berms can restrict transport of sediment and fauna between the foreshore and backshore environments. Also, because nourishment projects in estuarine environments will likely require finer-grained sediments, they may be targeted as "beneficial use" sites for sediments dredged from navigation routes in estuarine bays and creeks (Terwilliger Consulting, Inc., 2008). In one case in New Jersey, dredged sediments contained contaminants, which preferentially bind to finer sediment grains (Thorne and Nickless, 1981; Witkowski and others, 1987) at levels that could be detrimental to benthic fauna and shorebirds (Terwilliger Consulting, Inc., 2008) at the placement site and at any location to which those sediments were dispersed. Relative to other types of restoration considered in this report, there are few studies in the literature that evaluate the benefits or drawbacks to nourishment of estuarine beaches. Therefore, additional research and monitoring of placement on estuarine beaches and impacts to surrounding environments will be needed to achieve the same level of understanding of open-coast placement impacts.

\subsubsection{Effects Beyond the Placement Area}

Placing sediment on the barrier can potentially affect barrier island environments offshore of, next to, or even behind the placement location. This section addresses the nature of those effects. As soon as the placement project is completed, and often sooner, waves and currents begin to reshape the 
placed material, transporting sediment seaward, downdrift, and, in the case of storms, landward. Similarly, onshore winds transport beach sediment landward to build and grow dunes. In addition to these physical changes, postnourishment redistribution of sediment may create or destroy natural habitat, and the ecological effects on benthic and subaerial habitats are discussed in sections 4 and 6 , respectively.

\section{Changes in the Beach Profile/Planform}

The tendency of the beach/foreshore profile to return toward an equilibrium shape moves sand seaward and downdrift, as discussed above, which often alters barrier island environments beyond the project area. The seaward movement of material extends the lower shoreface, thereby changing the adjacent seafloor and possibly rapidly burying adjacent benthic habitats. If the habitats are not physically buried, seaward extension of the lower shoreface may result in changes in the grain-size distribution, mineralogy, and geochemistry of the seafloor, which, in turn, alters the quality of benthic habitats. These processes are discussed in more detail in section 4 . Changes in the planform shape of a placement project are driven by longshore transport, the rate of which is controlled by wave height, the angle of wave approach to the beach, and sediment characteristics (Dean, 2002). As noted above, longshore transport tends to spread placed material laterally, often with a preferred downdrift direction. The spreading of placed material to adjacent beaches is generally considered beneficial to downdrift communities from a physical perspective (Davison and others, 1992), providing some of the same erosion-protection and recreational benefits intended for the placement area. Dean $(1988,2002)$ determined that the damage-reduction and recreational benefits of beach nourishment projects increase as material is lost from the placement site and accumulates at adjacent sites. This transported material may alter the morphology and sediment characteristics of barrier island environments beyond the project area. For example, sediment transported alongshore away from nourishment projects may be finer than native material, reducing the local grain size, as found in a nourishment experiment in the Netherlands (Huisman and others, 2018). Because the value of each additional foot of beach width decreases with decreasing width, the loss in benefits as the beach narrows at the placement site may be offset by the gains associated with increasing beach width at adjacent sites. Material placed near inlets may result in alongshore island extension of the barrier, growth of ebb- and flood-tidal shoals, and shoaling in channels, all of which may affect navigation routes. Oftentimes, as is the case at Folly Beach, S.C., this downdrift loss of sand is mitigated with a terminal groin (Kaczkowski and others, 2019). Though groins and jetties promote updrift accumulation of sediment, at inlets, they may inhibit inlet sediment bypassing (as discussed in sec. 3.1.2), thereby starving barriers downdrift. Therefore, identifying the timing and extent of possible downdrift effects before nourishment activities, particularly around inlets, will ensure that adverse impacts to downdrift barriers and habitats do not outweigh the local benefits of sediment placement.

\section{Changes in Dunes}

Aeolian (windblown) sand transport is important for building coastal dunes (Bagnold, 1941; Pye, 1983; Horikawa and others, 1986; Nickling and Davidson-Arnott, 1990; Hesp and Walker, 2013; Davidson-Arnott and others, 2019). Aeolian transport rates depend on natural factors, such as wind speed, grain size, moisture content, beach roughness (for example, pebble and shell lags, and wrack), binding agents (salt crusts, snow, and ice), algal mats and vegetation cover, beach topography, and fetch (Davidson-Arnott and others, 2019; Poppema, 2020). Human obstacles, such as trash, snow/sand fences, and buildings can also alter aeolian sand transport (DavidsonArnott and others, 2019; Poppema, 2020). Any modifications to these controlling factors by beach nourishment can change aeolian transport and, in turn, dune formation and growth. Fetch is particularly important, and critical fetch distances (the distance required to achieve maximum sand-transport rates) can exceed $100 \mathrm{~m}$ on natural beaches (Delgado-Fernandez, 2010). In general, wider beaches aid dune growth (de Vries and others, 2011, 2012; Silva and others, 2019), and there are examples of this in the literature. For example, wider beaches at two large nourishment projects at Bridgehampton, N.Y., and Nags Head, N.C., resulted in substantial dune growth (Kaczkowski and others, 2018). Furthermore, combining processes that increase aeolian transport rates with those that anchor sediment for dune formation can be beneficial for dune growth. At a long-term nourishment project on Long Island, wider beaches increased sand transport, whereas vegetation and sand fencing served to anchor sediment, thereby supplying sediment for and promoting dune formation and growth (Bocamazo and others, 2011). There are differing ideas as to why wider beaches promote dune growth; some authors suggest that the main contribution is the protection of dunes from elevated wave energy during storms (Nordstrom and Arens, 1998), whereas others report that much of the sand supplied to dunes originates from the nourished intertidal region (Hoonhout and de Vries, 2017). Regardless of the exact mechanism, it follows that either shoreface or beach placement that increases beach width could beneficially affect dune growth rates if the barrier island sediment supplies persist.

Though wide, nourished beaches generally support dune growth, other factors should be considered. First, the grain size and composition of placed sediment may not always support dune growth. Van der Wal (1998) found that nourishment sands were less suitable for aeolian transport because they were poorly sorted and contained large amounts of shell fragments. In another study, selective transport of the finer fraction of poorly sorted, nourished sand altered the grain size of adjacent dunes (van der Wal, 2000). Also, dune growth and associated increases in vegetation could impinge on barrier island habitats, such as for piping plover (Cohen and 
others, 2009; Bocamazo and others, 2011). Furthermore, the seaward advance of the foredune line and increases in dune height may result in a more continuous dune line, which could reduce the transport of material via overwash and via wind to back-barrier environments (Psuty and Silveira, 2013) and marshes (Rodriguez and others, 2013). These outcomes may not be beneficial for the long-term resilience of the barrier island itself, particularly as sea levels rise (see further discussion of this point in sec. 7.2). Finally, emplacement of an artificial dune in front of where a natural dune would occur (as determined by local wind/wave/vegetation conditions), as well as nourishment/stabilization of the active dune in the absence of a consistent source of beach sediment delivery, may lead to deleterious changes to beach morphology. Dolan and others (1973) found that stabilizing dunes in the North Carolina Outer Banks resulted in a steepening and shortening of adjacent beach profiles because beaches were winnowed and eroded by waves reflected by immobile dunes. In the early 1970s, the National Park Service recognized this change occurring in systems where artificial dunes had been constructed and maintained since the 1930s, especially at Cape Hatteras National Seashore where, on average, almost $50 \mathrm{~m}$ of beach had been eroded (Binkley, 2007). Subsequently, the National Park Service discontinued aggressive dune maintenance and nourishment policies at Cape Hatteras National Seashore in 1973 (Binkley, 2007). In total, the literature suggests that nourishment-related increases in beach width result in greater aeolian transport to dunes. However, benefits of dune growth to other parts of the barrier system may be jeopardized by substantial sediment texture differences between native and placed sediment and (or) the alteration of natural sediment transport pathways among beach, dune, and backbarrier habitats.

\section{Changes in Marsh and Other Back-Barrier Environments}

Beach nourishment and dune construction can affect sediment supply to back-barrier and marsh environments. Beach and dune nourishment/construction will serve to increase the overall sediment budget of the barrier, resulting in sediment delivery to back-barrier environments that allow them to maintain or increase their elevations and continue to provide ecosystem services. However, the benefit of excessive dune growth is limited. A more continuous or higher dune line may reduce overwash transport of material (Psuty and Silveira, 2013), possibly making back-barrier environments more vulnerable to passive drowning or erosion over decadal and longer timescales (Magliocca and others, 2011; Rogers and others, 2015). Models suggest that the morphology of barrier islands exhibit wider variations through time when moderate overwash events are eliminated by high, artificial dunes because eventual narrowing and drowning of the barrier renders the landscape more susceptible to large sediment displacements during extreme storms (Magliocca and others, 2011). Back-barrier marshes are particularly sensitive to the fluxes of sediment from beaches and dunes. Too little supply from overwash can starve the marsh of important inorganic sediment, thereby limiting increases in marsh surface elevation (Smith and others, 2013). But too much supply can cause excessive loading on the organic-rich sediment matrix reducing marsh elevation and (or) excessive increases in elevation that make the marsh unsuitable for plant colonization (Walters and Kirwan, 2016). Additionally, vegetation changes have been associated with the combined reduction in overwash and saltspray resulting from dune growth and construction. For example, woody vegetation has increased behind large, artificial dunes on Ocracoke Island, N.C. (Schroeder and others, 1977), a transition that primes the back-barrier ecosystem for "extreme disruption" when dune breaching occurs (Dolan and others, 1977). Additionally, the construction of a road and dunes on Pea Island, N.C., has reduced overwash and increased vegetation cover (Culver and others, 2006; Smith and others, 2008), which might reduce habitat quality for shorebirds (see sec. 6.2 for more details). A reduction in overwash is not the only process that might limit sediment supply. Reductions in wind-blown sediment are also a result of excessively high dunes and have affected not only marshes but also back-barrier tidal flats (Culver and others, 2006; Rodriguez and others, 2013). Though constructing large dunes or creating circumstances that promote excessive dune growth could protect coastal infrastructure from storms, it is clear that maintaining or restoring natural sediment transport pathways is critical for sustainably preserving the physical and ecological integrity of back-barrier environments.

\section{Other Changes}

In addition to physical impacts to other barrier island environments, sediment placement may also affect access and recreational use of the beach and surrounding environments that may warrant consideration. For example, changes in sediment composition might lead to a coarsening/hardening of beach sediment and (or) an increase in the temperature of the beach sand, both of which may hinder user enjoyment. Morphologic adjustments to the project placement, such as those discussed in section 3.2.2, may make it difficult for beach goers to access the water. Furthermore, widening of the beach may necessitate the expansion of accessibility measures at public points of access. Nourishment projects can also affect the quality of surfing conditions. For example, short-term negative effects on surfability occur as beaches are steepened by nourishment but are reduced as equilibrium is restored (Benedet and others, 2007; Hearin, 2012). However, long-term changes in surfability of open, sandy beaches may occur if nourishment-related grain size changes persist (Benedet and others, 2007). In a modeling study, a nourishment project affected the quality of the surf break adversely by (1) compressing the surf zone, (2) increasing the occurrence of "closeouts," (3) shifting the breaker type toward collapsing breakers, particularly during high tide, and (4) increasing wave reflection; it took almost 2 years for pre-project conditions to return (Dally and Osiecki, 2018). 
Post nourishment changes in water clarity have also been documented at a few locations. Hanes (1994) found that post nourishment turbidity on a west Florida site (Longboat Key) was highly variable in space and time and depended primarily on wave conditions. Furthermore, Pagan and others (2018) attribute increased turbidity after nourishment to rapid breakdown and dissolution of shell fragments and small conglomerate grains in the source material. Perhaps more importantly, however, nourishment-related changes in water clarity may have adverse effects on adjacent ecosystems. For example, Manning and others (2014) studied surf-fish foraging habitat in wave-tank mesocosms and found that turbidity persisting 4-8 months after beach nourishment reduced feeding of Trachinotus carolinus (Linnaeus, 1766) (Florida pompano) on Donax variabilis (Say, 1822) and Emerita talpoida (Say, 1817) (mole crabs). On the other hand, Roman-Sierra and others (2011) studied a large (0.6 million cubic meter) Spanish beach-nourishment project and found that the increases in turbidity during dredging lasted only a few minutes and affected an area of less than $400 \mathrm{~m}$. Suspended-sediment concentrations in the surf zone remained at background levels, and dredging effects on aquatic flora were reversible and had recovered in 1.5 years. Though explored in more detail in sections 4 and 5 , the studies above suggest that adverse effects of turbidity on water column and benthic organisms may be related to how long the reduction in water clarity persists.

\subsection{Other Impacts, Opportunities for Further Research, and Recommendations}

\subsubsection{Other Physical Processes for Consideration}

\section{Biogeochemical Effects Resulting from Sediment Removal and Placement}

In addition to shaping and maintaining the barrier island system through sediment exchanges, physical processes (for example, waves, tides, currents, and water-level gradients) also affect the movement of fluid found in the pore space of island and seabed sediment. Movement of fluid within the pore or interstitial space and the exchange of pore water with the overlying water column can be referred to as benthic fluid exchange, porewater exchange (Berner, 1980), wave or tidal pumping (Riedl and others, 1972; Thibodeaux and Boyle, 1987), irrigation (Boudreau, 1997, chap. 3), submarine groundwater discharge (Cable and others, 1996), and so on (Taniguchi and others, 2002; Burnett and others, 2003). Movement of these interstitial fluids depends on the interactions of physical processes and sediment composition (Riedl and others, 1972; Thibodeaux and Boyle, 1987; Webster and Taylor, 1992); therefore, any disturbances to the land surface or seabed that add or remove sediment have the potential to change interstitial processes (Huettel and Gust, 1992; Boudreau and others, 2001; Huettel and Webster, 2001; Huettel and others, 2003; van de Velde and others, 2018; Ahmerkamp and others, 2020), thereby altering the biogeochemical framework of the benthic environment (Boudreau and others, 2001; Burnett and others, 2003). Biogeochemical processes serve as critical links between coastal environments (for example, seabed, shoreface, beach, and dunes) and the biota living there (for example, microbial, fauna, and flora; Boudreau and others, 2001). At the base of nearly every ecosystem is the (a)biotic transformation of organic matter into energy and nutrients for further use within the ecosystem (Berner, 1980; Schlesinger, 1997). Fundamental research has addressed the processes controlling interstitial fluid flow and the consequences of porewater exchange, constituent transport, and biogeochemical fluxes, but the application of these scientific concepts to scenarios concerning sediment dredging and (or) placement within barrier island systems is not well documented. Therefore, modifications to fundamental fluid flow and biogeochemical processes represent a knowledge gap with respect to understanding the consequences of dredging and nourishment in these environments. In section 4 , a brief review of fundamental scientific concepts is presented as it relates to effects on benthic habitat and communities.

\subsubsection{Opportunities for Future Research}

Though numerous studies have focused on the effects of sediment removal and placement on coastal systems, this review has revealed a few topics that require more research and monitoring to better estimate beneficial and adverse effects of coastal sediment management:

1. Sediment removal from inlet-associated shoals, tidal flats, and channels and impacts to inlet shorelines and downdrift sediment supply.

The highly dynamic nature of inlet shoreline processes and evolution and the uncertain lengths of time associated with the onset of downdrift effects from sediment removal and placement make this one of the more challenging environments in which to assess impacts. Establishing the range of natural variability of these systems and a robust monitoring design (see recommendations in sec. 3.3.3) will be essential for identifying physical impacts from these practices. Also, persistent removal from shoals for nourishment downdrift represents a net negative sediment loss to the updrift barrier island, suggesting that studies address choices in removal and placement locations. Finally, because inlets are often used for navigation, they are more likely to be subject to the effects of "soft" (for example, beach nourishment) and "hard" (for example, jetty construction) coastal engineering practices, which may complicate the isolation of effects from sediment removal and placement alone.

2. Sediment placement on estuarine or backbarrier beaches. 
Compared to the volume of literature on open-coast sediment management impacts, very little documentation exists regarding the practice of placing sediment on estuarine or back-barrier shorelines. Because sediment placed on these beaches is likely to be finer grained, a contaminant assessment should occur before placement as is often the practice (U.S. Environmental Protection Agency and USACE, 2004). Additionally, estuarine and back-barrier shoreline dynamics are controlled by different drivers than open-coast beaches, so different impact monitoring data types, metrics, and frequencies may have to be identified.

3. Impacts to physical and ecological feedbacks from sediment placement.

Existing models that predict the natural response to sediment placement activities are typically focused on physical (for example, storm defense) and economic gains and typically neglect effects to barrier island ecosystems. It is clear from the literature that these sometimes-competing interests could be more balanced, resulting in a more realistic representation of sediment placement "success." Regional-scale models that account for alterations in sediment exchanges between barrier island environments (for example, reduced overwash to back-barrier marsh or increased aeolian transport to dunes) and include ecology are essential for a more holistic understanding of impacts of removal and placement on physicalecological barrier island systems.

\subsubsection{Recommendations for Impact Monitoring and Evaluation}

Robust monitoring of the physical effects of sediment removal and (or) placement consists of three parts: (1) establishing pre-action system variability, (2) monitoring effects over site-specific temporal and spatial scales that account for physical and ecological processes and hypothesized responses, and (3) monitoring unaltered sites. Regardless of the environment from which sediment is removed or in which it is placed, assessing the effects of the action(s) will be limited without quantification of the physical and ecological variability of barrier island systems before the action. Coastal systems, whether natural or managed, vary seasonally with wave conditions, episodically with extratropical and tropical storms, and over the long term with natural variations in sediment supply and water levels. These drivers cause a range of expected behavior in each barrier island system, and this baseline can be used to evaluate the nature and scale of postaction effects. Additionally, to assess the system-wide response to sediment management, any impact monitoring program should monitor not only the location in which the action has taken place but also areas downdrift and those in which no changes have been made as a means of providing a control. Peterson and Manning (2001) argued that most of what we know about beach nourishment is derived from monitoring projects that do not meet experimental design standards, often concluding an absence of biological effect when, in fact, the monitoring design may not have been able to detect those effects. The same is true for physical processes, so matching the frequency and spatial scale of monitoring to the physical characteristics of the barrier island system in question will ensure that all local and any downdrift impacts can be quantified. Finally, monitoring unaltered (for example, control) sites is particularly important for understanding barrier system responses in a changing climate because changing drivers may result in unprecedented barrier island system responses, leading to lack of clarity about whether the effect was due to a change in the driver or the sediment management activity itself. In addition to these recommendations, we provide a list of relevant monitoring data types and metrics capable of assessing removal and placement effects, beneficial or otherwise, to physical barrier island environments in appendix 1.

\subsection{Impacts to Benthic Habitats and Their Importance}

By James G. Flocks, Jill Bourque, Christopher G. Smith, Jennifer L. Miselis, and Christopher R. Sherwood

Benthic habitats are regions of specific physical (for example, hydrodynamic and sedimentologic) characteristics that promote the colonization of organisms that live in the seabed and are directly and immediately affected by sediment removal and placement. Benthic habitats support the ecosystem function of offshore environments. They support commercial and recreational fisheries of finfish and shellfish and provide prey items to mobile predators such as demersal fish, shrimps, and crabs that in turn support bioenergetic transfer to larger fishes, sea birds, sea turtles, and marine mammals (Hill and others, 2011). Benthic communities are completely removed or buried during sediment extraction or placement operations (Byrnes and others, 2004a, 2004b; Xu and others, 2014), and time for recolonization by those communities is related to the reestablishment of pre-excavation hydrodynamic, sediment characteristics (for example, infilling), and additional biological factors. Prolonged or episodic infilling of the borrow site, or infilling with sediment different than what was removed (for example, different sediment grain size), will not only prevent reuse of the borrow area but will also prolong the ecological effects (Bergquist and others, 2009; McCoy and others, 2010 - as referenced in Xu and others, 2014). This section discusses the physical changes to the seabed and associated water column properties resulting from sediment removal and placement and the resulting impacts to benthic communities.

Main points from this section are as follows: 
- Sediment removal can change three principle physical factors: water depth, sediment composition, and the hydrodynamic conditions at the seafloor. These changes can affect habitat characteristics for benthic organisms.

- Changes in sediment characteristics after sediment removal, such as a borrow trench infilling with sediments that are finer in size than what was removed, may result in a change in benthic habitat type and subsequent recolonization by organisms more amenable to the new bottom structure.

- Immediate impacts in benthic communities from sediment removal are mortality and reduced abundances related to the physical removal of sediments. Over the short term, effects are typically characterized by temporary increased abundances of opportunistic taxa and low diversity associated with increased organic matter released during sediment removal. Longer-term impacts to benthic communities are typically related to persistent changes in physical sediment characteristics, such that the longer postremoval conditions differ from preremoval conditions, the longer the benthos will be affected.

- Recovery of benthic communities depends on multiple physical and biological factors, including location and depth of dredging, the dredging footprint, differences in sediment characteristics before and after removal, local hydrodynamics, and the composition of the benthic community. In general, benthic communities recover to preremoval conditions faster when postremoval sediment characteristics closely match preremoval conditions.

- In addition to localized changes, sediment removal can affect nearby sensitive habitats, including seagrasses, corals, and other hard bottoms through sediment plume effects (for example, increased turbidity and light attenuation) and subsequent sediment deposition that can smother sessile taxa and fragment habitats. Studies have found these impacts, in general, to be short lived and of limited extent.

- Sediment placement impacts to benthic communities are related to placement location. Beach placement results in initial mortality and persistent reduced abundances of prey taxa important to foraging shorebirds and surf fish, and the length of effects is related to changes in physical characteristics on the beach (such as beach slope) and timing of placement. Subtidal placement of sediments results in burial and mortality of sediment fauna and increased turbidity and nutrient particulates that can affect nearby sensitive sessile fauna (for example, corals). Thin-layer sediment placement in degraded marshes may have a positive effect by increasing vegetation cover and infaunal abundance.

\subsection{Physical Changes Resulting from Sediment Removal}

\subsubsection{Surficial Seabed Changes Resulting from Sediment Removal}

Benthic habitat is a combination of physical (for example, substrate type and dimension) and biological (for example, species tolerance and preference) components (Diaz and others, 2004). The biological component responds to changes in the physical component. Removal of sediment from offshore, the shoreface, or inlet-associated shoals will change three principle physical factors: water depth, sediment composition of the seabed, and the hydrodynamic conditions experienced at the seabed. Changes in depth and waves and their effects on shoreline configuration and sediment supplies are discussed in section 3. However, changes in sediment composition within and around the sediment removal area can change the habitat characteristics that benthic organisms require. The primary physical characteristics relevant to benthic habitats are grain size, stratigraphy, and compaction (Nairn and others, 2004), which are discussed below. Relatively little information could be found on other important physical characteristics (Nairn and others, 2004), such as mineralogy (briefly mentioned below), hypoxia, and organic content (discussed in sec. 4.1.2).

Grain-size changes occur when buried sediment units (or strata) with different characteristics are exposed by the removal process (Nairn and others, 2004). Stratigraphic differences are more likely to be within the same sediment size class (for example, transition from fine sand to medium sand) because most sediment removal is preceded by some level of stratigraphic exploration. However, if an entire seafloor sediment feature is targeted, exposure of underlying sediments of different character would be more likely. Grain-size differences may also occur if the borrow area is infilled with sediments different from the original character of the seabed (Desprez, 2000; Bergquist and others, 2009; McCoy and others, 2010 - as referenced in Xu and others, 2014), such as from a decrease in current strength resulting in the deposition of finer sediments (Newell and others, 1998). In two borrow areas offshore of South Carolina, Crowe and others (2016) found that sediments infilling the trench after excavation shifted to a finer grain size throughout the 6-year monitoring period. A mixed sediment (for example, heterogenous) site off the French coast became mostly sandy (for example, homogenous) as tidal currents deposited sand in dredge furrows (Desprez, 2000). In high-energy environments proximal to estuaries, deposition may be episodic leading to vertical changes in grain size in the borrow area (for example, alternating sands and muds; Xu and others, 2014). Prolonged accumulation of fine sediments may lead to a change in bottom 
texture or differing rates of postremoval compaction, creating a change in benthic habitat and subsequent recolonization by organisms more amenable to the new bottom structure (Newell and others, 1998; Byrnes and others, 2004b). Monitoring a dredge pit off the east coast of Florida, Johnson and Nelson (1985) observed a decrease in sediment grain size from a medium sand to a fine sand immediately after excavation, presumably because of the trapping of finer-grain-size sediment by the trench. Comparing faunal assemblages within the trench to those outside of the trench, they found that abundance decreased initially but returned to normal conditions after 12 months. However, they found that the dominant species shifted from crustaceans and bivalves to polychaetes. The dominance of polychaetes continued beyond 12 months after excavation (see also sec. 4.2). Particularly for removal sites that are very deep, accumulation of fine sediments or organic material may also promote anoxic or hypoxic (for example, low or no oxygen) conditions, which would deter recovery of the benthic community (Byrnes and others, 2004b). Mineralogical changes can occur after sediment removal, such as differing ratios of sand (for example, quartz) and shell (for example, carbonate), though it is unclear how this might affect the benthic community (Xu and others, 2014).

Grain-size changes can also occur outside the site of sediment removal. A study by Newell and others (1998) found that 80 percent of the sediment plume created by sediment removal was deposited within a few hundred meters of the borrow site. Furthermore, during prolonged or recurring sediment removal activities, originally heterogeneous seafloor texture adjacent to the borrow site may be blanketed by more highly sorted target sediment from the borrow site (Desprez, 2000). This is particularly common when finer-grained overburden sediments are cast aside to access sandy sediments beneath them. Depending on the thickness and persistence of these changes in surficial sediment characteristics outside of the borrow area, benthic communities adjacent to the borrow zone may be buried and (or) their continued colonization of the seabed may be deterred (see sec. 4.2.3 for more information).

\subsubsection{Potential Effects to Sediment and Porewater Biogeochemical Framework}

Biogeochemical processes serve as critical links or intermediaries between physical coastal environments (such as, seabed, shoreface, beach, and dunes) and the biota living there (such as, microbes, flora, and fauna). At the base of nearly every ecosystem is the (a)biotic transformation (recycling) of organic matter into energy and nutrients (for example, organic matter remineralization) for further consumption within the ecosystem. In settings where seabed sediments are often permeable and low in organic matter, as is common in barrier island settings, changes to seabed composition from either removing or adding sediment can perturb the biogeochemical processes driving organic matter remineralization. As such, these perturbations ultimately affect the conversion of organic matter to energy and other biologically available constituents and thus affect the energy balance throughout the benthic-pelagic food web (Rusch and others, 2000; Boudreau and others, 2001; Precht and Huettel, 2003; Jahnke and others, 2005; Ahmerkamp and others, 2020). Unfortunately, few studies, if any, have examined the effects of sediment removal or placement on interstitial fluid flow, or flow between sediment grains, and associated effects on biogeochemical processes; however, numerous scientific investigations have been conducted on physical and biogeochemical processes within permeable sediments. These studies (for example, Rusch and others, 2000; Precht and Huettel, 2003) provide fundamental knowledge about the effect of sediment texture/composition, water column, interstitial physical processes, and (bio)geochemical boundary conditions on the resulting biogeochemical framework and therefore are transferable to barrier island and other nearshore settings including those that have been modified (Hannides and others, 2019).

In coastal and shelf sediments, increases in grain size correspond to decreases in overall organic matter content but an increase in organic matter degradability, thus reflecting the importance of efficient inorganic matter remineralization in permeable sediments as an energy source to nearshore food webs (Boudreau and others, 2001; Jahnke and others, 2005). Furthermore, the oxidation of organic matter has substantial implications for nutrient cycling (for example, carbon, nitrogen, phosphorous, iron, and magnesium), metal and (or) contaminant mobility, and the overall (bio)geochemical framework (Jahnke and others, 2005; Rusch and others, 2006; Ahmerkamp and others, 2020). Much of our knowledge on organic matter cycling in permeable coastal sediments comes from observational studies on large sand flats such as those found in the North Sea (Rusch and others, 2000; Ahmerkamp and others, 2020), an open shelf setting like the South Atlantic Bight region (Jahnke and others, 2005), coastal aquifers (Roy and others, 2010, 2011) and (or) experimental laboratory studies (Precht and Huettel, 2003), rather than barrier islands.

The effect that sediment removal (or placement) may have on organic matter remineralization will largely depend on changes in sediment texture and (or) composition, seabed morphology, sediment layer thickness, and the initial biogeochemical or reduction-oxidation conditions (Jahnke and others, 2005). Huettel and Rusch (2000) found that in settings with active surface water and pore-water exchange, increasing the permeability (and median grain size) of sediment resulted in an increase in the total amount of organic matter tracer retained in pore spaces/sediment, a decrease in the amount of organic matter in the water column, and an increase in overall organic matter degradation. In a similar laboratory experiment, Ahmerkamp and others (2020) found rates of oxygen respiration and denitrification (in other words, oxic and suboxic metabolic pathways) expectedly increased as microbial abundance increased; however, microbes tended to increase as sediment shape became more irregular rather than as a simple function of permeability. Conceptually, the results of these studies suggest a change in seabed sediment texture (median 
grain size and shape), such as that resulting from sediment removal or placement, could affect the flux of particulate organic matter across the seabed-water interface, its retention in pore spaces, and the rates at which microbial communities use it, all of which affect food and nutrients available to lower trophic levels.

\subsubsection{Water Column Changes from Sediment Removal}

An increase in the concentration of suspended particles in the water column during excavation activities (for example, sediment plumes from cutterhead dredges and spillover from hopper barges) decreases water clarity and quality. Water column sampling and acoustic Doppler current profilers have been used to monitor plume concentration and migration during dredging activities. A monitoring study by Hitchcock and Bell (2004) found high variability in sediment plume transport and turbidity, and sediment concentrations ranged from 5 to 120 times background levels (predredge settled conditions) up to $750 \mathrm{~m}$ from the dredge site. Overall, their study concluded that, although it is difficult to measure, the overall effect of increased turbidity during dredging activities is short lived and of limited areal extent. However, removal of sediments over or underlain with fine-grained sediments may produce prolonged and larger turbidity plumes (CSA International, Inc., 2010), and prolonged exposure of benthic communities and habitats to higher turbidity can increase stress and reduce tolerance to other negative effects (Hitchcock and Bell, 2004). In some monitoring studies, organic material entrained in the sediment plume outside of the active dredging area enhanced benthic production, provided that contaminants are not also introduced into the water column simultaneously (Newell and others, 1998). The dispersal of suspended sediments can reduce local oxygen levels within the water column (CSA International, Inc., 2010), although any reduction would be short-lived and diluted when compared to potential hypoxic conditions within the enclosed dredge pit.

\subsection{Benthic Community Changes Resulting from Sediment Removal}

Sediment removal is most commonly used for one of two purposes: dredging of navigation channels where the location of dredging is fixed, or extraction for use in beach nourishment or other infill where an appropriate source with sediment characteristics similar to the target placement area is identified. Benthic communities include sediment dwelling and sediment-surface dwelling invertebrate taxa (such as, polychaetes, molluscs, crustaceans). Multiple reviews have assessed the impacts to benthic communities from sediment removal (for example, Greene, 2002; Nairn and others, 2004; Newell and others, 2004; Bergquist and Crowe, 2009; Michel and others, 2013; Fraser and others, 2017). Overall impacts to benthic communities and their recovery trajectory depend on multiple physical and biological factors, including the location and depth of dredging, area of dredging, differences in sediment characteristics before and after removal, hydrodynamics, and the composition of the original biological community.

\subsubsection{Short-Term Removal Effects}

Immediate impacts to benthic communities from sediment removal activities are related to the extraction of sediments, which removes surficial sediments and associated fauna. Extracting sediment reduces abundance, number of species, and biomass; estimates of declines in abundance range from 45 to 88 percent and declines in species richness range from 25 to 60 percent (see Michel and others, 2013). Removing sediments can also include the removal of biogenic structures such as worm tubes used by other taxa for habitat (CSA International, Inc., 2010). Postremoval seabed shape, depth, and light conditions can change, disrupting the existing benthic community and provoking change in community assemblages, or the abundance and composition of taxa. On local scales, the extraction location can have a substantial effect on recovery of communities. For example, adjacent sand shoals can harbor different sediment communities, and further community differences can occur among the leading edges, crests, trailing edges, and swales where subsequent infill processes will differ (CSA International, Inc., 2010). Recovery of infaunal communities follows a typical pattern related to the disturbance of the seafloor (Rhoads and others, 1978; Hill and others, 2011), and changes in sediment texture could slow recovery of infaunal abundance and diversity (Byrnes and others, 2004a). Infauna recolonization predominantly occurs through larval recruitment (CSA International, Inc., 2010), and estimates of lateral movement from adjacent sediments are considered to be minimal (Brooks and others, 2006; Michel and others, 2013). Sediment hypoxia (low oxygen), sediment anoxia (no oxygen), and chemical contamination (for example, ammonia and sulfide) can inhibit larval settlement after dredging activities have ceased (Engstrom and Marinelli, 2005).

Because dispersal potential for resident taxa is often unknown and possibly limited, large removal areas are likely to recover more slowly than small areas or groups of small areas (Jutte and others, 2002). Initial recovery of benthic communities (often referred to as succession) is characterized by colonization of small-bodied, quickly maturing, rapidly reproducing, and shallow-burrowing taxa that possess an opportunistic life history (Pearson and Rosenberg, 1978; Rhoads and others, 1978; Newell and others, 2004).

During initial recolonization, the specific opportunistic taxa that appear will differ between geographic areas. The process of recolonization may initially increase the overall abundance of fauna in removal areas but result in low diversity, often supported by high concentrations of organic matter released during dredging (Newell and others, 2004). Early colonizers are followed by transitional taxa, which burrow deeper into the sediment and provide greater sediment oxidation (Rhoads and others, 1978). Abundance typically decreases 
during the transitional phase, but diversity increases. The length of time for each of the recovery stages depends on the postremoval physical (such as, grain size and hydrodynamics) and biological (such as, recruitment and predation) factors at the removal site. For example, sand extraction resulting in deep dredge pits disrupts bottom water flow and makes dredge pits more likely to infill with fine-grained sediments. This change in sediment texture leads to slower succession of benthic communities resulting in longer recovery periods. For dredging of sand resources, recovery of abundance and biomass can occur within 3 months to 2.5 years (Brooks and others, 2006); faster recovery is associated with either similar postremoval physical characteristics and (or) in areas of frequent natural disturbance (discussed in sec. 4.2.4). Simonini and others (2007) found that, at borrow sites in the Adriatic Sea where dredging did not alter the sediment characteristics, there was rapid (6-12 months) initial recovery of the dominant predredging taxa, but that it took about 30 months for the full benthic community to be re-established. Recovery of abundance and biomass can be much longer when sediment characteristics are dissimilar to preremoval characteristics, such as when fine-grained sediment infills sand extraction sites (Palmer and others, 2008; Crowe and others, 2016). The composition of resultant short-term communities depends on the new physical characteristics at the removal site and will differ in composition and relative abundance of taxa from the original community. Overall, short-term impacts of sediment removal on benthic communities are related to the physical extraction of sediments, resulting in mortality and alteration of the sediment community from changes in the physical characteristics of the sediments.

\subsubsection{Long-Term Removal Effects}

Lasting changes to the sediment substrate, such as the replacement of coarse material with finer material, can cause shifts in the structure of the benthic community and large decreases in species richness and biomass (Desprez, 2000). After transitional taxa are established, equilibrium taxa are incorporated into the sediment community. Equilibrium taxa are larger, deeper burrowing, and long-lived, and have low reproduction rates (Pearson and Rosenberg, 1978; Rhoads and others, 1978). Their colonization suggests a stable physical environment that represents full recovery of the sediment community, assessed as having similar abundance, biomass, and diversity to preremoval communities. However, as noted above, the resultant stable community at a removal site may not consist of the same taxa as preremoval based on the new sediment properties and local hydrodynamic regime. Many studies typically only assess impacts $1-2$ years postdredging (for example, Naqvi and Pullen, 1982; Jutte and others, 2002; Peterson and Bishop, 2005; Bergquist and others, 2008, 2009) where community composition remains different from preremoval communities despite variable recovery in abundance and diversity. Substantially different community composition within dredge pits have been documented as long as 8 years postdredging (Palmer and others, 2008; Crowe and others, 2016) associated with fine-grained sediment infill. Information on the functional role of postremoval infaunal composition changes to higher trophic levels is scarce. Estimates of ecosystem function suggest that functional equivalency had not occurred 4 years postdredging, and functional diversity remained lower for 5 years in United Kingdom sediments (Cooper and others, 2008, 2011). Overall, long-term effects to benthic communities from sediment removal are closely related to the change in the physical sediment environment. Because impacts from sediment removal can be long-lasting (greater than 2 years), longer monitoring datasets are required to assess effects on sediment communities and related changes to higher trophic levels and to improve prediction of recovery rates to equilibrium communities. If additional sediment removal occurs before recovery of the affected communities, the cumulative effect may deter complete recovery.

\subsubsection{Effects to Areas Outside the Removal Area}

Mechanical disturbance from sediment removal activities can resuspend sediments in the water column that are then dispersed by currents and waves resulting in temporary sediment plumes and increased turbidity that extend outside the area of removal (Newell and others, 2004; Sutton and Boyd, 2009). The spatial and temporal extent of these plumes depend on the dredging process used and site-specific sediment characteristics and hydrodynamic regime (Hitchcock and Bell, 2004; Newell and others, 2004; Sutton and others, 2009). For example, the spatial extent of sediment plumes can range from 300 to $600 \mathrm{~m}$ for sand-sized particles and up to 3.5 kilometers $(\mathrm{km})$ for silt (Newell and others, 2004) (CSA International, Inc., 2010). Sedimentation from sediment plumes can bury adjacent benthic habitats, resulting in suffocation and mortality. Decreases in short-term abundance (34-70 percent) of macrofauna has been documented in soft-sediment habitats as far as $100 \mathrm{~m}$ from dredging (McCauley and others, 1977). Areas surrounding a borrow site off the coast of France were blanketed in sand resuspended during dredging, causing shortterm decreases in benthic species richness and longer-term (greater than 2 years) decreases in biomass (Desprez, 2000). This is particularly common when finer-grained overburden sediments are cast aside to access sandy sediments beneath them. Depending on the thickness and persistence of these changes in surficial sediment character outside of the borrow area, benthic communities near the borrow zone may be buried and (or) their continued colonization of the seabed may be deterred. Also, introducing non-nutritive particles to the sea floor during the settling of the sediment plume may reduce the food supply for filter feeders (Greene, 2002). Although reductions in abundance because of sedimentation typically decrease with distance from dredging (Johnson and Nelson, 1985; Desprez and others, 2010), increased faunal abundance and diversity have been observed near dredging associated with sedimentation of organic matter (Newell and others, 2004). 
Increased water column turbidity is a particular concern when sediment extraction occurs near sensitive habitats, such as coral reefs, other hard substrates, and aquatic vegetation. These habitats provide structural refuges for early life stages of fishes and crustaceans (for example, Lindeman and Snyder, 1999; CSA International, Inc., 2010) and harbor food sources for many invertebrates, sea turtles, finfish- and mollusk-eating diving birds, and marine mammals. Increased turbidity and sediment plumes can cause increased sedimentation that can smother nearby low-mobility fauna, corals, and other hard-substrate communities resulting in large-scale mortality (Dodge and Vaisnys, 1977) and suppressed growth (Anthony and Fabricius, 2000; the effects on mobile species are discussed in sec. 5.2.1). High sedimentation was observed on coral and hard bottom habitats in south Florida and was associated with coral mortality and bleaching, and macroalgae and epifaunal mortality (Courtenay and others, 1972; Michel and others, 2013; Miller and others, 2016; PortMiami and others, 2017). Followup monitoring indicated that coral damage had recovered within 7 years (Courtenay and others, 1980). Larval colonization of multiple invertebrates onto hard substrates can additionally be inhibited by sedimentation (Thorson, 1966; Rogers, 1990). Sedimentation and reduced water clarity from turbidity plumes in seagrass habitats can cause seagrass mortality and decreases in net community production (Caldwell, 1985). However, sedimentation events are usually short-lived; estimates from Florida indicated a return to predredging conditions after 2 weeks (Michel and others, 2013; PortMiami and others, 2017). Our review of the literature suggests that careful planning of sediment removal locations helps to reduce any impacts to sensitive habitats.

\subsubsection{Biological Controls on Effect Duration}

In addition to the physical factors affecting benthic communities, multiple biological factors can play a role in determining the length of impact from sediment removal. The composition of the preremoval community with relation to sediment disturbance can affect the length of recovery. Habitats subjected to increased frequencies of bottom disturbance from mechanisms such as storms and local hydrodynamic regimes naturally maintain benthic communities in earlier successional stages (for example, opportunistic and transitional taxa) and are expected to recover more rapidly after a defaunation event (Collie and others, 2000; Bolam and Rees, 2003). Another factor is the timing of sediment removal in relation to spawning and recruitment of the benthic fauna, which can also affect feeding and reproduction of shellfish and finfish that rely on benthic fauna (see sec. 5). Although some lateral movement of taxa occurs postremoval, the primary mechanism for recolonization of dredged areas is through recruitment of larvae and juveniles (see Zajac and Whitlatch, 1991). Sediment removal during peak spawning or settlement times may delay recovery of communities and have adverse effects on higher trophic levels (for example, Hobbs, 2002; Diaz and others, 2004).

\subsection{Benthic Community Changes Resulting from Sediment Placement}

Impacts of sediment placement on barrier island ecosystems is related to where the sediment is placed in the system, as discussed in section 3.2. Sediment placement generally occurs in two overall areas: intertidally as in the case of beach nourishment or marsh infilling, or subtidally in cases of shoreface placement or disposal such as muddy overburden after sediment extraction.

\subsubsection{Placement Effects on Beach Infauna}

Abundance of infauna on beaches is typically seasonal (abundances are highest during summer months; Van Dolah and others, 1992; Rosov and others, 2016), whereas diversity and composition vary spatially along the beach profile in relation to wave energy, tidal range, and sediment texture (Greene, 2002). When large volumes of sediment are placed on beaches, sediment-dwelling organisms such as polychaetes, mollusks, and crustaceans are immediately buried, resulting in mass mortality (Peterson and Bishop, 2005; Bergquist and others, 2008) and, ultimately, a reduction in prey for shorebirds and surf fish. Timing of sediment placement in reference to seasonal recruitment of important prey taxa can affect how long reduced abundances from mortality persist. For example, sediment placement occurring before the recruitment season reduced abundances of mole crabs and amphipods, whereas placement after the recruitment season reduced abundances of bean clams and three species of amphipods at Topsail Beach, N.C., with effects lasting all summer (Manning and others, 2014). More details about placement impacts to fish and birds are in sections 5 and 6 , respectively. Concurrent effects from sediment placement on beaches occur due to construction processes, including bulldozing of sediment and the use of heavy equipment. The use of heavy equipment can compact beach sediments (often referred to as press disturbance), whereas bulldozing actively reshapes the beach profile. Despite exhibiting similar profiles to nearby control areas 3 months postnourishment, Peterson and others (2000a) observed a 55-65 percent reduction in Ocypode spp. (Weber, 1795) (ghost crab) densities and a 35-37 percent reduction in mole crab densities on bulldozed beach segments. Reduced densities of ghost crabs can continue for 6-8 months on bulldozed beaches with primary recolonization occurring through larval recruitment (Lindquist and Manning, 2001), suggesting repeated bulldozing would have long-term impacts.

Postplacement recovery of beach infauna occurs primarily through vertical migration and recolonization through recruitment; survival of animals through dredging pipelines is minimal (May, 1973; Parr and others, 1978; Greene, 2002). In a study of post burial response of three taxa of benthic invertebrates (bivalve, crustacean, and polychaetes), Maurer and others (1986) observed upward vertical migration of the three taxa during and after placement; some infaunal taxa 
were capable of withstanding as much as 40-90 centimeters (cm) of sediment overburden. Recolonization through larval recruitment and adults from adjacent areas can occur rapidly (Oliver and others, 1977; Naqvi and Pullen, 1982; Van Dolah and others, 1992); individuals of the polychaete Scolelepis squamata (O. F. Mueller, 1806) were capable of recolonizing within 1 day after beach nourishment (Van Dolah and others, 1992). After the initial decline in abundance (Burlas and others, 2001), recovery of abundance, biomass, and diversity can occur within 2-7 months (Van Dolah and others, 1992; Burlas and others, 2001) but may take longer (greater than 1 year) (Rakocinski and others, 1996). The rate of recovery is affected by the timing of sediment placement and the time for physical processes to return the beach to its natural profile. Similarity of beach fill to natural sediments and placing sediment high on the beach allowing for gradual redistribution has been attributed to promote rapid benthic recovery (Van Dolah and others, 1992). For beaches, recovery time has been quicker when sediment placement ceases before the winter season when infaunal abundance is at its lowest (Burlas and others, 2001). Sediment placement also affects benthic microalgal communities, which are the primary producers that are the source of food for small benthic taxa. Placed sediment does not have the same benthic microalgal communities as natural foreshore sediments. At Folly Beach, S.C., a gradient of recovery was observed for benthic microalgae communities; the quickest recovery was in low intertidal zones, and the longest was in high intertidal zones, which did not fully recover within the 7-month study period (Hill-Spanik and others, 2019). Although data are lacking, the recovery trajectory of benthic microalgae communities may also play a role in the recovery of benthic fauna.

Long-term impacts to beach infauna from sediment placement on beaches are typically the result of changes in the beach profile and (or) changes to the sediment characteristics. Placement of sediment with higher proportions of fine-grained sediments relative to preplacement conditions can suffocate infauna (Peterson and others, 2000b), whereas higher proportions of coarse-grained sediment can crush infauna (Colosio and others, 2007; Peterson and others, 2014). Both scenarios cause declines in macrofaunal abundance and biomass and changes to community composition for multiple years. Longterm impacts can last for several years postplacement and have significant implications for foraging species such as shorebirds (see sec. 6). Long-term effects of beach nourishment have primarily been assessed for three species: the mole crab, coquina clams, and ghost crabs, all of which are an important prey resource for surf zone fish, crabs, and shorebirds (Pearse and others, 1942; Naqvi and Pullen, 1982; McLachlan and Defeo, 2017). Coquina clams and mole crabs residing in the lower beach suffered from mortality during beach nourishment and exhibited reduced body sizes for as long as 2 years (Reilly and Bellis, 1983; Peterson and Manning, 2001). Disruption of overwintering offshore populations of coquina clams can also prolong the impacts to intertidal coquina clam communities (Reilly and Bellis, 1983; Gorzelany and Nelson, 1987). Ghost crabs occupy the uppermost beach, and beach nourishment can be used to restore lost habitat (Greene, 2002); however, high postnourishment mortality levels have been reported (Reilly and Bellis, 1983; Peterson and others, 2000a). In addition, biogenic structures and reefs formed by Sabellariidae spp. (Johnston, 1865) polychaetes can be affected by sediment placement on beaches, primarily through burial. Long-term effects of burial of intertidal Sabellaria vulgaris (Verrill) reefs during beach nourishment in Delaware Bay lasted for 2-3 years until sufficient hard substrate was re-exposed for new larval settlement (Brown and Miller, 2011). Long-term impacts may be reduced when placement design and sediments closely match the beach profile and sediment characteristics before placement and when activities are limited to biologically inactive seasons (Peterson and others, 2000a).

\subsubsection{Placement Effects on Subtidal Areas}

Immediate effects of subtidal sediment placement include local increases in turbidity resulting in light attenuation and other associated changes (reduced photosynthesis, water temperature, and aesthetics). These increases are often temporary, and monitoring and abatement measures are common practice. A potential increase in nutrient particulates entrained in the sediments could promote eutrophication. But, perhaps most importantly, subtidal placement activities may bury benthic species and have temporary adverse effects on ecologically critical areas, submerged aquatic vegetation, and designated natural areas. The construction period may cause minor, short-term, but still adverse changes in noise quality, water quality, air quality, aquatic resources, water-based recreational opportunities in the immediate area, and aesthetics because of construction equipment required for sediment placement (see secs. 5.2 and 5.3, which discuss impacts to mobile marine species). These effects are typically alleviated after construction. By design, sediment placement on the shoreface or other subtidal areas will adjust the elevation and slope of the seafloor (see sec. 3). These adjustments may disturb benthic communities by elevating the seafloor and increasing exposure to wave energy or by changing other hydrodynamic characteristics so that there is a shift in habitat suitability for preplacement species. Certain construction actions may cause a change to specific microhabitat morphology that is desirable to specific taxa. This action may cause a redistribution or change in abundance of these taxa after construction (see sec. 5.4 for discussion). Like beach placement, subtidal placement can cause high mortality of infauna from suffocation during burial (Rhoads and others, 1978; Michel and others, 2013), although some taxa are capable of vertically migrating to the new sediment surface (Maurer and others, 1986; Miller and others, 2002). An assessment of sediment placement from the Charleston Harbor Deepening Project found persistent reduced abundances of infaunal taxa postplacement within and near the sediment disposal site, which were associated with changes in sediment composition from disposal activities (Jutte and others, 2005). Placing sediments in thin layers in subtidal areas may alleviate reductions in abundance and mortality caused by burial. 
After thin-layer placement of dredged material near the mouth of the Columbia River, Norton and others (2015) found no visible indication of sediment deposition with no mortality of acoustically tagged Cancer magister (Dana, 1852) (Dungeness crabs) and no discernable change in presence and abundance of mobile crabs and flatfish over a 2-year period. However, no sediment taxa were studied; therefore, more research is needed to assess the effects of subtidal thin-layer placement on lessmobile members of benthic communities.

Large-scale placement of dredged materials in or near seagrass habitats can smother benthos, increase turbidity, and change habitat type (Sheridan, 2004; see also sec. 6). In Lower Laguna Madre, Texas, elevated turbidity was observed for as long as 15 months at the deposition site and for 10 months in seagrasses at distances greater than $1.2 \mathrm{~km}$ from the deposition site (Onuf, 1994). Although seagrasses can often colonize dredged sediments, studies from Laguna Madre in Texas observed impacts to seagrass density, benthos, and nekton that were predicted to last 4-8 years (Sheridan, 2004). In Indian River Lagoon, Florida, reduced shoot densities were observed for as long as 31 years (Brown-Peterson and others, 1993). The broad range of turbidity effects of subtidal dredging placement has implications for adjacent communities as discussed above. Long-term recovery and effects of sediment placement in subtidal areas follow a similar pattern as described above for sediment removal, such as shifts in community assemblages based on changes in sediment characteristics, location of placement, hydrodynamics, and the original community composition.

\subsubsection{Placement Effects on Coastal Marsh Benthic Ecosystems}

Fine-grained sediment from maintenance dredging unsuitable for placement on high-energy beaches has been used to mitigate salt marsh subsidence (see sec. 3.2.2 for more information). Thin-layer $(0-30 \mathrm{~cm})$ placement of sediments onto degraded tidal marshes has been reported to increase stem densities (Slocum and others, 2005; Croft and others, 2006), above-ground biomass (DeLaune and others, 1990), and percent cover (Ford and others, 1999) of saltmarsh cordgrass with few negative effects observed on nondeteriorated areas when applied in layers as thick as $10 \mathrm{~cm}$ (Croft and others, 2006). As discussed in section 4.1.2, sediment properties (such as, organic matter composition and texture) are key considerations when sediments are added to or removed from an environment because there will be modifications to the biogeochemical framework. In some cases, changes in the biogeochemical framework can have beneficial results. For example, Croft and others (2006) observed, for (initially) deteoriated and nondeteroriated marshes, sediment additions of $10 \mathrm{~cm}$ (thickest addition of their experiment) corresponded with the largest increase in depth-integrated oxidation-reduction potential, which they attributed to a decrease in sulfide concentration and (or) sulfate reduction. This is important because sulfide can inhibit nitrogen uptake and assimilation in plants, reduce plant growth, and be toxic to infauna (Mendelssohn and McKee, 1988). Infaunal community response to marsh sediment addition is variable; immediate reduced abundances were observed when sediment additions were greater than $10 \mathrm{~cm}$, but overall abundance increased 1 year postplacement in deteriorated marshes and hardly changed in nondeteriorated marshes (Croft and others, 2006). Effects of marsh sediment placement can be detected long term; for example, increased percent cover and bulk densities of marsh plants, and reduced sediment sulfide concentrations were observed 7 years after adding 5-12 cm of sediment (Slocum and others, 2005). Stagg and Mendelssohn (2010) found that the optimum elevation range for sediment addition in salt marsh environments in Louisiana was 29-36 cm (North American Vertical Datum of 1988), and that that the addition of sediment treatment levels higher than $39 \mathrm{~cm}$ created conditions similar to a degraded marsh and decreased ecosystem function in general. Overall, placement of fine-grained sediments can have positive effects on marsh communities in degraded marsh areas when applied in thin layers.

\subsubsection{Placement Effects on Adjacent Habitats}

Sediment from placement areas may be eroded and transported by currents to adjacent areas, potentially affecting surrounding biologic communities. Fine-grained sediment winnowed from the placement deposits may settle to the seafloor downdrift from the placement zone and blanket hard bottom, coral, and sponges (Lindeman and Snyder, 1999). Monitoring downdrift deposition of fine-grained sediments from subtidal sediment placement on hard bottom communities offshore of Charleston, S.C., Crowe and others (2010) found increased downdrift suspended-sediment concentrations but overall little evidence of degradation on the reefs or associated fauna. However, Crowe and others (2010) noted multiple confounding factors that may have affected their results, including proximity to the Charleston Harbor sediment plume, distance from the deposition location, and natural variability among their few sampling sites. Sediment placement in subtidal areas can induce turbidity plumes that can negatively affect filterfeeding taxa in nearby hard bottom habitats (such as, corals and worm reefs) and in nearby sedimentary habitats (Michel and others, 2013), and can affect water clarity important for visual feeders/predators (sec. 5.2.1) and seagrasses (Caldwell, 1985) similar to the effects of sediment plumes described in section 4.2.3.

\subsection{Knowledge Gaps and Recommendations}

The primary knowledge gap for benthic communities is how sediment removal and placement affect benthic ecosystem functioning. Because the infaunal community can completely differ before and after removal despite similar abundance, biomass, and diversity, we still do not know the 
trophic value of the new community to higher organisms as prey items and foraging grounds. How efficiently resident taxa repopulate affected areas, and how less-mobile members of the benthic community repopulate affected areas, is poorly understood. Additional information is needed on long-term effects of removal and placement because most environmental impact studies cease after 2 years postconstruction, and some longerterm observations have shown that changes in community composition can last as long as 8 years because of changes in sediment properties (sec. 4.2.2).

Although effects on benthic communities from physical processes such as burial or changes in oceanographic conditions are well documented in the literature, effects caused by other processes such as changes in mineralogy or organic content are not as well studied and could compound environmental change.

\subsection{Another Consideration}

Though not explicitly referenced in the Grijalva letter, another consideration is the extent to which sediment removal or placement will alter the biogeochemical framework and introduce deleterious microbial species (for example, bacteria and [or] virus), harmful algal species (Pilkey and Cooper, 2014), or both. For example, virus and bacterial transport is well documented in groundwater studies. Where groundwater discharges along beaches and in nearshore marine waters, virus or bacterial loading can cause beach closures. Also, some of the microbes may remain within the nearshore sediments, attached to particles (Boehm and others, 2004). Thus, removing the sediment could have a substantial albeit temporary effect on microbial loads in nearshore waters. Similarly, sediment placement could introduce such species if the sediment is not treated. Furthermore, a recent study found that cysts of Pyrodinium bahamense (Plate, 1906), a harmful alga, remain dormant in shallow sediments $(0-10 \mathrm{~cm})$ (Lopez and others, 2019). However, when these dormant cysts are exposed to temperatures cooler than the ambient surface-water temperatures, germination success increases considerably. In the context of this report, if actions of sediment removal or placement contribute to or create the optimal temperatures for cyst rejuvenation, like those described by Lopez and others (2019) for $P$. bahamense, then this or other algal species with a dormant cyst life stage could be introduced or become active, generating harmful toxins. Additional research and monitoring efforts may be needed to evaluate such possibilities, particularly for locations where detrimental microbes and harmful algae are already an issue.

Metal cycling in seabed sediments, or more simply a transfer between mobile and immobile forms, is often related to organic matter cycling processes (such as, production, remineralization, and sorption). The most well-known relation between metal and organic matter cycles is the reduction of iron by bacteria to oxidize organic matter, but the use of other metals by bacteria in addition to iron leads to spatial and temporal variability of toxic metal sequestration and release. Based on joint guidance from the U.S. Environmental Protection Agency and USACE (2004), dredged sediment, whether contaminated or not, should be tested with specific consideration for various environmental properties including, but not limited to, (1) the concentration/abundance of contaminants, (2) the stability and (or) mobility of the contaminant and (or) compound in its current form, (3) environmental factors that will change between the origination and placement site, and (4) transformations (possible reactions) that may take place during dredging, during transport to new site, and when placed at new site. As such, linkages between metal cycling and organic matter remineralization suggest that policies developed for other environments (for example, fine-grained harbors) may be adequate and transferable to environments with permeable sediments, especially in reference to initial assessments and monitoring.

\subsection{Impacts of Sediment Removal and Placement on Fish and Other Marine Species}

By David Kazyak, David R. Smith, Kristen Hart, Bianca Prohaska, and Teresa Calleson

Recent comprehensive reviews of the effects of dredging (for example, sediment removal) on fish and other marine species (Erftemeijer and others, 2012; Rutecki and others, 2014; Wenger and others, 2017; Pickens and Taylor, 2020) have framed their evaluations as threat assessments, decomposing the cause-and-effect pathways and reviewing the evidence for direct and indirect effects (fig. 7). Although sediment removal and placement occur at specific sites, threats to marine species emerge from direct entrainment and entanglement of organisms (discussed in sec. 5.1), suspended/settled/contaminated sediment (sec. 5.2), noise (sec. 5.3), and net bathymetric change (sec. 5.4) that occur at those sites or beyond (see secs. 3 and 4). Placement impacts are discussed in section 5.5. In general, the scale and magnitude of impacts depend on volume and frequency of sediment removal and placement, characteristics of the dredged material, and currents at the dredge or deposition site (Wenger and others, 2017). It is important to note that the potential effects to fish habitat serve as proxies for effects at the population and species levels, which is ultimately the concern of the U.S. Fish and Wildlife Service (USFWS) and the National Marine Fisheries Service (NMFS). Therefore, this section follows the threat assessment organization from recent reviews but includes examples from several trust or indicator species, such as sturgeon, Limulus polyphemus (Linnaeus, 1758), horseshoe crabs, and sea turtles.

Importantly, the reviews cited in the previous paragraph categorized effects of dredging to account for the variation among the studies in methods, temporal and spatial scales, and 


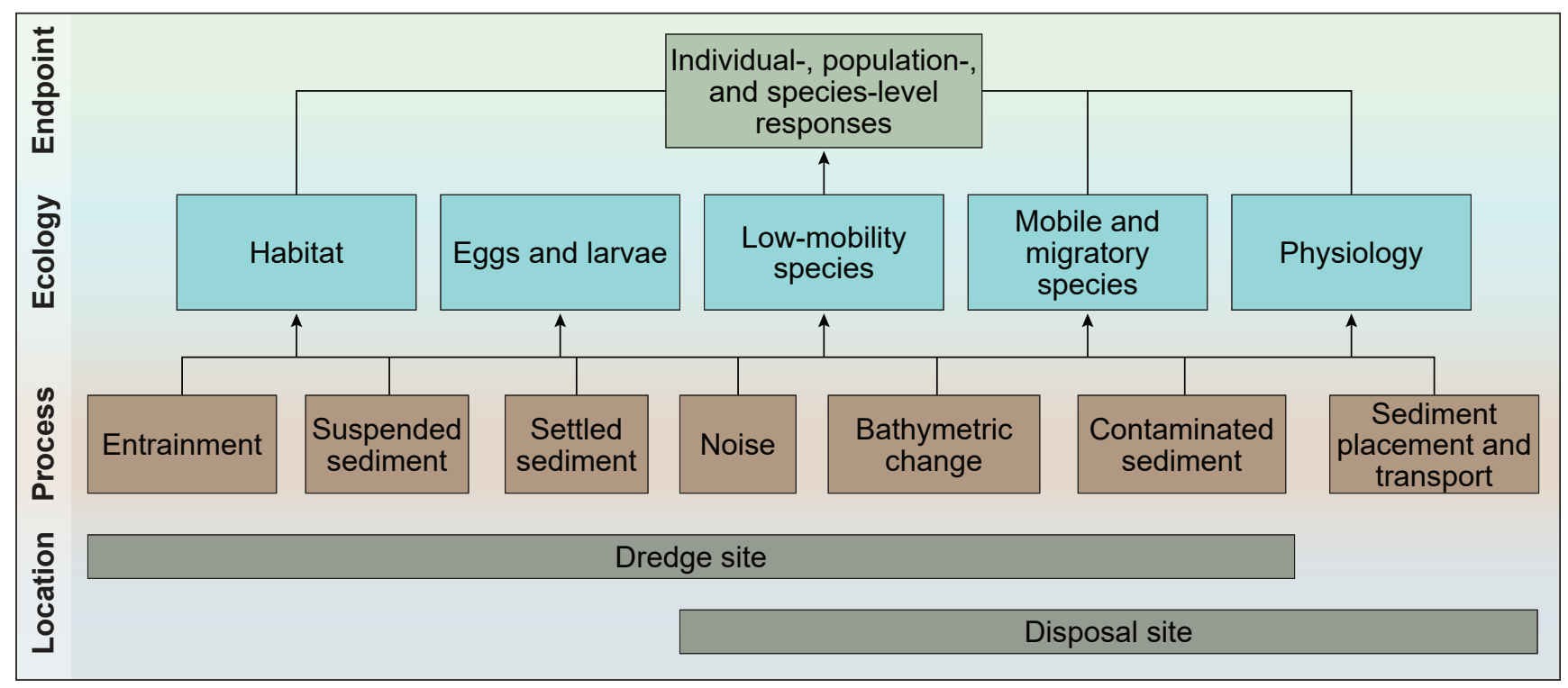

Figure 7. Conceptual model linking sediment dredging processes, ecological factors, and individual-, population-, and species-level responses, which are the endpoints of interest in this section. Location of the activities at dredge or disposal sites are the starting points for the effect pathways leading to potential effects.

ecological responses. For example, Wenger and others (2017) reviewed more than 430 papers and characterized the type of effect on a categorical scale that ranged from no effect to increased mortality or reduced hatching success, and intermediate effects included minor or moderate behavioral or physiological changes or damage (see Wenger and others, 2017, table 1). In another review, Pickens and Taylor (2020) evaluated relative vulnerability of species and life stages for the various dredging and sand-mining processes. Further, the 2020 South Atlantic Regional Biological Opinion for Dredging and Material Placement Activities in the southeastern United States considers dredging and material placement activities in Federal waters (National Marine Fisheries Service, 2020). Despite these robust evaluations, much remains poorly understood regarding impacts at the population and species levels, and these knowledge gaps can be found at the end of this section. For example, to mitigate against adverse effects, increased mortality, and reduced recruitment, future studies measuring the effects of dredging will need to be sensitive to the detection of nonfatal effects (Wenger and others, 2017).

Main takeaways of this section are as follows:

- Vulnerability to direct entrainment or indirect effects depends, in large part, on an organism's mobility relative to the size of the dredging footprint. Thus, early life stages (for example, eggs and larvae) or other less-mobile and (or) dormant stages (for example, burrowing to overwinter by Callinectes sapidus [M. J. Rathbun, 1896] [blue crabs] and horseshoe crabs) are generally more vulnerable than adults or mobile juveniles. Similarly, demersal species are typically more vulnerable than pelagic species.
- Direct impacts include species entanglement in buoys or lines marking projects and physical injury if struck by transiting vessels working on a project. Sea turtles and manatees are susceptible to vessel collisions, propeller strikes, and crushing because they regularly surface to breathe and may spend a considerable amount of time on or near the surface of the water.

- Effects caused by noises and suspended sediments vary widely among species and life stages. In some instances, suspended sediments can have positive effects, but higher concentrations are generally associated with a greater incidence of adverse effects. Noise levels associated with sand dredging are generally not strong enough to cause direct mortality or serious injury, but many sublethal effects, such as feeding patterns and predator avoidance, have been reported in the literature.

- Many negative impacts to fish from contaminants are known, but contaminants are generally found in finer sediments than sand. Thus, contaminants are likely not a major risk factor for sand removal and placement in most coastal marine waters. An exception might be near stream mouths and drowned paleostream valleys, where dredge processes liberate potentially antecedent fines.

- Impact is a function of the likelihood that the threats from sediment management operations overlap with occupied habitat and the degree that the activity affects behavior, physiology, or survival. Thus, potential for adverse effect is particularly acute when sediment 
removal overlaps spatially or temporally with sensitive habitats (for example, coral reefs), with migration paths or foraging areas in which individuals congregate, or with spawning, nursery, or overwintering habitats.

- Given the wide variation in known responses among fish species and life stages, prevalence of laboratory studies versus field studies, and existing knowledge gaps, additional on-site research is necessary to characterize population-, species-, and community-level effects of sand mining.

\subsection{Impacts Due to Entrainment and Entanglement}

Entrainment resulting in the direct uptake of an organism during sediment management operations is considered a type of bycatch or take and has the potential to cause considerable damage to or mortality of marine species. Susceptibility to entrainment depends on the individual organism's mobility and, therefore, is higher for early life stages (for example, eggs and larvae) that generally passively navigate through the marine environment or those that exhibit demersal (for example, bottom-dwelling) behaviors (Reine and Clarke, 1998; Wenger and others, 2017). A review by Reine and Clarke (1998) of entrainment of shellfish, bivalves, fish, and turtles concluded the rate of mortality from entrainment varied widely depending on dredge type, season, and life stage/size of the organism. Wenger and others (2017), who conducted a meta-analysis of effect sizes for entrainment impact studies, found that lethal effects were more frequently shown in larvae and eggs than for older life stages for a range of fish species. Reine and Clarke (1998) noted the difficulty of translating project-level entrainment rates and effects into a population dynamics framework to predict the consequences to a population or species, which continues to be a challenge. Furthermore, the volume of locally entrained eggs and larvae is not usually considered to be substantial relative to population productivity, although exceptions to this may occur when sediment removal occurs close to spawning or nursery areas. To reduce impacts to recruitment, areal or seasonal restrictions are usually used (Wenger and others, 2017).

Entrainment depends on mobility of species and life stages and is highest among those exhibiting demersal behaviors (Reine and Clarke 1998), such as horseshoe crabs and sea turtles. For example, a hydraulic dredge equipped with a 72-inch knife and 2- by 2-inch steel mesh liner on the dredge floor used to sample surf clams in New Jersey has been highly efficient at capturing adult horseshoe crabs, although the bycatch mortality rate for horseshoe crabs is not well studied (Atlantic States Marine Fisheries Commission [ASMFC], 2019). The risk for entrainment of sea turtles in dredges can be high (National Marine Fisheries Service, 2020), and biological opinions are issued under the Endangered Species Act of
1973 (16 U.S.C. ch. $35 \S 1531$ et seq.) with authorized "take" numbers for each dredging operation/project. Sites with a high density of sea turtles are only beginning to be defined, but they can be a high entrainment risk (National Marine Fisheries Service, 2020, p. 113-114). In fact, one mitigation measure is to deploy relocation trawlers to capture sea turtles and move them out of the way of the intake pipe (National Marine Fisheries Service, 2020). Reports show that predominately loggerhead sea turtles, Lepidochelys kempii (Garman, 1880) (Kemp's ridley sea turtles), and Chelonia mydas (Linnaeus, 1758) (green sea turtles) are captured during relocation trawling in the southeastern United States, within the action area (listed from highest to lowest reported captures), though there are also few reports of Dermochelys coriacea (Vandelli, 1761) (leatherback sea turtle) captures in the action area (Operations and Dredging Endangered Species System; contact at odess@usace.army.mil). Therefore, relocation trawling is likely to adversely affect green (North Atlantic and South Atlantic distinct population segments), Kemp's ridley, leatherback, and loggerhead sea turtles. Rates of damage or mortality depend on the design and parameters of the dredging process and operation regardless of species (Wenger and others, 2017).

To be entrained, the organism needs to be present during the dredging operation. Entrainment effects are limited to the footprint of dredging operation. For example, horseshoe crabs occupy the inner continental shelf mostly ( 75 percent) at depths less than $20 \mathrm{~m}$ and markedly (90 percent) at depths less than $30 \mathrm{~m}$ (Botton and Ropes 1987). Horseshoe crabs are distributed along the Atlantic coast and in the Gulf of Mexico (Botton and Ropes, 1987; Smith and others, 2017), but offshore density is higher in topographic seafloor lows (troughs) than on topographic seafloor highs (ridges) (Botton and Haskin, 1984; Hata and Berkson, 2003). Topographically, horseshoe crabs distribute more in troughs defined roughly as greater than or equal to $2.5 \mathrm{~m}$ deep, relative to adjacent ridges, with dimensions less than or equal to $2 \mathrm{~km}$ wide and less than or equal to $2 \mathrm{~km}$ long (Hata and Berkson, 2003). Troughs and adjacent ridges were incorporated into survey designs by Hata and Berkson (2003), initially identified by fisherman, as important topographic features for catching horseshoe crabs. Horseshoe crabs are benthic-feeding generalists (Botton and Haskin, 1984; Carmichael and others, 2004), and their spatial distribution correlates with prey density (Botton and Ropes, 1987); for example, the New Jersey surf clam dredge encountered horseshoe crabs in 32 percent of the 5-minute tows (ASMFC, 2019). Adult horseshoe crabs migrate from offshore to estuaries to spawn, the timing of which varies throughout the range depending on temperature (Smith and others, 2017); and, like other migratory species, they congregate along migratory pathways, which increases their susceptibility to dredging (Reine and Clarke, 1998). Thus, timing of dredging operations and area restrictions can effectively reduce the likelihood of entrainment.

The potential for entrainment increases in areas where horseshoe crabs congregate during migration or in overwintering areas. Evidence suggests sex-specific migration among 
older juveniles and adults (Rudloe, 1980; Brockmann and Penn, 1992; Smith and others, 2009, 2010a); thus, dredging could affect the sexes differently. Disproportionate protection of adult females is considered essential to fisheries management (ASMFC, 2019). Horseshoe crabs are entrained and discarded as bycatch in fisheries along the U.S. Atlantic coast that use dredges as fishing gear to scrape or penetrate benthic substrate; between 2004 and 2017, estimated dredge discards ranged from 34,230 to $2,465,346$ horseshoe crabs (ASMFC, 2019). Horseshoe crabs may be most susceptible to dredging operations in estuaries; this is especially the case for juveniles, which tend to be distributed closer to natal estuarine beaches where spawning occurs. In a review of six channel dredging projects, Ray and Clarke (2010) report entrainment of 10 to 5,521 horseshoe crabs per project; the highest entrainment values occurred in a project to dredge the entrance to the Savannah Harbor during winter. But ASMFC (2019) evaluated the status of the horseshoe crab population in the southeast, where Savannah Harbor is located, and determined it to be in good condition and better than all other regional populations along the Atlantic coast.

When considering impacts of removal and placement on fish and other marine species, the net effect on the population or species abundance and distribution must be considered. Population-level effects from entrainment are a function of entrainment rate and mortality rate given entrainment in relation to population abundance and growth rate. Entrainment rates depend on the dredging footprint overlap with occupied habitat (Pickens and Taylor, 2020). Mortality rates vary by species and life stage (Reine and Clarke, 1998). Although there has been substantial research on these components, documenting population-level effects of dredging is an important knowledge gap.

Pickens and Taylor (2020) used species distribution models to evaluate the vulnerability of fish species and their essential fish habitat (EFH) to sand dredging operations. They developed the Shoal Map and Assessment Tool for EFH (called "ShoalMATE"), which is currently being used to facilitate design of operations to mitigate adverse effects on federally managed fish species (Rimerez, 2020) and may be useful for CBRA-related assessments.

Dredging operations pose additional threats during sediment removal because of physical interaction with dredging equipment and vessels. For example, although manatees are more frequently found in rivers and estuaries throughout Florida on a year-round basis, they may also be sighted in nearshore Atlantic coast and Gulf of Mexico waters from Texas to Maryland during the warmer months of the year. Manatee movements through inlets and into offshore waters has been well documented (Deutsch and others, 2003). While in these environments, they may interact with sand dredging projects, and related risks to the species may include, but are not limited to, entanglement, equipment and (or) watercraft collisions, and crushing. Manatee protection measures related to standoff distance between barges and other large vessels, pipeline positioning and anchoring practices, observation protocols, and avoidance measures specified in the Statewide Programmatic Biological Opinion for Shore Protection Activities along the Coast of Florida and the associated Standard Manatee Construction Conditions (2011) are aimed at offsetting effects from this type of in-water activity (USFWS, 2015).

\subsection{Impacts Related to Suspended, Settled, and Contaminated Sediments}

Sediment removal and placement activities can result in sediment being distributed throughout the water column. These suspended sediments may affect marine biota through several pathways, including visual and respiratory impairment. Impacts are not necessarily restricted to the sediment removal site because currents can advect plumes of suspended sediment several kilometers or more from the disturbance (Fisher and others, 2015). The level of impact typically varies among species (Gray and others, 2014) and depends on how much sediment is suspended (concentration) and how long it persists in the water column (duration; Newcombe and MacDonald, 1991; Wenger and others, 2017). In general, it is thought that suspended-sediment effects seem to be most prevalent around the removal site because only modest, local increases of suspended sediments have been reported near placement sites during beach nourishment activities (Wilber and others, 2006).

\subsubsection{Behavioral Changes Caused by Suspended Sediment}

Suspended sediment (for example, turbidity) can have a wide range of effects on the behavior of fish and other marine species (Wilber and Clarke, 2001). First, many fishes will avoid areas with high concentrations of suspended sediments, likely because of increased difficulties in predator avoidance and feeding, as well as physiological challenges. (Robertson and others, 2006; Collin and Hart, 2015). For example, turbidity may alter swimming patterns and disrupt schooling behavior, potentially exposing fish to elevated rates of predation (Wildish and Power, 1985; Gray and others, 2014; Ohata and others, 2014). However, other studies have shown that turbid conditions can also provide a source of cover (Gregory, 1993; Gregory and Levings, 1998). Feeding behavior has been inhibited by turbidity because of reductions in visual acuity and reaction distance (Bruton, 1985; Utne-Palm, 2002). But under some circumstances, suspended sediments can enhance feeding, potentially because of increased visual contrast of prey items (Boehlert and Morgan, 1985). This may also be true for sea turtles. Active dredging operations may enhance feeding opportunities as sediment and benthic infauna are displaced (Whittock and others, 2017). However, no comparison of quantified turtle activity or movement patterns at different stages of a dredging program has been recorded or reported previously (Whittock and others, 2017). These changes in feeding and activity patterns can affect the growth and fitness 
of individual fish exposed to plumes of suspended sediment (O'Connor and others, 2016). In addition to alterations to predator avoidance and feeding behavior, larval fishes, which may rely on visual cues for settlement, may have difficulty finding suitable habitats if visibility is limited (Wenger and others, 2011). A review of the literature reveals suspended sediments can have positive effects, but higher concentrations are generally associated with a greater incidence of adverse effects. Overall, it is clear from the literature that connections between sediment and fishes are complex, suggesting that it may be necessary to evaluate sediment removal effects on fish species on a case-by-case basis, accounting for species and life-history stage and specific habitat requirements.

\subsubsection{Physiological Effects of Suspended Sediment}

In addition to possible behavioral effects, suspended sediments can cause lethal or sublethal effects through physical or physiological damage to fishes; increases in suspendedsediment concentrations generally result in greater incidence of adverse outcomes (Wenger and others, 2017). Particles may coat and damage the respiratory surfaces of the gills or block the flow of water across them (Au and others, 2004; Hess and others, 2015). In laboratory studies, physiological changes associated with oxygen deprivation were observed after exposure to suspended sediments (O'Connor and others, 1976; Wong and others, 2013). If enough oxygen cannot be obtained through the gills, direct mortality to fishes will result, though the sediment concentration associated with this outcome seems to vary widely among fish species (Sherk and others, 1975; Wenger and others, 2017). In addition to respiration, gill surfaces are also necessary for osmoregulation. Suspended sediments can lead to osmoregulatory stress (Au and others, 2004). Suspended sediments may impair olfaction, inhibiting the ability of fishes to locate resources (O'Connor and others, 2016). In general, early life stages are expected to be more sensitive to physiological damage to gills (Sutherland and Meyer, 2007). More specifically, high concentrations of suspended sediments can cause mortality in the eggs and larvae of economically important fishes along the Atlantic coast (Auld and Schubel, 1978).

\subsubsection{Effects Caused by Settled Sediment}

As wave and current energy decreases, suspended sediment in the water column will slowly settle to the seabed. This process, sedimentation, can result in burial of habitats and benthic communities depending on the spatial and temporal scale of the dredging operation and its proximity to the habitat, including corals and nonsedimented substrate (see sec. 4 for more information about direct impacts to these habitats). For example, Erftemeijer and others (2012) summarized published literature on effects of turbidity and settled sediment from dredging on corals. Coral reefs are not subject to direct entrainment but, if proximate to dredging operations, can be affected by the sediment plume. The intensity, duration, and frequency of exposure along with the resilience and background conditions of the coral reef determine the net effects. Based on the literature review, the tolerance for sedimentation ranged from less than 10 to greater than 400 milligrams per centimeter per day. Depending on the sensitivity of the coral species, high sedimentation rates can be tolerated for less than 24 hours to a few weeks. Effects on corals cascade to other species; the studies reviewed by Erftemeijer and others (2012) document substantial reductions in populations and change in the community structure of reef-associated fish species.

\subsubsection{Effects Caused by Contaminated Sediment}

Sediment removal can mobilize contaminated, finegrained sediments, which can be transported considerable distances from the activity site (Bridges and others, 2008; see also sec. 4). Contaminants may be released through a variety of pathways, including resuspension of particulates and mobilization of sediment pore water (Thibodeaux, 2005; Bridges and others, 2008). Released contaminants can adversely affect finfish, shellfish, and other Federal-trust species, and may have synergistic effects associated with dredging (Weis and Candelmo, 2012; Wenger and others, 2017). Though contamination is typically found in finer sediments rather than sand (Thorne and Nickless, 1981; Witkowski and others, 1987), recent evidence of elevated concentrations of polychlorinated biphenyls in Ammodytes personatus (Girard, 1856) (Pacific sand lance) suggest contaminant exposure among species that prefer sand habitats (Conn and others, 2020; Liedtke and Conn, 2021). Consequently, the current state of evidence is mixed but overall suggests a low risk that sediment removal would normally be associated with a release of contaminants and associated impacts to fishes.

\subsection{Effects Caused by Noise}

Operating dredging vessels, dredging equipment, and survey equipment can produce loud noises that potentially affect living resources. Sounds are used by fishes and other marine species for many purposes, including locating specific habitats, communication, and predator avoidance (Popper and others, 2003; Simpson and others, 2005; Popper and Hawkins, 2019). Accordingly, the range of potential effects on fish behavior from anthropogenic noises, such as those associated with sediment removal and placement, is varied.

Auditory impacts are expected to vary depending on the intensity and duration of exposure to noises associated with sediment removal and placement. The most severe effects of underwater noise, including potential mortality, generally occur very close to its source, whereas sublethal effects such as behavioral changes may extend over broader areas where sound levels are less intense. In one study of underwater sounds associated with sediment removal, sound levels 
attenuated to ambient within $2.65 \mathrm{~km}$ of the source (Reine and others, 2014), suggesting that the zone of sublethal effects may extend more than $1 \mathrm{~km}$ from the sediment removal $/$ placement activity. There is also evidence that the character of the sediment resource may influence auditory effects. For example, noises associated with dredging soft, finer-grained substrates, such as those that might be used for estuarine shoreline or marsh restoration, are comparable to those of loud merchant vessels and do not generally result in substantial mortality to fishes and other marine organisms (Robinson and others, 2011; Popper and Hawkins, 2019; Suedel and others, 2019). Sublethal effects associated with underwater-noise pollution are well documented and are discussed below.

Severe injuries to fishes and marine mammals from sounds are generally associated with very loud, impulsive noises that are not typical of sediment removal and placement (Götz and others, 2009; Suedel and others, 2019), although temporary impairments are possible (Smith and others, 2004). Recovery from temporary auditory impairment varies but generally occurs relatively quickly (that is, within several days; Popper and others, 2005). Intense noises can cause physical damage to the swim bladder, which is involved in hearing in some fishes (Popper and others, 2003), but such noises may only occur near the sediment management activity. The primary effects on fishes from removal and placement sounds are more likely to be behavioral, which are discussed below.

Behavioral disturbances may be subtle but sometimes include clear avoidance reactions (Götz and others, 2009). Noise exposure has caused changes in swimming speed and schooling behavior (Sarà and others, 2007; Hawkins and others, 2014; Shafiei Sabet and others, 2016). Startle responses are associated with the onset of loud noises (Kastelein and others, 2008). Elevated noise levels have been reported to inhibit antipredator behavior and increase mortality because of predation (Simpson and others, 2016; Spiga and others, 2017). In one study, noises associated with boat traffic resulted in elevated metabolic rates and increased mortality to predation (Simpson and others, 2016). Noise from maritime traffic has also altered feeding patterns and reduced body condition in some fishes (Bracciali and others, 2012). Noise from vessel traffic and other activities associated with dredging may mask biologically important sounds that fish and other marine biota use (Pine and others, 2016). Some larval fishes use noise associated with specific habitats to find suitable habitats, and anthropogenic noises can disrupt this signal (Simpson and others, 2016). Gerstein and others (2006) also evaluated underwater noise on the Trichechus manatus (Linnaeus, 1758) (West Indian manatee) to estimate masking zones near dredging activities. This study determined that noise levels associated with dredging may mask boat traffic sounds and thus increase the potential for manatee-boat collisions (Gerstein and others, 2006).

However, the applicability of these results to the noises associated with sediment removal and placement in situ is uncertain. Most behavioral studies have used fish in captivity or focused on impulsive sounds similar to pile driving rather than the sounds associated with managing soft sediments (Popper and Hawkins, 2019). Comparative studies have shown that behavioral responses to anthropogenic noise are not consistent among species (Kastelein and others, 2008). Finally, several studies report that some fishes are desensitized to sustained anthropogenic noises, which suggests some of the negative effects may be reduced during extended dredging operations (Nedelec and others, 2016; Holmes and others, 2017).

Sturgeon and sea turtles provide examples of noise-effect profiles in key species. Acipenser oxyrinchus oxyrinchus (Mitchill, 1815) (Atlantic sturgeon) regularly occur in coastal marine waters that are dominated by large sand features (D. Fox, Delaware State University and J. Madsen, University of Delaware, written commun., 2020) where they are potentially at risk to sediment removal operations. In a previous study, no changes in Atlantic sturgeon swimming behavior were observed while near a hydraulic cutterhead dredge (Balazik and others, 2020) or commercial vessel traffic (DiJohnson, 2019), suggesting that spawning migrations were not affected. However, the observed lack of a response to the noises associated with dredging may increase the risk of direct mortality from interactions with dredging equipment or vessels. In this species, mortality from ship strikes and dredging do happen (Brown and Murphy, 2010; Balazik and others, 2012; USACE, 2014). The response of sea turtles to noise is less well studied (but see Piniak and others, 2012; Tyson and others, 2017). No injurious effect to Endangered Species Act-listed species from cumulative noise exposure are expected (National Marine Fisheries Service, 2020) from acoustic sand resource assessment tools (for example, boomers and chirp sub-bottom profilers), which are an impulsive noise source. These species may be present in areas where surveying occurs and able to detect the sound source within $192 \mathrm{~m}$; however, if exposed to this mobile sound source, the exposure would only last a few seconds. Thus, we believe that behavioral effects to sea turtles, sturgeon, Epinephelus striatus (Bloch, 1792) (Nassau grouper), and elasmobranchs from boomer and chirp sub-bottom profilers may be insignificant.

\subsection{Effects Caused by Bathymetric Change}

Essential habitat is defined as those waters and substrate necessary for fish spawning, breeding, feeding, or growth to maturity and includes the shape and elevation of the seafloor. For example, abundance of some species seems to be associated with large shoals, which may also serve as hypoxia refuges, in some cases (Pickens and Taylor, 2020). Bathymetric change from removal of sediments from offshore shoals results in terrain flattening, which could be detrimental to species that prefer variation in seabed elevation. For example, wave energy, currents, and light are hypothesized to play important roles in orientation and movement during horseshoe crab migration (Botton and Ropes, 1987; Chabot and Watson, 2010); topographic changes, such as terrain flattening or burrow pit formation, and turbidity have the potential 
to interfere with horseshoe crab migration depending on the spatial and temporal extent and timing of the disturbance. Further, creation of seabed depressions or pits could result in long-term habitat loss depending on site size and proximity to the shoreline (Pickens and Taylor, 2020). Though it is difficult to predict, shoals can recover (see sec. 3.1.2 for a discussion), and Rutecki and others (2014) provided recommendations for the design of sediment removal operations to enhance shoal recovery and, in turn, recovery of essential habitat. From a review of the available literature, sediment removal from shoals could result in loss of essential habitat, although it is unclear how this translates to population-level species dynamics, which should be considered an important knowledge gap.

\subsection{Effects Caused by Sediment Placement on Estuarine Beaches}

The effect of nourishment on habitat suitability of estuarine beaches is an active area of research (Jackson and others, 2002). Habitat value, in general, is related to the interactive effects of wave energy, storm frequency, sediment characteristics, and water movement through the foreshore (Nordstrom and others, 2018). Among the methods to mitigate erosional loss, well-designed beach nourishment is more conducive to maintenance or enhancement of habitat suitability than alternatives, such as armoring and bulkheading. For example, the estuarine beach environment is critical to horseshoe crab egg and embryo development (Vasquez and others, 2015), and early life stage survival is critical to population growth (Sweka and others, 2007). The beach foreshore is the dominant horseshoe crab spawning habitat; intertidal and subtidal habitats can be used for spawning but are certainly used as nursery habitat for juveniles (Botton and Loveland, 2003; Burton and others, 2009). Horseshoe crabs prefer well-aerated, sandy beaches with low wave energy (Shuster and Botton, 1985; Botton and others, 1988; Penn and Brockmann, 1994; Jackson and others, 2004). But beach erosion and shoreline development are major threats to spawning habitat (Botton and others, 1988; Jackson and Nordstrom, 2009). Thus, well-designed sand placement on estuarine beaches, which are otherwise suitably located within the estuary relative to wave energy (Smith and others, 2011), can enhance horseshoe crab spawning habitat especially in contrast to other shoreline protections, such as armoring (Jackson and others, 2002, 2010, 2015; Jackson and Nordstrom, 2009). Importantly, improved spawning habitat has the potential to increase the abundance of horseshoe crab eggs available to foraging shorebirds in estuaries that serve as migratory stopovers (Karpanty and others, 2011). However, there is a lack of studies on potential adverse effects from burial of organisms on the prenourished beach or by eroded sediments on the low-tide terrace where, for example, juvenile horseshoe crabs live for the first couple years of life (Burton and others, 2009). Thus, the net effect of sediment management, which leads to adverse and beneficial impacts at the removal and placement sites, remains an important knowledge gap.

\subsection{Knowledge Gaps and Relevant Data}

Through the course of our review, we identified many gaps in the knowledge base available to assess the impacts of sediment removal and placement on fish and other marine species. Additional research in the following areas would help provide a comprehensive perspective to guide policy decisions:

1. Fine-scale movement studies in areas where dredge operations occur using a well-planned experimental design, such as Before-After-Control-Impact (Smokorowski and Randall, 2017), including species with diverse life history strategies. This could include studies using satellite telemetry, three-dimensional acoustic telemetry arrays, hydroacoustics, or environmental deoxyribonucleic acid. The information generated would be useful to identify taxa that avoid dredging operations versus those that exhibit no avoidance response (or taxis) to dredging operations.

2. Assessing contaminants in marine sand deposits would help ensure that disturbed sediments do not release toxins into the environment and food chain, particularly as new and deeper borrow sources are used that may contain fine material commonly associated with contaminant presence.

3. There is a need for more in situ research focusing on the actual responses of a variety of taxa to active sand mining operations (ECORP Consulting, Inc., 2009). Many of the studies referenced in our review focused on the responses of fishes in laboratory experiments, and it is possible that some responses may vary under environmental conditions. New tools such as popoff accelerometers allow researchers to quantify fine-scale activity patterns on free-ranging animals (for example, sea turtles, https://www.usgs.gov/center-news/trackingsea-turtles-new-data-collection-techniques-provide-finescale-data).

4. More research is needed to comprehensively determine the importance of marine sand deposits and sandbar morphology as key habitats for all life stages of fish and other marine species, throughout all seasons, and the ecosystem services of subtle differences in habitat complexity.

5. At present (2021), very little is known about the extent of connectivity among sand habitats for fishes. Although we know that some highly migratory taxa such as Atlantic sturgeon and Morone saxatilis (Walbaum, 1792) (striped bass) use these habitats (Secor and others, 
2020), we do not understand how habitat changes at specific sites may affect populations at the regional level. We note that Atlantic sturgeon from populations across the coast have been detected on coastal telemetry arrays deployed in sandy coastal habitats (Arendt and others, 2017).

6. The net population effect of sand dredging operations is not well assessed and is a research need to determine how project-scale impacts translate to effects on population growth, distribution, and abundance. Marine species are subject to multiple threats from harvest and habitat loss, which vary among regional populations; sediment removal operations add to those threats as a mortality source. The question is, "Is the spatial extent, intensity, and frequency of sediment removal and sediment placement enough to cause a population response, or do the effects remain local and not evident at the population level?" Development and testing of predictive models for population-level effects from sediment removal, including adverse and beneficial effects at the dredge and depositional sites, are needed. This will require a synthesis of research on component effects with integration into models. Generalizing to multiple species will be difficult because vulnerability depends on life-history and habitat requirements.

7. Many species of elasmobranchs (sharks, skates, and rays) rely on shallow nearshore coastal habitats as nursery grounds (Knip and others, 2010). Although elasmobranchs are essential components of coastal ecosystems (Cortés, 1999; Knip and others, 2010), there is a general lack of information regarding the effects of sediment removal and placement on elasmobranchs, and relative changes in species abundance have been observed in areas with increased beach nourishment (Schwartz and others, 2013). In North Carolina, the relative abundance of Rhizoprionodon terraenovae (Richardson, 1836) (Atlantic sharpnose sharks) has increased (Schwartz and others, 2010), although the relative abundance of Carcharhinus acronotus (Poey, 1860) (blacknose sharks) has decreased (Schwartz and others, 2013) in Onslow Bay from 1972 to the present (2021). Over a similar period (1961-2021), the volume and frequency of beach nourishment projects have increased in the same area (North Carolina Beach Nourishment Database). Unfortunately, it is unclear from this information if changes in relative abundance are related to increased sediment management activities or other abiotic or biotic factors, such as seawater temperature changes or geographic shifts in populations. It is clear that direct investigation of the effects of sediment removal and placement on elasmobranchs is necessary to understand if these trends are related and if they are relevant to other species and locations.
8. Effective mitigation of adverse impacts at dredging and deposition sites is a key knowledge gap. Acute adverse effects can occur when dredging overlaps with congregations along migratory corridors or at overwintering sites. Seasonal and area restrictions to protect congregations can mitigate dredging effects (Ray and Clarke, 2010). The overlap of the dredging operation with marine species spatial distribution, along with dredging intensity and extent, can be used to predict impact and define area closures. However, species distributions, although understood at a coarse scale, are often not well understood at a scale useful for assessing impacts of sediment removal. Thus, occupancy modeling or species distribution modeling would help fill that information need. The data from NMFS, State agency, and academic fishery independent surveys are relevant to that modeling effort. The estuarine beach nourishment projects can be designed to enhance habitat (Jackson and others, 2004), and the sand for nourishment can come from onshore sources rather than offshore shoals.

9. With the expanding footprint of human activities adversely affecting coastal habitats in general, improving our understanding of their cumulative effects and the relative effects of sediment management operations to species of concern is important.

\subsection{Impacts of Sediment Removal and Placement on Subaerial Beach Habitats}

By Sara L. Zeigler, Alicia Berlin, Kathryn Smith, Kristen M. Hart, Jennifer L. Miselis, and Kristi Yanchis

Sandy beaches provide several important ecosystem services, including habitat for federally and State-listed plants and animals. These ecosystems are also among the world's most threatened because of SLR, human development, and recreation (Schlacher and others, 2007; Halpern and others, 2015). Beach nourishment can reduce habitat loss and degradation by widening eroded beaches; however, this activity can also alter habitat quality and disturb endemic species. Here, we largely focus on the effect of ocean- or gulf-facing beach sand placement on plants and animals that use these environments for all or part of their annual cycle, although we do acknowledge some instances where sediment removal can affect these species. The ecological effects of sediment removal are the focus of other sections in this report (secs. 4, 5 , and 7).

The ecological effects of nourishment on beach ecosystems can be divided into those related to construction during the nourishment project and to the quality and quantity of fill sediments placed on the beach. These general effects are 
further affected by the location and timing of the nourishment project, as well as the nourishment technique used (Speybroek and others, 2006). Disturbances in the forms of pipes, heavy machinery (for example, bulldozers), artificial lighting, and people are introduced to the beach ecosystem during the construction phase of a nourishment project (reviewed in Greene, 2002). Nourishment projects can also change the elevation, width, slope, and other aspects of the morphology of the beach profile (Ernest and Martin, 1999; reviewed in Greene, 2002; see sec. 3) while altering natural overwash processes critical to the ecomorphologic function of a barrier island (see sec. 7). Sediments placed during nourishment can lead to alterations in sediment grain size, shape, color, moisture content, mineral content, water potential, and porosity (reviewed in Milton and others, 1997; Ernest and Martin, 1999; Brock and others, 2009). Such changes from prenourishment conditions can positively or negatively affect species diversity, abundance, survival, and reproductive output in sandy beach ecosystems.

Although Peterson and Bishop (2005) highlighted a paucity of nourishment impact studies with adequate experimental controls, several nourishment-related effects have been observed on two high-profile taxonomic groups - sea turtles and shore/waterbirds - that use sandy beaches along the Gulf and Atlantic coasts of the United States and the Caribbean. Sea turtles rely on beach habitats for nesting, whereas shore/ waterbirds use these habitats throughout their annual cycle during the nesting, migration, and overwintering phases. In this section, we review the direct and indirect impacts of beach nourishment on these taxonomic groups.

The main points from this section are as follows:

- Beach nourishment can lead to improved sea turtle and shore/waterbird use by widening severely eroded beaches.

- Depressed sea turtle nest success (that is, number of female emergences that lead to a nest) is associated with beach nourishment; on nourished beaches, female emergences in which no nest is started (in other words, "false crawl") or in which a nest is abandoned mid-dig are increased. Effects are attributed to the presence of scarps and other alterations to the beach profile (wider, flatter nourished beaches), as well as higher sediment compactness on nourished beaches. Effects tend to disappear after 1-2 years as the sediments and profiles of nourished beaches equilibrate.

- Some studies suggest that beach nourishment can reduce sea turtle hatching success (that is, number of eggs that fully develop and hatch) by increasing the likelihood that a nest will be washed out on nourished beaches with artificially low slopes. Nourished beaches also can cause low hatching success if fill sediments alter the mineral content, gas exchange, temperature, and moisture of the nest environment during embryonic development.
- One study found reduced hatchling survival on nourished beaches, but this result was not statistically significant. Other studies found no effect of beach nourishment on hatchling success, but studies on this topic are few.

- Extracting sediments from shoals, mudflats, and sandbars can remove foraging habitats that are vital to overwintering and migrating shore/waterbirds.

- Losses in the abundance and diversity of seagrass, macroinvertebrate, and benthic species during the removal and placement phases of renourishment projects can propagate up through the food web to shore/ waterbirds, resulting in reduced shore/waterbird populations on nourished beaches throughout the annual cycle. Detrimental effects to shore/waterbirds through the food web can persist for months to several years. However, the placement of dredged materials can also provide entirely new foraging grounds for these birds where such habitats were previously lacking (because of shoreline erosion, for example).

- Sediment placement during the shore/waterbird breeding season can harm reproductive success by increasing human disturbance, crushing or burying eggs and chicks, reducing prey species, and impeding access to back-barrier foraging habitats. Many of these effects should be avoidable by conducting nourishment activities outside of the breeding season. However, direct links between shore/waterbird reproductive success and beach nourishment projects are lacking.

- Sediment placement can benefit shore/waterbird communities by creating beach and backshore nesting habitats on eroding shorelines, minimizing vegetation growth and succession, and providing shell-hash that camouflages eggs.

\subsection{Nesting Sea Turtles}

Five of six federally protected species of sea turtles nest along U.S. Gulf or Atlantic coastlines. These species include loggerhead, Kemp's ridley, green, Eretmochelys imbricata (Linnaeus, 1766) (hawksbill), and leatherback sea turtles. In the United States, loggerheads nest from Texas to Virginia (NMFS and USFWS, 2008), and Kemp's ridley sea turtles nest in small numbers from Texas to North Carolina (NMFS and USFWS, 2015). Hawksbill, green, and leatherback sea turtles nest primarily along the coast of Florida (NMFS and USFWS, 1991, 1992, 2013), but green and leatherback sea turtles have been recently observed in the Carolinas. All species, except for Kemp's ridley, nest in the Caribbean (NMFS and USFWS, 1991, 1992, 2008, 2013, 2015). 
Sea turtles use the subaerial beach ecosystem only for nesting, and, in this section, we focus on potential effects of sand placement on reproductive success. Additional effects on sea turtles during other phases of the life cycle are discussed in section 5 .

Females emerge on high-energy ocean beaches between February and November (variations within that window depend on the species and region), where they crawl landward in search of a suitable location, dig pits in the sand, lay and bury eggs, and then return to the ocean within a relatively short window of time (Hailman and Elowson, 1992). Females typically place nests between the high-tide line and dune face on areas with steep slopes-what is believed to be an important cue for preventing nest loss to overwash and inundation (Provancha and Ehrhart, 1987; Wood and Bjorndal, 2000). Once laid, eggs require suitable humidity and temperature conditions for embryonic development, particularly because specific gas exchange and temperature ranges are critical (Miller and others, 2003; Lamont and others, 2020). Eggs hatch after sufficient incubation and development, at which point hatchlings dig upward and out of the nest all together and disperse into the ocean using temperature and light cues (Moran and others, 1999; Stewart and Wyneken, 2004).

Because beach nourishment can alter beach morphology and sediment characteristics (as discussed in sec. 3), nourishment projects can affect nesting success (or the number of female emergences that lead to a nest), hatching success (or the number of eggs that fully develop and hatch), and hatchling success (or the number of hatchlings that successfully emerge from the nest and crawl to the ocean).

\subsubsection{Nesting Success}

In one study, nourishment created sandy habitat where none previously existed on severely eroded beaches, which resulted in turtle nests for the first time in many years along several small stretches of coastline (Ernest and Martin, 1999). However, these authors also found that, despite a substantial increase in nesting habitat on two nourished beaches, the number of nests did not correspondingly increase. Furthermore, a substantially larger proportion of female emergences on nourished beaches resulted in false crawls, where females returned to the ocean without laying a nest-a pattern that was particularly evident in the first year after nourishment. Females also abandoned nests mid-dig without laying eggs more frequently on nourished beaches (Ernest and Martin, 1999). In a similar study, nest success (measured as the ratio of nesting emergences to false crawls) was substantially lower for loggerhead and green sea turtles on nourished beaches. This effect persisted for only the first year after nourishment, after which point nesting success on nourished and unnourished beaches was similar (Brock and others, 2009). Several other studies also found depressed nest success (females that nest/total emergences) on nourished beaches, particularly in the first year after nourishment (reviewed in Grain and others, 1995; Steinitz and others, 1998; Rumbold and others, 2001; Cisneros and others, 2017).

Lower nesting success on nourished beaches was primarily attributed to construction-related changes to beach profile and sediment compactness (Steinitz and others, 1998; Ernest and Martin, 1999; Rumbold and others, 2001; Brock and others, 2009; see sec. 3 for more details). Steep escarpments are usually created close to the ocean shoreline during nourishment, and these features can obstruct accessibility of emerging females to suitable habitat (Grain and others, 1995; Steinitz and others, 1998). The effect of nourishment-created scarps may depend on the species; Nelson and Bilhovde (in Byles and Fernandez, 1998) found that green sea turtles were able to traverse vertical scarps up to $20 \mathrm{~cm}$ high and were generally able to traverse higher and steeper scarps than leatherback sea turtles. However, Rivas and others (2016) report that between 18 and 24 percent of leatherback sea turtles did not climb over dune scarps on a Costa Rican beach and instead laid their eggs below the high-tide line, where they were more vulnerable to wash out. In contrast, Brock and others (2009) hypothesized that nourished beaches were too wide and flat, resulting in false crawls as females terminated their nesting attempts before reaching dune features.

Other studies also found that females spent more time digging nests or were more likely to abandon a nest without laying eggs on nourished beaches containing more-compact sediments (Steinitz and others, 1998; Ernest and Martin, 1999). Beach profile and sediment compactness tend to equilibrate through time to more natural conditions, explaining why nourishment impacts on sea turtle nesting success dissipate after about 1 year (reviewed in Grain and others, 1995; Steinitz and others, 1998; Ernest and Martin, 1999; Rumbold and others, 2001; Brock and others, 2009; Cisneros and others, 2017).

In addition, Lamont and Houser (2014) found that nesting female emergences exhibited a statistically significant clustering in space and time along the authors' peninsular study site. This clustering of emergences was correlated to nearshore characteristics such as wave height, bathymetry, and current velocities. These results support studies from other beaches in Florida (Provancha and Ehrhart, 1987; Weishampel and others, 2003) and elsewhere (Marcovaldi and Laurent, 1996) that demonstrate a clustering of emergences for loggerheads. The relation between nearshore characteristics and nest site selection has also been previously documented (Williams-Walls and others, 1983; Provancha and Ehrhart, 1987; Horrocks and Scott, 1991). Therefore, nest site selection likely begins while the turtles are in the nearshore environment, and activities that alter that nearshore environment-such as shoreface nourishment (see details in sec. 3), construction of jetties, dredging, or installation of pilings - may affect sea turtle nest distribution.

Finally, Greene (2002) also hypothesized that pipelines, heavy equipment, and artificial lighting used in the construction phase of nourishment projects could lead to a decline 
in emerging and nesting females. However, we were unable to find studies to support these hypotheses in the published literature.

\subsubsection{Hatching Success}

The conclusions regarding the effects of beach nourishment on sea turtle hatching success are varied. Several studies found no apparent effect of beach nourishment on hatching success (Milton and others, 1997; Davis and others, 1999; Brock and others, 2009). However, Ernest and Martin (1999) and Cisneros and others (2017) found evidence of reduced hatching success on nourished beaches. Although loggerhead nests were more likely to be overwashed on unnourished beaches (that is, overwashed but not lost), nests were more likely to wash out on wider, flatter nourished beaches (Ernest and Martin, 1999). This increased risk of nest washout persisted into the second year after nourishment. The authors attributed this effect to (1) the lower slope of the constructed beaches in the first year, which allowed swash to extend farther up the beach, and (2) the increased seaward placement of nests because of scarps in the second year after nourishment (Ernest and Martin, 1999). Cisneros and others (2017) attributed reduced hatching success on nourished beaches to the use of coarse-grained sediments and a higher carbonate content compared to native material.

When nests lost to washout and erosion were removed from analysis, nests on nourished beaches had similar (Ernest and Martin, 1999) or better (Brock and others, 2009) rates of hatching success compared to those on unnourished beaches. Therefore, reduced hatching success seems to be related to washout risk, and changes in sediment characteristics likely do not inhibit the embryonic development or percentage of eggs that hatched (Ernest and Martin, 1999). Ernest and Martin (1999) noted that incubation on nourished beaches had two equal but opposite effects on hatching success. Nourished beaches were more conducive to the initiation of embryonic development than unnourished beaches, but conditions on the constructed beaches became less favorable at later stages of development. The authors attribute these effects to suboptimal sediment temperature and (or) gas diffusion surrounding nests on nourished beaches (Ernest and Martin, 1999). Lamont and others (2020) note that temperatures and incubation durations on nesting beaches may be regulated by differing sources of sand and beach orientations, which could be affected by nourishment activities.

Although Milton and others (1997) reported similar rates of loggerhead sea turtle hatching success on nourished and unnourished beaches in Florida, the authors noted that nourishment with fill materials that contained aragonite sands resulted in cooler sediment temperatures than native silicate sandy beaches. Other nourishment projects that used darker fill materials elevated sediment temperatures compared to unnourished beaches (reviewed in Grain and others, 1995). Because temperature during incubation determines sex in sea turtles (reviewed in Grain and others, 1995), altered temperatures could skew the sex ratios in sea turtle populations. However, we found no experimental study in the literature to support the effect of nourishment on sex ratio and prevailing population dynamics.

Finally, Grain and others (1995) also discussed several other potential effects of beach nourishment on sea turtle hatching success. These include nourishment-related changes to mineral content, gas exchange, temperature, and moisture, as well as an increased prevalence of contaminants from certain fill sediments (especially those borrowed from canals, harbors, and channels) - all of which could slow or halt embryonic development. Authors also note the risk of burying nests under excess sand. However, evidence is lacking in the published literature to support the extent of these effects.

\subsubsection{Hatchling Survival}

Few studies evaluate the effect of nourishment on hatchling, and further study may be required. Based on what evidence is available, most studies suggest that nourishment does not negatively affect hatchling survival. Several studies noted no significant differences between emergence success on nourished and unnourished beaches (Raymond, 1984; Broadwell, 1991; Milton and others, 1997; Brock and others, 2009). In one instance (Ernest and Martin, 1999), authors did find higher numbers of dead hatchlings in nests on nourished beaches and that it took longer for surviving hatchlings to emerge, although these results were not statistically significant.

\subsection{Shorebirds and Waterbirds}

Shorebirds and other waterbirds rely on sandy beach habitats throughout their annual cycle along United States coastlines. Waterbirds include any avian species that lives on or near water, such as gulls, terns (including Sternula antillarum [Lesson, 1847] [least terns] and Sterna dougallii [Montagu, 1813] [roseate terns]), Haematopus palliatus (Temminck, 1820) (American oystercatchers), Rynchops niger (Linnaeus, 1758) (black skimmers), and Phalacrocorax auritus (Lesson, 1831) (double-crested cormorants). Shorebirds are a subset of waterbirds in the order Charadriiformes that live along shorelines and tidal flats and include species of interest like piping plovers, Charadrius nivosus (Cassin, 1858) (snowy plovers), and Calidris canutus (Linnaeus, 1758) (red knots). About 50 species of shorebirds are common to North America, and about one-third of them are projected to reach "Endangered" status within the next century (Guilfoyle and others, 2007). Therefore, many avian species, including many of conservation concern, can be affected by beach nourishment irrespective of when and where nourishment projects are implemented.

Shorebirds and many species of waterbirds lay eggs in small depressions in the sand each year between February and September (exact length of season depends on species; Natural Resources Conservation Service [NRCS], 2000). Nests are 
typically constructed in beach and backshore areas, sand flats, overwash fans, natural, low-elevation dune complexes, and dredge material deposits (Plauny, 2000; McGowan and others, 2005; USFWS, 2010, 2020; Webber and others, 2013; Maslo and others, 2016; Zeigler and others, 2021). These settings are often far enough from high-energy shorelines to prevent nest flooding but not so far into the vegetated interior that adults and nests are at risk of predation. Nesting habitat also tends to occur in areas with substrates that are a mix of sand and coarser materials (for example, shell) with minimal vegetation (Plauny, 2000; McGowan and others, 2005; USFWS, 2010, 2020; Webber and others, 2013; Maslo and others, 2016; Zeigler and others, 2021). After incubation, hatched chicks of many shore/waterbird species are precocial, meaning they can walk and feed themselves. However, because chicks are unable to fly until several weeks after hatching, access to adequate foraging habitat on foot is a critical component of habitat suitability for many of these species (Webber and others, 2013; American Oystercatcher Working Group and others, 2020; Gochfeld and others, 2020; Thompson and others, 2020; Zeigler and others, 2021). For these reasons, stormcreated overwash fans offer important habitat for many species because they have minimal vegetation, shelly substrates, and access to low-energy intertidal areas on the back-barrier (Convertino and others, 2011b; Maslo and others, 2016; Zeigler and others, 2019). Nourishment activities can affect these sandy beach habitats critical for nesting and foraging (discussed in sec. 6.2.1).

Sandy beaches, intertidal zones, and offshore shoals along the Gulf and Atlantic coasts also offer critical overwintering and stopover habitats for migratory shore/waterbirds; about 10-20 million birds migrate through the Atlantic coastal waters each year. Listed species and species of concern - such as Gavia spp. (J. R. Forster, 1788) (loons), Melanitta spp. (F. Boie, 1822) (seaducks), red knots, piping plovers, Numenius phaeopus (Linnaeus, 1758) (whimbrel), and Limosa fedoa (Linnaeus, 1758) (marbled godwit) — rely on these habitats for food and rest, typically between July and March each year (Guilfoyle and others, 2007). An adequate food supply is critical for these species because they perform long, energy-expensive migrations two times per year. Poor fat composition resulting from inadequate food supplies during migration and overwintering can affect a bird's ability to survive and reproduce throughout the annual cycle (Buehler and Piersma, 2008).

Shore/waterbirds rely on a variety of marine habitats for food during all phases of the annual life cycle. Shorebird prey include insects, worms, amphipods and other crustaceans, small fish, and clams and other shellfish (Schneider, 1983). Other waterbirds forage on animal (for example, amphipods, crustaceans, fish, and mollusks) and plant (for example, seagrass seeds, tubers, and leaves) food items (Perry and others, 2007). Plant and prey taxa are predominantly found in or on moist substrates along intertidal zones, ponds, ephemeral water bodies, and sea wrack, as well as tidal flats, sandbars, and shoals in the nearshore and offshore zones (Plauny, 2000;
Fraser and others, 2005; Burger and others, 2007; Perry and others, 2007; Cohen and Fraser, 2010; Maslo and others, 2012). Therefore, nourishment effects on foraging habitats and (or) prey species could have consequences for shore/waterbirds during the nesting, migratory, and overwintering seasons.

Beach nourishment can affect shorebird and waterbird populations throughout the annual cycle depending on where and when sediments are extracted and placed. In this section, we report what is known about the effects of dredging and beach nourishment activities on foraging habitat and reproductive success for these avian taxa.

\subsubsection{Foraging Habitat}

As discussed in more detail in section 3, sediments are usually extracted from inlet-associated and ebb-tidal delta shoals and sandbars, as well as the shoreface. These activities can cause the direct physical removal of habitats used by foraging shore/waterbirds (Guilfoyle and others, 2007). Dredging activities can also indirectly affect shore/waterbirds by damaging seagrass meadows during the removal process and by creating high turbidity and siltation conditions that are lethal to these plant species (Caldwell, 1985; Dennison, 1991; Onuf, 1994; Hemminga and Duarte, 2000; Sabol and Shafer, 2005). Seagrass meadows offer important habitats for macroinvertebrates that serve as prey for shore/waterbird communities (Heck and others, 2008). Furthermore, as much as 50 percent of seagrass biomass annual production can be deposited on the beach via currents and waves (Mateo and others, 2003; Mateo and others, 2006), and intertidal isopods that break down seagrass wrack are an important food source for shorebirds (Lenanton and others, 1982; Lenanton and Caputi, 1989; Heck and others, 2008). Finally, dredging and sediment placement can remove and bury, respectively, beach wrack deposits. Shorebird population abundance has been linked to the quantity of beach wrack, indicating a strong connection between intertidal plant production and shorebird populations (Bradley and Bradley, 1993). Numerous waterbird species rely on seagrasses for food during winter and along migration routes, and declines in these food resources have affected their abundance, distribution, and habitat use (Perry and Uhler, 1988; Perry and others, 2007).

Placed sediments during nourishment activities can also affect shore/waterbird populations by reducing prey availability. As discussed in section 3, placed sediments are often layered on the shoreface, beach, foredune, marsh/back-barrier flats, or along estuarine shorelines - areas where shore/ waterbirds frequently forage throughout the annual cycle. Several studies documented reductions in the abundance and diversity of macroinvertebrates and benthic assemblageswhich include shorebird prey species - on nourished beaches (McLachlan, 1996; Rakocinski and others, 1996; Peterson and others, 2000b; Peterson and others, 2006; Colosio and others, 2007). As discussed in greater detail in section 4 , placed sediments can suffocate (Rakocinski and others, 1996; Peterson and others, 2000b), crush (McLachlan, 1996; 
Colosio and others, 2007), or otherwise create a more stressful environment for macroinvertebrates and benthic assemblages (McLachlan, 1996; Rakocinski and others, 1996). Authors generally attribute the loss of these species to the volume of sand placed on top of these communities (McLachlan, 1996; Colosio and others, 2007), use of substantially different grain sizes compared to native sediments (Rakocinski and others, 1996; Peterson and others, 2000b; Colosio and others, 2007), changes to the beach profile (McLachlan, 1996; Rakocinski and others, 1996), or the colonization of competing nonnative species (Norkko and others, 2002; Thrush and others, 2003; Martin and others, 2005; Lohrer and others, 2006; Tu Do and others, 2012). Reductions in macroinvertebrate and benthic species abundance and diversity occur immediately after nourishment (Peterson and others, 2000b, 2006), and the recolonization and recovery of these communities can take months to several years (Tu Do and others, 2012; Peterson and others, 2014).

Evidence suggests that nourishment-related changes to macroinvertebrate and benthic communities propagate up to shorebirds through the food web throughout the entire annual cycle. Convertino and others (2011a) observed declines in nesting snowy plovers and in wintering snowy and piping plovers in the year after a beach nourishment project. Peterson and others (2006) noted a sevenfold reduction in feeding shorebird numbers on beaches that were nourished between March and September of that year, although there was no significant difference in shorebird numbers between nourished and unnourished beaches by November. In another study, the die-off of a polychaete after nourishment led to a drop-off in the number of foraging Calidris alba (Pallas, 1764) (sanderling; reviewed in Speybroek and others, 2006). Although reductions in shorebird numbers were largely attributed to reductions in the benthic prey community, some authors posited that higher levels of sediment compaction, larger grain sizes, and higher concentrations of shell hash compared to native sediments on nourished beaches could also affect the ability of birds to probe for prey (Peterson and others, 2006; reviewed in Speybroek and others, 2006).

In general, changes to prey availability and foraging habitat conditions resulting from beach nourishment can greatly affect the availability of prey and the amount of energy a shore/waterbird expends to forage (as reduced prey availability and sediment compaction increases search time for prey).

The food taken at any one time depends on the preferences of the birds and the availability of the food items. Thus, as the availability of any food item changes, the food habits and possibly the relative abundance of the birds may change and result in movement into or away from an area (Berlin, 2008).

In contrast, Leewis and others (2012) found no negative long-term effects of sand placement on four macroinvertebrates studied, and Grippo and others (2007) did not find strong evidence that migratory shorebird abundance or feeding activity were significantly altered by a nourishment project. Peterson and others (2000b) noted rapid macroinvertebrate recovery after nourishment in some studies and attributed this recovery to the use of sediments with grain sizes similar to those of native materials. Some studies also indicate that the placement of dredged materials creates entirely new habitats that are quickly colonized by breeding, migrating, and overwintering shore/waterbirds (examples throughout Guilfoyle and others, 2006, 2007) - although grain size, slope, and use of rip rap and sand bags on these constructed islands or tidal flats affected use and suitability (Guilfoyle and others, 2006, p. 37-39). Comparisons between tidal flats constructed using dredge material and natural tidal flats showed similarities in species richness, species composition, and diversity within 2 years of construction (Ray, 2000). Given competing results in studies of beach nourishment impacts on foraging shore/ waterbirds, further study on which nourishment project conditions lead to null effects on avian species compared to conditions that lead to negative effects may be warranted.

\subsubsection{Reproductive Success}

Sand placement during beach nourishment also can affect the reproductive success of breeding shore/waterbirds through changes to habitat availability, the cues adults use to establish breeding territories, and the survival of chicks to fledging. The nature of these effects is mixed, potentially enhancing reproductive success in some ways and reducing it in others.

We discussed the negative effects of beach nourishment on prey species in the previous section (as well as sec. 4). Sand placement is expected to affect prey resources for shore/ waterbirds and their chicks for at least one breeding season after every nourishment cycle. The effect of frequent and repeated nourishment cycles (for example, a 4-year cycle) is likely nonlinear but requires additional study.

Elevation gains and complementary activities to stabilize the shoreline - such as sand fencing, constructed dunes, and jetty construction - are also often associated with beach nourishment (see sec. 3). These activities could limit natural overwash processes or restrict chick access to high-quality foraging habitat along inlets or the back-barrier shoreline (Guilfoyle and others, 2006, p. 21-22; reviewed in Lott and others, 2007; Schupp and others, 2013). Adults may be less likely to select beach habitats that do not have access to these foraging habitats (Elias and others, 2000; Cohen and others, 2009; Zeigler and others, 2021), whereas studies have found that chick survival is substantially lower on beaches that do not have access to these foraging habitats (Patterson and others, 1991; Loegering and Fraser, 1995; Goldin and Regosin, 1998). If nourishment alters the quality, quantity, or access to foraging habitats - by reducing prey availability (sec. 4) or by impeding overwash or access to back-barrier foraging habitats (secs. 3 and 7) - beach nourishment could reduce reproductive success by limiting habitat availability or by reducing chick survival. However, to our knowledge, direct causal links between beach nourishment and shore/waterbird productivity have not been studied and represent a knowledge gap. 
In addition, Greene (2002) indicated that nourishmentrelated construction activities and materials - including pipelines, construction vehicles, and human activity on the beach — could displace or disturb nesting shorebirds. Beaches around inlets, which are usually the site of dredging activities, are important shorebird habitats, and the risk of disturbance is high in these locations (Guilfoyle and others, 2006, p. 10-11; Guilfoyle and others, 2007). Beach nourishment can also widen beaches and promote increased human use and recreation of these sensitive ecosystems. Although we were unable to find information on the direct effects of nourishment projects on the health of shore/waterbirds, a few studies have established the cumulative effects of human disturbance on these species and their survival throughout the annual cycle (Martin and others, 2005; Gibson and others, 2018; van der Kolk and others, 2020). Human disturbance in the early breeding season can result in territory abandonment and disruption of pair bonds. Adults that take frequent recesses or make restless movements from a nest, which could occur in response to human disturbance during nourishment projects, increase the likelihood of failed nests (Smith and others, 2012) because of abandonment, predation, and overheating (Smith and others, 2012; Andes and others, 2020). Chicks that hatched on beaches with high human recreational use spent less time foraging and had lower survival rates (DeRose-Wilson and others, 2018). Finally, disturbance during the end of the breeding season into the fall can disrupt prospecting activities of recently fledged offspring, which can affect nest site selection in the following year (Davis and others, 2017). Although there are no studies available that link human disturbance related to beach nourishment activities to low shore/waterbird reproductive success, the research described here does suggest that - if beach nourishment activities disturb breeding shore/ waterbirds - one could expect repercussions for adults and chicks that ultimately result in lower productivity rates.

Nourishment-related sand placement and construction activities, such as the use of pipelines, the use of bulldozers, and human foot traffic, during the nesting season could also crush or bury eggs and chicks (Greene, 2002), which are highly camouflaged by native sediments and would be difficult to avoid. However, beach nourishment projects rarely occur during the shore/waterbird breeding season, and we were unable to find causal linkages between beach nourishment and shore/waterbird reproductive success in the literature.

Several studies also demonstrate beneficial effects of nourishment on shore/waterbird habitats. Beach nourishment can widen eroding beaches, creating backshore nesting habitats where none existed before nourishment (Nordstrom, 2005; Fraser and others, 2006; Guilfoyle and others, 2006; reviewed in Lott and others, 2007). Compared to native materials, placed sediments also tend to have coarser grains and a higher concentration of shell fragments - sediment characteristics that are frequently selected by nesting shorebirds (reviewed in Speybroek and others, 2006; Zeigler and others, 2021). Sandy substrates, particularly those mixed with shell or rock fragments, provide camouflage for mottled shorebird eggs and allow adults and chicks to "hide in plain sight" (Fraser and Catlin, 2019). Sediments placed during nourishment can also slow vegetation regrowth (reviewed in Speybroek and others, 2006). This reduction in vegetation increases a bird's ability to detect approaching predators and maximize the benefits of cryptic coloration through common nest defense behaviors (for example, false brooding, running, feigning injury, or staying motionless; Cairns, 1982). Some studies have suggested that high shell hash and minimal vegetation increase nest success for plovers and other ground-nesting species (Gaines and Ryan, 1988; Colwell and others, 2011; Troscianko and others, 2016), although others have found contrary results (Patterson and others, 1991; Darrah and others, 2018). Through these mechanisms, beach nourishment could increase the quantity and quality of available nesting habitat, ultimately improving the productivity and reproductive success of shore/waterbird populations.

\subsection{Impacts on Other Taxa, Opportunities for Further Research, and Recommendations}

\subsubsection{Other Taxa}

A variety of other taxa rely on sandy beach habitats in the United States - including federally listed insects like the Habroscelimorpha dorsalis dorsalis (Say, 1817) (northeastern beach tiger beetle), plants like Amaranthus pumilus (Raf.) (seabeach amaranth), and mammals like Peromyscus polionotus sp. (Wagner, 1843) (beach mice). Literature on the effects of nourishment on species beyond sea turtles and shore/waterbirds exists but remains scarce. For instance, Fenster and others (2006) suggested that beach nourishment improved tiger beetle habitat by replenishing eroded beaches to more preferred widths. Beach mice can also benefit from beach nourishment but generally only when such restoration projects also include dune rebuilding and vegetation plantings (USFWS, 2014, 2019). Adding sand to sedimentstarved beaches promotes the natural development of primary, secondary, and scrub dune ecosystems, which serve as critical habitat for beach mice. The associated construction of artificial berms with vegetation plantings directly creates beach mouse habitat while also allowing for functional connectivity among subpopulations. Activities that foster movement among subpopulations is particularly important for this species because reduced genetic variation and genetic bottlenecks are cited as a threat to several beach mouse subspecies (USFWS, 2014, 2019). However, beach nourishment alone may have little benefit to beach mice without complementary restoration efforts (K. Yanchis, USFWS, written commun., 2020). Additional research is warranted to more clearly understand how beach nourishment, complementary practices (such as, bulldozing and artificial dune construction), and associated activities (for example, off-road vehicle use and increased human recreation use) affect the diverse community of species that inhabit sandy beaches. 


\subsubsection{Opportunities for Further Research, Impact Monitoring, and Evaluation}

Peterson and Bishop (2005) noted "numerous inadequacies" in the designs of studies evaluating the biological impacts of beach nourishment. These authors indicated that, of 49 studies found at that time, only 11 percent accounted for natural spatial and temporal variation in the ecosystem, and 56 percent of studies reached conclusions that were not adequately supported by their results. Furthermore, Peterson and Bishop (2005) noted that monitoring is conducted predominantly by project promoters without independent peer review or adequate expertise in biostatistical analyses. For our review in this report, 15 years later, we continue to find only a few studies that evaluated the direct effects of beach nourishment on coastal taxa, and most of these studies focused on sea turtles and shorebirds. In addition to the data types and metrics recommended for impact monitoring in appendix 1, the following additional areas of research and monitoring may be warranted:

1. The effects of beach nourishment on other coastal taxa.

Most beach nourishment impact studies focused on sea turtles and shorebirds, two high-profile, charismatic taxa. However, a variety of other federally and State-listed species rely on these sandy habitats, and the effects of beach nourishment on plants, insects, and other species should be evaluated.

2. Statistically rigorous before-and-after monitoring studies on species' population dynamics.

Additional research is needed that examines species use, survival, and reproductive success and productivity throughout the annual life cycle. Particularly, pelagic waterbird species lack historical, comprehensive datasets to examine population trends over time (Guilfoyle and others, 2007). Species-use and population dynamics should be evaluated before and after nourishment projects, requiring several years before and after to capture natural variability and trends before nourishment projects compared to after their implementation. In addition, monitoring survival and productivity for several years after completing a nourishment project can elucidate how long any nourishment-related effects on population dynamics last. Monitoring and research should use adequate controls (for example, non-nourished and [or] "pristine" beaches) and be completed or vetted by independent agencies (in other words, not the project promoter).

3. Evaluation of the effects of repeated nourishment cycles.

Most studies we reviewed examined the effects of a single beach nourishment application on the population dynamics of sea turtles and shorebird prey species. However, many beach nourishment projects occur in cycles (for example, every 4 years), and the cumulative effects of several applications on relevant species and their prey are unknown. Furthermore, the effect of an event on population dynamics may not be seen for several years because time lags exist between reductions in survival or reproduction and population size (for example, Zeigler and others, 2019). To directly assess cumulative impacts of repeated nourishment on coastal species, the evaluation period for quantifying effects should be extended.

4. Evaluation of the biological effects of construction, disturbance, and other related practices.

Greene (2002) hypothesized that pipelines, heavy equipment, artificial lighting, and human disturbance used in the construction phase of nourishment projects could lead to a decline in the reproductive success of sea turtles and shorebirds. However, no studies to our knowledge have examined these potential effects.

5. Evaluation of other beach nourishment-related effects on sea turtles.

Grain and others (1995) discussed potential nourishment-related changes like excessive burial and changes to mineral content, gas exchange, temperature, moisture, and contaminant load on developing sea turtle eggs. However, no studies to our knowledge have examined these potential effects. Furthermore, studies show conflicting evidence of beach nourishment impacts on sea turtle embryonic development and hatchling success. Additional studies may be needed to more definitively understand how beach nourishment affects sea turtle reproductive success.

\subsection{Impacts of Sediment Removal and Placement on Coastal Resiliency}

By Davina L. Passeri, Daniel J. Ciarletta, Christopher G. Smith, Kathryn Smith, and Sara L. Zeigler

Coastal resiliency is defined as the ability of a coastal system to respond to and recover from perturbations, natural or otherwise. In their natural states, barrier islands are inherently resilient to short- and long-term drivers such as storms and SLR, respectively. During storms, sediment is exchanged among the dunes, beach, and shoreface to reduce wave energy. During poststorm periods of recovery, waves and currents return sediment to the beach to increase elevation and width, whereas winds transport beach sediment to the dunes so that they grow and revegetate. Over longer timescales, barrier islands migrate landward or seaward in response to changes in sea level, constantly maintaining elevations and widths in balance with sea level through dune overwash, alongshore 
transport, and marsh accretion. Connectivity through these short- and long-term exchanges of inorganic sediments and organic materials across the barrier island are critical for maintaining the form and function of its ecosystems. As such, it is this natural physical and ecological resiliency that has allowed barrier islands to successfully support coastal communities and their economies. For example, beaches are a key element of the travel and tourism industry (Houston, 2013). Barrier islands also protect mainland communities during storms (for example, Irish and others, 2010). In addition to human communities, barrier islands contain ecologically and economically significant ecosystems for a variety of species. However, there are costs associated with the services barrier islands provide over short and long timescales. This section discusses how sediment removal and placement can affect short- and long-term coastal resiliency. Efforts aimed at improving coastal resiliency through sediment placement are presented first, followed by discussions of negative effects caused by sediment removal. Examples of the former were more prominent in the literature than the latter.

The main points from this section are as follows:

- Sediment placement either through nourishment or emergency sand berms is a short-term strategy that can help protect coastal infrastructure and critical habitats from storm inundation.

- Sediment removal, such as channel dredging, may increase tide and storm-surge inundation in coastal embayments, which can adversely affect infrastructure and habitats.

- A few studies suggest that nourishment may be helpful in reducing erosion under future SLR; however, artificially high nourished dunes may reduce overwash and deprive back-barrier environments of deposition needed to keep pace with SLR.

- The effects of sediment removal, such as downdrift shoreline erosion and reduced sediment supply, may be exacerbated by SLR.

- Sediment removal and placement can have varying effects on coastal ecosystems.

\subsection{Impacts of Sediment Placement and Removal on Short-Term Coastal Resilience}

\subsubsection{Sediment Placement and Short-Term Resiliency}

As described in detail in section 3.2, several types of nourishment strategies can be used to protect and restore coasts. Depending on the desired location of maximum benefit, sand can be placed on dunes, the subaerial beach (beach berm), along the entire beach profile (subaerial and submerged), or on the shoreface or sandbar (submerged fill or feeder berm) (z; Campbell and Benedet, 2004). In the United States, beach nourishment is the most commonly used soft engineering method to mitigate flooding and damage during storms along beaches where managed retreat is unlikely (Kress and others, 2016; Beck and Wang, 2019). Through field observations and modeling assessments, beach and dune nourishment have been accredited with reducing infrastructure damage caused by major storms and hurricanes (Dean, 2005; Rogers, 2006). This is a result of higher, wider beaches and (or) dunes from sand placement, which reduces storm flooding and erosion (see sec. 3.2.2. for details). For example, field surveys that were conducted after Hurricanes Dennis and Floyd (1999) on the North Carolina coast revealed that no buildings were threatened by shoreline erosion on nourished beaches. In comparison, 903 buildings were threatened and 65 buildings were destroyed on adjacent non-nourished beaches (Rogers, 2006).

Nourishment can provide storm protection, but the benefits are often considered temporary, thus requiring maintenance or "re-nourishment" schedules. The persistent effects of sediment placement often depend on several site-specific characteristics, making it difficult to define or quantify success over time. Monitoring of nourishment projects after sediment placement is typically performed over short periods; however, postproject monitoring assessments are not easily found in peer-reviewed scientific literature, and longer-term assessments (multiple years after a project) of the effectiveness of a project are rare. A 1998 beach and dune nourishment project in Wrightsville Beach, N.C., was assessed using remotely sensed data. The study showed that 1 year after the project was completed, about two-thirds of initial infill material had been eroded from the subaerial beach as a result of Hurricanes Bonnie (1998) and Floyd (1999), which caused extensive dune overwash and breaching. There was little evidence that the fill material moved alongshore to adjacent subaerial beaches and minimal evidence of poststorm beach recovery 2 years after the storms (Gares and others, 2006). Nourishment on beaches in Spain was also only effective for a short period; shoreline configurations returned to prenourishment conditions about 1.5 years after placement because of small amounts of available sand and disequilibrium of the beach profile (Ojeda and Guillen, 2006). Over time, the intended reductions in coastal risk from nourishment may be offset or even reversed by increased coastal development; the appearance of a reduced risk from a wide, nourished beach may lead to more development behind nourished beaches, whereas the lack of risk reduction may inhibit development in non-nourished areas (Armstrong and others, 2016).

As described in section 3.2.2., shoreface nourishment is intended to feed sediment to the upper shoreface, decrease water depths and slopes near the shore, and therefore reduce wave energy. It can provide sand to adjacent shorelines especially during storms, thereby creating a "buffer" against storm-induced erosion (Huisman and others, 2019). But, similar to beach nourishment, the effects of shoreface nourishment have only lasted over periods ranging from months to 
years (Grunnet and Ruessink, 2005; Ojeda and others, 2008; Brutsché and others, 2014, 2015, 2017). More studies are needed to better understand and quantify the effectiveness of shoreface and profile nourishment for storm protection compared to other placement methods.

Although not implemented as "traditional" nourishment projects, emergency sand berms (for example, shore-parallel, linear mounds of sediment used to mitigate natural or anthropogenic hazards; also called emergency breaker berms) have had mixed short-term effects to barrier island resiliency. For example, sand removed from the washover deposits on the landward side of Dauphin Island, Alabama, in early 2007 was used to create an emergency sand berm across a breach in the island and on the shoreface. Later that same year, winter waves eroded and breached the berm, having had little effect on the overall position of the gulf-facing shoreline (Froede, 2007) and potentially leaving the island more vulnerable (USACE and others, 2020). A similar berm was constructed along the northern Chandeleur Islands, Louisiana, to mitigate oil transport into critical bird habitat after the Deepwater Horizon Oil Spill of 2010 (Lavoie and others, 2010). Unlike with the Dauphin Island berm, sand from the Chandeleur Islands berm was reworked onto and behind the island, resulting in a short-term increase in the subaerial footprint of the island (Plant and others, 2014; Sherwood and others, 2014; Bernier and others, 2019). Collectively, these examples of planned and emergency sand placement demonstrate some increase in barrier resiliency to storms but only in the short term, such as 1-5 years after project completion.

Additionally, artificial, submerged sandbars (also called submerged, nearshore, or feeder berms) placed offshore can provide shore protection and supply sand to the nearby beach (Charlier and De Meyer, 1995; Grunnet and Ruessink, 2005; Hwung and others, 2010). Sandbars are common, naturally occurring features along sandy coasts, and artificial sandbars may have less impact on natural coastal processes than other beach nourishment or artificial shoreline protection techniques (das Neves and others, 2015; Utizi and others, 2016). Artificial, submerged sandbars increase onshore sediment transport through wave-induced current because of wave breaking (Grunnet and Ruessink, 2005) and by reducing the sediment-carrying capacity within the sheltered area between the sandbar and the beach (Jacobsen and Fredsoe, 2014), thereby increasing beach shoreline resiliency by reducing sediment erosion of nearby beaches. Jacobsen and Fredsoe (2014) determined that a high, narrow artificial sandbar will protect the beach, whereas a low, wide artificial sandbar will cause erosion, illustrating the importance of configuration on artificial sandbars as protective and nourishment features for beaches. Utizi and others (2016) documented short-term benefits of feeder berms on shoreline stability, documenting sediment grain size, volume, and position as key factors affecting its performance as a protective feature. Overall, nearshore artificial sandbars (berms) for either emergency or long-term maintenance of nourished or natural beaches present a viable option for stabilizing eroding beach shorelines.

\subsubsection{Sediment Removal and Short-Term Resiliency}

Although sediment placement can be effective for storm protection, sediment removal may adversely affect tide and storm-surge inundation. Dredging of channels and inlets can reduce the effects of friction, resulting in increased tidal amplitudes in coastal embayments (Orton and others, 2015; Familkhalili and Talke, 2016; Aretxabaleta and others, 2017; Ralston and others, 2019), which can negatively affect estuarine habitats (as further discussed in sec. 7.3). During storms, dredged channels can cause increased storm-surge depths and propagation of surge further landward (Familkhalili and Talke, 2016; Ralston and others, 2019), thereby threatening mainland infrastructure and estuarine habitats with additional flooding. On the other hand, upstream flood risks caused by river discharges may decrease because of a deeper channel being able to convey additional riverine flood waters seaward (Ralston and others, 2019). Similarly, reducing dredged channel depths (shallowing) has decreased peak water levels at inshore locations during storms (Orton and others, 2015).

\subsection{Impacts of Sediment Placement and Removal on Long-Term Coastal Resiliency}

\subsubsection{Sediment Placement and Long-Term Resiliency}

Over longer timescales (decades to centuries), climate change (including SLR and changes in storminess) threatens coastlines with increased inundation and erosion (Passeri and others, 2015). Projecting long-term coastal evolution is challenging because of the stochastic nature of coastal processes, as well as their dynamic interactions and feedbacks (Sampath and others, 2011). Simulating multiscale coastal evolution is possible because of recent improvements in process-based modeling. As a result, there have been multiple modeling assessments of the effectiveness of beach nourishment as a strategy to mitigate the effects of SLR. Studies have shown that beach nourishment can offset shoreline erosion under increased sea levels (Houston, 2017), aid in disaster prevention (Yoshida and others, 2014), and reduce land loss and associated costs related to SLR (Hinkel and others, 2013). However, the combined ecological, economic, and physical (including landscape and sand quality) impacts are not often considered robustly enough to determine whether nourishment is a viable long-term mitigation strategy (Parkinson and Ogurcak, 2018). In a study focused on assessing restoration actions to enhance barrier island and habitat resiliency at Dauphin Island, Ala., integrated morphological and ecological models were used to simulate island evolution and resulting changes in habitat under scenarios of variable storminess and SLR over a 10 -year period. The study showed that beach and dune nourishment prevented breaching and reduced negative effects to oyster and seagrass habitat suitability under high 
storminess and SLR (Enwright and others, 2020; Mickey and others, 2020). As discussed in section 7.1.1, sand placement through beach nourishment can be eroded during storms through overwash processes. It is unknown if overwash deposition on the back barrier increases because of additional sediment availability from nourishment and if this could contribute to barrier island migration and increase resiliency over longer timescales. On the other hand, artificially high nourished dunes could disrupt the transport of natural overwash sediment from the front of the barrier to the back barrier (Smith and others, 2008; Magliocca and others, 2011), reducing the ability of marshes to keep pace with SLR (Lorenzo-Trueba and Mariotti, 2017) and subjecting the island back-barrier platform to passive drowning and erosion (Magliocca and others, 2011; Rogers and others, 2015). Another consideration is that sediment placement on the back barrier may offer more protection from severe erosion during future storms and SLR than placement on the beach and dune system (Smallegan and others, 2017). For these reasons, beach nourishment is often considered a near-term strategy to address existing vulnerabilities associated with erosion and inundation (Parkinson and Ogurcak, 2018).

As mentioned in section 7.1, shoreface nourishment can dissipate wave energy; however, we were unable to find any studies that have assessed how shoreface nourishment may mitigate future SLR, which can increase wave heights in nearshore environments (Smith and others, 2010b). In 2011, the Netherlands started a meganourishment project in which beach and shoreface nourishment were combined to create a 128-hectare man-made peninsula intended to serve as a "sand engine" to redistribute sand over a 20 -year period to adjacent shorelines and reduce increased coastal erosion in the $21 \mathrm{st}$ century under SLR (Stive and others, 2013). If proven successful, this innovative project could be a solution for many coastlines to improve long-term resilience. It is clear from the literature reviewed here that studies of nourishment activities are primarily focused on short-term storm effects, and more studies are needed to assess how past and present nourishment activities may improve long-term barrier island resiliency especially under future SLR.

\subsubsection{Sediment Removal and Long-Term Resiliency}

As discussed in section 3.2.2, offshore bars are a critical sand source for sediment transport to beaches. Storm waves, circulation, and sediment transport force offshore migration during storms (Gallagher and others, 1998). Typically (but not always - see Plant and others, 2006; Ruessink and others, 2007), poststorm onshore migration occurs during low-energy wave conditions after the storm. However, borrow pits can trap sediment that would otherwise be transported onshore after the storm. Modeling and monitoring studies have shown that borrow pit infilling is increased during storms (Kennedy and others, 2010; Gonçalves and others, 2014). In the future, borrow pit infilling may accelerate under increased SLR because of increased inundation frequency and deposition rate (Marijnissen and others, 2020); this could be further exacerbated by increased storminess caused by climate change, thereby reducing sediment availability for longshore transport and natural beach nourishment after storms, as well as sand supply to downdrift shorelines.

Dredging of ebb-tidal delta material and reconfiguration of channels can have deleterious effects on downdrift coasts, including reductions in beach sediment input and enhanced shoreline retreat (Walton and Dean, 2011; see sec. 3.1.1 for details). Depending on the scale of the ebb-tidal delta and subsequent modifications, such effects have persisted over multiannual to multidecadal timeframes (Walton and Dean, 2011; Garel and others, 2014). Developed coastal systems, which demand consistent nourishment to maintain beach and foredune dimensions for high-water and storm-wave protection, already face substantial downdrift erosion because of inlet modification (Houston and Dean, 2016). Such erosion is likely to be exacerbated by SLR, which a recent modeling study suggests could result in around $130 \mathrm{~m}$ of shoreline retreat on North American coasts by the year 2100 (Vousdoukas and others, 2020). However, this may be an overestimation because of shortcomings in the study's methods, such as not accounting for changes in sediment availability and the ability for natural beaches to migrate landward (Cooper and others, 2020). On the other hand, SLR can alter erosion and deposition patterns on dredged ebb-tidal deltas and may result in less bed-level erosion and deposition, as well as less shoaling in the dredged channel (Passeri and others, 2018). In addition to SLR, the combined effects of historical changes in land use and channel dredging have increased sediment runoff and accumulation offshore over decades to centuries (Grossman and others, 2020). In the future, climate change may cause substantial seasonal changes in natural and regulated river flows (Lee and others, 2016), which may enhance offshore sediment accumulation. Importantly, although the long-term effects of channel dredging have been inferred at some sites, including downdrift beaches, postdredge monitoring generally occurs over short timescales, and assessments at multiyear and longer timeframes are rare (van Kessel and van Maren, 2014).

In the back-barrier environment, dredging of active or relict flood-tidal delta sediments may increase a barrier's long-term vulnerability to SLR (Nienhuis and LorenzoTrueba, 2019). Numerical modeling and field observations demonstrate that flood-tidal delta deposition is an important control on long-term barrier migration, in some cases stabilizing the barrier structure by providing a shallow platform for landward-migrating islands to build upon (Simms and others, 2006; Mallinson and others, 2010; Shawler and others, 2019). Additionally, flood deltas deposited by migrating inlets store sediment that can be reincorporated into the active beach and shoreface during long-term barrier retreat, potentially contributing to decadal- and centennial-scale resiliency (Moslow and Heron, 1978; Mallinson and others, 2010; Nienhuis and Lorenzo-Trueba, 2019). For landward-migrating barriers 
responding to SLR, a lack/disruption of flood-tidal delta sedimentation caused by sediment removal such as dredging may cause island narrowing, as well as potential disintegration of the barrier structure (Smith and others, 2008; Nienhuis and Lorenzo-Trueba, 2019). Moreover, Walters and others (2014) and Lorenzo-Trueba and Mariotti (2017) noted that modeled long-term barrier shoreline retreat rate is tied to the extent of fringing back-barrier marshes, which similarly serve to provide a platform for island migration and are usually formed directly atop flood-tidal delta deposits (Barnhardt and others, 2002; Shawler and others, 2019). Further effects to the marshestuarine system are described in the next section.

\subsection{Impacts of Sediment Removal and Placement on Coastal-Ecosystem Connectivity}

\subsubsection{Coastal Ecosystem Resiliency}

Barrier islands are dynamic environments that contain ecosystems that support a variety of species. Six major ecological or vegetative states are common on the subaerial part of barrier islands along the North American Atlantic coast: open or nonvegetated beach shoreline, grasslands, shrublands, woodlands or forests, freshwater marshes, and intertidal marshes (Godfrey, 1976). Many of these ecosystems are also on the North American Gulf coast. These ecosystems use a variety of adaptive mechanisms and feedbacks that increase resiliency to and recovery from SLR and coastal storms, reducing the likelihood that areas containing these land-cover types would be permanently inundated and transition to open-water states. First, beaches and grasslands often consist of unconsolidated sediments that move in response to wind and wave action (Oertel, 1985), and common types of beach and grass vegetation (for example, Ammophila breviligulata [Fernald] [American beachgrass]) adapted to periodic burial can survive and stabilize beach and dune landscapes (Zinnert and others, 2017). Because many coastal shrublands and forests are not adapted to saltwater, they generally occupy coastal locations that are already resilient to SLR effects. They are usually associated with higher elevations and steeper slopes that make inundation even under SLR less likely (Brinson and others, 1995). Competition (for example, shading of marsh-associated graminoid growth forms by the tree canopy), organic matter accumulation, and the longlife history of trees and shrubs also make these ecosystems resistant to canopy die-back and ecosystem state changes that may otherwise occur with periodic saltwater inundation from storms (Brinson and others, 1995; Field and others, 2016). Even with increased inundation levels associated with SLR, forests and shrublands are likely to transition to high marsh well before transitioning to open water (Brinson and others, 1995). Because marshes are often intertidal, they are adapted to periods of inundation. For example, marshes may increase biomass production in response to increased water depths, which allows for increased deposition and stabilization of the marsh platform. In this way, vegetated marsh platforms resist conversion to open water (Kirwan and Murray 2007; Kirwan and Megonigal 2013). Marshes are also able to migrate and sustain elevation by incorporating inorganic sediment delivered by eolian (for example, Rodriguez and others, 2013) and overwash (for example, Walters and Kirwan, 2016) processes to offset sustained pressures like SLR (Kirwan and Megonigal, 2013). Though the upland location of coastal vegetated landscapes may change with SLR, it is likely they will continue to provide ecosystem services over long timescales as long as ecosystem form and function are not compromised by human development. In addition to natural drivers like SLR, sediment removal and placement can alter the natural resiliency of the coastal barrier island-estuarine-marsh landscape and its ecosystems.

Although individual ecosystems have mechanisms that allow them to persist in dynamic coastal environments, connectivity and long-distance interactions among these ecosystems play important roles in maintaining ecosystem form and function (van de Koppel and others, 2015; Liebowitz and others, 2016). Some have argued that these individual ecosystems may be better described as a single "meta-ecosystem" or "coastal ecosystem mosaic," connected by the flow of energy, materials, and organisms across ecosystem boundaries (Loreau and others, 2003; Sheaves, 2009). Complexity, which is enabled through connectivity and high biocover and landcover diversity, has a stabilizing effect in ecological networks (Elmqvist and others, 2003; Loreau and de Mazancourt, 2013). These characteristics (complexity and connectivity) allow coastal landforms to respond dynamically to SLR and storms as opposed to being permanently inundated (Lentz and others, 2016). On beaches, the flow of sediments from the beach to the barrier interior and marsh through storm overwash is critical for barrier island and ecosystem resiliency, allowing islands to migrate and gain elevation with SLR (for example, Walters and Kirwan 2016; Lorenzo-Trueba and Mariotti, 2017). In addition, sandy beaches typically lack organisms responsible for primary production and instead rely on nutrient subsidies from the ocean, such as phytoplankton and macrophytes. These organisms provide nutrition for secondary producers (for example, amphipods and other invertebrates; Michaud and others, 2019), ultimately supporting a food web that propagates up to shorebirds and other large vertebrates (reviewed in Liebowitz and others, 2016; see secs. 4, 5, and 6). Wrack deposits from the ocean can also trap windblown sand and seeds, which promote plant recruitment and dune formation after storms (reviewed in Liebowitz and others, 2016). As described in the following section, sediment placement and removal can affect coastal ecosystem resiliency and recovery by altering connectivity. 


\subsubsection{Short- and Long-Term Effects of Sediment Placement and Removal on Ecosystem Resilience}

Most beach nourishment projects are designed to widen the beach and increase the elevation of the beach berm or primary dune line. Complementary activities, such as the use of sand fencing or bulldozing, are also typically used with sediment placement to further stabilize the shoreline. These actions extend the lifetime of the nourishment project, protecting against wave erosion and overwash. However, they also compartmentalize coastal ecosystems that rely on a flux of sediments, organic materials, and organisms across the barrier island profile. As discussed in section 6, activities that create barriers (for example, scarps, sand fencing, nourished dunes) or impede overwash could have detrimental effects on nesting sea turtles and shorebirds. As discussed in section 7.2.1, beach and dune nourishment reduced island breaching over decadal timescales at Dauphin Island, Ala., thereby maintaining acreage of subaerial habitat types and enhancing and preserving seagrass and oyster suitability under high storminess and SLR (Enwright and others, 2020). We were unable to find studies that examine the direct effects of beach nourishment by itself on ecosystem connectivity, and this topic may represent an important knowledge gap.

Deepening of tidal channels can increase suspendedsediment concentrations in upstream tidal rivers and can increase up-estuary suspended-sediment transport because of enhanced salinity-induced estuarine circulation (van Maren and others, 2015). Tidal range (and therefore tidal prism) in estuaries may be amplified from the combined effects of dredging and marsh erosion (Orton and others, 2015), which can affect vertical marsh accretion (Reed, 1990). For example, increases in tidal prism caused by channel dredging increased the rates of landward retreat of marsh shorelines, resulting in marsh loss (Cox and others, 2003). Maintenance dredging and removal of dredged sediment can also be a substantial factor in sediment balance of estuaries. Inlet maintenance and jetty construction that prevent sand from moving into the inlet can result in a loss of sediment available for mudflat and marsh development (Hackney and Cleary, 1987). Maintenance dredging creates channels that trap sediments, resulting in reduced sediment availability for delivery into salt marshes (Baptist and others, 2016), which is needed to keep pace with SLR. This illustrates how localized channel dredging can affect the broader coastal system.

Although sediment removal can negatively affect estuaries and marshes, placement of material can be used as a method to increase ecosystem resilience. Placing dredged sediments in thin layers (or thin-layer deposition, as discussed in secs. 3.2.2 and 4.3.3) has been used as a means for sediment management, beneficial use of dredged material, and habitat restoration or enhancement in marshes. Tidalinundation depths and the relative elevation of the marsh table govern biomass productivity in salt marshes (Morris and others, 2002). The relative elevation of the marsh can increase because of organic and inorganic sediment accumulation or decrease because of SLR, decomposition of organic material, or compaction of deposited soil (Morris and others, 2002; Kirwan and Murray, 2007). In the future, the combination of storms and SLR threaten coastal marshes with degradation and loss (Reed, 1990; Friedrichs and Perry, 2001; Mariotti and Fagherazzi, 2010; Hauser and others, 2015; Alizad and others, 2018). Thin-layer deposition can aid in maintaining marsh elevations, improving soil stability, and enhancing wetland functions while maintaining characteristic plant communities (DeLaune and others, 1990; Mendelssohn and Kuhn, 2003). This may be especially important to maintain back-barrier marshes under scenarios of high SLR but low storm frequency (that is, low overwash deposition) (Enwright and others, 2020). Thin-layer deposition has also jump-started marsh recovery by maintaining native vegetation seed sources, rhizomes, and microbes in near-surface soils (VanZomeren and others, 2018). Marshes treated with moderate intensities of thin-layer deposition may have reduced inundation stress and increased stability when compared to natural, untreated marshes. However, if too much sediment is placed, tidal flooding may be reduced, causing decreased stability and decline (Stagg and Mendelssohn, 2011). Additionally, marsh plants must recover after initial placement of material; the rate of recovery depends on the depth of sediment placed on the marsh surface (that is, deeper sediments impede plant recovery) (Burger and Shisler, 1983). Layering sediments thin enough to allow plant regrowth can increase plant cover and root biomass expansion leading to an increase in marshsurface elevation (Ford and others, 1999). Although thinlayer deposition can be beneficial in the near term, over long timescales (decades), it may not be a cost-effective method to enhance marsh resilience, especially under high rates of SLR that can cause rapid loss (Propato and others, 2018).

Similar to thin-layer deposition, strategic placement of dredged estuarine sediments can augment sediment supply to assist accretion of mudflats and marsh with sediment deficits. Numerical modeling of sediment dispersal suggests that dredged material placements were effective at supplying sediments to surrounding mudflat and salt ponds, resulting in an increase in accretion rate (Bever and others, 2014). The effectiveness of open water placement of fine sediments depends on wind and wave forcing, and small salinity deficits can affect mud transport (Baptist and others, 2019). However, resuspension, movement, and beneficial placement of dredge sediments from contaminated estuarine bottom sediments could introduce these contaminants to the trophic chain. Heavy metals from contaminated estuarine sediments bioaccumulate in marsh plants (Luque and others, 1999). Hatchery fish exposed to dredged sediments accumulate polychlorinated biphenyls, mercury, and other contaminants (Seelye and others, 1982); to avoid this, toxicity of dredged sediments should be assessed before placement for beneficial use.

In addition to these sediment-placement strategies, new marshes can be created from dredged material. However, these artificial marshes do not replicate all the functions of natural 
marsh, such as geomorphological features such as elevation, slopes, and edge-to-area ratios (Streever, 2000). Bird density, species assemblage, and seasonality have differed between dredge-created marsh and natural marsh (Melvin and Webb, 1998). Although vegetation structure in marshes created from dredge spoil can be similar to natural marshes within a few years, soil characteristics may take decades or much longer to replicate (Race and Christie, 1982; Edwards and Proffitt, 2003). Collectively, these studies illustrate the varied effects of sediment placement and removal on coastal ecosystems.

\subsection{Knowledge Gaps and Recommendations}

Based on the literature reviewed in this section, several current (2021) knowledge gaps exist concerning the effects of sediment removal and placement on short- and long-term coastal resiliency. These observational and research needs are summarized below:

1. Studies to assess how past and present nourishment activities, specifically in beach, dune, and shoreface environments, can improve long-term barrier island resiliency especially under future SLR. For example, does beach nourishment help improve longer-term coastal resilience through increased overwash deposition on back-barrier shorelines to aid in barrier island migration?

2. Studies that evaluate the effects of shoreface and profile nourishment in the context of storm protection and short-term coastal resiliency. Additionally, more studies on storm impacts caused by downdrift shoreline erosion from sediment removal are needed.

3. Evaluation of the long-term effects of sediment removal from ebb-tidal deltas or channel dredging on sediment pathways and erosion and deposition patterns along adjacent shorelines.

4. Analysis of beach nourishment and frequent complementary activities (for example, berm construction and sand fencing) on ecosystem connectivity over short and long timescales. Multiyear and multiscale monitoring is required to evaluate ecosystem health and function in situations where connectivity may have been disrupted.

The knowledge gaps and research needs identified here can be fulfilled through monitoring and modeling studies. Monitoring studies of existing and future sediment removal and placement activities should assess effects on human and ecological communities spanning more than 1 year after construction to assess short-term coastal resiliency (also see sec. 6). To assess long-term resiliency, physics-based and ecological models can be used to predict effects of sediment removal and placement, particularly under scenarios of future storms and SLR (for example, Enwright and others, 2020;
Mickey and others, 2020). Further recommendations on data types and metrics for impact monitoring are described in appendix 1 .

\section{References Cited}

ABC7 [American Broadcasting Company, Channel 7] Staff, 2020, Parts of Holmes, Coquina Beaches to be closed during Anna Maria Island renourishment: ABC7 News (station WWSB) website, June 19, 2020, accessed October 8, 2020, at https://www.mysuncoast.com/2020/06/19/parts-holmescoquina-beaches-be-closed-during-anna-maria-islandrenourishment/. [News story updated June 19, 2020, at 3:12 p.m.]

Ahmerkamp, S., Marchant, H.K., Peng, C., Probandt, D., Littmann, S., Kuypers, M.M.M., and Holtappels, M., 2020, The effect of sediment grain properties and porewater flow on microbial abundance and respiration in permeable sediments: Scientific Reports, v. 10, art. 3573, 12 p., accessed June 25, 2020, at https://doi.org/10.1038/s41598-02060557-7.

Alizad, K., Hagen, S.C., Medeiros, S.C., Bilskie, M.V., Morris, J.T., Balthis, L., and Buckel, C.A., 2018, Dynamic responses and implications to coastal wetlands and the surrounding regions under sea level rise: PLoS One, v. 13, no. 10, 27 p., accessed September 1, 2020, at https://doi. org/10.1371/journal.pone.0205176.

Allison, M.A., and Meselhe, E.A., 2010, The use of large water and sediment diversions in the lower Mississippi River (Louisiana) for coastal restoration: Journal of Hydrology, v. 387, nos. 3-4, p. 346-360, accessed August 11, 2020, at https://doi.org/10.1016/j.jhydrol.2010.04.001.

American Oystercatcher Working Group, Nol, E., and Humphrey, R.C., 2020, American oystercatcher (Haematopus palliatus) (ver. 1.0), in Poole, A.F., ed., Birds of the world: Cornell Lab of Ornithology website, accessed August 5, 2020, at https://doi.org/10.2173/bow.ameoys.01.

Anderson, J.B., Thomas, M.A., Siringan, F.P., and Smyth, W.C., 1992, Quaternary evolution of the east Texas coast and continental shelf: Quaternary Coasts of the United States-Marine and Lacustrine Systems, Society for Sedimentary Geology (SEPM) special publication no. 48, p. 235-263, accessed June 23, 2020, at http://archives. datapages.com/data/sepm_sp/SP48/Quaternary_Evolution_of_the_East.htm.

Andes, A.K., Sherfy, M.H., Shaffer, T.L., and Ellis-Felege, S.N., 2020, Plasticity of least tern and piping plover nesting behaviors in response to sand temperature: Journal of Thermal Biology, v. 91, art. 102579, 9 p., accessed August 5, 2020, at https://doi.org/10.1016/j.jtherbio.2020.102579. 
Anthony, E.J., Cohen, O., and Sabatier, F., 2011, Chronic offshore loss of nourishment on Nice Beach, French RivieraA case of over-nourishment of a steep beach?: Coastal Engineering, v. 58, no. 4, p. 374-383, accessed August 7, 2020, at https://doi.org/10.1016/j.coastaleng.2010.11.001.

Anthony, K.R.N., and Fabricius, K.E., 2000, Shifting roles of heterotrophy and autotrophy in coral energetics under varying turbidity: Journal of Experimental Marine Biology and Ecology, v. 252, no. 2, p. 221-253, accessed July 13, 2020, at https://doi.org/10.1016/S0022-0981(00)00237-9.

Arendt, M., Post, W., Frazier, B., Taliercio, M., Farrae, D., Darden, T., Geer, P., and Kalinowsky, C., 2017, Temporal and spatial distribution of Atlantic sturgeon (Acipenser oxyrinchus) in U.S. Territorial waters off South Carolina and Georgia-Final (2013-2017) Report to the National Marine Fisheries Service for Grant Number NA13NMF4720045: Charleston, S.C., South Carolina Department of Natural Resources, Marine Resources Division, 34 p.

Aretxabaleta, A.L., Ganju, N.K., Butman, B., and Signell, R.P., 2017, Observations and a linear model of water level in an interconnected inlet-bay system: Journal of Geophysical Research, Oceans, v. 122, no. 4, p. 2760-2780, accessed September 1, 2020, at https://doi. org/10.1002/2016JC012318.

Armstrong, S.B., Lazarus, E.D., Limber, P.W., Goldstein, E.B., Thorpe, C., and Ballinger, R.C., 2016, Indications of a positive feedback between coastal development and beach nourishment: Earth's Future, v. 4, no. 12, p. 626-635, accessed May 12, 2021, at https://doi.org/10.1002/2016EF000425.

Atlantic States Marine Fisheries Commission, 2019, 2019 horseshoe crab-Benchmark stock assessment and peer review report: [Arlington, Va.], Atlantic States Marine Fisheries Commission under National Oceanic and Atmospheric Administration award no. NA15NMF4740069, 316 p., accessed August 19, 2020, at https://www.asmfc.org/ uploads/file/5cd5d6f1HSCAssessment_PeerReviewReport_May2019.pdf.

Au, D.W.T., Pollino, C.A., Wu, R.S.S., Shin, P.K.S., Lau, S.T.F., and Tang, J.Y.M., 2004, Chronic effects of suspended solids on gill structure, osmoregulation, growth, and triiodothyronine in juvenile green grouper Epinephelus coioides: Marine Ecology Progress Series, v. 266, p. 255-264, accessed May 14, 2021, at https://doi.org/10.3354/ meps266255.
Augris, C., Bonne, W., Carlin, D., Cato, I., Cowling, M., van Dalfsen, J., Delpech, J.-P., Desprez, M., Sutton, G., ed., and Boyd, S., ed., 2009, Effects of extraction of marine sediments on the marine environment 1998-2004: Copenhagen, Denmark, International Council for the Exploration of the Sea, ICES Cooperative Research Report no. 297, 180 p., accessed June 30, 2020, at http://www.vliz.be/imisdocs/publications/ocrd/155963.pdf.

Auld, A.H., and Schubel, J.R., 1978, Effects of suspended sediment on fish eggs and larvae-A laboratory assessment: Estuarine and Coastal Marine Science, v. 6, no. 2, p. 153-164, accessed August 19, 2020, at https://doi. org/10.1016/0302-3524(78)90097-X.

Bagnold, R.A., 1941, The physics of blown sand and desert dunes ( $2 \mathrm{~d}$ ed.): New York, Chapman and Hall, $265 \mathrm{p}$.

Balazik, M., Barber, M., Altman, S., Reine, K., Katzenmeyer, A., Bunch, A., and Garman, G., 2020, Dredging activity and associated sound have negligible effects on adult Atlantic sturgeon migration to spawning habitat in a large coastal river: PLoS One, v. 15, no. 3, 13 p, accessed August 28, 2020, at https://doi.org/10.1371/journal.pone.0230029.

Balazik, M.T., Reine, K.J., Spells, A.J., Fredrickson, C.A., Fine, M.L., Garman, G.C., and McIninch, S.P., 2012, The potential for vessel interactions with adult Atlantic sturgeon in the James River, Virginia: North American Journal of Fisheries Management, v. 32, no. 6, p. 1062-1069, accessed August 28, 2020, at https://doi.org/10.1080/02755947.2012 .716016 .

Baptist, M.J., de Groot, A.V., and van Duin, W.E., 2016, Contrasting biogeomorphic processes affecting salt-marsh development of the Mokbaai, Texel, The Netherlands: Earth Surface Processes and Landforms, v. 41, no. 9, p. 12411249, accessed June 1, 2020, at https://doi.org/10.1002/ esp.3949.

Baptist, M.J., Gerkema, T., van Prooijen, B.C., van Maren, D.S., van Regteren, M., Schulz, K., Colosimo, I., Vroom, J., van Kessel, T., Grasmeijer, B., Willemsen, P., Elschot, K., de Groot, A.V., Cleveringa, J., van Eekelen, E.M.M., Schuurman, F., de Lange, H.J., and van Puijenbroek, M.E.B., 2019, Beneficial use of dredged sediment to enhance salt marsh development by applying a 'Mud Motor': Ecological Engineering, v. 127, p. 312-323, accessed June 1, 2020, at https://doi.org/10.1016/j.ecoleng.2018.11.019.

Barnard, P.L., Erikson, L.H., and Hansen, J.E., 2009, Monitoring and modeling shoreline response due to shoreface nourishment on a high-energy coast: Journal of Coastal Research, Special issue no. 56, v. 1, p. 29-33, accessed August 7, 2020, at https://www.jstor.org/stable/25737531. 
Barnhardt, W.A., Gonzalez, R., Kelley, J.T., Neal, W.J., Pilkey, O.H., Jr., Jose, H., and Dias, J.A., 2002, Geologic evidence for the incorporation of flood tidal deltas at Tavira Island, southern Portugal: Journal of Coastal Research, v. 36, p. 28-36, accessed July 7, 2020, at https://doi. org/10.2112/1551-5036-36.sp1.28.

Bart, L.J.C., 2017, Long-term modelling with XBeachCombining stationary and surfbeat mode in an integrated approach: Rotterdam, Netherlands, Technical University of Delft, M.S. thesis, 109 p., accessed August 7, 2020, at https://repository.tudelft.nl/islandora/object/uuid:e2550e2636c5-4a30-afa1-169e82b4b811?collection=education.

Beck, T.M., and Wang, P., 2019, Morphodynamics of barrier-inlet systems in the context of regional sediment management, with case studies from west-central Florida, U.S.A: Ocean and Coastal Management, v. 177, p. 31-51, accessed May 1, 2020, at https://doi.org/10.1016/j.ocecoaman.2019.04.022.

Belknap, D.F., and Kraft, J.C., 1985, influence of antecedent geology on stratigraphic preservation potential and evolution of Delaware's barrier systems: Marine Geology, v. 63, nos. 1-4, p. 235-262, accessed March 23, 2021, at https:// doi.org/10.1016/0025-3227(85)90085-4.

Bender, C.J., and Dean, R.G., 2003, Wave transformation by two-dimensional bathymetric anomalies with sloped transitions: Coastal Engineering, v. 50, nos. 1-2, p. 61-84, accessed June 23, 2020, at https://doi.org/10.1016/j.coastaleng.2003.08.002.

Benedet, L., and List, J.H., 2008, Evaluation of the physical process controlling beach changes adjacent to nearshore dredge pits: Coastal Engineering, v. 55, no. 12, p. 12241236, accessed June 23, 2020, at https://doi.org/10.1016/j. coastaleng.2008.06.008.

Benedet, L., Finkl, C.W., and Dobrochinski, J.P.H., 2013, Optimization of nearshore dredge pit design to reduce impacts on adjacent beaches: Journal of Coastal Research, v. 29 , no. 3, p. 519-525, accessed June 23, 2020, at https:// doi.org/10.2112/JCOASTRES-D-12-00126.1.

Benedet, L., Pierro, T., and Henriquez, M., 2007, Impacts of coastal engineering projects on the surfability of sandy beaches: Shore and Beach, v. 75, no. 4, p. 3-20, accessed October 19, 2020, at https://www.researchgate. net/profile/Lindino-Benedet/publication/242517727 Impacts_of_coastal_engineering_projects_on_the_surfability_of_sandy_beaches/links/56c91bc208ae5488f0d708c1/ Impacts-of-coastal-engineering-projects-on-the-surfabilityof-sandy-beaches.pdf.
Berg, D.W., and Duane, D.B., [1969], Effect of particle size and distribution on stability of artificially filled beach, Presque Isle Peninsula, Pennsylvania: U.S. Army Corps of Engineers, Coastal Engineering Research Center, reprint 1-69, p. 161-178 [and errata sheet], accessed July 20, 2020, at https://hdl.handle.net/11681/22892. [Reprinted from the Proceedings, 11th Conference on Great Lakes Research, 1968, Milwaukee, Wisconsin, p. 161-178, published by the International Association for Great Lakes Research.]

Bergquist, D.C., and Crowe, S.E., 2009, Using historical data and meta-analyses to improve monitoring and management of beach nourishment in South Carolina-Final report: South Carolina Department of Health and Environmental Control, prepared by South Carolina Department of Natural Resources, Marine Resources Division, Charleston, S.C., 99 p., accessed July 13, 2020, at https://www.dnr.sc.gov/ marine/mrri/environ/pdf/OCRMMetaanalysis.pdf.

Bergquist, D.C., Crowe, S.E., and Levisen, M., 2009, The 2006-2007 Hilton Head Island renourishment projectPhysical and biological responses of the Joiner and Barrett Shoals borrow areas to dredging - Final report: Town of Hilton Head, S.C., prepared by Marine Resources Research Institute, Marine Resources Division, South Carolina Department of Natural Resources, Technical Report 104, 108 p., accessed June 5, 2020, at https://dc.statelibrary. sc.gov/bitstream/handle/10827/30379/DNR_The_20062007_Hilton_Head_2009-8.pdf? sequence $=1 \&$ is Allowed $=\mathrm{y}$.

Bergquist, D.C., Crowe, S.E., Levisen, M., and Van Dolah, R.F., 2008, Change and recovery of physical and biological characteristics at beach and borrow areas impacted by the 2005 Folly Beach renourishment project: U.S. Army Corps of Engineers, prepared by Marine Resources Research Institute, Marine Resources Division, South Carolina Department of Natural Resources, Technical Report 102, 112 p., accessed July 13, 2020, at https://dc.statelibrary.sc.gov/ handle/10827/25684.

Berkowitz, J.F., Piercy, C., Welp, T., and VanZomeren, C., 2019, Thin layer placement-Technical definition for U.S. Army Corps of Engineers applications: U.S. Army Engineer Research and Development Center, Technical Report ERDC TN-19-1, 9 p., accessed August 11, 2020, at https://apps. dtic.mil/sti/citations/AD1067526.

Berlin, A.M., 2008, Foraging values of Mulinia lateralis and Ischadium recurvum -Energetic effects on surf scoters wintering in the Chesapeake Bay: College Park, Md., University of Maryland, Ph.D. dissertation, 137 p., accessed August 17, 2020, at https://drum.lib. umd.edu/bitstream/handle/1903/8055/umi-umd-5211. pdf? is Allowed $=y \&$ sequence $=1$. 
Berner, R.A., 1980, Early diagenesis-A theoretical approach: Princeton, N.J., Princeton University Press, Princeton series in geochemistry, 260 p. [Also available at https://doi. org/10.1515/9780691209401.]

Bernier, J.C., Miselis, J.L., Buster, N.A., and Flocks, J.G., 2019, Application of sediment end-member analysis for understanding sediment fluxes, northern Chandeleur Islands, Louisiana, in Wang, P., Rosati, J.D., and Vallee, M., eds., Coastal sediments 2019-Proceedings of the 9th International Conference, Tampa/St. Petersburg, Florida, USA, May 27-31, 2019: Singapore, World Scientific, p. 25-38, accessed September 16, 2020, at https://doi. org/10.1142/9789811204487_0003.

Bever, A.J., MacWilliams, M.L., Wu, F., Andes, L., and Conner, C.S., 2014, Numerical modeling of sediment dispersal following dredge material placements to examine possible augmentation of the sediment supply to marshes and mudflats, San Francisco Bay, USA, in 33rd PIANC International Navigation Congress 2014-Navigating the new millennium, San Francisco, California, USA, 1-5 June 2014: Red Hook, N.Y., Curran Associates, p. 933-950, accessed June 1, 2020, at https:/www.southbayrestoration.org/sites/ default/files/documents/PIANC2014Congress_SouthBayDredgePlacement_Bever_etal.pdf.

Binkley, C., 2007, The creation and establishment of Cape Hatteras National Seashore-The Great Depression through mission 66: Atlanta, Ga., Cultural Resources Division, Southeast Regional Office, National Park Service, 264 p., accessed August 11, 2020, at https:/www.nps.gov/parkhistory/online_books/caha/caha_ah.pdf.

Blum, M.D., Sivers, A.E., Zayac, T., and Goble, R.J., 2003, Middle Holocene sea-level and evolution of the Gulf of Mexico coast: Gulf Coast Association of Geological Societies Transactions, v. 53, p. 64-77. [Also available at http:// archives.datapages.com/data/gcags/data/053/053001/0064. htm.]

Bocamazo, L.M., Grosskopf, W.G., and Buonuiato, F.S., 2011, Beach nourishment, shoreline change, and dune growth at Westhampton Beach, New York, 1996-2009: Journal of Coastal Research, Special issue no. 59, p. 181-191, accessed August 11, 2020, at https://doi.org/10.2112/SI59019.1 .

Boehlert, G.W., and Morgan, J.B., 1985, Turbidity enhances feeding abilities of larval Pacific herring, Clupea harengus pallasi: Hydrobiologia, v. 123, no. 2, p. 161-170, accessed August 19, 2020, at https://doi.org/10.1007/BF00018978.

Boehm, A.B., Shellenbarger, G.G., and Paytan, A., 2004, Groundwater discharge-Potential association with fecal indicator bacteria in the surf zone: Environmental Science \& Technology, v. 38, no. 13, p. 3558-3566, accessed August 25, 2020, at https://doi.org/10.1021/es035385a.
Bolam, S.G., and Rees, H.L., 2003, Minimizing impacts of maintenance dredged material disposal in the coastal environment-A habitat approach: Environmental Management, v. 32, no. 2, p. 171-188, accessed June 30, 2020, at https://doi.org/10.1007/s00267-003-2998-2.

Botton, M.L., and Haskin, H.H., 1984, Distribution and feeding of the horseshoe-crab, Limulus polyphemus, on the continental shelf off New-Jersey: Fish Bulletin, v. 82, no. 2, p. 383-389, accessed September 23, 2020, at https://spo.nmfs. noaa.gov/sites/default/files/pdf-content/fish-bull/botton.pdf.

Botton, M.L., and Ropes, J.W., 1987, Populations of horseshoe crabs, Limulus polyphemus, on the northwestern Atlantic continental shelf: Fishery Bulletin, v. 85, no. 4, p. 805-812.

Botton, M.L., Loveland, R.E., and Jacobsen, T.R., 1988, Beach erosion and geochemical factors-Influence on spawning success of horseshoe crabs (Limulus polyphemus) in Delaware Bay: Marine Biology, v. 99, no. 3, p. 325-332, accessed July 15, 2020, at https://doi.org/10.1007/ BF02112124.

Botton, M.L., Loveland, R.E., 2003, Abundance and dispersal potential of horseshoe crab (Limulus polyphemus) larvae in the Delaware estuary: Estuaries, v. 26, p. 1472-1479, accessed May 14, 2021, at https://doi.org/10.1007/ BF02803655.

Boudreau, B.P., 1997, Model construction, chap. 3 of Diagenetic models and their implementation-Modelling transport and reactions in aquatic sediments: New York, Springer-Verlag, $414 \mathrm{p}$.

Boudreau, B.P., Huettel, M., Forster, S., Jahnke, R.A., McLachlan, A., Middelburg, J.J., Nielsen, P., Sansone, F., Taghon, G., Raaphorst, W.V., Webster, I., Weslawski, J.M., Wiberg, P., and Sundby, B., 2001, Permeable marine sediments - Overturning an old paradigm: Eos, v. 82, no. 11, p. 133-136, accessed August 11, 2020, at https://doi. org/10.1029/EO082i011p00133-01.

Bracciali, C., Campobello, D., Giacoma, C., and Sarà, G., 2012, Effects of nautical traffic and noise on foraging patterns of Mediterranean damselfish (Chromis chromis): PLoS One, v. 7, no. 7, art. e40582, 11 p., accessed August 19, 2020, at https://doi.org/10.1371/journal.pone.0040582.

Bradley, R.A., and Bradley, D.W., 1993, Wintering shorebirds increase after kelp (Macrocystis) recovery: The Condor, v. 95, no. 2, p. 372-376, accessed June 3, 2020, at https://doi. org/10.2307/1369359. 
Bridges, T.S., Ells, S., Hayes, D., Mount, D., Nadeau, S.C., Palermo, M.R., Patmont, C., and Schroeder, P., 2008, The four Rs of environmental dredging-Resuspension, release, residual, and risk: U.S. Army Corps of Engineers, Engineer Research and Development Center, Dredging Operations and Environmental Research Program Report ERDC/EL TR-08-4, 54 p., accessed August 28, 2020, at https://hdl. handle.net/11681/6855.

Brinson, M.M., Christian, R.R., and Blum, L.K., 1995, Multiple states in the sea-level induced transition from terrestrial forest to estuary: Estuaries, v. 18, no. 4, p. 648-659, accessed June 15, 2020, at https://doi.org/10.2307/1352383.

Broadwell, A.L., 1991, Effects on beach renourishment on the survival of loggerhead sea turtles: Boca Raton, Fla., Florida Atlantic University, M.S. thesis, 42 p., accessed May 12, 2021, at http://fau.digital.flvc.org/islandora/object/ fau $\% 3 \mathrm{~A} 11540$.

Brock, K.A., Reece, J.S., and Ehrhart, L.M., 2009, The effects of artificial beach nourishment on marine turtles-Differences between loggerhead and green turtles: Restoration Ecology, v. 17, no. 2, p. 297-307, accessed June 15, 2020, at https://doi.org/10.1111/j.1526-100X.2007.00337.x.

Brockmann, H.J., and Penn, D., 1992, Male mating tactics in the horseshoe crab, Limulus polyphemus: Animal Behaviour, v. 44, no. 4, p. 653-665, accessed July 15, 2020, at https://doi.org/10.1016/S0003-3472(05)80293-3.

Brooks, R.A., Purdy, C.N., Bell, S.S., and Sulak, K.J., 2006, The benthic community of the eastern US continental shelf-A literature synopsis of benthic faunal resources: Continental Shelf Research, v. 26, no. 6, p. 804-818, accessed June 30, 2020, at https://doi.org/10.1016/j. csr.2006.02.005.

Brown-Peterson, N.J., Peterson, M.S., Rydene, D.A., and Eames, R.W., 1993, Fish assemblages in natural versus well-established recolonized seagrass meadows: Estuaries, v. 16 , no. 2 , p. $177-189$, accessed July 27,2020 , at https:// doi.org/10.2307/1352489.

Brown, J.J., and Murphy, G.W., 2010, Atlantic sturgeon vessel-strike mortalities in the Delaware Estuary: Fisheries v. 35, no. 2, p. 72-83, accessed August 19, 2020, at https:// doi.org/10.1577/1548-8446-35.2.72.

Brown, J.R., and Miller, D.C., 2011, Persistence and distribution of temperate intertidal worm reefs in Delaware Bay-A comparison of biological and physical factors: Estuaries and Coasts, v. 34, no. 3, p. 583-596, accessed July 27, 2020, at https://doi.org/10.1007/s12237-011-9387-5.

Brunn, P., 1954, Coast erosion and the development of beach profiles: Washington, D.C., U.S. Army Corps of Engineers Beach Erosion Control Board, Technical Memo no. 44.
Bruton, M.N., 1985, The effects of suspensoids on fish, in Davies, B.R. and Walmsley, R.D. eds., Perspectives in southern hemisphere limnology: Springer Netherlands, Dordrecht, p. 221-241, accessed August 19, 2020, at https:// doi.org/10.1007/978-94-009-5522-6_16.

Brutsché, K.E., McFall, B.C., Li, H., McNinch, J.E., Ousley, J.D., Engle, J.A., and Maglio, C.K., 2017, Strategic nearshore placement of dredged sediment at Vilano Beach, Florida: Shore \& Beach, v. 85, no. 3, p. 77-84. [Also available at https://www.researchgate.net/publication/320443554 Strategic_nearshore_placement_of_dredged_sediment_at Vilano_Beach_Florida.]

Brutsché, K.E., Wang, P., Beck, T.M., Rosati, J.D., and Legault, K.R., 2014, Morphological evolution of a submerged artificial nearshore berm along a low-wave microtidal coast, Fort Myers Beach, west-central Florida, USA: Coastal Engineering, v. 91, p. 29-44, accessed September 1, 2020, at https://doi.org/10.1016/j.coastaleng.2014.04.010.

Brutsché, K.E., Wang, P., Rosati, J.D., and Beck, T.M., 2015, Evolution of a swash zone berm nourishment and influence of berm elevation on the performance of beach-nearshore nourishments along Perdido Key, Florida, USA: Journal of Coastal Research, v. 31, no. 4, p. 964-977, accessed August 7, 2020, at https://doi.org/10.2112/JCOASTRESD-14-00087.1.

Bryant, D.B., and McFall, B.C., 2016, Transport of nearshore dredge material berms, in 6th International Conference on the Application of Physical Modelling in Coastal and Port Engineering and Science, Ottawa, Ontario, Canada, 10-13 May 2016, CoastLab 2016, proceedings: Ottawa, Ontario, Canada, University of Ottawa, 8 p., accessed August 7, 2020, at http://rdio.rdc.uottawa.ca/publications/coastlab16/ coastlab10.pdf.

Buehler, D.M., and Piersma, T., 2008, Travelling on a budget-Predictions and ecological evidence for bottlenecks in the annual cycle of long-distance migrants: Philosophical Transactions of the Royal Society, Series B, Biological Sciences, v. 363, no. 1490, p. 247-266, accessed June 15, 2020, at https://doi.org/10.1098/rstb.2007.2138.

Burger, J., Carlucci, S.A., Jeitner, C.W., and Niles, L., 2007, Habitat choice, disturbance, and management of foraging shorebirds and gulls at a migratory stopover: Journal of Coastal Research, v. 23, no. 5, p. 1159-1166, accessed August 20, 2020, at https://doi.org/10.2112/04-0393.1.

Burger, J., and Shisler, J., 1983, Succession and productivity on perturbed and natural Spartina salt-marsh areas in New Jersey: Estuaries, v. 6, no. 1, p. 50-56, accessed September 1, 2020, at https://doi.org/10.2307/1351806. 
Burlas, M., Ray, G., and Clarke, D., 2001, The New York District's biological monitoring program for the Atlantic Coast of New Jersey, Asbury Park to Manasquan section beach erosion control project-Final report: U.S. Army Engineer District, New York, and U.S. Army Engineer Research and Development Center, Waterways Experiment Station report accessed August 7, 2020, at https://www.nan.usace.army. mil/Missions/Civil-Works/Projects-in-New-Jersey/SandyHook-to-Barnegat-Inlet/Biological-Monitoring-Program/.

Burnett, W.C., Bokuniewicz, H., Huettel, M., Moore, W.S., and Taniguchi, M., 2003, Groundwater and pore water inputs to the coastal zone: Biogeochemistry, v. 66, nos. 1-2, p. 3-33, accessed August 11, 2020, at https://doi. org/10.1023/B:BIOG.0000006066.21240.53.

Burton, W.H., Kelley, F.S., and Franks, E.A., 2009, Distribution of juvenile horseshoe crabs in subtidal habitats of Delaware Bay using a suction-dredge sampling device, in Part IB-Reproduction, physiology, and development of Tanacredi, J.T., Botton, M.L., and Smith, D. eds., Biology and conservation of horseshoe crabs: New York, Springer, p. 285-293, accessed August 20, 2020, at https://doi. org/10.1007/978-0-387-89959-6_18.

Byles, R., and Fernandez, Y., comp., 1998, Proceedings of the Sixteenth Annual Symposium on Sea Turtle Biology and Conservation, 28 February-March 1, 1996, Hilton Head, South Carolina: National Marine Fisheries Service, National Oceanic and Atmospheric Administration Technical Memorandum NMFS-SEFSC-412, 158 p., accessed August 5, 2020, at https://repository.library.noaa.gov/view/noaa/3051/ noaa_3051_DS1.pdf.

Byrnes, M.R., Griffee, S.F., and Osler, M.S., 2010, Channel dredging and geomorphic response at and adjacent to Mobile Pass, Alabama: U.S. Army Engineer Research and Development Center Coastal and Hydraulics Lab Technical Report ERDC/CHL TR-10-8, 330 p., accessed June 23, 2020, at https://apps.dtic.mil/sti/citations/ADA536622.

Byrnes, M.R., Hammer, R.M., Thibaut, T.D., and Snyder, D.B., 2004a, Effects of sand mining on physical processes and biological communities offshore New Jersey, U.S.A: Journal of Coastal Research, v. 20, no. 1, p. 25-43, accessed June 23, 2020, at https://doi.org/10.2112/15515036(2004)20[25:EOSMOP]2.0.CO;2.

Byrnes, M.R., Hammer, R.M., Thibaut, T.D., and Snyder, D.B., 2004b, Physical and biological effects of sand mining offshore Alabama, U.S.A.: Journal of Coastal Research, v. 20, no. 1, p. 6-24, accessed May 14, 2021, at https://doi. org/10.2112/1551-5036(2004)20[6:PABEOS]2.0.CO;2.
Cable, J.E., Burnett, W.C., Chanton, J.P., and Weatherly, G.L., 1996, Estimating groundwater discharge into the northeastern Gulf of Mexico using radon-222: Earth and Planetary Science Letters, v. 144, nos. 3-4, p. 591-604, accessed August 11, 2020, at https://doi.org/10.1016/S0012821X(96)00173-2.

Cahoon, D.R., Jr., and Cowan, J.H., Jr., 1988, Environmental impacts and regulatory policy implications of spray disposal of dredged material in Louisiana wetlands: Coastal Management, v. 16, no. 4, p. 341-362. [Also available at https://doi. org/10.1080/08920758809362067.]

Cairns, W.E., 1982, Biology and behavior of breeding piping plovers: The Wilson Bulletin, v. 94, no. 4, p. 531-545, accessed June 15, 2020, at https://www.jstor.org/stable/4161678.

Caldwell, J.W., 1985, Effects of elevated turbidity and nutrients on the net production of a tropical seagrass community: Gainesville, Fla., University of Florida, Ph.D. dissertation, 137 p., accessed July 13, 2020, at https://www.osti.gov/biblio/7243854.

Campbell, T.J., and Benedet, L., 2004, Beach nourishment magnitudes and trends in the US: Journal of Coastal Research, Special issue no. 39, p. 57-64, accessed September 1, 2020, at http://siaiacad09.univali.br/ics2004/arquivos/09_tom.pdf.

Carmichael, R.H., Rutecki, D., Annett, B., Gaines, E., and Valiela, I., 2004, Position of horseshoe crabs in estuarine food webs - $\mathrm{N}$ and $\mathrm{C}$ stable isotopic study of foraging ranges and diet composition: Journal of Experimental Marine Biology and Ecology, v. 299, no. 2, p. 231-253, accessed July 15, 2020, at https://doi.org/10.1016/j. jembe.2003.09.006.

Castelle, B., Marieu, V., Bujan, S., Ferreira, S., Parisot, J.-P., Capo, S., Sénéchal, N., and Chouzenoux, T., 2014, Equilibrium shoreline modelling of a high-energy meso-macrotidal multiple-barred beach: Marine Geology, v. 347, p. 85-94, accessed June 23, 2020, at https://doi.org/10.1016/j.margeo.2013.11.003.

Chabot, C.C., and Watson, W.H., III, 2010, Circatidal rhythms of locomotion in the American horseshoe crab Limulus polyphemus - Underlying mechanisms and cues that influence them: Current Zoology, v. 56, no. 5, p. 499-517, accessed July 15, 2020, at https://doi.org/10.1093/czoolo/56.5.499.

Charlier, R.H., and De Meyer, C.P., 1995, Beach nourishment as efficient coastal protection: Environmental Management and Health, v. 6, no. 5, p. 26-34, accessed August 26, 2020, at https://doi.org/10.1108/09566169510096511. 
Cialone, M.A., and Stauble, D.K., 1998, Historical findings on ebb shoal mining: Journal of Coastal Research, v. 14, no. 2, p. 537-563, accessed June 23, 2020, at https://www.jstor. org/stable/4298808.

Cisneros, J.A., Briggs, T.R., and Martin, K., 2017, Placed sediment characteristics compared to sea turtle nesting and hatching patterns - A case study from Palm Beach County, FL: Shore \& Beach, v. 85 , no. 2, p. 35 , accessed June 15 , 2020, at https://www.researchgate.net/profile/TiffanyBriggs/publication/317958764_Placed_Sediment_Characteristics_Compared_to_Sea_Turtle_Nesting_and_Hatching_Patterns_Case_Study_from_Palm_Beach_County_FL/ links/5953ce94458515a207029600/Placed-Sediment-Characteristics-Compared-to-Sea-Turtle-Nesting-and-HatchingPatterns-Case-Study-from-Palm-Beach-County-FL.pdf.

Cohen, J.B., and Fraser, J.D., 2010, Piping plover foraging distribution and prey abundance in the pre-laying period: The Wilson Journal of Ornithology, v. 122, no. 3, p. 578-582, accessed June 15, 2020, at https://doi.org/10.1676/09-145.1.

Cohen, J., Houghton, L.M., and Fraser, J.D., 2009, Nesting density and reproductive success of piping plovers in response to storm- and human-created habitat changes: Wildlife Monographs, v. 173, no. 1, p. 1-24, accessed June 15, 2020, at https://doi.org/10.2193/2007-553.

Collie, J.S., Hall, S.J., Kaiser, M.J., and Poiner, I.R., 2000, A quantitative analysis of fishing impacts on shelf-sea benthos: Journal of Animal Ecology, v. 69, no. 5, p. 785-798, accessed July 13, 2020, at https://doi.org/10.1046/j.13652656.2000.00434.x.

Collin, S.P., and Hart, N.S., 2015, Vision and photoentrainment in fishes-The effects of natural and anthropogenic perturbation: Integrative Zoology, v. 10, Special issue no. 1, p. 15-28, accessed June 8, 2020, at https://doi. org/10.1111/1749-4877.12093.

Combe, A.J., and Soileau, C.W., 1987, Behavior of man-made beach and dune, Grand Isle, Louisiana: Coastal Sediments '87, American Society of Civil Engineers, v. 2, p. 12321242.

Colosio, F., Abbiati, M., and Airoldi, L., 2007, Effects of beach nourishment on sediments and benthic assemblages: Marine Pollution Bulletin, v. 54, no. 8, p. 1197-1206, accessed August 11, 2020, at https://doi.org/10.1016/j.marpolbul.2007.04.007.

Colwell, M.A., Meyer, J.J., Hardy, M.A., McAllister, S.E., Transou, A.N., LeValley, R.R., and Dinsmore, S.J., 2011, Western snowy plovers Charadrius alexandrinus nivosus select nesting substrates that enhance egg crypsis and improve nest survival: Ibis, v. 153, no. 2, p. 303-311, accessed June 15, 2020, at https://doi.org/10.1111/j.1474919X.2011.01100.x.
Conn, K.E., Liedtke, T.L., Takesue, R.K., and Dinicola, R.S., 2020, Legacy and current-use toxic contaminants in Pacific sand lance (Ammodytes personatus) from Puget Sound, Washington, USA: Marine Pollution Bulletin, v. 158, art. 111287, 14 p., accessed March 23, 2021, at https://doi. org/10.1016/j.marpolbul.2020.111287.

Convertino, M., Donoghue, J.F., Chu-Agor, M.L., Kiker, G.A., Muñoz-Carpena, R., Fischer, R.A., and Linkov, I., 2011a, Anthropogenic renourishment feedback on shorebirds-A multispecies Bayesian perspective: Ecological Engineering, v. 37, no. 8, p. 1184-1194, accessed June 15, 2020, at https://doi.org/10.1016/j.ecoleng.2011.02.019.

Convertino, M., Elsner, J.B., Munoz-Carpena, R., Kiker, G.A., Martinez, C.J., Fischer, R.A., and Linkov, I., 2011b. Do tropical cyclones shape shorebird habitat patterns? Biogeoclimatology of snowy plovers in Florida: PLoS One, v. 6, no. 1, art. e15683, 9 p., accessed August 20, 2020, at https:// doi.org/10.1371/journal.pone. 0015683 .

Cooke, B.C., Jones, A.R., Goodwin, I.D., and Bishop, M.J., 2012, Nourishment practices on Australian sandy beachesA review: Journal of Environmental Management, v. 113, p. 319-327, accessed August 7, 2020, at https://doi. org/10.1016/j.jenvman.2012.09.025.

Cooper, A., Masselink, G., Coco, G., Short, A., Castelle, B., Rogers, K., Anthony, E., Pilkey, O.H., and Jackson, D.W.T., 2020, Sandy beaches can survive sea-level rise: EarthArXiv, preprint ver. 1.0 (March 18, 2020), 5 p. [Not peer reviewed; also available at https://doi.org/10.31223/osf.io/4md6e.]

Cooper, K.M., Barrio Froján, C.R.S., Defew, E., Curtis, M., Fleddum, A., Brooks, L., and Paterson, D.M., 2008, Assessment of ecosystem function following marine aggregate dredging: Journal of Experimental Marine Biology and Ecology, v. 366, nos. 1-2, p. 82-91, accessed July 13, 2020, at https://doi.org/10.1016/j.jembe.2008.07.011.

Cooper, K.M., Curtis, M., Wan Hussin, W.M.R., Barrio Froján, C.R.S., Defew, E.C., Nye, V., and Paterson, D.M., 2011, Implications of dredging induced changes in sediment particle size composition for the structure and function of marine benthic macrofaunal communities: Marine Pollution Bulletin, v. 62 , no. 10, p. 2087-2094, accessed July 13, 2020, at https://doi.org/10.1016/j.marpolbul.2011.07.021.

Cortés, E., 1999, Standardized diet compositions and trophic levels of sharks: ICES Journal of Marine Science, v. 56, no. 5, p. 707-717, accessed August 21, 2020, at https://doi. org/10.1006/jmsc.1999.0489. 
Courtenay, W.R., Hartig, B.C., and Loisel, G.R., 1980, Evaluation of fish populations adjacent to borrow areas of beach nourishment project, Hallandale (Broward County), Florida_-Volume I of Ecological evaluation of a beach nourishment project at Hallandale (Broward County), Florida: U.S. Army Corps of Engineers Coastal Engineering Research Center, Miscellaneous report no. 80-1, prepared by Florida Atlantic University, Department of Biological Science, 23 p., accessed July 13, 2020, at https://hdl.handle. net/11681/5158.

Courtenay, W.R., Herrema, D.J., Thompson, M.J., Azzinaro, W.P., and van Montfrans, J., 1972, Ecological monitoring of two beach nourishment projects in Broward County, Florida: Shore and Beach, v. 40, no. 2, p. 8-13. [Also available at http://www.vliz.be/imisdocs/publications/36251.pdf.]

Cox, R., Wadsworth, R.A., and Thomson, A.G., 2003, Longterm changes in salt marsh extent affected by channel deepening in a modified estuary: Continental Shelf Research, v. 23, nos. 17-19, p. 1833-1846, accessed June 1, 2020, at https://doi.org/10.1016/j.csr.2003.08.002.

Croft, A.L., Leonard, L.A., Alphin, T.D., Cahoon, L.B., and Posey, M.H., 2006, The effects of thin layer sand renourishment on tidal marsh processes - Masonboro Island, North Carolina: Estuaries and Coasts, v. 29, no. 5, p. 737-750, accessed August 11, 2020, at https://doi.org/10.1007/ BF02786525.

Crowe, S.E., Bergquist, D.C., Sanger, D.M., and Van Dolah, R.F., 2016, Physical and biological alterations following dredging in two beach nourishment borrow areas in South Carolina's coastal zone: Journal of Coastal Research, v. 32, no. 4, p. 875-889, accessed June 23, 2020, at https://doi. org/10.2112/JCOASTRES-D-15-00075.1.

Crowe, S.E., Gayes, P.T., Viso, R.F., Bergquist, D.C., Jutte, P.C., and Van Dolah, R.F., 2010, Impact of the Charleston Ocean Dredged Material Disposal Site on nearby hard bottom reef habitats: Marine Pollution Bulletin, v. 60, no. 5, p. 679-691, accessed June 3, 2020, at https://doi. org/10.1016/j.marpolbul.2009.12.007.

CSA International, Inc., 2010, Analysis of potential biological and physical impacts of dredging on offshore ridge and shoal features - Final report: U.S. Department of Interior Minerals Management Service, Leasing Division, Marine Minerals Branch, OCS Study MMS 2010-010, prepared by CSA International, Inc., Stuart, Fla., under contract number 1435-01-03 CT-72020, 160 p., accessed August 6, 2020, at https://espis.boem.gov/final\%20reports/5199.pdf.
Culver, S.J., Ames, D.V., Corbett, D.R., Mallinson, D.J., Riggs, S.R., Smith, C.G., and Vance, D.J., 2006, Foraminiferal and sedimentary record of late Holocene barrier island evolution, Pea Island, North Carolina - The role of storm overwash, inlet processes, and anthropogenic modification: Journal of Coastal Research, v. 22, no. 4, p. 836-846, accessed August 11, 2020, at https://doi.org/10.2112/030103.1 .

Dabees, M.A., and Moore, B.D., 2011, Inlet evolution modeling of multiple inlet systems in southwest and central Florida: Journal of Coastal Research, Special issue no. 59, p. 130-137, accessed August 7, 2020, at https://doi. org/10.2112/SI59-013.1.

Dallas, K., Eshleman, J., and Beavers, R., 2012, National Park Service beach nourishment guidance: Natural Resource Technical Report NPS/NRSS/GRD/NRTR—2012/581, 59 p., accessed June 23, 2020, at https://irma.nps.gov/DataStore/DownloadFile/455109.

Dally, W.R., and Osiecki, D.A., 2018, Evaluating the impact of beach nourishment on surfing - Surf City, Long Beach Island, New Jersey, U.S.A: Journal of Coastal Research, v. 34, no. 4, p. 793-805, accessed October 19, 2020, at https:// doi.org/10.2112/JCOASTRES-D-17-00162.1.

Dalyander, P., Mickey, R.C., Long, J.W., and Flocks, J.G., 2015, Effects of proposed sediment borrow pits on nearshore wave climate and longshore sediment transport rate along Breton Island, Louisiana (ver. 2.0, August 2017): U.S. Geological Survey Open-File Report 2015-1055, 44 p., accessed June 23, 2020, at https://doi.org/10.3133/ ofr20151055.

Dame, J.K., 1990, Origin of a solitary sand shoal offshore of Sandbridge Beach, Virginia: Williamsburg, Va., College of William and Mary, M.A. thesis, 180 p., accessed June 23, 2020, at https://doi.org/10.25773/v5-cvzp-fe95.

Darrah, A.J., Cohen, J.B., and Castelli, P.M., 2018, A Bayesian multinomial logistic exposure model for estimating probabilities of competing sources of nest failure: The Ibis, v. 160, no. 1, p. 23-35, accessed June 15, 2020, at https://doi. org/10.1111/ibi.12510.

das Neves, L., Moreira, A., Taveira-Pinto, F., Lopes, M.L., and Veloso-Gomes, F., 2015, Performance of submerged nearshore sand-filled geosystems for coastal protection: Coastal Engineering, v. 95, p. 147-159, accessed September 01, 2020, at https://doi.org/10.1016/j.coastaleng.2014.10.005.

Davidson-Arnott, R., Bauer, B., and Houser, C., 2019, Introduction to coastal processes and geomorphology: New York, Cambridge University Press, 523 p. [Also available at https://doi.org/10.1017/9781108546126.] 
Davis, K.L., Schoenemann, K.L., Catlin, D.H., Hunt, K.L., Friedrich, M.J., Ritter, S.J., Fraser, J.D., and Karpanty, S.M., 2017, Hatch-year piping plover (Charadrius melodus) prospecting and habitat quality influence second-year nest site selection: The Auk, v. 134, no. 1, p. 92-103, accessed August 21, 2020, at https://doi.org/10.1642/AUK-16-80.1.

Davis, R.A., Jr., and FitzGerald, D.M., 2004, Beaches and coasts: Wiley-Blackwell, 432 p. [Also available at https://www.wiley.com/en-us/Beaches+and+Coastsp-9780632043088.]

Davis, R.A., Jr., FitzGerald, M.V., and Terry, J., 1999, Turtle nesting on adjacent nourished beaches with different construction styles - Pinellas County, Florida: Journal of Coastal Research, v. 15, no. 1, p. 111-120, accessed June 15, 2020, at https://www.jstor.org/stable/4298919.

Davis, R.A., Jr., and Hayes, M.O., 1984, What is a wave-dominated coast?: Marine Geology, v. 60, nos. 1-4, p. 313-329, accessed July 7, 2020, at https://doi.org/10.1016/0025$3227(84) 90155-5$.

Davidson, M.A., Splinter, K., and Turner, I.L., 2013, A simple equilibrium model for predicting shoreline change: Coastal Engineering, v. 73, p. 191-202, accessed May 13, 2021, at https://doi.org/10.1016/j.coastaleng.2012.11.002.

Davison, T., Nichols, R., and Leatherman, S., 1992, Beach nourishment as a coastal management tool-An annotated bibliography on developments associated with the artificial nourishment of beaches: Journal of Coastal Research, v. 8, no. 4, p. 984-1022, accessed March 6, 2020, at https://www. jstor.org/stable/4298052.

de Alegria-Arzaburu, A.R., Mariño-Tapia, I., Silva, R., and Pedrozo-Acuña, A., 2013, Post-nourishment beach scarp morphodynamics: Journal of Coastal Research, Special issue no. 65, p. 576-581, accessed October 19, 2020, at https://doi.org/10.2112/SI65-098.1.

de Lange, W.P., and Healy, T.R., 1990, Renourishment of a flood-tidal delta adjacent beach, Tauranga Harbour, New Zealand: Journal of Coastal Research, v. 6, no. 3, p. 627-640, accessed June 23, 2020, at https://www.jstor.org/ stable/4297725.

de Lange, W.P., and Moon, V.G., 2017, Shoreline changes for southeastern Matakana Island (Panepane Point) following capital dredging (2015-16): [Tauranga, New Zealand], Port of Tauranga Ltd., prepared by Environmental Research Institute, Faculty of Science and Engineering, University of Waikato, ERI report 95, 13 p., accessed June 23, 2020, at https://hdl.handle.net/10289/11091. de Vries, S., Arens, B., Stive, M., and Ranasinghe, R., 2011, Dune growth trends and the effect of beach width on annual timescales, in Wang, P., Rosati, J.D., and Roberts, T.M., eds., Coastal Sediments 2011-International Conference on Coastal Sediments, 7th, Miami, Florida, USA, 2 May-6 May 2011, proceedings: Hackensack, N.J., World Scientific, v. 1, p. 712-724, accessed August 11, 2020, at https://doi. org/10.1142/9789814355537_0054.

de Vries, S., Southgate, H.N., Kanning, W., and Ranasinghe, R., 2012, Dune behavior and aeolian transport on decadal timescales: Coastal Engineering, v. 67, p. 41-53, accessed August 11, 2020, at https://doi.org/10.1016/j.coastaleng.2012.04.002.

Dean, R.G., 1983, Principles of beach nourishment, in Komar, P.D., ed., CRC handbook of coastal processes and rrosion: Boca Raton, CRC Press, p. 217-232.

Dean, R.G., 1988, Realistic economic benefits from beach nourishment in Edge, B.L., ed., Coastal Engineering 1988-International Conference on Coastal Engineering, 21st, Torremolinos, Costa del Sol, Malaga (Spain), 20-25 June 1988, proceedings: New York, American Society of Civil Engineers, p. 1558-1572, accessed August 7, 2020, at https://doi.org/10.1061/9780872626874.117.

Dean, R.G., 1991, Equilibrium beach profiles - Characteristics and applications: Journal of Coastal Research, v. 7, no. 1, p. 53-84, accessed June 23, 2020, at https://www.jstor.org/ stable/4297805.

Dean, R.G., 2002, Beach nourishment-Theory and practice: Hackensack, N.J., World Scientific Press, 399 p.

Dean, R.G., 2005, Beach nourishment-Benefits, theory and case examples, in Zimmermann, C., Dean, R.G., Penchev, V., and Verhagen, H.J., eds., Environmentally friendly coastal protection-Proceedings of the NATO Advanced Research Workshop on Environmentally Friendly Coastal Protection Structures, Varna, Bulgaria, 25-27 May 2004: Dordrecht, Netherlands, Springer, p. 25-40, accessed September 1, 2020, at https://doi.org/10.1007/1-40203301-X_2.

Dean, R.G., and Walton, T.L., 1973, Sediment transport characteristics in the vicinity of inlets with special reference to sand trapping [Proceedings]: International Estuarine Research Conference, 2d, Myrtle Beach, S.C., p. 129-149.

Dean, R.G., and Yoo, C.-H., 1992, Beach-nourishment performance predictions: Journal of Waterway, Port, Coastal, and Ocean Engineering, v. 118, no. 6, p. 567-586, accessed October 19, 2020, at https://doi.org/10.1061/(ASCE)0733950X(1992)118:6(567). 
DeLaune, R.D., Pezeshki, S.R., Pardue, J.H., Whitcomb, J.H., and Patrick, W.H., Jr., 1990, Some influences of sediment addition to a deteriorating salt marsh in the Mississippi River deltaic plain-A pilot study: Journal of Coastal Research, v. 6, no. 1, p. 181-188, accessed June 23, 2020, at https://www.jstor.org/stable/4297655.

Delft Hydraulics Laboratory, 1987, Manual on artificial beach nourishment: Gouda, Netherlands, Delft Hydraulics, Centre for Civil Engineering Research, Codes and Specifications, Rijkswaterstaat, Report 130, 195 p.

Delgado-Fernandez, I., 2010, A review of the application of the fetch effect to modelling sand supply to coastal foredunes: Aeolian Research, v. 2, nos. 2-3, p. 61-70, accessed August 11, 2020, at https://doi.org/10.1016/j. aeolia.2010.04.001.

Delmarva Now Staff Reports [USA Today Network], 2019, Beach nourishment scheduled for Rehoboth, Dewey beaches: Delmarva Now website, accessed July 7, 2020, at https://www.delmarvanow.com/story/news/2019/10/23/ beach-nourishment-scheduled-rehoboth-deweybeaches/4063554002/. [Published October 23, 2019 at 7:00 a.m. eastern time.]

Demir, H., Otay, E.N., Work, P.A., and Börekçi, O.S., 2004, Impacts of dredging on shoreline change: Journal of Waterway, Port, Coastal, and Ocean Engineering, v. 130, no. 4, p. 170-178, accessed June 23, 2020, at https://doi.org/10.1061/ (ASCE)0733-950X(2004)130:4(170).

Demirbilek, Z., and Rosati, J.D., 2011, Verification and validation of the coastal modeling system; Report 1: U.S. Army Engineer Research and Development Center, Coastal and Hydraulics Laboratory report ERDC/CHL TR-11-10 1, 90 p., accessed August 7, 2020, at https://hdl.handle. net/11681/7660.

Dennison, W.C., 1991, Photosynthetic and growth responses of tropical and temperate seagrasses in relation to Secchi depth, light attenuation and daily light period, in Kenworthy, W.J., and Haunert, D.E., eds., The light requirements of seagrasses - Proceedings of a workshop to examine the capability of water quality criteria, standards and monitoring programs to protect seagrasses: NOAA Technical Memorandum NMFS-SEFC-287, p. 133-144, accessed June 15, 2020, at https://repository.library.noaa.gov/view/ noaa/9147.

DeRose-Wilson, A.L., Hunt, K.L., Monk, J.D., Catlin, D.H., Karpanty, S.M., and Fraser, J.D., 2018, Piping plover chick survival negatively correlated with beach recreation: The Journal of Wildlife Management, v. 82, no. 8, p. 1608-1616, accessed August 21, 2020, at https://doi.org/10.1002/ jwmg. 21552.
Desprez, M., Pearce, B., and Le Bot, S., 2010, The biological impact of overflowing sands around a marine aggregate extraction site-Dieppe (eastern English Channel): ICES Journal of Marine Science, v. 67, no. 2, p. 270-277, accessed May 14, 2021, at https://doi.org/10.1093/icesjms/ fsp245.

Desprez, M., 2000, Physical and biological impact of marine aggregate extraction along the French coast of the eastern English Channel-Short- and long-term post-dredging restoration: ICES Journal of Marine Science, v. 57, no. 5, p. 1428-1438, accessed July 6, 2020, at https://doi. org/10.1006/jmsc.2000.0926.

Deutsch, C.J., Reid, J.P., Bonde, R.K., Easton, D.E, Kochman, H.I., and O'Shea, T.J., 2003, Seasonal movements, migratory behavior, and site fidelity of West Indian manatees along the Atlantic coast of the United States: Wildlife Monographs, no. 151, p. 1-77, accessed May 14, 2021, at https://www.jstor.org/stable/3830830. [Supplement to the Journal of Wildlife Management, v. 67, no. 1.]

Diaz, R.J., Solan, M., and Valente, R.M., 2004, A review of approaches for classifying benthic habitats and evaluating habitat quality: Journal of Environmental Management, v. 73, no. 3, p. 165-181, accessed June 5, 2020, at https://doi org/10.1016/j.jenvman.2004.06.004.

DiJohnson, A.M., 2019, Atlantic sturgeon (Acipenser oxyrinchus oxyrinchus) behavioral responses to vessel traffic and habitat use in the Delaware River, USA: Dover, Del., Delaware State University, M.S. thesis, 100 p. [Also available at https://desu.dspacedirect.org/bitstream/ handle/20.500.12090/442/DiJohnson_desu_1824M_10122. pdf? sequence $=1 \&$ isAllowed $=\mathrm{y}$.]

Dodge, R.E., and Vaisnys, J.R., 1977, Coral populations and growth patterns - Responses to sedimentation and turbidity associated with dredging: Journal of Marine Research, v. 35, no. 4, p. 715-730, accessed July 13, 2020, at https:// nsuworks.nova.edu/occ facarticles/35/. [Reprint of original article.]

Dolan, R., Godfrey, P.J., and Odum, W.E., 1973, Man's impact on the barrier islands of North Carolina-A case study of the implications of large-scale manipulation of the natural environment: American Scientist, v. 61, no. 2, p. 152-162, accessed August 7, 2020, at http:/www.jstor.com/ stable/27843661.

Dolan, R., Haden, B., and Heywood, J., Carswell, J.G., and Garber, R., 1977, Atlas of environmental dynamics-Assateague Island National Seashore: National Park Service, Natural Resource Report 11, 39 p. [Also available at http://npshistory.com/publications/asis/nrr-11.pdf.] 
ECORP Consulting, 2009, Literature review (for studies conducted prior to 2008): Fish behavior in response to dredging and dredged material placement activities: Report submitted to the U.S. Army Corps of Engineers, October 09, 2009, 48 p.

Edge, B.L., Dowd, M., Dean, R.G., and Johnson, P., 1995, The reconstruction of Folly Beach, in Edge, B.L., ed., Coastal Engineering 1994-International Conference on Coastal Engineering, 24th, Kobe, Japan, October 23-28, 1994, proceedings: New York, American Society of Civil Engineers, p. 3491-3506, accessed June 23, 2020, at https:// doi.org/10.1061/9780784400890.253. [Published online December 31, 2016.]

Edwards, K.R., and Proffitt, C.E., 2003, Comparison of wetland structural characteristics between created and natural salt marshes in southwest Louisiana, USA: Wetlands, v. 23, no. 2, p. 344-356, accessed June 01, 2020, at https://doi. org/10.1672/10-20.

Elias, S.P., Fraser, J.D., and Buckley, P.A., 2000, Piping plover brood foraging ecology on New York barrier islands: Journal of Wildlife Management, v. 64, no. 2, p. 346-354, accessed August 5, 2020, at https://doi. org/10.2307/3803232.

Elko, N., Brodie, K., Stockdon, H., Nordstrom, K., Houser, C., McKenna, K., Moore, L., Rosati, J., Ruggiero, P., Thuman, R., and Walker, I., 2016, Dune management challenges on developed coasts: Shore \& Beach, v. 84, no. 1, p. 15-28. [Also available at https://apps.dtic.mil/sti/citations/ AD1028246.]

Elko, N.A., Holman, R.A., and Gelfenbaum, G., 2005, Quantifying the rapid evolution of a nourishment project with video imagery: Journal of Coastal Research, v. 21, no. 4, p. 633-645, accessed August 7, 2020, at https://doi. org/10.2112/04-0280.1.

Elko, N.A., and Wang, P., 2007, Immediate profile and planform evolution of a beach nourishment project with hurricane influences: Coastal Engineering, v. 54, no. 1, p. 49-66, accessed August 7, 2020, at https://doi.org/10.1016/j. coastaleng.2006.08.001.

Elmqvist, T., Folke, C., Nyström, M., Peterson, G., Bengtsson, J., Walker, B., and Norberg, J., 2003, Response diversity, ecosystem change, and resilience: Frontiers in Ecology and the Environment, v. 1, no. 9, p. 488-494, accessed June 15, 2020, at https://doi.org/10.1890/15409295(2003)001[0488:RDECAR]2.0.CO;2.

Emanuel, K.A., 2013, Downscaling CMIP5 climate models shows increased tropical cyclone activity over the $21 \mathrm{st}$ century: Proceedings of the National Academy of Sciences, v. 110, no. 30, p. 12219-12224, accessed May 13, 2021, at https://doi.org/10.1073/pnas.1301293110.
Engstrom, S.J., and Marinelli, R.L., 2005, Recruitment responses of benthic infauna to manipulated sediment geochemical properties in natural flows: Journal of Marine Research, v. 63, no. 2, p. 407-436, accessed July 7, 2020, at https://doi.org/10.1357/0022240053693716.

Enwright, N.M., Wang, H., Dalyander, P.S., and Godsey, E., eds., 2020, Predicting barrier island habitats and oyster and seagrass habitat suitability for various restoration measures and future conditions for Dauphin Island, Alabama: U.S. Geological Survey Open-File Report 2020-1003, 99 p., accessed September 1, 2020, at https://doi.org/10.3133/ ofr20201003.

Erftemeijer, P.L.A., Riegl, B., Hoeksema, B.W., and Todd, P.A., 2012, Environmental impacts of dredging and other sediment disturbances on corals - A review: Marine Pollution Bulletin, v. 64, no. 9, p. 1737-1765, accessed July 15, 2020, at https://doi.org/10.1016/j.marpolbul.2012.05.008.

Ernest, R.G., and Martin, R.E., 1999, Martin County beach nourishment project, sea turtle monitoring and studies_-1997 Annual report and final assessment: Jensen Beach, Fla., Ecological Associates, Inc., 323 p. [Also available at http://edocs.dlis.state.fl.us/fldocs/dep/beaches/ sea-turtles.pdf.]

Familkhalili, R., and Talke, S.A., 2016, The effect of channel deepening on tides and storm surge - A case study of Wilmington, NC: Geophysical Research Letters, v. 43, no. 17, p. 9138-9147, accessed August 11, 2020, at https://doi. org/10.1002/2016GL069494.

Fenster, M.S., Knisley, C.B., and Reed, C.T., 2006, Habitat preference and the effects of beach nourishment on the federally threatened northeastern beach tiger beetle, Cicindela dorsalis dorsalis_-Western Shore, Chesapeake Bay, Virginia: Journal of Coastal Research, v. 22, no. 5, p. 1133-1144, accessed August 24, 2020, at https://doi. org/10.2112/05-0485.1.

Field, C.R., Gjerdrum, C., and Elphick, C.S., 2016, Forest resistance to sea-level rise prevents landward migration of tidal marsh: Biological Conservation, v. 201, p. 363-369, accessed June 15, 2020, at https://doi.org/10.1016/j.biocon.2016.07.035.

Finkl, C.W., 2012, Pitfalls of ebb-shoal mining, in Cooper, J.A.G. and Pilkey, O.H., eds., Pitfalls of shoreline stabilization-Selected case studies: Dordrecht, Netherlands, Springer, p. 37-52, accessed June 23, 2020, at https://doi. org/10.1007/978-94-007-4123-2_3.

Finkl, C.W., and Walker, H.J., 2002, Beach nourishment, in Chen, J., Eisma, D., Hotta, K., and Walker, H.J., eds., Engineered coasts: Dordrecht, Netherlands, Springer, 22 p., accessed June 23, 2020, at https://doi.org/10.1007/978-94017-0099-3_1. 
Finkl, C.W., Benedet, L., Andrews, J.L., Suthard, B., and Locker, S.D., 2007, Sediment ridges on the West Florida inner Continental Shelf-Sand resources for beach nourishment: Journal of Coastal Research, v. 23, no. 1, p. 143-159, accessed June 23, 2020, at https://doi. org/10.2112/06A-0014.1.

Fioto, L., and Ward, J., 2015, Engineering the recovery from Hurricane Sandy: U.S. Army Corps of Engineers, North Atlantic Division website, accessed May 21, 2021, at https://www.nad.usace.army.mil/Media/News-Stories/ Article/572222/engineering-the-recovery-from-hurricanesandy/.

Fisher, J.I., 1968, Barrier island formation-Discussion: Geological Society of America Bulletin, v. 79, no. 10, p. 1421-1425, accessed May 1, 2020, at https://doi. org/10.1130/0016-7606(1968)79[1421:BIFD]2.0.CO;2.

Fisher, R., Stark, C., Ridd, P., and Jones, R., 2015, Spatial patterns in water quality changes during dredging in tropical environments: PLoS One, v. 10, no. 12, art. e0143309, 22 p., accessed August 18, 2020, at https://doi.org/10.1371/ journal.pone.0143309.

Flocks, J., Miner, M.D., Twichell, D.C., Lavoie, D.L., and Kindinger, J., 2009, Evolution and preservation potential of fluvial and transgressive deposits on the Louisiana inner shelf-Understanding depositional processes to support coastal management: Geo-Marine Letters, v. 29, no. 6, 20 p., accessed June 23, 2020, at https://doi.org/10.1007/ s00367-009-0164-4.

Flocks, J.G., Buster, N.A., and Brenner, O.T., 2020, Seafloor change around the Mississippi barrier islands, 1920 to 2016-The influence of storm effects on inlet and island morphodynamics: U.S. Geological Survey Open-File Report 2019-1140, 23 p., accessed September 9, 2020, at https://doi.org/10.3133/ofr20191140.

Flocks, J.G., DeWitt, N.T., and Stalk, C.A., 2017, Analysis of seafloor change around Dauphin Island, Alabama, 1987-2015: U.S. Geological Survey Open-File Report 2017-1112, 19 p., accessed June 23, 2020, at https://doi. org/10.3133/ofr20171112.

Fontolan, G., Pillon, S., Quadri, F.D., and Bezzi, A., 2007, Sediment storage at tidal inlets in northern Adriatic lagoons-Ebb-tidal delta morphodynamics, conservation and sand use strategies: Estuarine, Coastal and Shelf Science, v. 75, nos. 1-2, p. 261-277, accessed June 23, 2020, at https://doi.org/10.1016/j.ecss.2007.02.029.

Ford, M.A., Cahoon, D.R., and Lynch, J.C., 1999, Restoring marsh elevation in a rapidly subsiding salt marsh by thinlayer deposition of dredged material: Ecological Engineering, v. 12, nos. 3-4, p. 189-205, accessed August 11, 2020 , at https://doi.org/10.1016/S0925-8574(98)00061-5.
Fraser, C., Hutchings, P., and Williamson, J., 2006, Long-term changes in polychaete assemblages of Botany Bay (NSW, Australia) following a dredging event: Marine Pollution Bulletin, v. 52, no. 9, p. 997-1010, accessed June 23, 2020, at https://doi.org/10.1016/j.marpolbul.2005.12.016.

Fraser, J., and Catlin, D.H., 2019, Habitat ecology and conservation of charadrius plovers in Colwell, M.A., and Haig, S.M., eds., The population ecology and conservation of charadrius plovers: Boca Raton, Fla., CRC Press, p. 217-244, accessed August 5, 2020, at https://doi. org/10.1201/9781315152882-9.

Fraser, J.D., Keane, S.E., and Buckley, P.A., 2005, Prenesting use of intertidal habitats by piping plovers on South Monomoy Island, Massachusetts: Journal of Wildlife Management, v. 69, no. 4, p. 1731-1736, accessed June 15, 2020, at https://doi.org/10.2193/0022-541X(2005)69[1731:PUOIHB ]2.0.CO;2.

Fraser, M.W., Short, J., Kendrick, G., McLean, D., Keesing, J., Byrne, M., Caley, M.J., Clarke, D., Davis, A.R., Erftemeijer, P.L.A., Field, S., Gustin-Craig, S., Huisman, J., Keough, M., Lavery, P.S., Masini, R., McMahon, K., Mengersen, K., Rasheed, M., Statton, J., Stoddart, J., and Wu, P., 2017, Effects of dredging on critical ecological processes for marine invertebrates, seagrasses and macroalgae, and the potential for management with environmental windows using Western Australia as a case study: Ecological Indicators, v. 78, p. 229-242, accessed July 7, 2020, at https://doi. org/10.1016/j.ecolind.2017.03.026.

Frazier, F., 2020, Driving on Vilano Beach restricted during months-long renourishment project (Vilano Beach, Fla.): News4Jax website, accessed October 8, 2020, at https:// www.news4jax.com/news/local/2020/09/02/driving-onvilano-beach-restricted-during-months-long-renourishmentproject/. [Published September 2, 2020 at 10:15 a.m.]

Friedrichs, C.T., and Perry, J.E., 2001, Tidal salt marsh morphodynamics - A synthesis: Journal of Coastal Research, Special issue no. 27, p. 7-37, accessed September 1, 2020, at https://www.jstor.org/stable/25736162.

Froede, C.R., Jr., 2007, Elevated waves erode the western end of the recently completed sand berm on Dauphin Island, Alabama (U.S.A.): Journal of Coastal Research, v. 23, no. 6, p. 1602-1604, accessed July 7, 2020, at https://doi. org/10.2112/07A-0019.1.

Gaines, E.P., and Ryan, M., 1988, Piping plover habitat use and reproductive success in North Dakota: Journal of Wildlife Management, v. 52, no. 2, p. 266-273, accessed June 15, 2020, at https://doi.org/10.2307/3801233. 
Gallagher, E.L., Elgar, S., and Guza, R.T., 1998, Observations of sand bar evolution on a natural beach: Journal of Geophysical Research, Oceans, v. 103, no. C2, p. 3203-3215, accessed May 12, 2021, at https://doi. org/10.1029/97JC02765.

Ganju, N.K., 2019, Marshes are the new beaches-Integrating sediment transport into restoration planning: Estuaries and Coasts, v. 42, no. 4, p. 917-926, accessed August 11, 2020, at https://doi.org/10.1007/s12237-019-00531-3.

Ganju, N.K., Schoellhamer, D.H., Warner, J.C., Barad, M.F., and Schladow, S.G., 2004, Tidal oscillation of sediment between a river and a bay-A conceptual model: Estuarine, Coastal and Shelf Science, v. 60, no. 1, p. 81-90, accessed August 11, 2020, at https://doi.org/10.1016/j. ecss.2003.11.020.

Garel, E., Sousa, C., Ferreira, Ó., and Morales, J.A., 2014, Decadal morphological response of an ebb-tidal delta and down-drift beach to artificial breaching and inlet stabilisation: Geomorphology, v. 216, p. 13-25, accessed May 6, 2020, at https://doi.org/10.1016/j.geomorph.2014.03.031.

Gares, P.A., Wang, Y., and White, S.A., 2006, Using LIDAR to monitor a beach nourishment project at Wrightsville Beach, North Carolina, USA: Journal of Coastal Research, v. 22, no. 5, p. 1206-1219, accessed September 1, 2020, at https:// doi.org/10.2112/06A-0003.1.

Gerstein, E. R., Blue, J.E., Pinto, G.F., and Barr, S., 2006, Underwater noise and zones of masking with respect to hopper dredging and manatees in the St. Johns River in Jacksonville, FL: Journal of the Acoustical Society of America, v. 120, p. 3145-3222, accessed May 14, 2021, at https://doi.org/10.1121/1.4787832.

Gibson, D., Chaplin, M.K., Hunt, K.L., Friedrich, M.J., Weithman, C.E., Addison, L.M., Cavalieri, V., Coleman, S., Cuthbert, F.J., Fraser, J.D., Golder, W., Hoffman, D., Karpanty, S.M., Van Zoeren, A., and Catlin, D.H., 2018, Impacts of anthropogenic disturbance on body condition, survival, and site fidelity of nonbreeding piping plovers: The Condor, v. 120, no. 3, p. 566-580, accessed June 15, 2020, at https://doi.org/10.1650/CONDOR-17-148.1.

Gochfeld, M., Burger, J., and Lefevre, K.L., 2020, Black skimmer (Rynchops niger) (ver. 1.0), in Billerman, S.M., ed., Birds of the World: Cornell Lab of Ornithology website, accessed August 5, 2020, at https://doi.org/10.2173/bow. blkski.01.

Godfrey, P.J., 1976, Comparative ecology of East Coast barrier islands-Hydrology, soil, vegetation, in Barrier islands and beaches-Technical proceedings of the 1976 Barrier Island Workshop, Annapolis, Maryland, May 17-18, 1976: Washington, D.C., Conservation Foundation, p. 5-31.
Goldin, M.R., and Regosin, J.V., 1998, Chick behavior, habitat use, and reproductive success of piping plovers at Goosewing Beach, Rhode Island: Journal of Field Ornithology, v. 69 , no. 2, p. 228-234, accessed June 15, 2020, at https:// www.jstor.org/stable/4514311.

Gonçalves, D.S., Pinheiro, L.M., Silva, P.A., Rosa, J., Rebêlo, L., Bertin, X., Teixeira, S.B., and Esteves, R., 2014, Morphodynamic evolution of a sand extraction excavation offshore Vale do Lobo, Algarve, Portugal: Coastal Engineering, v. 88, p. 75-87, accessed June 23, 2020, at https://doi. org/10.1016/j.coastaleng.2014.02.001.

Gorzelany, J.F., and Nelson, W.G., 1987, The effects of beach replenishment on the benthos of a sub-tropical Florida beach: Marine Environmental Research, v. 21, no. 2, p. 75-94, accessed July 27, 2020, at https://doi. org/10.1016/0141-1136(87)90043-2.

Götz, T., Hastie, G., Hatch, L.T., Raustein, O., Southall, B.L., Tasker, M., and Thomsen, F., 2009, Overview of the impacts of anthropogenic underwater sound in the marine environment: OSPAR Commission Biodiversity Series, v. 441, p. 1-134, accessed August 23, 2020, at https://tethys.pnnl.gov/ publications/overview-impacts-anthropogenic-underwatersound-marine-environment.

Graca, B., Burska, D., and Matuszewska, K., 2004, The impact of dredging deep pits on organic matter decomposition in sediments: Water, Air, and Soil Pollution, v. 158, no. 1, p. 237-259, accessed June 23, 2020, at https://doi. org/10.1023/B:WATE.0000044853.63461.53.

Grain, D.A., Bolten, A.B., and Bjorndal, K.A., 1995, Effects of beach nourishment on sea turtles-Review and research initiatives: Restoration Ecology, v. 3, no. 2, p. 95-104, accessed August 14, 2020, at https://doi.org/10.1111/j.1526100X.1995.tb00082.x.

Grasso, F., Michallet, H., and Barthélemy, E., 2011, Experimental simulation of shoreface nourishments under storm events - A morphological, hydrodynamic, and sediment grain size analysis: Coastal Engineering, v. 58, no. 2, p. 184-193, accessed June 23, 2020, at https://doi. org/10.1016/j.coastaleng.2010.09.007.

Gray, S.M., Bieber, F.M.E., Mcdonnell, L.H., Chapman, L.J., and Mandrak, N.E., 2014, Experimental evidence for species-specific response to turbidity in imperilled fishes: Aquatic Conservation-Marine And Freshwater Ecosystems, v. 24, no. 4, p. 546-560, accessed August 28, 2020, at https://doi.org/10.1002/aqc.2436.

Greene, K., 2002, Beach nourishment-A review of the biological and physical impacts: Atlantic States Marine Fisheries Commission, ASMFC Habitat Management Series report 7, 174 p., accessed August 7, 2020, at https://tamugir.tdl.org/bitstream/handle/1969.3/28924/beachNourishment[1].pdf? sequence $=1$. 
Gregory, R.S., 1993, Effect of turbidity on the predator avoidance behaviour of juvenile chinook salmon (Oncorhynchus tshawytscha): Canadian Journal of Fisheries and Aquatic Sciences, v. 50, no. 2, p. 241-246, accessed August 19, 2020, at https://doi.org/10.1139/f93-027.

Gregory, R.S., and Levings, C.D., 1998, Turbidity reduces predation on migrating juvenile Pacific salmon: Transactions of the American Fisheries Society, v. 127, no. 2, p. 275-285, accessed August 19, 2020, at https://doi.org/10.1577/15488659(1998) $127<0275:$ TRPOMJ>2.0.CO;2.

Grippo, M.A., Cooper, S., and Massey, A.G., 2007, Effect of beach replenishment projects on waterbird and shorebird communities: Journal of Coastal Research, v. 23, no. 5, p. 1088-1096, accessed June 15, 2020, at https://doi. org/10.2112/04-0276.1.

Grootjans, A.P., Geelen, H.W.T., Jansen, A.J.M., and Lammerts, E.J., 2002, Restoration of coastal dune slacks in the Netherlands, in Nienhuis, P.H. and Gulati, R.D., eds., Ecological restoration of aquatic and semi-aquatic ecosystems in the Netherlands (NW Europe): Dordecht, Netherlands, Springer, p. 181-203, accessed August 7, 2020, at https:// doi.org/10.1007/978-94-017-1335-1_10.

Grossman, E.E., Stevens, A.W., Dartnell, P., George, D., and Finlayson, D., 2020, Sediment export and impacts associated with river delta channelization compound estuary vulnerability to sea-level rise, Skagit River Delta, Washington, USA: Marine Geology, v. 430, art. 106336, 21 p., accessed May 12, 2021, at https://doi.org/10.1016/j. margeo.2020.106336.

Grunnet, N.M., and Ruessink, B.G., 2005, Morphodynamic response of nearshore bars to a shoreface nourishment: Coastal Engineering, v. 52, no. 2, p. 119-137, accessed August 11, 2020, at https://doi.org/10.1016/j.coastaleng.2004.09.006.

Grunnet, N.M., Ruessink, B.G., and Walstra, D.J.R., 2005, The influence of tides, wind and waves on the redistribution of nourished sediment at Terschelling, The Netherlands: Coastal Engineering, v. 52, no. 7, p. 617-631, accessed June 23, 2020, at https://doi.org/10.1016/j.coastaleng.2005.04.001.

Grunnet, N.M., Walstra, D.-J.R., and Ruessink, B.G., 2004, Process-based modelling of a shoreface nourishment: Coastal Engineering, v. 51, no. 7, p. 581-607, accessed August 7, 2020, at https://doi.org/10.1016/j.coastaleng.2004.07.016.
Guilfoyle, M.P., Fischer, R.A., Pashley, D.N., and Lott, C.A., eds., 2006, Summary of first regional workshop on dredging, beach nourishment, and birds on the south Atlantic coast: U.S. Army Engineer Research and Development Center, Environmental Laboratory Technical Report ERDC/ EL TR-06-10, 74 p., accessed June 15, 2020, at https://hdl. handle.net/11681/7107.

Guilfoyle, M.P., Fischer, R.A., Pashley, D.N., and Lott, C.A., eds., 2007, Summary of second regional workshop on dredging, beach nourishment, and birds on the north Atlantic Coast: U.S. Army Engineer Research and Development Center, Environmental Laboratory Technical Report ERDC/ EL TR-07-26, 87 p., accessed August 5, 2020, at https:// hdl.handle.net/11681/6862.

Guillén, J., and Hoekstra, P., 1997, Sediment distribution in the nearshore zone-Grain size evolution in response to shoreface nourishment (Island of Terschelling, The Netherlands): Estuarine, Coastal and Shelf Science, v. 45, no. 5, p. 639-652, accessed August 7, 2020, at https://doi. org/10.1006/ecss.1996.0218.

Hackney, C.T., and Cleary, W.J., 1987, Saltmarsh loss in southeastern North Carolina lagoons-Importance of sea level rise and inlet dredging: Journal of Coastal Research, v. 3, no. 1, p. 93-97, accessed June 1, 2020, at https://www. jstor.org/stable/4297253.

Hailman, J.P., and Elowson, M., 1992, Ethogram of the nesting female loggerhead (Caretta caretta): Herpetologica, v. 48, no. 1, p. 1-30, accessed June 15, 2020, at https://www. jstor.org/stable/3892915.

Halpern, B.S., Frazier, M., Potapenko, J., Casey, K.S., Koenig, K., Longo, C., Lowndes, J.S., Rockwood, R.C., Selig, E.R., Selkoe, K.A., and Walbridge, S., 2015, Spatial and temporal changes in cumulative human impacts on the world's ocean: Nature Communications, v. 6, art. 8615, 7 p., accessed August 18, 2020, at https://doi.org/10.1038/ncomms8615.

Hamm, L., Capobianco, M., Dette, H.H., Lechuga, A., Spanhoff, R., and Stive, M.J.F., 2002, A summary of European experience with shore nourishment: Coastal Engineering, v. 47, no. 2, p. 237-264, accessed August 11, 2020, at https:// doi.org/10.1016/S0378-3839(02)00127-8.

Hanes, D.M., 1994, Turbidity and suspended sediment associated with beach nourishment dredging, in Edge, B.L., ed., Coastal Engineering 1994-International Conference on Coastal Engineering, 24th, Kobe, Japan, October 23-28, 1994, proceedings: New York, American Society of Civil Engineers, p. 3016-3029, accessed August 11, 2020, at https://doi.org/10.1061/9780784400890.218. 
Hannides, A., Elko, N., and Humiston, K., 2019, An ASBPA White Paper-The state of understanding of the effects of beach nourishment activities on coastal biogeochemical processes and conditions: Shore \& Beach, v. 87, no. 3, p. 46-57, accessed May 7, 2020, at https://doi. org/10.34237/1008734.

Hanson, H., and Kraus, N.C., 1989, GENESIS - Generalized model for simulating shoreline change-Report 1, technical reference: Washington, D.C., U.S. Army Corps of Engineers, U.S. Army Engineer Waterways Experiment Station report CERC-89-19, 247 p., accessed August 7, 2020, at http://hdl.handle.net/11681/12450.

Hanson, H., and Kraus, N.C., 2011, Long-term evolution of a long-term evolution model: Journal of Coastal Research, Special issue no. 59, p. 118-129, accessed August 7, 2020, at https://doi.org/10.2112/SI59-012.1.

Hanson, H., Brampton, A., Capobianco, M., Dette, H.H., Hamm, L., Laustrup, C., Lechuga, A., and Spanhoff, R., 2002, Beach nourishment projects, practices, and objectives-A European overview: Coastal Engineering, v. 47, no. 2, p. 81-111, accessed August 11, 2020, at https://doi. org/10.1016/S0378-3839(02)00122-9.

Hardaway C.S., Jr., Milligan, D.A., Wilcox, C.A., and Smith, C., 2015, Wallops Assateague Chincoteague Inlet (WACI) geologic and coastal management summary report: Williamsburg, Va., College of William \& Mary, Virginia Institute of Marine Science report, accessed July 7, 2020, at https://doi.org/10.25773/WPQA-0Q05.

Hata, D., and Berkson, J., 2003, Abundance of horseshoe crabs (Limulus polyphemus) in the Delaware Bay area: Fishery Bulletin, v. 101, no. 4, p. 933-938, accessed September 23, 2020, at https://spo.nmfs.noaa.gov/content/abundancehorseshoe-crabs-limulus-polyphemus-delaware-bay-area.

Hauser, S., Meixler, M.S., and Laba, M., 2015, Quantification of impacts and ecosystem services loss in New Jersey coastal wetlands due to Hurricane Sandy storm surge: Wetlands, v. 35, no. 6, p. 1137-1148, accessed May 29, 2020, at https://doi.org/doi:10.7282/T3GF0WFH.

Hawkins, A.D., Roberts, L., and Cheesman, S., 2014, Responses of free-living coastal pelagic fish to impulsive sounds: The Journal of the Acoustical Society of America, v. 135, no. 5, p. 3101-3116, accessed Month August 19, 2020, at https://doi.org/10.1121/1.4870697.

Hayes, M.O., 1979, Barrier island morphology as a function of tidal and wave regime, in Leatherman, S.P., ed., Barrier islands-From the Gulf of St. Lawrence to the Gulf of Mexico; Coastal Research Symposium, Boston, Mass., 1978, proceedings: New York, Academic Press, p. 1-27. [Also available at https://www.researchgate.net/publication/259646763_Barrier_Island_Morphology_as_a_Function_of_Tidal_and_Wave_Regime.]
Hayes, M.O., 1994, The Georgia bight barrier system, chap. 7 of Davis, R.A., ed., Geology of Holocene barrier island systems: Berlin, Germany, Springer-Verlag, p. 233-304, accessed July 7, 2020, at https://doi.org/10.1007/978-3-64278360-9_7.

Hayes, M.O., 1980, General morphology and sediment patterns in tidal inlets: Sedimentary Geology, v. 26, nos. 1-3, p. 139-156, accessed October 19, 2020, at https://doi. org/10.1016/0037-0738(80)90009-3.

Hearin, J.M., 2012, A detailed analysis of beach nourishment and its impact on the surfing wave environment of Brevard County, Florida: Melbourne, Fla., Florida Institute of Technology, Ph.D. dissertation, 341 p., accessed August 11, 2020, at https://doi.org/10.13140/RG.2.1.4795.0165.

Heck, K.L., Jr., Carruthers, T.J., Duarte, C.M., Hughes, A.R., Kendrick, G., Orth, R.J., and Williams, S.W., 2008, Trophic transfers from seagrass meadows subsidize diverse marine and terrestrial consumers: Ecosystems v. 11, no. 7, p. 11981210, accessed June 15, 2020, at https://doi.org/10.1007/ s10021-008-9155-y.

Hemminga, M.A., and Duarte, C.M., 2000, Seagrass ecology: Cambridge, United Kingdom, Cambridge University Press, 298 p., accessed August 5, 2020, at https://doi.org/10.1017/ CBO9780511525551.

Hesp, P.A., and Walker, I.J., 2013, Coastal dunes, chap. 11.17 of Aeolian geomorphology, v. 11 of Shroder, J.F., ed., Treatise on geomorphology: San Diego, Calif., Academic Press, p. 328-355, accessed August 11, 2020, at https://doi. org/10.1016/B978-0-12-374739-6.00310-9.

Hess, S., Wenger, A.S., Ainsworth, T.D., Rummer, J.L., 2015, Exposure of clownfish larvae to suspended sediment levels found on the Great Barrier Reef-Impacts on gill structure and microbiome: Scientific Reports, v. 5, art. 10561, 8 p., accessed May 14, 2012, at https://doi.org/10.1038/ srep 10561.

Hill-Spanik, K.M., Smith, A.S., and Plante, C.J., 2019, Recovery of benthic microalgal biomass and community structure following beach renourishment at Folly Beach, South Carolina: Estuaries and Coasts, v. 42, no. 1, p. 157-172, accessed July 7, 2020, at https://doi.org/10.1007/s12237018-0456-x.

Hill, J.M., Marzialetti, S., and Pearce, B., 2011, Recovery of seabed resources following marine aggregate extraction: Marine Aggregate Levy Sustainability Fund (MALSF), Science Monograph Series no. 2, 44 p., accessed July 7, 2020, at https://www.researchgate.net/profile/BryonyPearce/publication/329569222_Recovery_of_Seabed Resources_Following_Marine_Aggregate_Extraction_Science_Monograph_Series/links/5c0fdaeba6fdcc494fed1 f22/ Recovery-of-Seabed-Resources-Following-Marine-Aggregate-Extraction-Science-Monograph-Series.pdf. 
Hinkel, J., Nicholls, R.J., Tol, R.S.J., Wang, Z.B., Hamilton, J.M., Boot, G., Vafeidis, A.T., McFadden, L., Ganopolski, A., and Klein, R.J.T., 2013, A global analysis of erosion of sandy beaches and sea-level rise-An application of DIVA: Global and Planetary Change, v. 111, p. 150-158, accessed September 1, 2020, at https://doi.org/10.1016/j.gloplacha.2013.09.002.

Hitchcock, D.R., and Bell, S., 2004, Physical impacts of marine aggregate dredging on seabed resources in coastal deposits: Journal of Coastal Research, v. 20, no. 1, p. 101-114, accessed June 10, 2020, at https://doi. org/10.2112/1551-5036(2004)20[101:PIOMAD]2.0.CO;2.

Hobbs, C.H., III, 2002, An investigation of potential consequences of marine mining in shallow water-An example from the mid-Atlantic coast of the United States: Journal of Coastal Research, v. 18, no. 1, p. 94-101, accessed July 13, 2020, at https://www.jstor.org/stable/4299057.

Hoekstra, P., Houwman, K.T., Kroon, A., Ruessink, B.G., Roelvink, J.A., and Spanhoff, R., 1997, Morphological development of the Terschelling shoreface nourishment in response to hydrodynamic and sediment transport processes, chap. 224 of Edge, B.L., ed., Coastal Engineering 1996-International Conference on Coastal Engineering, 25th, Orlando, Florida, 2-6 September, 1996, proceedings: New York, American Society of Civil Engineers, p. 2897-2910, accessed May 12, 2021, at https://doi. org/10.1061/9780784402429.224.

Holmes, L.J., McWilliam, J., Ferrari, M.C.O., and McCormick, M.I., 2017, Juvenile damselfish are affected but desensitize to small motor boat noise: Journal of Experimental Marine Biology and Ecology, v. 494, p. 63-68, accessed August 28, 2020, at https://doi.org/10.1016/j. jembe.2017.05.009.

Hoonhout, B., and de Vries, S., 2017, Field measurements on spatial variations in aeolian sediment availability at the Sand Motor mega nourishment: Aeolian Research, v. 24, p. 93-104, accessed August 11, 2020, at https://doi. org/10.1016/j.aeolia.2016.12.003.

Horikawa, K., Hotta, S., and Kraus, N.C., 1986, Literature review of sand transport by wind on a dry sand surface: Coastal Engineering, v. 9, no. 6, p. 503-526, accessed August 11, 2020, at https://doi.org/10.1016/03783839(86)90001-3.

Horrocks, J.A., and Scott, N.McA., 1991, Nest site location and nest success in the hawksbill turtle Eretmochelys imbricata in Barbados, West Indies: Marine Ecology Progress Series, v. 69, nos. 1-2, 8 p., accessed August 15, 2020, at https://www.jstor.org/stable/44634759.
Houston, J.R., 2013, The value of Florida beaches: Shore \& Beach, v. 81, no. 1, p. 3-11, accessed September 1, 2020, at https://www.researchgate.net/publication/284772036_The_ economic_value_of_beaches_a_2013_update.

Houston, J.R., 2017, Shoreline change in response to sea-level rise on Florida's west coast: Journal of Coastal Research, v. 33, no. 6, p. 1243-1260, accessed September 1, 2020, at https://doi.org/10.2112/JCOASTRES-D-17-00024.1.

Houston, J.R., and Dean, R.G., 2016, Erosional impacts of modified inlets, beach encroachment, and beach nourishment on the east coast of Florida: Journal of Coastal Research, v. 32, no. 2, p. 227-240, accessed May 6, 2020, at https://doi.org/10.2112/JCOASTRES-D-15-00105.1.

Hoyt, J.H., 1967, Barrier island formation: Geological Society of America Bulletin, v. 78, no. 9, p. 1125-1136, accessed May 1, 2020, at https://doi.org/10.1130/00167606(1967)78[1125:BIF]2.0.CO;2.

Hoyt, J.H., 1968, Barrier island formation-Reply: Geological Society of America Bulletin, v. 79, no. 7, p. 947, accessed May 1, 2020, at https://doi.org/10.1130/00167606(1968)79[947:BIFD]2.0.CO;2.

Huettel, M., and Gust, G., 1992, Solute release mechanisms from confined sediment cores in stirred benthic chambers and flume flows: Marine Ecology Progress Series, v. 82, no. 2, p. 187-197, accessed August 11, 2020, at https://doi. org/10.3354/meps082187.

Huettel, M., Røy, H., Precht, E., and Ehrenhauss, S., 2003, Hydrodynamical impact on biogeochemical processes in aquatic sediments, in Part $\mathrm{C}$-Evaluating change in saline and/or freshwater habitat of Kronvang, B., ed., The interactions between sediments and water-Proceedings of the 9th International Symposium on the Interactions between Sediments and Water, held 5-10 May 2002 in Banff, Alberta, Canada: Dordrecht, Netherlands, Springer, , p. 231-236, accessed August 11, 2020, at https://doi.org/10.1007/97894-017-3366-3_31.

Huettel, M., and Rusch, A., 2000, Advective particle transport into permeable sediments-Evidence from experiments in an intertidal sandflat: Limnology and Oceanography, v. 45, no. 3, p. 525-533, accessed June 29, 2020, at https://doi. org/10.4319/1o.2000.45.3.0525.

Huettel, M., and Webster, I.T., 2001, Porewater flow in permeable sediments, chap. 7 of Boudreau, B.P., and Jørgensen, B.B., eds., The benthic boundary layer-Transport processes and biogeochemistry: New York, Oxford University Press, p. 144-177. 
Huisman, B.J.A., Ruessink, B.G., de Schipper, M.A., Luijendijk, A.P., and Stive, M.J.F., 2018, Modelling of bed sediment composition changes at the lower shoreface of the Sand Motor: Coastal Engineering, v. 132, p. 33-49, accessed August 7, 2020, at https://doi.org/10.1016/j.coastaleng.2017.11.007.

Huisman, B.J.A., Walstra, D.J.R., Radermacher, M., de Schipper, M.A., and Ruessink, B.G., 2019, Observations and modelling of shoreface nourishment behaviour: Journal of Marine Science and Engineering, v. 7, no. 3, art. 59, 26 p., accessed July 6, 2020, at https://doi.org/10.3390/ jmse7030059.

Hwung, H.-H., Huang, Z.-C., and Hwang, K.-S., 2010, An experimental study of the cross-shore evolution of artificial submerged sand bars: Coastal Engineering Journal, v. 52, no. 4, p. 261-285, accessed September 16, 2020, at https:// doi.org/10.1142/S057856341000221X.

Irish, J.L., Frey, A.E., Rosati, J.D., Olivera, F., Dunkin, L.M., Kaihatu, J.M., Ferreira, C.M., and Edge, B.L., 2010, Potential implications of global warming and barrier island degradation on future hurricane inundation, property damages, and population impacted: Ocean and Coastal Management, v. 53 , no. 10, p. 645-657, accessed September 1, 2020, at https://doi.org/10.1016/j.ocecoaman.2010.08.001.

Jackson, N.L. and Nordstrom, K.F., 2009, Strategies to conserve and enhance sandy barrier habitat for horseshoe crabs (Limulus polyphemus) on developed shorelines in Delaware Bay, United States, in Tanacredi, J.T., Botton, M.L., and Smith, D., eds., Biology and conservation of horseshoe crabs: Springer, p. 399-416, accessed May 14, 2021, at https://doi.org/10.1007/978-0-387-89959-6_25.

Jackson, N.L., Nordstrom, K.F., Saini, S., and Smith, D.R., 2010, Effects of nourishment on the form and function of an estuarine beach: Ecological Engineering, v. 36, no. 12, p. 1709-1718, accessed August 11, 2020, at https://doi. org/10.1016/j.ecoleng.2010.07.016.

Jackson, N.L., Nordstrom, K.F., and Smith, D.R., 2002, Geomorphic- biotic interactions on beach foreshores in estuaries: Journal of Coastal Research, Special issue no. 36, p. 414-424, accessed July 15, 2020, at https://doi. org/10.2112/1551-5036-36.sp1.414.

Jackson, N.L., Smith, D.R., and Nordstrom, K.F., 2004, Using geomorphology to assess and enhance beach habitat for horseshoe crabs, no. 80 in Janelle D.G., Warf B., Hansen K., eds., WorldMinds - Geographical perspectives on 100 problems: Dordrecht, Netherlands, Springer, p. 493-496, accessed July 15, 2020, at https://doi.org/10.1007/978-14020-2352-1_80.
Jackson, N.L., Nordstrom, K.F., Saini S., and Smith, D.R., 2015, Influence of configuration of bulkheads on use of estuarine beaches by horseshoe crabs and foraging shorebirds: Environmental Earth Science, v. 74, p. 5749-5758, accessed May 14, 2021, at https://doi.org/10.1007/s12665015-4592-3.

Jacobsen, N.G., and Fredsoe, J., 2014, Cross-shore redistribution of nourished sand near a breaker bar: Journal of Waterway, Port, Coastal, and Ocean Engineering, v. 140, no. 2, p. 125-134, accessed August 26, 2020, at https://doi. org/10.1061/(ASCE)WW.1943-5460.0000233.

Jahnke, R., Richards, M., Nelson, J., Robertson, C., Rao, A., and Jahnke, D., 2005, Organic matter remineralization and porewater exchange rates in permeable South Atlantic Bight continental shelf sediments: Continental Shelf Research, v. 25, no. 12-13, p. 1433-1452, accessed August 25, 2020, at https://doi.org/10.1016/j.csr.2005.04.002.

Johnson, B. D., Kobayashi, N., and Gravens, M.B., 2012, Cross-Shore Numerical Model CSHORE for waves, currents, sediment transport and beach profile evolution: Prepared for U.S. Army Corps of Engineers Engineer Research and Development Center, ERDC/CHL TR-12-22, 147 p. [Also available at http://greatlakescoast.org/pubs/reports/ CHL+TR-12-22.pdf.]

Johnson, R.O., and Nelson, W.G., 1985, Biological effects of dredging in an offshore borrow area: Florida Scientist, v. 48, no. 3, p. 166-188, accessed June 2, 2020, at https://www. jstor.org/stable/24319836.

Jutte, P.C., Crowe, S.E., Van Dolah, R.F., and Weinbach, P.R., 2005, An environmental assessment of the Charleston Ocean Dredged Material Disposal Site and surrounding areas-Physical and biological conditions after completion of the Charleston Harbor deepening project—Final report: U.S. Army Corps of Engineers (Charleston district) report, prepared by South Carolina Department of Natural Resources, Marine Resources Research Institute, accessed July 13, 2020, at http://hdl.handle.net/10827/11161.

Jutte, P.C., Van Dolah, R.F., and Gayes, P.T., 2002, Recovery of benthic communities following offshore dredging, Myrtle Beach, South Carolina: Shore \& Beach, v. 70, no. 3, p. 25-30.

Kaczkowski, H., Traynum, S., Giles, D., and Kaczkowski, S., 2019, Sand retaining structure to increase longevity of beach nourishment-A case study in the USA, in Goseberg, N., and Schlurmann, T., eds., Coastal Structures 2019, International Coastal Structures conference, 8th, Hannover, Germany, September 29th-October 2nd, 2019, proceedings: Reston, Va., Coasts, Oceans, Ports, and Rivers Institute, p. 2897-2910, accessed August 11, 2020, at https://doi. org/10.18451/978-3-939230-64-9_037. 
Kaczkowski, H.L., Kana, T.W., Traynum, S.B., and Visser, R., 2018, Beach-fill equilibration and dune growth at two large-scale nourishment sites: Ocean Dynamics, v. 68, no. 9, p. 1191-1206, accessed August 11, 2020, at https://doi. org/10.1007/s10236-018-1176-2.

Karpanty, S.M., Cohen, J., Fraser, J.D., and Berkson, J., 2011, Sufficiency of horseshoe crab eggs for red knots during spring migration stopover in Delaware Bay USA: The Journal of Wildlife Management, v. 75, no. 5, p. 984-994, accessed July 15, 2020, at https://doi.org/10.1002/ jwmg. 129.

Kastelein, R.A., van der Heul, S., Verboom, W.C., Jennings, N., van der Veen, J., and de Haan, D., 2008, Startle response of captive North Sea fish species to underwater tones between 0.1 and 64kHz: Marine Environmental Research, v. 65, no. 5, p. 369-377, accessed August 19, 2020, at https:// doi.org/10.1016/j.marenvres.2008.01.001.

Kennedy, A.B., Slatton, K.C., Starek, M., Kampa, K., and Cho, H.C., 2010, Hurricane response of nearshore borrow pits from airborne bathymetric lidar: Journal of Waterway, Port, Coastal, and Ocean Engineering, v. 136, no. 1, p. 46-58, accessed June 23, 2020, at https://doi.org/10.1061/ (ASCE)WW.1943-5460.0000024.

Keulegan, G.H., and Krumbein, W.C., 1949, Stable configuration of bottom slope in a shallow sea and its bearing on geological process: Eos, v. 30, no. 6, p. 855-861, accessed May 13, 2021, at https://doi.org/10.1029/TR030i006p00855.

Kinsela, M.A., Hanslow, D.J., Carvalho, R.C., Linklater, M., Ingleton, T.C., Morris, B.D., Allen, K.M., Sutherland, M.D., and Woodroffe, C.D., 2020, Mapping the shoreface of coastal sediment compartments to improve shoreline change forecasts in New South Wales, Australia: Estuaries and Coasts, Special issue (Shallow water mapping), p. 1-27, accessed May 15, 2021 at https://doi.org/10.1007/s12237020-00756-7.

Kirwan, M.L., and Megonigal, J.P., 2013, Tidal wetland stability in the face of human impacts and sea-level rise: Nature, v. 504, no. 7478, p. 53-60, accessed June 15, 2020, at https://doi.org/10.1038/nature12856.

Kirwan, M.L., and Murray, A.B., 2007, A coupled geomorphic and ecological model of tidal marsh evolution: Proceedings of the National Academy of Sciences of the United States of America, v. 104, no. 15, p. 6118-6122, accessed June 15, 2020, at https://doi.org/10.1073/pnas.0700958104.

Knip, D.M., Heupel, M.R., and Simpfendorfer, C.A., 2010, Sharks in nearshore environments-Models, importance, and consequences: Marine Ecology Progress Series, v. 402, p. 1-11, accessed August 21, 2020, at https://doi. org/10.3354/meps08498.
Kobashi, D., and Jose, F., 2018, Potential impacts of sand mining on hydrodynamics and fine sediment suspension and deposition on an inner-shelf shoal: Journal of Coastal Research, Special issue no. 81, p. 76-85, accessed August 7, 2020, at https://doi.org/10.2112/SI81-010.1.

Krafft, D.R., Young, D.L., Brutsche, K.E., McFall, B.C., and Bruder, B.L., 2020, Nearshore Placement Workshop 2019Sediment nourishment of the nearshore environment: U.S. Army Engineer Research and Development Center, Coastal and Hydraulics Laboratory report ERDC/CHL SR-20-02, 28 p., accessed August 7, 2020, at https://erdc-library.erdc. dren.mil/jspui/handle/11681/36915.

Krauss, K.W., Shaffer, G.P., Keim, R.F., Chambers, J.L., Wood, W.B., and Hartley, S.B., 2017, Performance measures for a Mississippi River reintroduction into the forested wetlands of Maurepas Swamp: U.S. Geological Survey Scientific Investigations Report 2017-5036, 56 p., https:// doi.org/10.3133/sir20175036.

Kress, M.M., Touzinsky, K.F., Vuxton, E.A., Greenfeld, B., Lillycrop, L.S., and Rosati, J.D., 2016, Alignment of U. S. ACE civil works missions to restore habitat and increase environmental resiliency: Coastal Management, v. 44, no. 3, p. 193-208, accessed September 1, 2020, at https://doi.org/1 0.1080/08920753.2016.1160203.

Kroon, A., De Schipper, M., Van Gelder, P., and Aarninkhof, S., 2019, Quantification of model uncertainty in lifetime predictions of nourishments, in Wang, P., Rosati, J.D., and Vallee, M., eds., Coastal Sediments 2019-Proceedings of the 9th International Conference, Tampa/St. Petersburg, Florida, USA, May 27-31, 2019: Singapore, World Scientific, , p. 338-346, accessed October 19, 2020, at https://doi. org/10.1142/9789811204487_0032.

Kulp, M., Penland, S., and Ramsey, K., 2001, Ship ShoalSand resource synthesis report: Coastal Research Laboratory, Department of Geology and Geophysics, University of New Orleans, 84 p.

La Peyre, M.K., Gossman, B., and Piazza, B.P., 2009, Shortand long-term response of deteriorating brackish marshes and open-water ponds to sediment enhancement by thinlayer dredge disposal: Estuaries and Coasts, v. 32, no. 2, p. 390-402, accessed August 11, 2020, at https://doi. org/10.1007/s12237-008-9126-8.

Lamont, M.L., Johnson, D., and Carthy, R.C., 2020, The incubation environment of nests deposited by a genetically distinct group of loggerhead sea turtles in northwest Florida: Global Ecology and Conservation, v. 23, art. e01070, 11 p., accessed August 17, 2020, at https://doi.org/10.1016/j. gecco.2020.e01070. 
Lamont, M.M., and Houser, C., 2014, Spatial distribution of loggerhead turtle (Caretta caretta) emergences along a highly dynamic beach in the northern Gulf of Mexico: Journal of Experimental Marine Biology and Ecology, v. 453, p. 98-107, at https://doi.org/10.1016/j.jembe.2013.11.006.

Lavoie, D., Flocks, J.G., Kindinger, J.L., Sallenger, A.H., Jr., and Twichell, D.C., 2010, Effects of building a sand barrier berm to mitigate the effects of the Deepwater Horizon oil spill on Louisiana marshes: U.S. Geological Survey OpenFile Report 2010-1108, 7 p, accessed August 21, 2020, at https://pubs.usgs.gov/of/2010/1108/.

Leatherman, S.P., 1979, Migration of Assateague Island, Maryland, by inlet and overwash processes: Geology, v. 7, no. 2, p. 104-107, accessed July 7, 2020, at https://doi. org/10.1130/0091-7613(1979)7<104:MOAIMB>2.0.CO;2.

Leatherman, S.P., 1985, Geomorphic and stratigraphic analysis of Fire Island, New York: Marine Geology, v. 63, nos. 1-4, p. 173-195, accessed July 7, 2020, at https://doi. org/10.1016/0025-3227(85)90083-0.

Lee, S.-Y., Hamlet, A.F., and Grossman., E., 2016, Impacts of climate change on flood control, hydropower production, regulated low flows, and sediment discharge in the Skagit River Basin: Northwest Science, v. 90, no. 1, p. 23-43, at https://doi.org/10.3955/046.090.0104.

Leewis, L., van Bodegom, P.M., Rozema, J., and Janssen, G.M., 2012, Does beach nourishment have long-term effects on intertidal macroinvertebrate species abundance?: Estuarine, Coastal and Shelf Science, v. 113, p. 172-181, accessed June 15, 2020, at https://doi.org/10.1016/j. ecss.2012.07.021.

Lenanton, R.C.J., and Caputi, N., 1989, The roles of food supply and shelter in the relationship between fishes, in particular Cnidoglanis macrocephalus (Valenciennes), and detached macrophytes in the surf zone of sandy beaches: Journal of Experimental Marine Biology and Ecology, v. 128, no. 2, p. 165-176, accessed June 6, 2020, at https://doi. org/10.1016/0022-0981(89)90144-5.

Lenanton, R.C.J., Robertson, A.I., and Hansen, J.A., 1982, Nearshore accumulations of detached macrophytes as nursery areas for fish: Marine Ecology Progress Series, v. 9, p. 51-57, accessed June 6, 2020, at https://doi.org/10.3354/ meps009051.

Lentz, E.E., Thieler, E.R., Plant, N.G., Stippa, S.R., Horton, R.M., and Gesch, D.B., 2016, Evaluation of dynamic coastal response to sea-level rise modifies inundation likelihood: Nature Climate Change, v. 6, no. 7, p. 696-700, accessed June 15, 2020, at https://doi.org/10.1038/nclimate2957.
Leonard, L., Clayton, T., and Pilkey, O., 1990, An analysis of replenished beach design parameters on U.S. east coast barrier islands: Journal of Coastal Research, v. 6, no. 1, p. 15-36, accessed October 19, 2020, at https://www.jstor.org/ stable/4297640.

Lesser, G.R., Roelvink, J.A., van Kester, J.A.T.M., and Stelling, G.S., 2004, Development and validation of a threedimensional morphological model: Coastal Engineering, v. 51, nos. 8-9, p. 883-915, accessed August 7, 2020, at https://doi.org/10.1016/j.coastaleng.2004.07.014.

Liebowitz, D.M., Nielsen, K.J., Dugan, J.E., Morgan, S.G., Malone, D.P., Largier, J.L., Hubbard, D.M., and Carr, M.H., 2016, Ecosystem connectivity and trophic subsidies of sandy beaches: Ecosphere, v. 7, no. 10, art. e01503, 19 p., accessed June 12, 2020, at https://doi.org/10.1002/ ecs2.1503.

Liedtke, T.L., and Conn, K.E., 2021, Maternal transfer of polychlorinated biphenyls in Pacific sand lance (Ammodytes personatus), Puget Sound, Washington: Science of the Total Environment, v. 764, article 142819, 12 p., accessed March 23, 2021, at https://doi.org/10.1016/j.scitotenv.2020.142819.

Lindeman, K.C., and Snyder, D.B., 1999, Nearshore hardbottom fishes of southeast Florida and effects of habitat burial caused by dredging: Fishery Bulletin, v. 97, no. 3, p. 508-525, accessed June 24, 2020, at https://spo.nmfs.noaa. gov/sites/default/files/09lindem.pdf.

Lindquist, N., and Manning, L., 2001, Impacts of beach nourishment and beach scraping on critical habitat and productivity of surf fishes-Final report: [Raleigh, N.C.], N.C. Sea Grant, Fisheries Resource Grant Program report 98-EP-05, 107 p. [Also available at http://www.vliz.be/imisdocs/publications/ocrd/255807.pdf.]

List, J.H., Hanes, D.M., and Ruggiero, P., 2007, Predicting longshore gradients in longshore transport-Comparing the CERC formula to DELFT3D, in McKee Smith, J., ed., Coastal Engineering 2006-Proceedings of the 30th international conference-San Diego, California, USA, 3-8 September 2006: Hackensack, N.J., World Scientific, p. 3370-3380, accessed August 7, 2020, at https://doi. org/10.1142/9789812709554_0284.

Locker, S.D., Hine, A.C., and Brooks, G.R., 2003, Regional stratigraphic framework linking continental shelf and coastal sedimentary deposits of west-central Florida: Marine Geology, v. 200, nos. 1-4, p. 351-378, accessed March 23, 2021, at https://doi.org/10.1016/S0025-3227(03)00191-9.

Loegering, J.P., and Fraser, J.D., 1995, Factors affecting piping plover chick survival in different brood-rearing habitats: The Journal of Wildlife Management, v. 59, no. 4, p. 646-655, accessed June 15, 2020, at https://doi. org/10.2307/3801940. 
Lohrer, A.M., Thrush, S.F., Lundquist, C.J., Vopel, K., Hewitt, J.E., and Nicholls, P.E., 2006, Deposition of terrigenous sediment on subtidal marine macrobenthos-Response of two contrasting community types: Marine Ecology Progress Series, v. 307, p. 115-125, accessed June 15, 2020, at https://doi.org/10.3354/meps307115.

Lopez, C.B., Karim, A., Murasko, S., Marot, M., Smith, C.G., and Corcoran, A.A., 2019, Temperature mediates secondary dormancy in resting cysts of Pyrodinium bahamense (Dinophyceae): Journal of Phycology, v. 55, no. 4, p. 924-935, accessed August 25, 2020, at https://doi.org/10.1111/ jpy. 12883 .

Loreau, M., and de Mazancourt, C., 2013, Biodiversity and ecosystem stability-A synthesis of underlying mechanisms: Ecology Letters, v. 16, Special issue, Supplement 1, p. 106-115, accessed June 15, 2020, at https://doi. org/10.1111/ele.12073.

Loreau, M., Mouquet, N., and Holt, R.D., 2003, Metaecosystems - A theoretical framework for a spatial ecosystem ecology: Ecology Letters, v. 6, no. 8, p. 673-679, accessed June 12, 2020, at https://doi.org/10.1046/j.14610248.2003.00483.x.

Lorenzo-Trueba, J., and Mariotti, G., 2017, Chasing boundaries and cascade effects in a coupled barrier-marshlagoon system: Geomorphology, v. 290, p. 153-163, accessed June 12, 2020, at https://doi.org/10.1016/j.geomorph.2017.04.019.

Lott, C.A., Fischer, R.A., and Pashley, D.N., 2007, Towards the integration of federal dredging and beach nourishment activities with North American coastal bird conservation programs, in Randall, R.E., ed., Proceedings of the Eighteenth World Dredging Congress (WODCON XVIII) - May 27-June 1, 2007, Lake Buena Vista, Florida, USA: Bryan, Tex., Newman, p. 355-364, accessed June 15, 2020, at https://www.researchgate.net/publication/257812256 TOWARDS_THE_INTEGRATION_OF_FEDERAL DREDGING_AND_BEACH_NOURISHMENT_ACTIVITIES_WITH_NORTH_AMERICAN_COASTAL_BIRD_ CONSERVATION_PROGGAMS.

Luijendijk, A.P., Ranasinghe, R., de Schipper, M.A., Huisman, B.A., Swinkels, C.M., Walstra, D.J.R., and Stive, M.J.F., 2017, The initial morphological response of the Sand Engine-A process-based modelling study: Coastal Engineering, v. 119, p. 1-14, accessed August 07, 2020, at https://doi.org/10.1016/j.coastaleng.2016.09.005.
Lunemann, M., Marano, M., and Douglas, W.S., 2017, Resilience of upland confined disposal facilities and beneficial re-use of dredged material for coastal protection, in Hayes, D.F., and Hughes, H.R., eds., Proceedings of the Dredging Summit \& Expo 2017, June 26-29, 2017, Vancouver, BC: Bonsall, Calif., Western Dredging Association, 14 p., accessed August 11, 2020, at https://www.westerndredging. org/phocadownload/2017_Vancouver/Proceedings/4a_2.pdf.

Luo, S., Liu, Y., Jin, R., Zhang, J., and Wei, W., 2016, A guide to coastal management-Benefits and lessons learned of beach nourishment practices in China over the past two decades: Ocean \& Coastal Management, v. 134, p. 207-215, accessed August 7, 2020, at https://doi.org/10.1016/j.ocecoaman.2016.10.011.

Luque, C.J., Castellanos, E.M., Castillo, J.M., Gonzalez, M., Gonzalez-Vilches, M.C., and Figueroa, M.E., 1999, Metals in halophytes of a contaminated estuary (Odiel Saltmarshes, SW Spain): Marine Pollution Bulletin, v. 38, no. 1, p. 49-51, accessed June 1, 2020, at https://doi.org/10.1016/ S0025-326X(99)80012-5.

Maa, J.P.-Y., Hobbs, C.H., III, Kim, S.C., and Wei, E., 2004, Potential impacts of sand mining offshore of Maryland and Delaware-Part 1-Impacts on physical oceanographic processes: Journal of Coastal Research, v. 20, no. 1, p. 44-60, accessed June 23, 2020, at https://doi.org/10.2112/15515036(2004)20[44:PIOSMO]2.0.CO;2.

Maa, J.P.-Y., and Hobbs, C.H., 1998, Physical impact of waves on adjacent coasts resulting from dredging at Sandbridge Shoal, Virginia: Journal of Coastal Research, v. 14, no. 2, p. 525-536, accessed June 23, 2020, at https://www.jstor.org/ stable/4298807.

Magliocca, N.R., McNamara, D.E., and Murray, A.B., 2011, Long-term, large-scale morphodynamic effects of artificial dune construction along a barrier island coastline: Journal of Coastal Research, v. 27, no. 5, p. 918-930, accessed August 11, 2020, at https://doi.org/10.2112/JCOASTRESD-10-00088.1.

Mallinson, D.J., Smith, C.W., Culver, S.J., Riggs, S.R., and Ames, D., 2010, Geological characteristics and spatial distribution of paleo-inlet channels beneath the outer banks barrier islands, North Carolina, USA: Estuarine, Coastal and Shelf Science, v. 88, no. 2, p. 175-189, accessed July 07, 2020, at https://doi.org/10.1016/j.ecss.2010.03.024.

Manatee County, Florida, 2020, Beach renourishment updates web page: Manatee County, Fla., website, accessed July 7, 2020, at https://www.mymanatee.org/departments/ parks_natural_resources/parks__preserves__ beaches/ beach_renourishment_update. 
Manning, L.M., Peterson, C.H., and Bishop, M.J., 2014, Dominant macrobenthic populations experience sustained impacts from annual disposal of fine sediments on sandy beaches: Marine Ecology Progress Series, v. 508, p. 1-15, accessed June 23, 2020, at https://doi.org/10.3354/ meps 10870 .

Marcovaldi, M.Â., and Laurent, A., 1996, A six season study of marine turtle nesting at Praia do Forte, Bahia, Brazil, with implications for conservation and management: Chelonian Conservation and Biology, v. 2, no. 1, p. 55-59, accessed August 15, 2020, at http://www.tamar.org.br/publicacoes_html/pdf/1996/1996_A_Six_Study_of_Marine_Turtle.pdf

Marijnissen, R., Esselink, P., Kok, M., Kroeze, C., and van Loon-Steensma, J.M., 2020, How natural processes contribute to flood protection-A sustainable adaptation scheme for a wide green dike: Science of The Total Environment, v. 739, article 139698, 17 p., accessed August 25, 2020, at https://doi.org/10.1016/j.scitotenv.2020.139698.

Mariotti, G., and Fagherazzi, S., 2010, A numerical model for the coupled long-term evolution of salt marshes and tidal flats: Journal of Geophysical Research, Earth Surface, v. 115, no. F1, accessed August 31, 2020, at https://doi. org/10.1029/2009JF001326.

Martin, D., Bertasi, F., Colangelo, M.A., De Vries, M., Frost, M., Hawkins, S.J., Macpherson, E., Moschella, P.S., Satta, M.P., Thompson, R.C., and Ceccherelli, V.U., 2005, Ecological impact of coastal defence structures on sediment and mobile fauna-Evaluating and forecasting consequences of unavoidable modifications of native habitats: Coastal Engineering, v. 52, nos. 10-11, p. 1027-1051, accessed June 15, 2020, at https://doi.org/10.1016/j.coastaleng.2005.09.006.

Maslo, B., Burger, J., and Handel, S.N., 2012, Modeling foraging behavior of piping plovers to evaluate habitat restoration success: Journal of Wildlife Management, v. 76, no. 1, p. 181-188, accessed June 15, 2020, at https://doi. org/10.1002/jwmg.210.

Maslo, B., Leu, K., Faillace, C., Weston, M.A., Pover, T., and Schlacher, T.A., 2016, Selecting umbrella species for conservation-A test of habitat models and niche overlap for beach-nesting birds: Biological Conservation, v. 203, p. 233-242, accessed June 15, 2020, at https://doi. org/10.1016/j.biocon.2016.09.012.

Mateo, M.A., Cebrian, J., Dunton, K., and Mutchler, T., 2006, Carbon flux in seagrass ecosystems, chap. 7 of Larkum, A.W.D., Orth, R.J., and Duarte, C.M., eds., SeagrassesBiology, ecology and conservation: Dordrecht, Netherlands, Springer, p. 159-192, accessed June 15, 2020, at https:// www.disl.edu/assets/uploads/publications/carbon_flux_in_ seagrass_ecosystems.pdf.
Mateo, M.Á., Sanchez-Lizaso, J.L., and Romero, J., 2003, Posidonia oceanica 'banquettes'-A preliminary assessment of the relevance for meadow carbon and nutrients budget: Estuarine, Coastal and Shelf Science, v. 56, no. 1, p. 85-90, accessed June 15, 2020, at https://doi.org/10.1016/ S0272-7714(02)00123-3.

Maurer, D., Keck, R.T., Tinsman, J.C., Leathem, W.A., Wethe, C., Lord, C., and Church, T.M., 1986, Vertical migration and mortality of marine benthos in dredged material-A synthesis: Internationale Revue der Gesamten Hydrobiologie und Hydrographie, [International Review of Complete Hydrobiology and Hydrography], v. 71, no. 1, p. 49-63, accessed July 13, 2020, at https://doi.org/10.1002/ iroh. 19860710106.

May, E.B., 1973, Environmental effects of hydraulic dredging in estuaries: Alabama Marine Resources Bulletin, v. 9, p. 1-85, accessed August 7, 2020, at https://babel.hathitrust. org $/$ cgi/pt?id=uc1.b3355540\&view=1up\&seq=467.

McBride, R., Anderson, J., Buynevich, I., Cleary, W., Fenster, M., FitzGerald, D., Harris, M., Hein, C., Klein, A., Liu, B., and Wang, P., 2013, Morphodynamics of barrier systemsA synthesis, Ch. 10.8 of Sherman, D.J., ed., Treatise on Geomorphology: Elsevier, v. 10, p. 166-244, accessed May 12, 2021, at https://doi.org/10.1016/B978-0-12-3747396.00279-7.

McBride, R.A., and Byrnes, M.R., 1995, A megascale systems approach for shoreline change analysis and coastal management along the northern Gulf of Mexico: Gulf Coast Association of Geological Societies Transactions, v. 45, p. 405-414, accessed July 7, 2020, at http://archives.datapages.com/data/gcags/data/045/045001/0405.htm.

McCauley, J.E., Parr, R.A., and Hancock, D.R., 1977, Benthic infauna and maintenance dredging - A case study: Water Research, v. 11, no. 2, p. 233-242, accessed July 13, 2020, at https://doi.org/10.1016/0043-1354(77)90131-2.

McCoy, C., Hill, J., Gayes, P., Marshall, J., Okano, S., Johnson, B., Howe, M., and Klotsko, S., 2010, 2007-2010 Grand Strand Beach nourishment study-Final report: U.S. Army Corps of Engineers (Charleston District) report, 311 p., accessed June 4, 2020, at https://scmss.coastal.edu/sites/ default/files/uploaded_files/GSR_Final_Report.pdf.

McGowan, C.P., Simons, T.R., Golder, W., and Cordes, J., 2005, A comparison of American oystercatcher reproductive success on barrier beach and river island habitats in coastal North Carolina: Waterbirds, v. 28, no. 2, p. 150-155, accessed August 20, 2020, at https://doi.org/10.1675/15244695(2005)028[0150:ACOAOR]2.0.CO;2. 
McLachlan, A., 1996, Physical factors in benthic ecologyEffects of changing sand particle size on beach fauna: Marine Ecology Progress Series, v. 131, nos. 1-3, p. 205217, accessed August 11, 2020, at https://doi.org/10.3354/ meps 131205 .

McLachlan, A., and Defeo, O., 2017, The ecology of sandy shores (3d ed.): San Diego, Calif., Academic Press, 572 p. [Also available at https://doi.org/10.1016/c2015-0-047736.]

Melvin, S.L., and Webb, J.W., 1998, Differences in the avian communities of natural and created Spartina alterniflora salt marshes: Wetlands, v. 18, no. 1, p. 59-69, accessed September 1, 2020, at https://doi.org/10.1007/BF03161443.

Mendelssohn, I.A., and Kuhn, N.L., 2003, Sediment subsidy - Effects on soil-plant responses in a rapidly submerging coastal salt marsh: Ecological Engineering, v. 21, nos. 2-3, p. 115-128, accessed August 31, 2020, at https://doi. org/10.1016/j.ecoleng.2003.09.006.

Mendelssohn, I.A., and McKee, K.L., 1988, Spartina alterniflora die-back in Louisiana-Time-course investigation of soil waterlogging effects: Journal of Ecology, v. 76, no. 2, p. 509-521, accessed August 7, 2020, at https://doi. org/10.2307/2260609.

Meselhe, E.A., Sadid, K.M., and Allison, M.A., 2016, Riverside morphological response to pulsed sediment diversions: Geomorphology, v. 270, p. 184-202, accessed August 11, 2020, at https://doi.org/10.1016/j.geomorph.2016.07.023.

Michalsen, D.R., Haller, M.C., and Suh, K.D., 2008, Wave reflection from nearshore depressions: Journal of Waterway, Port, Coastal, and Ocean Engineering, v. 134, no. 1, p. 1-11, accessed June 23, 2020, at https://doi.org/10.1061/ (ASCE)0733-950X(2008)134:1(1).

Michaud, K.M., Emery, K.A., Dugan, J.E., Hubbard, D.M., and Miller, R.J., 2019, Wrack resource use by intertidal consumers on sandy beaches: Estuarine, Coastal and Shelf Science, v. 221, p. 66-71, accessed March 23, 2021, at https://doi.org/10.1016/j.ecss.2019.03.014.

Michel, J., Bejarano, A.C., Peterson, C.H., and Voss, C., 2013, Review of biological and biophysical impacts from dredging and handling of offshore sand: Bureau of Ocean Energy Management, Gulf of Mexico OCS region report BOEM 2013-0119, prepared by Research Planning, Inc., Columbia, S.C., under contract M11PD00219, 260 p. [Also available at https://www.researchgate.net/publication/255686914_Review_of_Biological_and_Biophysical_Impacts_from_Dredging_and_Handling_of_Offshore Sand\#fullTextFile $\bar{C}$ ontent.]
Mickey, R.C., Godsey, E., Dalyander, P.S., Gonzalez, V., Jenkins, R.L., III, Long, J.W., Thompson, D.M., and Plant, N.G., 2020, Application of decadal modeling approach to forecast barrier island evolution, Dauphin Island, Alabama: U.S. Geological Survey Open-File Report 2020-1001, 54 p., accessed September 1, 2020, at https://doi.org/10.3133/ ofr20201001.

Miller, J.D., Limpus, C.J., and Godfrey, M.H., 2003, Nest site selection, oviposition, eggs, development, hatching, and emergence of loggerhead turtles, in Mosier, A., Foley, A., and Brost, B., comps., Proceedings of the Twentieth Annual Symposium on Sea Turtle Biology and Conservation, 29 February through 4 March, 2000, Orlando, Florida, USA: Symposium on Sea Turtle Biology and Conservation, 20th, 2000, Orlando, Fla., NOAA Technical Memorandum NMFS-SEFSC-477, p. 125-143.

Miller, D.C., Muir, C.L., and Hauser, O.A., 2002, Detrimental effects of sedimentation on marine benthos-What can be learned from natural processes and rates?: Ecological Engineering, v. 19, no. 3, p. 211-232, accessed on May 14, 2021, at https://doi.org/10.1016/S0925-8574(02)00081-2.

Miller, J.K., and Dean, R.G., 2004, A simple new shoreline change model: Coastal Engineering, v. 51, no. 7, p. 531556, accessed August 7, 2020, at https://doi.org/10.1016/j. coastaleng.2004.05.006.

Miller, M.W., Karazsia, J., Groves, C.E., Griffin, S., Moore, T., Wilber, P., and Gregg, K., 2016, Detecting sedimentation impacts to coral reefs resulting from dredging the Port of Miami, Florida USA: PeerJ, v. 4, no. 11, art. e2711, 19 p., accessed July 13, 2020, at https://doi.org/10.7717/ peerj. 2711.

Milton, S.L., Schulman, A.A., and Lutz, P.L., 1997, The effect of beach nourishment with aragonite versus silicate sand on beach temperature and loggerhead sea turtle nesting success: Journal of Coastal Research, v. 13, no. 3, p. 904-915, accessed June 15, 2020, at https://www.jstor.org/ stable/4298683.

Miselis, J.L., Long, J.W., Dalyander, P.S., Flocks, J.G., Buster, N.A., and Mickey, R.C., 2015, Integrating geophysical and oceanographic data to assess interannual variability in longshore sediment transport in Wang, P., Rosati, J.D., and Cheng, J., eds., Coastal sediments 2015-The proceedings of the Coastal Sediments 2015: Singapore, World Scientific, 14 p., accessed June 23, 2020, at https://doi. org/10.1142/9789814689977_0011.

Montague, C.L., 2008, Recovering the sand deficit from a century of dredging and jetties along Florida's Atlantic coastA reevaluation of beach nourishment as an essential tool for ecological conservation: Journal of Coastal Research, v. 2008, no. 244, p. 899-916, accessed June 23, 2020, at https://doi.org/10.2112/06-0710.1. 
Montaño, J., Coco, G., Antolínez, J.A.A., Beuzen, T., Bryan, K.R., Cagigal, L., Castelle, B., Davidson, M.A., Goldstein, E.B., Ibaceta, R., Idier, D., Ludka, B.C., Masoud-Ansari, S., Méndez, F.J., Murray, A.B., Plant, N.G., Ratliff, K.M., Robinet, A., Rueda, A., Senechal, N., Simmons, J.A., Splinter, K.D., Stephens, S., Townend, I., Vitousek, S., and Vos, K., 2020, Blind testing of shoreline evolution models: Scientific Reports, v. 10, no. 1, art. 2137, 10 p., accessed June 23, 2020, at https://doi.org/10.1038/s41598-020-59018-y.

Moore, B.D., 1982, Beach profile evolution in response to changes in water level and wave height: Newark, Del., University of Delaware, M.S. thesis, 328 p.

Moran, K.L., Bjorndal, K.A., and Bolten, A.B., 1999, Effects of the thermal environment on the temporal pattern of emergence of hatchling loggerhead turtles Caretta caretta: Marine Ecology Progress Series, v. 189, November, p. 251-261, accessed June 15, 2020, at https://doi.org/10.3354/ meps 189251 .

Morris, J.T., Sundareshwar, P.V., Nietch, C.T., Kjerfve, B., and Cahoon, D.R., 2002, Responses of coastal wetlands to rising sea level: Ecology, v. 83, no. 10, p. 2869-2877, accessed August 31, 2020, at https://doi.org/10.1890/00129658(2002)083[2869:ROCWTR]2.0.CO;2.

Moslow, T.F., and Heron, S.D., 1978, Relict inlets; preservation and occurrence in the Holocene stratigraphy of southern core banks, North Carolina: Journal of Sedimentary Research, v. 48, no. 4, p. 1275-1286, accessed July 7 , 2020, at https://doi.org/10.1306/212F765D-2B24-11D78648000102C1865D.

Nahon, A., Bertin, X., Fortunato, A.B., and Oliveira, A., 2012, Process-based 2DH morphodynamic modeling of tidal inlets-A comparison with empirical classifications and theories: Marine Geology, v. 291-294, p. 1-11, accessed July 7, 2020, at https://doi.org/10.1016/j.margeo.2011.10.001.

Nairn, R., Johnson, J.A., Hardin, D., and Michel, J., 2004, A biological and physical monitoring program to evaluate long-term impacts from sand dredging operations in the United States outer Continental Shelf: Journal of Coastal Research, v. 20, no. 1, p. 126-137, accessed June 3, 2020, at https://doi.org/10.2112/1551-5036(2004)20[126:ABAPMP ]2.0.CO;2.

Naqvi, S.M., and Pullen, E.J., 1982, Effects of beach nourishment and borrowing on marine organisms: U.S. Army Corps of Engineers, Coastal Engineering Research Center, Miscellaneous Report 82-14, 45 p., accessed July 7, 2020, at https://apps.dtic.mil/dtic/tr/fulltext/u2/a123951.pdf.
National Marine Fisheries Service [NMFS] and U.S. Fish and Wildlife Service [USFWS], 1991, Recovery plan for U.S. population of Atlantic green turtle Chelonia mydas: Washington, D.C., National Marine Fisheries Service, Southeast Region, and Atlanta, Ga., U.S. Fish and Wildlife Service, prepared by Loggerhead/Green Turtle Recovery Team, 52 p., accessed June 15, 2020, at https://ecos.fws.gov/docs/ recovery_plan/911126c.pdf.

National Marine Fisheries Service [NMFS] and U.S. Fish and Wildlife Service [USFWS], 1992, Recovery plan for leatherback turtles (Dermochelys coriacea) in the U.S. Caribbean, Atlantic and Gulf of Mexico: Washington, D.C., National Marine Fisheries Service, Southeast Region, and Atlanta, Ga., U.S. Fish and Wildlife Service, prepared by the Leatherback/Hawksbill Turtle Recovery Team, 65 p., accessed June 15, 2020, at https://ecos.fws.gov/docs/recovery_plan/920406.pdf.

National Marine Fisheries Service [NMFS] and U.S. Fish and Wildlife Service [USFWS], 2008, Recovery plan for the northwest Atlantic population of the loggerhead sea turtle (Caretta caretta) - Second revision: Silver Spring, Md., National Marine Fisheries Service, and Atlanta, Ga., U.S. Fish and Wildlife Service, 325 p., accessed June 15, 2020, at https://ecos.fws.gov/docs/recovery_plan/090116.pdf.

National Marine Fisheries Service [NMFS] and U.S. Fish and Wildlife Service [USFWS], 2013, Hawksbill sea turtle (Eretmochelys imbricata) 5-year review-Summary and evaluation: Washington D.C., National Marine Fisheries Service, and Atlanta, Ga., U.S. Fish and Wildlife Service, 89 p., accessed June 15, 2020, at https://ecos.fws.gov/docs/ five_year_review/doc4168.pdf.

National Marine Fisheries Service [NMFS] and U.S. Fish and Wildlife Service [USFWS], 2015, Kemp's ridley sea turtle (Lepidochelys kempii) 5-year review-Summary and evaluation: Silver Spring, Md., National Marine Fisheries Service, Office of Protected Resources, and Albuquerque, N. Mex., U.S. Fish and Wildlife Service, 61 p., accessed June 15, 2020, at https://ecos.fws.gov/docs/five_year_review/ doc4585.pdf.

National Marine Fisheries Service and U.S. Fish and Wildlife Service, 2007, Hawksbill sea turtle (Eretmochelys imbricata) 5-year review-Summary and evaluation: Silver Spring, Md., National Marine Fisheries Service, Office of Protected Resources, and Jacksonville, Fla., U.S. Fish and Wildlife Service, Southeast Region, 92 p. [Also available at https://repository.library.noaa.gov/view/noaa/17041.] 
National Marine Fisheries Service, 2018, USACE deepening and maintenance of the Delaware River Federal Navigation Channel: National Marine Fisheries Service, Greater Atlantic Regional Fisheries Office, Endangered Species Act Section 7 Consultation Series, Biological Opinion, GARFO-2018-00242/NER-2018-15005, 391 p., accessed May 12, 2021, at https://doi.org/10.25923/ngb9-p549.

National Marine Fisheries Service, 2020, 2020 South Atlantic regional biological opinion for dredging and material placement activities in the southeast United States (2020 SARBO) - North Carolina/Virginia Border through and including Key West, Florida and the Islands of Puerto Rico and the U.S. Virgin Islands: National Marine Fisheries Service, Endangered Species Act Section 7 Consultation Series, Biological Opinion, SERO-2019-03111, 648 p, accessed September 23, 2020, at https://www.fisheries.noaa.gov/webdam/download/109184041.

National Research Council, 1995, Beach nourishment and protection: Washington, D.C., National Academy Press, 334 p., accessed June 23, 2020, at https://doi.org/10.17226/4984.

Nedelec, S.L., Mills, S.C., Lecchini, D., Nedelec, B., Simpson, S.D., and Radford, A.N., 2016, Repeated exposure to noise increases tolerance in a coral reef fish: Environmental Pollution, v. 216, p. 428-436, accessed August 28, 2020, at https://doi.org/10.1016/j.envpol.2016.05.058.

Nelson, W.G., 1993, Beach restoration in the southeastern US-Environmental effects and biological monitoring: Ocean and Coastal Management, v. 19, no. 2, p. 157-182, accessed August 07, 2020, at https://doi. org/10.1016/0964-5691(93)90004-I.

Newcombe, C.P., and MacDonald, D.D., 1991, Effects of suspended sediments on aquatic ecosystems: North American Journal of Fisheries Management, v. 11, no. 1, p. 72-82, accessed August 18, 2020, at https://doi.org/10.1577/15488675(1991)011<0072:EOSSOA>2.3.CO;2.

Newell, R.C., Seiderer, L.J., and Hitchcock, D.R., 1998, The impact of dredging works in coastal waters-A review of the sensitivity to disturbance and subsequent recovery of biological resources on the sea bed: Oceanography and Marine Biology — an Annual Review, v. 36, p. 127-178, accessed June 30, 2020, at http://www.sussex.ac.uk/geography/researchprojects/coastview/dredging/Impact_of_Dredging_Oc_Bio.Ann_Rev.pdf.

Newell, R.C., Seiderer, L.J., Simpson, N.M., and Robinson, J.E., 2004, Impacts of marine aggregate dredging on benthic macrofauna off the south coast of the United Kingdom: Journal of Coastal Research, v. 20, no. 1, p. 115-125, accessed August 7, 2020, at https://doi.org/10.2112/15515036(2004)20[115:IOMADO]2.0.CO;2.
Nickling, W., and Davidson-Arnott, R., 1990, Aeolian sediment transport on beaches and coastal sand dunes, in Davidson-Arnott, R., ed., Canadian Symposium on Coastal Sand Dunes 1990, Guelph, Ontario, Canada, September 12-14, 1990, proceedings: Guelph, Ontario, Canada, Canadian Coastal Science and Engineering Association, 35 p., accessed August 11, 2020, at https://www.researchgate.net/ publication/274192369_Aeolian_Sediment_Transport_on_ Beaches_and_Coastal_Sand_dunes.

Nienhuis, J.H., and Ashton, A.D., 2016, Mechanics and rates of tidal inlet migration-Modeling and application to natural examples: Journal of Geophysical Research, Earth Surface, v. 121, no. 11, p. 2118-2139, accessed May 12, 2021, at https://doi.org/10.1002/2016JF004035.

Nienhuis, J.H., and Lorenzo-Trueba, J., 2019, Can barrier islands survive sea-level rise? Quantifying the relative role of tidal inlets and overwash deposition: Geophysical Research Letters, v. 46, no. 24, p. 14613-14621, accessed July 7, 2020, at https://doi.org/10.1029/2019GL085524.

Nordstrom, K.F., 2005, Beach nourishment and coastal habitats-Research needs to improve compatibility: Restoration Ecology, v. 13, no. 1, p. 215-222, accessed June 15, 2020, at https://doi.org/10.1111/j.1526-100X.2005.00026.x.

Nordstrom, K.F., and Arens, S.M., 1998, The role of human actions in evolution and management of foredunes in The Netherlands and New Jersey, USA: Journal of Coastal Conservation, v. 4, no. 2, p. 169-180, accessed August 11, 2020, at https://doi.org/10.1007/BF02806509.

Nordstrom, K.F., Jackson, N.L., Rader, A.M., and Garilao, E.S., 2018, Protecting natural landforms and habitats by nourishing an eroding estuarine beach: Environmental Earth Sciences, v. 77, no. 19, art. 680, 14 p., accessed July 15, 2020, at https://doi.org/10.1007/s12665-018-7826-3.

Norkko, A., Thrush, S.F., Hewitt, J.E., Cummings, V.J., Norkko, J., Ellis, J.I., Funnell, G.A., Schultz, D., and Macdonald, I., 2002, Smothering of estuarine sandflats by terrigenous clay-The role of wind-wave disturbance and bioturbation in site-dependent macrofaunal recovery: Marine Ecology Progress Series, v. 234, p. 23-42, accessed June 15, 2020, at https://doi.org/10.3354/meps234023.

Norton, J., Moritz, R., Ott, M., Briner, W., and Roegner, C., 2015, Balancing benefits and impacts when using a nearshore dredged material placement site at the mouth of the Columbia River, in Wang, P., Rosati, J.D., and Cheng, J., eds., Coastal Sediments 2015-The Proceedings of the Coastal Sediments 2015: Singapore, World Scientific, accessed August 7, 2020, at https://doi. org/10.1142/9789814689977_0147. 
O’Connor, J.J., Lecchini, D., Beck, H.J., Cadiou, G., Lecellier, G., Booth, D.J., and Nakamura, Y., 2016, Sediment pollution impacts sensory ability and performance of settling coral-reef fish: Oecologia, v. 180, no. 1, p. 11-21, accessed August 19, 2020, at https://doi.org/10.1007/s00442-0153367-6.

O’Connor, J. M., Neumann, D.A., and Sherk, J.A., 1976, Lethal effects of suspended sediment on estuarine fish, U.S. Army Engineer Coastal Engineering Research Center, Technical paper 76-20, Fort Belvoir, Virginia.

Obelcz, J., Xu, K., Bentley, S.J., O’Connor, M., and Miner, M.D., 2018, Mud-capped dredge pits-An experiment of opportunity for characterizing cohesive sediment transport and slope stability in the northern Gulf of Mexico: Estuarine, Coastal and Shelf Science, v. 208, p. 161-169, accessed June 23, 2020, at https://doi.org/10.1016/j. ecss.2018.04.039.

Oertel, G.F., 1985, The barrier island system: Marine Geology, v. 63, nos. 1-4, p. 1-18, accessed August 31, 2020, at https://doi.org/10.1016/0025-3227(85)90077-5.

Ohata, R., Masuda, R., Takahashi, K., and Yamashita, Y., 2014, Moderate turbidity enhances schooling behaviour in fish larvae in coastal waters: ICES Journal of Marine Science, v. 71, no. 4, p. 925-929, accessed August 19, 2020, at https://doi.org/10.1093/icesjms/fss194.

Ojeda, E., and Guillen, J., 2006, Monitoring beach nourishment based on detailed observations with video measurements: Journal of Coastal Research, Special issue no. 48, p. 100-106, accessed September 1, 2020, at https://www.jstor. org/stable/25737388.

Ojeda, E., Ruessink, B.G., and Guillen, J., 2008, Morphodynamic response of a two-barred beach to a shoreface nourishment: Coastal Engineering, v. 55, no. 12, p. 1185-1196, accessed July 6, 2020, at https://doi.org/10.1016/j.coastaleng.2008.05.006.

Oliver, J.S., Slattery, P.N., Hulberg, L.W., and Nybakken, J.W., 1977, Patterns of succession in benthic infaunal communities following dredging and dredged material disposal in Monterey Bay_Final report: U.S. Army Engineer Waterways Experiment Station, Dredged Material Research Program, prepared by the Moss Landing Marine Laboratories, Moss Landing, Calif., under contract no. DACW39-74-COI51 with the Environmental Effects Laboratory, U.S. Army Engineer Waterways Experiment Station, Technical report D-77-27, 186 p., accessed July 13, 2020, at http://aquaticcommons.org/2612/.

Onuf, C.P., 1994, Seagrasses, dredging and light in Laguna Madre, Texas, U.S.A: Estuarine, Coastal and Shelf Science, v. 39, no. 1, p. 75-91, accessed July 27, 2020, at https://doi. org/10.1006/ecss.1994.1050.
Ortiz, A.C., and Ashton, A.D., 2016, Exploring shoreface dynamics and a mechanistic explanation for a morphodynamic depth of closure: Journal of Geophysical Research, Earth Surface, v. 121, no. 2, p. 442-464, accessed October 7, 2020, at https://doi.org/10.1002/2015JF003699.

Orton, P.M., Talke, S.A., Jay, D.A., Yin, L., Blumberg, A.F., Georgas, N., Zhao, H., Roberts, H.J., and MacManus, K., 2015, Channel shallowing as mitigation of coastal flooding: Journal of Marine Science and Engineering, v. 3, no. 3, p. 654-673, accessed August 11, 2020, at https://doi. org/10.3390/jmse3030654.

Otvos, E.G., 1981, Barrier Island formation through nearshore aggradation-Stratigraphic and field evidence: Marine Geology, v. 43, nos. 3-4, p. 195-243, accessed July 7, 2020, at https://doi.org/10.1016/0025-3227(81)90181-X.

Otvos, E.G., 1985, Coastal evolution-Louisiana to northwest Florida-Guidebook, American Association of Petroleum Geologists, annual meeting, New Orleans, field trip March 27-29, 1985: New Orleans, La., New Orleans Geological Society, $91 \mathrm{p}$.

Otvos, E.G., 2018, Coastal barriers, northern Gulf-Last eustatic cycle; genetic categories and development contrasts - A review: Quaternary Science Reviews, v. 193, p. 212-243, accessed May 1, 2020, at https://doi. org/10.1016/j.quascirev.2018.04.001.

Pagan, C.L., Lopez, J.I., Tenza-Abril, I., Aragones, A.J., and Sanchez, L., 2018, The effects of sediment used in beach nourishment - Study case El Portet de Moraira beach: Science of the Total Environment, v. 628-629, p. 64-73, accessed May 14, 2020, at https://doi.org/10.1016/j.scitotenv.2018.02.042.

Palmer, T.A., Montagna, P.A., and Nairn, R.B., 2008, The effects of a dredge excavation pit on benthic macrofauna in offshore Louisiana: Environmental Management, v. 41, no. 4, p. 573-583, accessed July 7, 2020, at https://doi. org/10.1007/s00267-007-9063-5.

Parkinson, R.W., and Ogurcak, D.E., 2018, Beach nourishment is not a sustainable strategy to mitigate climate change: Estuarine, Coastal and Shelf Science, v. 212, p. 203-209, accessed August 27, 2020, at https://doi.org/10.1016/j. ecss.2018.07.011.

Parr, T., Diener, D., and Lacy, S., 1978, Effects of beach replenishment on the nearshore sand fauna at Imperial Beach, California: U.S. Army Corps of Engineers, Coastal Engineering Research Center, Miscellaneous report 78-4, prepared by WESTEC Services, Inc., Environmental Consultants, San Diego, Calif., under contract no. DACW7276-C-0007, 125 p., accessed July 13, 2020, at https://apps. dtic.mil/dtic/tr/fulltext/u2/a067308.pdf. 
Parson, L.E., and Swafford, R., 2012, Beneficial use of sediments from dredging activities in the Gulf of Mexico: Journal of Coastal Research, Special issue no. 60, p. 45-50, accessed August 11, 2020, at https://doi.org/10.2112/ SI_60_5.

Passeri, D.L., Hagen, S.C., Medeiros, S.C., Bilskie, M.V., Alizad, K., and Wang, D., 2015, The dynamic effects of sea level rise on low-gradient coastal landscapes-A review: Earth's Future, v. 3, no. 6, p. 159-181, accessed September 1, 2020, at https://doi.org/10.1002/2015EF000298.

Passeri, D.L., Long, J.W., Jenkins, R.L., III, and Thompson, D.M., 2018, Effects of proposed navigation channel improvements on sediment transport in Mobile Harbor, Alabama: U.S. Geological Survey Open-File Report 2018-1123, 22 p., accessed September 1, 2020, at https:// doi.org/10.3133/ofr20181123.

Patterson, M.E., Fraser, J.D., and Roggenbuck, J.W., 1991, Factors affecting piping plover productivity on Assateague Island: Journal of Wildlife Management, v. 55, no. 3, p. 525-531, accessed June 15, 2020, at https://doi. org/10.2307/3808985.

Pearse, A.S., Humm, H.J., and Wharton, G.W., 1942, Ecology of sand beaches at Beaufort, N.C.: Ecological Monographs, v. 12 , no. 2, p. $135-190$, accessed July 21 , 2020, at https:// doi.org/10.2307/1943276.

Pearson, T.H., and Rosenberg, R., 1978, Macrobenthic succession in relation to organic enrichment and pollution of the marine environment: Oceanography and Marine Biology-An Annual Review, v. 16, p. 229-311, accessed July 7, 2020, at https://www.researchgate.net/ publication/243785865_Pearson_TH_Rosenberg_R_Macrobenthic_succession_in_relation_to_organic_enrichment_and_pollution_of the marine_environment_Oceanogr_Mar_Biol_Ann_Rev_16_229-311.

Pelnard-Considère, R., 1956, Model tests confirm the theory of the changing shapes of sand and stone beaches, in Question III, Energie mécanique de la houle-Essais sur modèles of Énergie mécanique de la houle-Essais sur modèles: Les énergies de la mer, Quatriemes journees de l'hydraulique, v. 13-15, tome 1, p. 289-298. [Also available at https://www. persee.fr/doc/jhydr_0000-0001_1957_act_4_1_3370.]

Penland, S., Suter, J.R., and Boyd, R., 1985, Barrier island arcs along abandoned Mississippi River deltas: Marine Geology, v. 63, nos. 1-4, p. 197-233, accessed July 07, 2020, at https://doi.org/10.1016/0025-3227(85)90084-2.

Penn, D., and Brockmann, H.J., 1994, Nest-site selection in the horseshoe crab, Limulus polyphemus: Biological Bulletin, v. 187, no. 3, p. 373-384, accessed July 15, 2020, at https://doi.org/10.2307/1542294.
Perry, M., and Uhler, F., 1988, Food habits and distribution of wintering canvasbacks, Aythya valisineria, on Chesapeake Bay: Estuaries, v. 11, no. 1, p. 57-67, accessed July 2, 2020, at https://www.researchgate.net/publication/225477852_ Food_Habits_and_Distribution_of_Wintering_Canvasbacks_Aythya_valisineria_on_Chesapeake_Bay.

Perry, M.C., Wells-Berlin, A.M, Kidwell, D.M., and Osenton, P.C., 2007, Temporal changes of populations and trophic relationships of wintering diving ducks in Chesapeake Bay: Waterbirds, v. 30, Special issue no. 1, p. 4-16, accessed July 2, 2020, at https://doi.org/10.1675/15244695(2007)030[0004:TCOPAT]2.0.CO;2.

Peterson, C.H., and Bishop, M.J., 2005, Assessing the environmental impacts of beach nourishment: Bioscience, v. 55, no. 10 , p. 887-896, accessed June 15, 2020, at https://doi. org/10.1641/0006-3568(2005)055[0887:ATEIOB]2.0.CO;2.

Peterson, C.H., and Manning, L., 2001, How beach nourishment affects the habitat value of intertidal beach prey for surf fish and shorebirds and why uncertainty still exists, in Proceedings of the Coastal Ecosystems and Federal Activities Technical Training Symposium, August 20-22, 2001, Gulf Shores, Alabama: U.S. Fish and Wildlife Service, Fifth Coastal Ecosystems and Federal Activities Technical Training Symposium, 2 p., accessed July 13, 2020, at http://www. vliz.be/imisdocs/publications/54890.pdf.

Peterson, C.H., Bishop, M.J., D’Anna, L.M., and Johnson, G.A., 2014, Multi-year persistence of beach habitat degradation from nourishment using coarse shelly sediments: Science of the Total Environment, v. 487, p. 481-492, accessed July 27, 2020, at https://doi.org/10.1016/j.scitotenv.2014.04.046.

Peterson, C.H., Bishop, M.J., Johnson, G.A., D’Anna, L.M., and Manning, L.M., 2006, Exploiting beach filling as an unaffordable experiment-Benthic intertidal impacts propagating upwards to shorebirds: Journal of Experimental Marine Biology and Ecology, v. 338, no. 2, p. 205-221, accessed May 12, 2021, at https://doi.org/10.1016/j. jembe.2006.06.021.

Peterson, C.H., Hickerson, D.H.M., and Johnson, G.G., 2000a, Short-term consequences of nourishment and bulldozing on the dominant large invertebrates of a sandy beach: Journal of Coastal Research, v. 16, no. 2, p. 368-378, accessed July 27, 2020, at https://www.jstor.org/stable/4300045.

Peterson, C.H., Summerson, H.C., Thomson, E., Lenihan, H.S., Grabowski, J., Manning, L., Micheli, F., and Johnson, G., 2000b, Synthesis of linkages between benthic and fish communities as a key to protecting essential fish habitat: Bulletin of Marine Science, v. 66, no. 3, p. 759-774, accessed July 27, 2020, at https://www.ingentaconnect. com/content/umrsmas/bullmar/2000/00000066/00000003/ $\operatorname{art00019.~}$ 
Pickens, B.A., and Taylor, J.C., eds., 2020, Regional essential fish habitat geospatial assessment and framework for offshore sand features: [U.S.] Bureau of Ocean Energy Management, Environmental Studies Program, prepared with the National Oceanic and Atmospheric Administration, National Centers for Coastal Ocean Science under interagency agreement BOEM NOAA IA M17PG00028; v. 1-3 also prepared under NOAA/NCCOS contract GS-00F-217CA by CSS, Inc., Fairfax, Va., and v. 4 also prepared under NOAA contract EA133C16CQ0044 by Quantum Spatial, Inc., St. Petersburg, Fla.; as OCS Study BOEM 2020-002 and NOAA NCCOS Technical Memorandum 270, [variously paged as 4 v., 362 p.], accessed September 23, 2020, at https://doi.org/10.25923/akzd-8556.

Pilkey, O.H., and Cooper, J.A.G., 2014, The last beach: Durham, N.C., Duke University Press, 256 p. [Also available at https://doi.org/10.1515/9780822375944.]

Pilkey, O.H., 1990, Editorial-A time to look back at beach replenishment: Journal of Coastal Research, v. 6, no. 1, p. iii-vii, accessed May 12, 2021, at https://www.jstor.org/ stable/4297638

Pilkey, O.H., Young, R.S., Riggs, S.R., Smith, A.W.S., Wu, H., and Pilkey, W.D., 1993, The concept of shoreface profile of equilibrium-A critical review: Journal of Coastal Research, v. 9, no. 1, p. 255-278, accessed July 2, 2020, at https://www.jstor.org/stable/4298082.

Pine, M.K., Jeffs, A.G., Wang, D., and Radford, C.A., 2016, The potential for vessel noise to mask biologically important sounds within ecologically significant embayments: Ocean \& Coastal Management, v. 127, p. 63-73, accessed August 19, 2020, at https://doi.org/10.1016/j.ocecoaman.2016.04.007.

Piniak, W.E.D., Eckert, S.A., Harms, C.A., and Stringer, E.M., 2012, Underwater hearing sensitivity of the leatherback sea turtle (Dermochelys coriascea)_-Assessing the potential effect of anthropogenic noise: Herndon, Va., Bureau of Ocean Energy Management, OCS Study BOEM 201201156, Prepared under BOEM Contract M10PX00330 by Wider Caribbean Sea Turtle Conservation Network, accessed May 14, 2021, at https://www.researchgate.net/ publication/280559013_Underwater_hearing_sensitivity_of_the_leatherback_sea_turtle_Dermochelys_coriacea Assessing_the_potential_effect_of_anthropogenic_noise.

Plant, N.G., Flocks, J., Stockdon, H.F., Long, J.W., Guy, K., Thompson, D.M., Cormier, J.M., Smith, C.G., Miselis, J.L., and Dalyander, P.S., 2014, Predictions of barrier island berm evolution in a time-varying storm climatology: Journal of Geophysical Research, Earth Surface, v. 119, no. 2, p. 300-316, accessed September 16, 2020, at https://doi. org/10.1002/2013JF002871.
Plant, N.G., Holland, K.T., and Holman, R.A, 2006, A dynamical attractor governs beach response to storms: Geophysical Research Letters, v. 33, no. 17, L17607, p. 1-6, accessed October 7, 2020 at https://doi.org/10.1029/2006GL027105.

Plauny, H.L., 2000, Shorebirds: Natural Resources Conservation Service Fish and Wildlife Habitat Management Leaflet no. 17, 11 p., accessed June 15, 2020, at https:// directives.sc.egov.usda.gov/OpenNonWebContent. aspx? content $=18480$. wba.

Poppema, D.W., 2020, The effect of buildings on the morphological development of the beach-dune system-Literature report: Amsterdam, The Netherlands, University of Twente Civil Engineering \& Management Research Report 2020R001/WEM-001, 40 p., accessed June 23, 2020, at https:// ris.utwente.nl/ws/portalfiles/portal/168667961/2020R_001_ WEM_001_Daan_Poppema.pdf.

Popper, A.N., and Hawkins, A.D., 2019, An overview of fish bioacoustics and the impacts of anthropogenic sounds on fishes: Journal of Fish Biology, v. 94, no. 5, p. 692-713, accessed August 19, 2020, at https://doi.org/10.1111/ jfb. 13948 .

Popper, A.N., Fay, R.R., Platt, C., and Sand, O., 2003, Sound detection mechanisms and capabilities of teleost fishes, in Collin, S.P. and Marshall, N.J., eds., Sensory processing in aquatic environments: New York, Springer, p. 3-38, accessed August 19, 2020, at https://doi.org/10.1007/978-0387-22628-6_1.

Popper, A.N., Smith, M.E., Cott, P.A., Hanna, B.W., MacGillivray, A.O., Austin, M.E., and Mann, D.A., 2005, Effects of exposure to seismic airgun use on hearing of three fish species: Journal of the Acoustical Society of America, v. 117, no. 6, p. 3958-3971, accessed August 19, 2020, at https:// doi.org/10.1121/1.1904386.

PortMiami, Coastal Systems International, and Florida Department of Environmental Protection, 2017, Miami Harbor phase III Federal channel expansion project, permit no. 0305721-001-BI-Impact assessment for hardbottom middle and outer reef benthic communities at cross sitesFinal: [Florida Department of Environmental Protection], prepared by Dial Cordy and Associates Inc., Miami, Fla., 154 p., accessed October 19, 2020, at https://usace.contentdm.oclc.org/digital/collection/p16021 coll7/id/5854/.

Precht, E., and Huettel, M., 2003, Advective pore-water exchange driven by surface gravity waves and its ecological implications: Limnology and Oceanography, v. 48, no. 4, p. 1674-1684, accessed May 12, 2021, at https://doi. org/10.4319/1o.2003.48.4.1674. 
Propato, M., Clough, J.S., and Polaczyk, A., 2018, Evaluating the costs and benefits of marsh-management strategies while accounting for uncertain sea-level rise and ecosystem response: PLoS One, v. 13, no. 8, art. e0200368, 21 p., accessed May 29, 2020, at https://doi.org/10.1371/journal. pone. 0200368 .

Provancha, J.A., and Ehrhart, L.M., 1987, Sea turtle nesting trends at Kennedy Space Center and Cape Canaveral Air Force Station, Florida, and relationships with factors influencing nest site selection, in Witzell, W.N., ed., Ecology of east Florida sea turtles-Proceedings of the Cape Canaveral, Florida Sea Turtle Workshop, Miami, Florida, February 26-27, 1985: National Oceanic and Atmospheric Administration Technical Report NMFS 53, p. 33-44, accessed August 5, 2020, at https://ntrl.ntis.gov/NTRL/dashboard/ searchResults/titleDetail/PB87226445.xhtml.

Psuty, N.P., and Silveira, T.M., 2013, Restoration of coastal foredunes, a geomorphological perspective-Examples from New York and from New Jersey, USA, chap. 3 of Martínez, M.L., Gallego-Fernández, J.B., and Hesp, P.A., eds., Restoration of coastal dunes: Berlin, Germany, SpringerVerlag, p. 33-47, accessed October 19, 2020, at https://doi. org/10.1007/978-3-642-33445-0_3.

Pye, K., 1983, Coastal dunes: Progress in Physical Geography, Earth and Environment, v. 7, no. 4, p. 531-557. [Also available at https://doi.org/10.1177/030913338300700403.]

Race, M.S., and Christie, D.R., 1982, Coastal zone development-Mitigation, marsh creation, and decisionmaking: Environmental Management, v. 6, no. 4, p. 317-328, accessed June 1, 2020, at https://doi.org/10.1007/ BF01875063.

Raff, J.L., Shawler, J.L., Ciarletta, D.J., Hein, E.A., LorenzoTrueba, J., and Hein, C.J., 2018, Insights into barrier-island stability derived from transgressive/regressive state changes of Parramore Island, Virginia: Marine Geology, v. 403, p. 1-19, accessed March 23, 2021, at https://doi.org/10.1016/j. margeo.2018.04.007.

Rakocinski, C.F., Heard, R.W., LeCroy, S.E., McLelland, J.A., and Simons, T., 1996, Responses by macrobenthic assemblages to extensive beach restoration at Perdido Key, Florida, U.S.A: Journal of Coastal Research, v. 12, no. 1, p. 326-353, accessed August 11, 2020, at https://www.jstor. org/stable/4298484.

Ralston, D.K., Talke, S., Geyer, W.R., Al-Zubaidi, H.A.M., and Sommerfield, C.K., 2019, Bigger tides, less flooding-Effects of dredging on barotropic dynamics in a highly modified estuary: Journal of Geophysical Research, Oceans, v. 124, no. 1, p. 196-211, accessed August 11, 2020, at https://doi.org/10.1029/2018JC014313.
Rampino, M.R., and Sanders, J.E., 1981, Evolution of the barrier islands of southern Long Island, New York: Sedimentology, v. 28, no. 1, p. 37-47, accessed March 23, 2021, at https://doi.org/10.1111/j.1365-3091.1981.tb01661.x.

Randall, R., Edge, B., Basilotto, J., Cobb, D., Graalum, S., He, Q., and Miertschin, M., 2000, Texas Gulf Intracoastal Waterway (GIWW) dredged material—Beneficial uses, estimating costs, disposal analysis alternatives, and separation techniques: Texas Transportation Institute, Texas A\&M University System Research Project Report 1733-S, 306 p., accessed August 11, 2020, at https://rosap.ntl.bts.gov/view/ $\operatorname{dot} / 42294$.

Ray, G.L., 2000, Infaunal assemblages on constructed intertidal mudflats at Jonesport, Maine (USA): Marine Pollution Bulletin, v. 40, no. 12, p. 1186-1200, accessed June 1, 2020, at https://doi.org/10.1016/S0025-326X(00)00083-7.

Ray, G.L., and Clarke, D.G., 2010, Issues related to entrainment of horseshoe crabs (Limulus polyphemus by hopper dredges, in Randall, R.E., ed., 30th Western Dredging Association Technical Conference, held with the 41st Texas A\&M Dredging Seminar, San Juan, Puerto Rico, 6-9 June 2010, proceedings: Red Hook, N.Y., Curran Associates, p. 82-94, accessed July 15, 2020, at https:// www.westerndredging.org/phocadownload/ConferencePresentations/2010_SanJuanPR/Session2A-EnvironmentalAspectsOfDredging/3\%20-\%20Ray\%20-\%20Issues $\% 20$ Related $\% 20$ to $\% 20$ Entrainment $\% 20$ of $\% 20$ Horseshoe $\% 20$ Crabs\%20by\%20Hopper\%20Dredges.pdf.

Raymond, P.W., 1984, The effects of beach restoration on marine turtles' nesting in south Brevard County, Florida: Orlando, Fla., University of Central Florida, Master's thesis, 121 p., accessed August 5, 2020, at https://stars.library.ucf. edu/rtd/4718/.

Redfield, A.C., 1972, Development of a New England salt marsh: Ecological Monographs, v. 42, no. 2, p. 201-237, accessed August 11, 2020, at https://doi. org/10.2307/1942263.

Reed, D.J., 1990, The impact of sea-level rise on coastal salt marshes: Progress in Physical Geography, v. 14, no. 4, p. 465-481, accessed September 1, 2020, at https://doi. org/10.1177/030913339001400403.

Reilly, F.J., Jr., and Bellis, V.J., 1983, The ecological impact of beach nourishment with dredged materials on the intertidal zone at Bogue Banks, North Carolina: U.S. Army Corps of Engineers, Coastal Engineering Research Center, prepared by East Carolina University, Greenville, N.C., Miscellaneous report no. 83-3, 74 p., accessed July 27, 2020, at https://erdc-library.erdc.dren.mil/jspui/handle/11681/5164. 
Reine, K., and Clarke, D., 1998, Entrainment by hydraulic dredges - A review of potential impacts: U.S. Army Engineer Waterways Experiment Station, Environmental Laboratory, Technical Note DOER-E1, 14 p, accessed August 18, 2020, at https://apps.dtic.mil/dtic/tr/fulltext/u2/a358595.pdf.

Reine, K.J., Clarke, D., Dickerson, C., and Wikel, G., 2014, Characterization of underwater sounds produced by trailing suction hopper dredges during sand mining and pump-out operations -Final report: U.S. Army Engineer Research and Development Center, Environmental Laboratory Report ERDC/EL TR-14-3, accessed August 28, 2020, at https:// apps.dtic.mil/sti/citations/ADA597877.

Rhoads, D.C., McCall, P.L., and Yingst, J.Y., 1978, Disturbance and production on the estuarine seafloor-Dredgespoil disposal in estuaries such as Long Island Sound can be managed in ways that enhance productivity rather than diminish it: American Scientist, v. 66, no. 5, p. 577-586, accessed June 30, 2020, at https://www.jstor.org/stable/27848852.

Riedl, R.J., Huang, N., and Machan, R., 1972, The subtidal pump-A mechanism of interstitial water exchange by wave action: Marine Biology, v. 13, no. 3, p. 210-221, accessed August 11, 2020, at https://doi.org/10.1007/BF00391379.

Rimerez, A., 2020, Volume 4-Development of ShoalMATE-Shoal map assessment tool for essential fish habitat, in Pickens, B.A., Taylor J.C., eds., Regional essential fish habitat geospatial assessment and framework for offshore sand features: [U.S.] Bureau of Ocean Energy Management; v. 4 prepared as part of Interagency Agreement M17PG00028 under NOAA contract EA133C16CQ0044 by Quantum Spatial, Inc., St. Petersburg, Fla.; OCS Study BOEM 2020-002 and NOAA NCCOS Technical Memorandum 270, 82 p., accessed August 18, 2020, at https://doi. org/10.25923/akzd-8556.

Rivas, M.L., Santidrián Tomillo, P., Diéguez-Uribeondo, J., and Marco, A., 2016, Potential effects of dune scarps caused by beach erosion on the nesting behavior of leatherback turtles: Marine Ecology Progress Series, v. 551, p. 239248, accessed August 5, 2020, at https://doi.org/10.3354/ meps 11748 .

Roberts, T.M., and Wang, P., 2012, Four-year performance and associated controlling factors of several beach nourishment projects along three adjacent barrier islands, westcentral Florida, USA: Coastal Engineering, v. 70, p. 21-39, accessed August 7, 2020, at https://doi.org/10.1016/j. coastaleng.2012.06.003.
Robertson, M.J., Scruton, D.A., Gregory, R.S, and Clarke, K.D., 2006, Effect of suspended sediment on freshwater fish and fish habitat: St. John's, Newfoundland, Canada, Fisheries and Oceans Canada, Canadian Technical Report of Fisheries and Aquatic Sciences no. 2644, 37 p., accessed on May 14, 2021, at https://www.researchgate.net/publication/271838879_Effect_of_suspended_sediment_on_freshwater_fish_and_fish_habitat.

Robinson, S.P., Theobald, P.D., Lepper, P.A., Hayman, G., Humphrey, V.F., Wang, L.-S., and Mumford, S., 2011, Measurement of underwater noise arising from marine aggregate operations, in Popper, A.N. and Hawkins, A., eds., The effects of noise on aquatic life: New York, Springer, p. 465-468, accessed August 19, 2020, at https://doi. org/10.1007/978-1-4419-7311-5_105.

Rodriguez, A.B., Fegley, S.R., Ridge, J.T., VanDusen, B.M., and Anderson, N., 2013, Contribution of aeolian sand to backbarrier marsh sedimentation: Estuarine, Coastal and Shelf Science, v. 117, p. 248-259, accessed August 11, 2020, at https://doi.org/10.1016/j.ecss.2012.12.001.

Rodriguez, A.B., and Meyer, C.T., 2006, Sea-level variation during the Holocene deduced from the morphologic and stratigraphic evolution of Morgan Peninsula, Alabama, U.S.A.: Journal of Sedimentary Research, v. 76, no. 2, p. 257-269, accessed September 21, 2020, at https://doi. org/10.2110/jsr.2006.018.

Roelvink, D., Reniers, A., van Dongeren, A., van Thiel de Vries, J., McCall, R., and Lescinski, J., 2009, Modelling storm impacts on beaches, dunes and barrier islands: Coastal Engineering, v. 56, nos. 11-12, p. 1133-1152, accessed August 7, 2020, at https://doi.org/10.1016/j.coastaleng.2009.08.006.

Rogers, B.E., Kulp, M.A., and Miner, M.D., 2009, Late Holocene chronology, origin, and evolution of the St. Bernard Shoals, Northern Gulf of Mexico, USA: Geo-Marine Letters, v. 29, no. 6, p. 379-394, accessed June 23, 2020, at https://doi.org/10.1007/s00367-009-0162-6.

Rogers, C.S., 1990, Responses of coral reefs and reef organisms to sedimentation: Marine Ecology Progress Series, v. 62, p. 185-202, accessed July 13, 2020, at https://doi. org/10.3354/meps062185.

Rogers, L.J., Moore, L.J., Goldstein, E.B., Hein, C.J., Lorenzo-Trueba, J., and Ashton, A.D., 2015, Anthropogenic controls on overwash deposition-Evidence and consequences: Journal of Geophysical Research, Earth Surface, v. 120 , no. 12, p. 2609-2624, accessed August 11, 2020, at https://doi.org/10.1002/2015JF003634. 
Rogers, S., 2006, Beach nourishment for hurricane protection-North Carolina project performance in Hurricanes Dennis and Floyd: Shore \& Beach, v. 75, no. 1, p. 37-42. [Also available at https:/www.researchgate.net/ publication/228406579_\%27Beach_nourishment_for_hurricane_protection_North_Carolina_project_performance_in Hurricanes_Dennis_and_Floyd.]

Roman-Sierra, J., Navarro, M., Muñoz-Perez, J.J., and Gomez-Pina, G., 2011, Turbidity and other effects resulting from Trafalgar sandbank dredging and Palmar beach nourishment: Journal of Waterway, Port, Coastal, and Ocean Engineering, v. 137, no. 6, p. 332-343, accessed August 11, 2020, at https://doi.org/10.1061/(ASCE)WW.19435460.0000098 .

Rosati, J.D., Stone, G.W., Dean, R.G., and Kraus, N.C., 2006, Restoration of barrier islands overlying poorly-consolidated sediments, south-central Louisiana: Gulf Coast Association of Geological Societies Transactions, v. 56, p. 727-740, accessed August 7, 2020, at https://www.researchgate. net/profile/Julie-Rosati/publication/251706631_Restoration_of_Barrier_Islands_Overlying_PoorlyConsolidated_Sediments_South-Central_Louisiana/ links/00b7d529f3b0ac2131000000/Restoration-of-BarrierIslands-Overlying-Poorly-Consolidated-Sediments-SouthCentral-Louisiana.pdf.

Rosov, B., Bush, S., Briggs, T.R., and Elko, N., 2016, The state of understanding the impacts of beach nourishment activities on infaunal communities - ASBPA white paper: Shore \& Beach, v. 84, no. 3, p. 51-55, accessed July 13, 2020, at http://asbpa.org/wpv2/wp-content/uploads/2016/03/ White_Paper_Infaunal_Communities_Summer2016_84_3. pdf.

Roy, M., Martin, J.B., Cherrier, J., Cable, J.E., and Smith, C.G., 2010, Influence of sea level rise on iron diagenesis in an east Florida subterranean estuary: Geochimica et Cosmochimica Acta, v. 74, no. 19, p. 5560-5573, accessed October 19, 2020, at https://doi.org/10.1016/j.gca.2010.07.007.

Roy, M., Martin, J.B., Smith, C.G., and Cable, J.E., 2011, Reactive-transport modeling of iron diagenesis and associated organic carbon remineralization in a Florida (USA) subterranean estuary: Earth and Planetary Science Letters, v. 304, nos. 1-2, p. 191-201, accessed October 19, 2020, at https://doi.org/10.1016/j.epsl.2011.02.002.

Rudloe, A., 1980, The breeding behavior and patterns of movement of horseshoe crabs, Limulus polyphemus, in the vicinity of breeding beaches in Apalachee Bay, Florida: Estuaries, v. 3, no. 3, p. 177-183, accessed July 15, 2020, at https://doi.org/10.2307/1352067.
Ruessink, B.G., Kuriyama, Y., Reniers, A. J. H. M., Roelvink, J. A., and Walstra, D. J. R., 2007, Modeling cross-shore sandbar behavior on the timescale of weeks: Journal of Geophysical Research, v. 112, no. F3, F03010, 15 p., accessed October 7, 2020, at https://doi.org/10.1029/2006JF000730.

Rumbold, D.G., Davis, P.W., and Perretta, C., 2001, Estimating the effect of beach nourishment on Caretta caretta (loggerhead sea turtle) nesting: Restoration Ecology, v. 9, no. 3, p. 304-310, accessed June 15, 2020, at https://doi. org/10.1046/j.1526-100x.2001.009003304.x.

Rusch, A., Huettel, M., and Forster, S., 2000, Particulate organic matter in permeable marine sands-Dynamics in time and depth: Estuarine, Coastal and Shelf Science, v. 51, no. 4, p. 399-414, accessed October 19, 2020, at https://doi. org/10.1006/ecss.2000.0687.

Rusch, A., Huettel, M., Wild, C., and Reimers, C.E., 2006, Benthic oxygen consumption and organic matter turnover in organic-poor, permeable shelf sands: Aquatic Geochemistry, v. 12, no. 1, p. 1-19, accessed June 29, 2020, at https://doi. org/10.1007/s10498-005-0784-X.

Rutecki, D., Dellapenna, T., Nestler, E., Scharf, F., Rooker, J., Glass, C., and Pembroke, A., 2014, Understanding the habitat value and function of shoals and shoal complexes to fish and fisheries on the Atlantic and Gulf of Mexico outer Continental Shelf-Literature synthesis and gap analysis: [U.S.] Bureau of Ocean Energy Management, prepared by Normandeau Associates, Inc., Bedford, N.H., under contract M12PS00009, BOEM 2015-012, 176 p., accessed July 15, 2020, at http://safmc.net/wp-content/uploads/2016/06/ Attach9_BOEMBarReport.pdf.

Sabol, B.M., and Shafer, D.J., 2005, Dredging effects on seagrasses-Case studies from New England and Florida, in Proceedings of the Western Dredging Association Twenty-fifth Technical Conference and Thirty-seventh Annual Texas A\& M Dredging Seminar-June 19-22, 2005, New Orleans, Louisiana: College Station, Tex., Texas A\&M University, CDA Report no. 507, p. 335-346, accessed June 15, 2020, at https://www.westerndredging. org/index.php/information/category/49-25th-annual-wedaconference ?download=429:16-sabol-dredging-effects-onseagrasses-case-studies-from-new-england-and-florida.

Sampath, D.M.R., Boski, T., Silva, P.L., and Martins, F.A., 2011, Morphological evolution of the Guadiana estuary and intertidal zone in response to projected sea-level rise and sediment supply scenarios: Journal of Quaternary Science, v. 26, no. 2, p. 156-170, accessed September 01, 2020, at https://doi.org/10.1002/jqs.1434. 
Sarà, G., Dean, J.M., D’Amato, D., Buscaino, G., Oliveri, A., Genovese, S., Ferro, S., Buffa, G., Lo Martire, M., and Mazzola, S., 2007, Effect of boat noise on the behaviour of bluefin tuna Thunnus thynnus in the Mediterranean Sea: Marine Ecology Progress Series, v. 331, p. 243-253, accessed August 28, 2020, at https://doi.org/10.3354/meps331243.

Schlacher, T.A., Dugan, J., Schoeman, D.S., Lastra, M., Jones, A., Scapini, F., McLachlan, A., and Defeo, O., 2007, Sandy beaches at the brink: Diversity and Distributions, v. 13, no. 5, p. 556-560, accessed June 15, 2020, at https://doi. org/10.1111/j.1472-4642.2007.00363.x.

Schlesinger, W.H., 1997, Biogeochemistry-An analysis of global change ( $2 \mathrm{~d}$ ed.): San Diego, Calif., Academic Press, $588 \mathrm{p}$.

Schneider, D., 1983, The food and feeding of migratory shorebirds: Oceanus, v. 26, no. 1, p. 38-43, accessed June 15, 2020, at https://www.researchgate.net/publication/317036238_The_Food_and_Feeding_of_Migratory_ Shorebirds.

Schroeder, P.M., Dolan, R., and Hayden, B.P., 1977, Vegetation changes associated with barrier-dune construction on the outer banks of North Carolina: Environmental Management, v. 1, no. 2, p. 105-114, accessed August 11, 2020, at https://doi.org/10.1007/BF01866101.

Schupp, C.A., Winn, N.T., Pearl, T.L., Kumer, J.P., Carruthers, T.J.B., and Zimmerman, C.S., 2013, Restoration of overwash processes creates piping plover (Charadrius melodus) habitat on a barrier island (Assateague Island, Maryland): Estuarine, Coastal and Shelf Science, v. 116, p. 11-20, accessed August 07, 2020, at https://doi.org/10.1016/j. ecss.2012.07.003.

Schwab, W.C., Baldwin, W.E., Denny, J.F., Hapke, C.J., Gayes, P.T., List, J.H., and Warner, J.C., 2014, Modification of the Quaternary stratigraphic framework of the innercontinental shelf by Holocene marine transgression-An example offshore of Fire Island, New York: Marine Geology, v. 355, p. 346-360, accessed June 23, 2020, at https:// doi.org/10.1016/j.margeo.2014.06.011.

Schwab, W.C., Baldwin, W.E., Hapke, C.J., Lentz, E.E., Gayes, P.T., Denny, J.F., List, J.H., and Warner, J.C., 2013, Geologic evidence for onshore sediment transport from the inner Continental Shelf_-Fire Island, New York: Journal of Coastal Research, v. 29, no. 3, p. 526-544, accessed June 23, 2020, at https://doi.org/10.2112/JCOASTRESD-12-00160.1.
Schwab, W.C., Baldwin, W.E., Warner, J.C., List, J.H., Denny, J.F., Liste, M., and Safak, I., 2017, Change in morphology and modern sediment thickness on the inner continental shelf offshore of Fire Island, New York between 2011 and 2014-Analysis of hurricane impact: Marine Geology, v. 391, p. 48-64, accessed June 23, 2020, at https://doi. org/10.1016/j.margeo.2017.07.010.

Schwartz, M., 1971, The multiple causality of barrier islands: Journal of Geology, v. 79, no. 1, p. 91-94, accessed October 19, 2020, at https://doi.org/10.1086/627589.

Schwartz, F.J., McCandless, C.T., and Hoey, J., 2010, Standardized catch rates for blacknose, dusky and sandbar sharks caught during a UNC longline survey conducted between 1972 and 2009 in Onslow Bay, NC: SouthEast Data, Assessment, and Review (SEDAR) website, SEDAR 21 Data Workshop Document S21DW33, 26 p. [Also available at http://sedarweb.org/s21dw33-standardized-catchrates-blacknose-dusky-and-sandbar-sharks-caught-duringunc-longline.]

Secor, D.H., O’Brien, M.H.P., Gahagan, B.I., Watterson, J.C., and Fox, D.A., 2020, Differential migration in Chesapeake Bay striped bass: PLoS One, v. 15, no. 5, art. e0233103, 19 p., accessed August 20, 2020, at https://doi.org/10.1371/ journal.pone. 0233103 .

Seelye, J.G., Hesselberg, R.J., and Mac, M.J., 1982, Accumulation by fish of contaminants released from dredged sediments: Environmental Science \& Technology, v. 16, no. 8, p. 459-464, accessed September 1, 2020, at https://doi. org/10.1021/es00102a006.

Shafiei Sabet, S., Wesdorp, K., Campbell, J., Snelderwaard, P., and Slabbekoorn, H., 2016, Behavioural responses to sound exposure in captivity by two fish species with different hearing ability: Animal Behaviour, v. 116, p. 1-11, accessed August 19, 2020, at https://doi.org/10.1016/j. anbehav.2016.03.027.

Shawler, J.L., Ciarletta, D.J., Lorenzo-Trueba, J., and Hein, C.J., 2019, Drowned foredune ridges as evidence of prehistorical barrier-island state changes between migration and progradation, in Wang, P., Rosati, J.D., and Vallee, M., eds.,Coastal Sediments 2019_-Proceedings of the 9th International Conference, Tampa/St. Petersburg, Florida, USA, May 27-31, 2019: Singapore, World Scientific, p. 158-171, accessed July 7, 2020, at https://doi. org/10.1142/9789811204487_0015.

Shawler, J.L., Ciarletta, D.J., Connell, J.E., Boggs, B.Q., Lorenzo-Trueba, J., and Hein, C.J., 2021, Relative influence of antecedent topography and sea-level rise on barrierisland migration: Sedimentology, v. 68, no. 2, p. 639-669, accessed March 22, 2021, at https://doi.org/10.1111/ sed.12798. 
Schwartz, F.J., McCandless, C.T., and Hoey, J., 2013, Standardized indices of abundance for Atlantic sharpnose sharks from the University of North Caroline bottom longline survey, in HMS Atlantic sharpnose shark: North Charleston, S.C., SEDAR [Southeast Data, Assessment, and Review], SEDAR 34 Stock Assessment Report, p. 39-65, accessed May 14, 2021, at http://sedarweb.org/sedar-34-final-stockassessment-report-atlantic-sharpnose-shark.

Sheaves, M., 2009, Consequences of ecological connectivity-The coastal ecosystem mosaic: Marine Ecology Progress Series, v. 391, p. 107-115, accessed July 12, 2020, at https://doi.org/10.3354/meps08121.

Shellenbarger, G.G., Wright, S.A., and Schoellhamer, D.H., 2013, A sediment budget for the southern reach in San Francisco Bay, CA-Implications for habitat restoration: Marine Geology, v. 345, p. 281-293, accessed August 11, 2020, at https://doi.org/10.1016/j.margeo.2013.05.007.

Sheridan, P., 2004, Recovery of floral and faunal communities after placement of dredged material on seagrasses in Laguna Madre, Texas: Estuarine, Coastal and Shelf Science, v. 59, no. 3, p. 441-458, accessed July 27, 2020, at https://doi. org/10.1016/j.ecss.2003.10.004.

Sherk, J.A., O'Connor, J.M., and Neumann, D.A., 1975, Effects of suspended and deposited sediments on estuarine environments, in Cronin, L.E., ed., Estuarine research 2: New York, Academic Press, p. 541-558.

Sherwood, C.R., Long, J.W., Dickhudt, P.J., Dalyander, P.S., Thompson, D.M., and Plant, N.G., 2014, Inundation of a barrier island (Chandeleur Islands, Louisiana, USA) during a hurricane - Observed water-level gradients and modeled seaward sand transport: Journal of Geophysical Research, Earth Surface, v. 119, no. 7, p. 1498-1515, accessed September 1, 2020, at https://doi.org/10.1002/2013JF003069.

Shuster, C.N., and Botton, M.L., 1985, A contribution to the population biology of horseshoe crabs, Limulus polyphemus (L.), in Delaware Bay: Estuaries, v. 8, no. 4, p. 363-372, accessed July 15, 2020, at https://doi.org/10.2307/1351874.

Silva, F.G., Wijnberg, K.M., de Groot, A.V., and Hulscher, S.J.M., 2019, The effects of beach width variability on coastal dune development at decadal scales: Gemorphology, v. 329, p. 58-69, accessed on May 14, 2021, at https://doi. org/10.1016/j.geomorph.2018.12.012.

Simms, A.R., Anderson, J.B., and Blum, M., 2006, Barrierisland aggradation via inlet migration-Mustang Island, Texas: Sedimentary Geology, v. 187, nos. 1-2, p. 105-125, accessed July 7, 2020, at https://doi.org/10.1016/j.sedgeo.2005.12.023.
Simonini, R., Ansaloni, I., Bonini, P., Grandi, V., Graziosi, F., Iotti, M., Massamba-N'Siala, G., Mauri, M., Montanari, G., Preti, M., De Nigris, N., and Prevedelli, D., 2007, Recolonization and recovery dynamics of the macrozoobenthos after sand extraction in relict sand bottoms of the Northern Adriatic Sea: Marine Environmental Research, v. 64, no. 5, p. 574-589, accessed June 23, 2020, at https://doi. org/10.1016/j.marenvres.2007.06.002.

Simpson, S.D., Meekan, M., Montgomery, J., McCauley, R., and Jeffs, A., 2005, Homeward sound: Science, v. 308, no. 5719, p. 221, accessed August 19, 2020, at https://doi. org/10.1126/science.1107406.

Simpson, S.D., Radford, A.N., Nedelec, S.L., Ferrari, M.C.O., Chivers, D.P., McCormick, M.I., and Meekan, M.G., 2016, Anthropogenic noise increases fish mortality by predation: Nature Communications, v. 7, art. 10544, 7 p., accessed August 19, 2020, at https://doi.org/10.1038/ncomms 10544.

Slocum, M.G., Mendelssohn, I.A., and Kuhn, N.L., 2005, Effects of sediment slurry enrichment on salt marsh rehabilitation-Plant and soil responses over seven years: Estuaries, v. 28, no. 4, p. 519-528, accessed August 11, 2020, at https://doi.org/10.1007/BF02696063.

Smallegan, S.M., Irish, J.L., and van Dongeren, A.R., 2017, Developed barrier island adaptation strategies to hurricane forcing under rising sea levels: Climatic Change, v. 143, nos. 1-2, p. 173-184, accessed September 1, 2020, at https://doi.org/10.1007/s10584-017-1988-y.

Smith, C.G., Culver, S.J., Riggs, S.R., Ames, D., Corbett, D.R., and Mallinson, D., 2008, Geospatial analysis of barrier island width of two segments of the Outer Banks, North Carolina, USA - Anthropogenic curtailment of natural self-sustaining processes: Journal of Coastal Research, v. 24, no. 1, p. 70-83, accessed July 20, 2020, at https://doi. org/10.2112/05-0595.1.

Smith, C.G., Osterman, L.E., and Poore, R.Z., 2013, An examination of historical inorganic sedimentation and organic matter accumulation in several marsh types within the Mobile Bay and Mobile-Tensaw River Delta region: Journal of Coastal Research, Special issue no. 63, p. 68-83, accessed August 11, 2020, at https://doi.org/10.2112/SI63007.1.

Smith, D.R., Brockmann, H.J., Beekey, M.A., King, T.L., Millard, M.J., and Zaldívar-Rae, J., 2017, Conservation status of the American horseshoe crab, (Limulus polyphemus) - A regional assessment: Reviews in Fish Biology and Fisheries, v. 27 , no. 1, p. 135-175, accessed July 15, 2020, at https:// doi.org/10.1007/s11160-016-9461-y. 
Smith, D.R., Brousseau, L.J., Mandt, M.T., and Millard, M.J., 2010a, Age and sex specific timing, frequency, and spatial distribution of horseshoe crab spawning in Delaware BayInsights from a large-scale radio telemetry array: Current Zoology, v. 56, no. 5, p. 563-574, accessed July 15, 2020, at https://doi.org/10.1093/czoolo/56.5.563.

Smith, D.R., Jackson, N.L., Nordstrom, K.F., and Weber, R.G., 2011, Beach characteristics mitigate effects of onshore wind on horseshoe crab spawning - Implications for matching with shorebird migration in Delaware Bay: Animal Conservation, v. 14 , no. 5, p. 575-584, accessed July 15, 2020, at https://doi.org/10.1111/j.1469-1795.2011.00481.x.

Smith, D.R., Mandt, M.T., and MacDonald, P.D.M., 2009, Proximate causes of sexual size dimorphism in horseshoe crabs (Limulus polyphemus) of the Delaware Bay: Journal of Shellfish Research, v. 28, no. 2, p. 405-417, accessed July 15, 2020, at https://doi.org/10.2983/035.028.0225.

Smith, J.M., Cialone, M.A., Wamsley, T.V., and McAlpin, T.O., 2010b, Potential impact of sea level rise on coastal surges in southeast Louisiana: Ocean Engineering, v. 37, no. 1, p. 37-47, accessed August 26, 2020, at https://doi. org/10.1016/j.oceaneng.2009.07.008.

Smith, M.E., Kane, A.S., and Popper, A.N., 2004, Noiseinduced stress response and hearing loss in goldfish (Carassius auratus): Journal of Experimental Biology, v. 207, no. 3, p. 427-435, accessed July 8, 2020, at https://doi. org/10.1242/jeb.00755.

Smith, P.A., Tulp, I., Schekkerman, H., Gilchrist, H.G., and Forbes, M.R., 2012, Shorebird incubation behaviour and its influence on the risk of nest predation: Animal Behaviour, v. 84, no. 4, p. 835-842, accessed June 15, 2020, at https://doi. org/10.1016/j.anbehav.2012.07.004.

Smokorowski, K.E., and Randall, R.G., 2017, Cautions on using the Before-After-Control-Impact design in environmental effects monitoring programs: Facets, v. 2, no. 1, p. 212-232, accessed August 20, 2020, at https://doi. org/10.1139/facets-2016-0058.

Speybroeck, J., Bonte, D., Courtens, W., Gheskiere, T., Grootaert, P., Maelfait, J.-P., Mathys, M., Provoost, S., Sabbe, K., Stienen, E.W.M., van Lancker, V., Vincx, M., and Degraer, S., 2006, Beach nourishment-An ecologically sound coastal defence alternative? A review: Aquatic Conservation, v. 16, no. 4, p. 419-435, accessed June 15, 2020, at https://doi.org/10.1002/aqc.733.

Spiga, I., Aldred, N., and Caldwell, G.S., 2017, Anthropogenic noise compromises the antipredator behaviour of the European seabass, Dicentrarchus labrax (L.): Marine Pollution Bulletin, v. 122, nos. 1-2, p. 297-305, accessed June 23, 2020, at https://doi.org/10.1016/j.marpolbul.2017.06.067.
Splinter, K.D., Turner, I.L., Davidson, M.A., Barnard, P., Castelle, B., and Oltman-Shay, J., 2014, A generalized equilibrium model for predicting daily to interannual shoreline response: Journal of Geophysical Research, Earth Surface, v. 119, no. 9, p. 1936-1958, accessed June 23, 2020, at https://doi.org/10.1002/2014JF003106.

Stagg, C.L., and Mendelssohn, I.A., 2010, Restoring ecological function to a submerged salt marsh: Restoration Ecology, v. 18 , no. S1, p. 10-17, accessed July 27, 2020, at https://doi.org/10.1111/j.1526-100X.2010.00718.x.

Stagg, C.L., and Mendelssohn, I.A., 2011, Controls on resilience and stability in a sediment-subsidized salt marsh: Ecological Applications, v. 21, no. 5, p. 1731-1744, accessed May 29, 2020, at https://doi.org/10.1890/09-2128.1.

Standard Manatee Construction Conditions, 2011, Permit review-Potential adverse impacts to manatees: Florida Fish and Wildlife Conservation Commission website, accessed May 21, 2021, at https://myfwc.com/wildlifehabitats/wildlife/manatee/permit-review/.

Stauble, D.K., Hansen, M., and Blake, W., 1985, An assessment of beach nourishment sediment characteristics, in Edge, B.L., ed., Nineteenth Coastal Engineering Conference-Proceedings of the international conference, September 3-7, 1984, Houston, Texas: New York, American Society of Civil Engineers, p. 1471-1487, accessed October 19, 2020, at https://doi.org/10.1061/9780872624382.101.

Stauble, D.K., and Kraus, N.C., eds., 1993, Beach nourishment engineering and management considerations, in Magoon, O.T., ed., Coastal Zone '93-Proceedings of the eighth Symposium on Coastal and Ocean Management, July 19-23, 1993, New Orleans, Louisiana: New York, American Society of Civil Engineers, 245 p.

Steinitz, M.J., Salmon, M., and Wyneken, J., 1998, Beach renourishment and loggerhead turtle reproduction-A seven year study at Jupiter Island, Florida: Journal of Coastal Research, v. 14, no. 3, p. 1000-1013, accessed June 15, 2020, at https://www.jstor.org/stable/4298852.

Stewart, K.R., and Wyneken, J., 2004, Predation risk to loggerhead hatchlings at a high-density nesting beach in southeast Florida: Bulletin of Marine Science, v. 74, no. 2, p. 325-335, accessed June 15, 2020, at https://www.researchgate.net/profile/Jeanette-Wyneken/publication/233693699 Predation_Risk_to_Loggerhead_Hatchlings_at_a High-density_Nesting_Beach_in_Southeast_Florida/ links/0deec5296a6b41330a000000/Predation-Risk-to-Loggerhead-Hatchlings-at-a-High-density-Nesting-Beach-inSoutheast-Florida.pdf. 
Stive, M.J.F., de Schipper, M.A., Luijendijk, A.P., Aarninkhof, S.G.J., van Gelder-Maas, C., van Thiel de Vries, J.S.M., de Vries, S., Henriquez, M., Marx, S., and Ranasinghe, R., 2013, A new alternative to saving our beaches from sealevel rise-The sand engine: Journal of Coastal Research, v. 29, no. 5, p. 1001-1008, accessed August 25, 2020, at https://doi.org/10.2112/JCOASTRES-D-13-00070.1.

Stockton University Coastal Research Center, 2019, Observations at Little Egg Inlet and adjacent shorelines December 2017 to October 2018: New Jersey Department of Environmental Protection report, prepared by Stockton University Coastal Research Center, Port Republic, N.J., 20 p.

Stockton University Coastal Research Center, 2020, Observations at Little Egg Inlet and adjacent shorelines October 2018 to January 2020: New Jersey Department of Environmental Protection report, prepared by Stockton University Coastal Research Center, Port Republic, N.J., 15 p.

Stone, G.W., Pepper, D.A., Xu, J., and Zhang, X., 2004, Ship Shoal as a prospective borrow site for barrier island restoration, coastal south-central Louisiana, USA-Numerical wave modeling and field measurements of hydrodynamics and sediment transport: Journal of Coastal Research, v. 20 , no. 1 , p. 70-88, accessed June 23, 2020, at https://doi. org/10.2112/1551-5036(2004)20[70:SSAAPB]2.0.CO;2.

Streever, W.J., 2000, Spartina alterniflora marshes on dredged material-A critical review of the ongoing debate over success: Wetlands Ecology and Management, v. 8, no. 5, p. 295-316, accessed June 1, 2020, at https://doi. org/10.1023/A:1008483203083.

Suedel, B.C., McQueen, A.D., Wilkens, J.L., and Fields, M.P., 2019, Evaluating effects of dredging-induced underwater sound on aquatic species - a literature review: U.S Army Engineer Research and Development Center Environmental Laboratory final report ERDC/EL TR-19-18, 124 p., accessed August 28, 2020, at https://erdc-library.erdc.dren. $\mathrm{mil} / \mathrm{jspui} / \mathrm{handle} / 11681 / 34245$.

Sutherland, A.B., and Meyer, J.L., 2007, Effects of increased suspended sediment on growth rate and gill condition of two southern Appalachian minnows: Environmental Biology of Fishes, v. 80, p. 389-403, accessed May 14, 2021, at https://doi.org/10.1007/s10641-006-9139-8.

Sweka, J.A., Smith, D.R., and Millard, M.J., 2007, An age-structured population model for horseshoe crabs in the Delaware Bay area to assess harvest and egg availability for shorebirds: Estuaries and Coasts, v. 30, no. 2, p. 277-286, accessed July 15, 2020, at https://doi.org/10.1007/ BF02700170.
Taniguchi, M., Burnett, W.C., Cable, J.E., and Turner, J.V., 2002, Investigation of submarine groundwater discharge: Hydrological Processes, v. 16, no. 11, p. 2115-2129, accessed August 14, 2020, at https://doi.org/10.1002/ hyp. 1145.

Terwilliger Consulting, Inc., 2008, Conservation plan for Stone Harbor Point Stone Harbor, New Jersey: National Fish and Wildlife Foundation report, prepared by Terwilliger Consulting, Inc., [Locustville, Va.], 118 p., accessed March 21, 2021, at https://stoneharbornj.org/wp-content/ uploads/2014/07/Stone-HarborPT_PLAN_FINAL_Mar08. pdf.

Thibodeaux, L.J., 2005, Recent advances in our understanding of sediment-to-water contaminant fluxes-The soluble release fraction: Aquatic Ecosystem Health \& Management, v. 8, no. 1, p. 1-9, accessed August 19, 2020, at https://doi. org/10.1080/14634980590914917.

Thibodeaux, L.J., and Boyle, J.D., 1987, Bedform-generated convective transport in bottom sediment: Nature, v. 325, no. 6102, p. 341-343, accessed August 11, 2020, at https://doi. org/10.1038/325341a0.

Thieler, E.R., Brill, A.L., Cleary, W.J., Hobbs, C.H., III, and Gammisch, R.A., 1995, Geology of the Wrightsville Beach, North Carolina shoreface-Implications for the concept of shoreface profile of equilibrium: Marine Geology, v. 126, nos. 1-4, p. 271-287, accessed August 11, 2020, at https:// doi.org/10.1016/0025-3227(95)00082-A.

Thieler, E.R., Gayes, P.T., Schwab, W.C., and Harris, M.S., 1999, Tracing sediment dispersal on nourished beachesTwo case studies, in Kraus, N.C. and McDougal, W.G., eds., Coastal Sediments '99-Proceedings of the 4th International Symposium on Coastal Engineering and Science of Coastal Sediment Processes - Conference theme-Scales of coastal sediment motion and geomorphic change, Hauppauge, Long Island, New York, June 21-23, 1999: Reston, Va., American Society of Civil Engineers, 22 p., accessed August 7, 2020, at https:/www.researchgate.net/ profile/Michael-Harris-33/publication/228492262_Tracing_sediment_dispersal_on_nourished_beaches_Two_case studies/links/0deec51f7ca5c7ea09000000/Tracing-sediment-dispersal-on-nourished-beaches-Two-case-studies.pdf. [Reprinted from Coastal Sediments '99.]

Thieler, E.R., Pilkey, O.H., Jr., Young, R.S., Bush, D.M., and Chai, F., 2000, The use of mathematical models to predict beach behavior for U.S. Coastal Engineering-A critical review: Journal of Coastal Research, v. 16, no. 1, p. 48-70, accessed August 7, 2020, at https://www.jstor.org/ stable/4300011. 
Thompson, B.C., Jackson, J.A., Burger, J., Hill, L.A., Kirsch, E.M., and Atwood, J.L., 2020, Least Tern (Sternula antillarum) (ver. 1.0), in Poole, A.F., and Gill, F.B., eds., Birds of the World: Cornell Lab of Ornithology website, accessed August 5, 2020, at https://doi.org/10.2173/bow.leater1.01.

Thorne, L.T., and Nickless, G., 1981, The relation between heavy metals and particle size fractions within the Severn Estuary (U.K.) intertidal sediments: Science of the Total Environment, v. 19, no. 3, p. 207-213, accessed May 14, 2021, at https://doi.org/10.1016/0048-9697(81)90017-6.

Thorson, G., 1966, Some factors influencing the recruitment and establishment of marine benthic communities: Netherlands Journal of Sea Research, v. 3, no. 2, p. 267-293, accessed July 13, 2020, at https://doi.org/10.1016/00777579(66)90015-9.

Thrush, S.F., Hewitt, J.E., Norkko, A., Cummings, V.J., and Funnell, G.A., 2003, Macrobenthic recovery processes following catastrophic sedimentation on estuarine sandflats: Ecological Applications, v. 13, no. 5, p. 1433-1455, accessed June 15, 2020, at https://doi.org/10.1890/02-5198.

Troscianko, J., Wilson-Aggarwal, J., Stevens, M., and Spottiswoode, C.N., 2016, Camouflage predicts survival in ground-nesting birds: Scientific Reports, v. 6, art. 19966, 8 p., accessed June 15, 2020, at https://doi.org/10.1038/ srep19966.

Tu Do, V., de Montaudouin, X., Blanchet, H., and Lavesque, N., 2012, Seagrass burial by dredged sediments-Benthic community alteration, secondary production loss, biotic index reaction and recovery possibility: Marine Pollution Bulletin, v. 64, no. 11, p. 2340-2350, accessed June 1, 2020, at https://doi.org/10.1016/j.marpolbul.2012.08.025.

Tyson, R.B., Piniak, W.E.D., Domit, C., Mann, D., Hall, M., Nowacek, D.P., 2017, Novel bio-logging tool for studying fine-scale behaviors of marine turtles in response to sound: Frontiers in Marine Science, v. 4, p. 219, accessed on May 14, 2021, at https://doi.org/10.3389/fmars.2017.00219.

U.S. Army Corps of Engineers [USACE], 2008, Coastal engineering manual-Part V: Washington, D.C., Department of the Army, U.S. Army Corps of Engineers, Coastal Engineering Manual EM 1110-2-1100 (change 2), [variously paged, 633 p.], accessed August 11, 2020, at https://www.publications.usace.army.mil/LinkClick.aspx?fileticket=ueOFzCUh Cck\%3d\&tabid $=16439 \&$ portalid $=76 \&$ mid $=43544$.

U.S. Army Corps of Engineers [USACE], 2014, Assessing impacts of navigation dredging on Atlantic sturgeon (Acipenser oxyrinchus): U.S. Army Corps of Engineers Engineer Research and Development Center, ERDC/EL Report TR-14-12, accessed May 14, 2021, at https://doi. org/10.13140/RG.2.1.5064.6565.
U.S. Army Corps of Engineers [USACE] and U.S. Geological Survey, 2020, Final Alabama barrier island restoration assessment report: U.S. Army Corps of Engineers and U.S. Geological Survey report, 108 p., https://gom.usgs.gov/ DauphinIsland/data/ALBarrierIslRestoFinalRpt_2020.pdf

U.S. Army Corps of Engineers, U.S. Geological Survey, State of Alabama, and National Fish and Wildlife Foundation, 2020, Final Alabama barrier island restoration assessment report: U.S. Geological Survey, cooperator report, accessed May 13, 2021, at https://gom.usgs.gov/DauphinIsland/data/ ALBarrierIslRestoFinalRpt_2020.pdf.

U.S. Environmental Protection Agency and U.S. Army Corps of Engineers [USACE], 2004, Evaluating environmental effects of dredged material management alternatives-A technical framework (revised May 2004): U.S. Environmental Protection Agency report EPA842-B-92-008, 95 p., accessed August 11, 2020, at https://apps.dtic.mil/sti/citations/ADA636567.

U.S. Fish and Wildlife Service [USFWS], 2010, Caribbean roseate tern and North Atlantic roseate tern (Sterna dougallii dougallii), 5-year review-Summary and evaluation: U.S. Fish and Wildlife Service, accessed June 15, 2020, at https://ecos.fws.gov/docs/five_year_review/doc3588.pdf.

U.S. Fish and Wildlife Service [USFWS], 2014, Perdido Key beach mouse (Peromyscus polionotus trissyllepsis) - 5-year review-Summary and evaluation: Panama City, Fla., U.S. Fish and Wildlife Service, 24 p. [Also available at https:// www.cabi.org/isc/FullTextPDF/2011/20117202379.pdf]

U.S. Fish and Wildlife Service [USFWS], 2015, Shore protection activities along the coast of Florida, Statewide Programmatic Biological Opinion: U.S. Fish and Wildlife Service, accessed May 14, 2021, at https://www.fws.gov/ panamacity/resources/2015SPBO.pdf.

U.S. Fish and Wildlife Service [USFWS], 2019, Alabama beach mouse (Peromyscus polionotus ammobates) - 5-year review-Summary and evaluation: Daphne, Ala., U.S. Fish and Wildlife Service, 34 p. [Also available at https://www. cabi.org/ISC/FullTextPDF/2011/20117202375.pdf.]

U.S. Fish and Wildlife Service [USFWS], 2020, Piping plover (Charadrius melodus) - 5-year review-Summary and evaluation: U.S. Fish and Wildlife Service, p. 163, accessed June 15, 2020, at https://ecos.fws.gov/docs/five_year_ review/doc6378.pdf.

Utizi, K., Corbau, C., Rodella, I., Nannini, S., and Simeoni, U., 2016, A mixed solution for a highly protected coast (Punta Marina, Northern Adriatic Sea, Italy): Marine Geology, v. 381, p. 114-127, accessed August 27, 2020, at https://doi.org/10.1016/j.margeo.2016.09.002. 
Utne-Palm, A.C., 2002, Visual feeding of fish in a turbid environment-Physical and behavioural aspects: Marine and Freshwater Behaviour and Physiology, v. 35, nos. 1-2, p. 111-128, accessed August 19, 2020, at https://doi. org/10.1080/10236240290025644.

van Dalfsen, J.A., Essink, K., Madsen, H.T., Birklund, J., Romero, J., and Manzanera, M., 2000, Differential response of macrozoobenthos to marine sand extraction in the North Sea and the Western Mediterranean: ICES Journal of Marine Science, v. 57, no. 5, p. 1439-1445, accessed August 7, 2020, at https://doi.org/10.1006/jmsc.2000.0919.

van de Koppel, J., van der Heide, T., Altieri, A.H., Eriksson, B.K., Bouma, T.J., Olff, H., and Silliman, B.R., 2015, Longdistance interactions regulate the structure and resilience of coastal ecosystems: Annual Review of Marine Science, v. 7, p. 139-158, accessed June 15, 2020, at https://doi. org/10.1146/annurev-marine-010814-015805.

van de Velde, S., Van Lancker, V., Hidalgo-Martinez, S., Berelson, W.M., and Meysman, F.J.R., 2018, Anthropogenic disturbance keeps the coastal seafloor biogeochemistry in a transient state: Scientific Reports, v. 8, no. 1, art. 5582, 10 p., accessed August 11, 2020, at https://doi.org/10.1038/ s41598-018-23925-y.

van der Kolk, H., Krijgsveld, K.L., Linssen, H., Diertens, R., Dolman, D., Jans, M., Frauendorf, M., Ens, B.J., and van de Pol, M., 2020, Cumulative energetic costs of military aircraft, recreational and natural disturbance in roosting shorebirds: Animal Conservation, v. 23, no. 4, p. 359-372, accessed June 15, 2020, at https://doi.org/10.1111/ acv.12546.

Van Der Veer, H.W., Bergman, M.J.N., and Beukema, J.J., 1985, Dredging activities in the Dutch Wadden SeaEffects on macrobenthic infauna: Netherlands Journal of Sea Research, v. 19, no. 2, p. 183-190, accessed June 23, 2020, at https://doi.org/10.1016/0077-7579(85)90022-5.

van der Wal, D., 1998, The impact of the grain-size distribution of nourishment sand on aeolian sand transport: Journal of Coastal Research, v. 14, no. 2, p. 620-631, accessed October 19, 2020, at https://www.jstor.org/stable/4298816.

van der Wal, D., 2000, Grain-size-selective aeolian sand transport on a nourished beach: Journal of Coastal Research, v. 16, no. 3, p. 896-908, accessed October 19, 2020, at https:// www.jstor.org/stable/4300100.

Van Dolah, R.F., Wendt, P.H., Martore, R.M., Levisen, M.V., and Roumillat, W.A., 1992, A physical and biological monitoring study of the Hilton Head Beach nourishment project-Final Report: Charleston, S.C., Marine Research Institute, 159 p. [Submitted to Town of Hilton Head Island, S.C., and the South Carolina Coastal Council.] van Duin, M.J.P., Wiersma, N.R., Walstra, D.J.R., van Rijn, L.C., and Stive, M.J.F., 2004, Nourishing the shorefaceObservations and hindcasting of the Egmond case, The Netherlands: Coastal Engineering, v. 51, nos. 8-9, p. 813837, accessed August 14, 2020, at https://doi.org/10.1016/j. coastaleng.2004.07.011.

van Kessel, T., and van Maren, D.S., 2014, Far-field and long-term dispersion of released dredged material, in 20th World Dredging Congress and Exhibition 2013 (WODCON $\mathrm{XX)}$ The Art of Dredging, Brussels, Belgium, 3-7 June 2013: Red Hook, N.Y., Curran Associates, p. 863-871. [Also available at https://www.researchgate.net/publication/267266269_Far-field_and_long-term_dispersion_of_ released_dredged_material.]

van Maren, D.S., van Kessel, T., Cronin, K., and Sittoni, L., 2015, The impact of channel deepening and dredging on estuarine sediment concentration: Continental Shelf Research, v. 95, p. 1-14, accessed April 30, 2020, at https:// doi.org/10.1016/j.csr.2014.12.010.

van Rijn, L.C., 2012, Principles of sedimentation and erosion engineering in rivers, estuaries and coastal seas including mathematical modelling package (toolkit on CD-ROM): Flanders, Belgium, Aqua Publications, Flanders Marine Institute, $623 \mathrm{p}$.

VanZomeren, C.M., Berkowitz, J.F., Piercy, C.D., and White, J.R., 2018, Restoring a degraded marsh using thin layer sediment placement-Short term effects on soil physical and biogeochemical properties: Ecological Engineering, v. 120, p. 61-67, accessed October 19, 2020, at https://doi. org/10.1016/j.ecoleng.2018.05.012.

Vasquez, M.C., Murillo, A., Brockmann, H.J., and Julian, D., 2015, Multiple-stressor interactions influence embryo development rate in the American horseshoe crab, Limulus polyphemus: The Journal of Experimental Biology, v. 218, no. 15 , p. 2355-2364, accessed July 15, 2020, at https://doi. org/10.1242/jeb.117184.

Velasquez-Montoya, L., Overton, M.F., and Sciaudone, E.J., 2020, Natural and anthropogenic-induced changes in a tidal inlet-Morphological evolution of Oregon Inlet: Geomorphology, v. 350, art. 106871, 18 p., accessed June 23, 2020, at https://doi.org/10.1016/j.geomorph.2019.106871.

Verhagen, H.J., 1993, Method for artificial beach nourishment, in Edge, B.L., ed., Coastal Engineering 1992—Proceedings of the twenty-third international conference, October 4-9, 1992, Venice, Italy: New York, American Society of Civil Engineers, p. 2474-2485, accessed October 19, 2020, at https://doi.org/10.1061/9780872629332.189.

Verhagen, H.J., 1996, Analysis of beach nourishment schemes: Journal of Coastal Research, v. 12, no. 1, p. 179-185, accessed October 19, 2020, at https://www.jstor.org/stable/4298472. 
Vousdoukas, M.I., Ranasinghe, R., Mentaschi, L., Plomaritis, T.A., Athanasiou, P., Luijendijk, A., and Feyen, L., 2020, Sandy coastlines under threat of erosion: Nature Climate Change, v. 10, no. 3, p. 260-263, accessed May 6, 2020, at https://doi.org/10.1038/s41558-020-0697-0.

Walters, D., Moore, L.J., Duran Vinent, O., Fagherazzi, S., and Mariotti, G., 2014, Interactions between barrier islands and backbarrier marshes affect island system response to sea level rise-Insights from a coupled model: Journal of Geophysical Research, Earth Surface, v. 119, no. 9, p. 2013-2031, accessed July 7, 2020, at https://doi. org/10.1002/2014JF003091.

Walters, D.C., and Kirwan, M.L., 2016, Optimal hurricane overwash thickness for maximizing marsh resilience to sea level rise: Ecology and Evolution, v. 6, no. 9, p. 2948-2956, accessed August 11, 2020, at https://doi.org/10.1002/ ece3.2024.

Walton, T.L., Jr., and Dean, R.G., 2011, Addressing an optimal schedule for inlet bypassing: Journal of Coastal Research, v. 27, no. 6A, p. 87-93, accessed May 6, 2020, at https://doi. org/10.2112/JCOASTRES-D-11-00053.1.

Wang, Z. and Dean, R.G., 2007, Reevaluation of equilibrium beach profile scale parameter, in Kraus, N.C. and Rosati, J.D., eds., Coastal Sediments '07-Proceedings of the 6th International Symposium on Coastal Engineering and Science of Coastal Sediment Processes-May 13-17, 2007, New Orleans, Louisiana: Reston, Va., American Society of Civil Engineers, 7 p., accessed May 14, 2021, at https://doi. org/10.1061/40926(239)47.

Webber, A.F., Heath, J.A., and Fischer, R.A., 2013, Human disturbance and stage-specific habitat requirements influence snowy plover site occupancy during the breeding season: Ecology and Evolution, v. 3, no. 4, p. 853-863, accessed August 20, 2020, at https://doi.org/10.1002/ ece3.511.

Webster, I.T., and Taylor, J.H., 1992, Rotational dispersion in porous media due to fluctuating flows: Water Resources Research, v. 28, no. 1, p. 109-119, accessed August 14, 2020, at https://doi.org/10.1029/91WR02323.

Weis, J.S., and Candelmo, A., 2012, Pollutants and fish predator/prey behavior - A review of laboratory and field approaches: Current Zoology, v. 58, no. 1, p. 9-20, accessed August 28, 2020, at https://doi.org/10.1093/czoolo/58.1.9.

Weishampel, J.F., Bagley, D.A., Ehrhart, L.M., and Rodenbeck, B.L., 2003, Spatiotemporal patterns of annual sea turtle nesting behaviors along an east central Florida beach: Biological Conservation, v. 110, no. 2, p. 295-303, accessed August 17, 2020, at https://doi.org/10.1016/ S0006-3207(02)00232-X.
Wenger, A.S., Harvey, E., Wilson, S., Rawson, C., Newman, S.J., Clarke, D., Saunders, B.J., Browne, N., Travers, M.J., Mcilwain, J.L., Erftemeijer, P.L.A., Hobbs, J.-P.A., Mclean, D., Depczynski, M., and Evans, R.D., 2017, A critical analysis of the direct effects of dredging on fish: Fish and Fisheries, v. 18, no. 5, p. 967-985, accessed July 15, 2020, at https://doi.org/10.1111/faf.12218.

Wenger, A.S., Johansen, J.L., and Jones, G.P., 2011, Suspended sediment impairs habitat choice and chemosensory discrimination in two coral reef fishes: Coral Reefs, v. 30, no. 4, p. 879-887, accessed August 18, 2020, at https://doi. org/10.1007/s00338-011-0773-z.

Whittock, P.A., Pendoley, K.L., Larsen, R., and Hamann, M., 2017, Effects of a dredging operation on the movement and dive behaviour of marine turtles during breeding: Biological Conservation, v. 206, p. 190-200, accessed July 15, 2020, at https://doi.org/10.1016/j.biocon.2016.12.015.

Wilber, D.H., and Clarke, D.G., 2001, Biological effects of suspended sediments - A review of suspended sediment impacts on fish and shellfish with relation to dredging activities in estuaries: North American Journal of Fisheries Management, v. 21, no. 4, p. 855-875, accessed August 28, 2020, at https://doi.org/10.1577/15488675(2001)021<0855:BEOSSA > 2.0.CO;2.

Wilber, D.H., Clarke, D.G., and Burlas, M.H., 2006, Suspended sediment concentrations associated with a beach nourishment project on the northern coast of New Jersey: Journal of Coastal Research, v. 22, no. 5 p. 1035-1042, accessed August 18, 2020, at https://doi.org/10.2112/040268.1 .

Wildish, D.J., and Power, J., 1985, Avoidance of suspended sediments by smelt as determined by a new "single fish" behavioral bioassay: Bulletin of Environmental Contamination and Toxicology, v. 34, no. 1, p. 770-774, accessed August 18, 2020, at https://doi.org/10.1007/BF01609805.

Williams-Walls, N., O’Hara, J., Gallagher, R.M., Worth, D.F., Peery, B.D.., and Wilcox, J.R., 1983, Spatial and temporal trends of sea turtle nesting on Hutchinson Island, Florida, 1971-1979: Bulletin of Marine Science, v. 33, no. 1, p. 55-66, accessed August 16, 2020, at https:// www.ingentaconnect.com/contentone/umrsmas/bullmar/1983/00000033/00000001/art00003?crawler=true.

Williams, S.J., Flocks, J., Jenkins, C., Khalil, S., and Moya, J., 2012, Offshore sediment character and sand resource assessment of the northern Gulf of Mexico, Florida to Texas: Journal of Coastal Research, Special issue no. 60, p. 30-44, accessed July 8, 2020, at https://doi.org/10.2112/SI_60_4. 
Willson, K., Thomson, G., Briggs, T.R., Elko, N., and Miller, J., 2017, Beach nourishment profile equilibration-What to expect after sand is placed on a beach: Shore and Beach, v. 85 , no. 2, p. 49-51, accessed June 23, 2020, at http://asbpa. org/wpv2/wp-content/uploads/2016/03/WhitePaper_85_2_ Profile_Eq.pdf.

Witkowski, P.J., Smith, J.A., Fusillo, T.V., and Chiou, C.T., 1987, A review of surface-water sediment fractions and their interactions with persistent manmade organic compounds: U.S. Geological Survey Circular 993, 39 p., accessed May 14, 2021, at https://doi.org/10.3133/cir993.

Wong, C.K., Pak, I.A.P, and Jiang Liu X., 2013, Gill damage to juvenile orange-spotted grouper Epinephelus coioides following exposure to suspended sediments: Aquaculture Research v. 44, p. 1685-1695, accessed May 14, 2021, at https://doi.org/10.1111/j.1365-2109.2012.03173.x.

Wood, D.W., and Bjorndal, K.A., 2000, Relation of temperature, moisture, salinity and slope to nest site selection in loggerhead sea turtles: Copeia, v. 2000, no. 1, p. 119-128, accessed June 14, 2020, at https://doi.org/10.1643/00458511(2000)2000[0119:ROTMSA]2.0.CO;2.

Wright, L.D., Short, A.D., and Green, M.O., 1985, Short-term changes in the morphodynamic states of beaches and surf zones-An empirical predictive model: Marine Geology, v. 62 , nos. 3-4, p. 339-364, accessed June 23, 2020, at https:// doi.org/10.1016/0025-3227(85)90123-9.

Xu, K., Sanger, D., Riekerk, G., Crowe, S., Van Dolah, R.F., Wren, P.A., and Ma, Y., 2014, Seabed texture and composition changes offshore of Port Royal Sound, South Carolina before and after the dredging for beach nourishment: Estuarine, Coastal and Shelf Science, v. 149, p. 57-67, accessed June 3, 2020, at https://doi.org/10.1016/j.ecss.2014.07.012.

Yates, M.L., Guza, R.T., and O'Reilly, W.C., 2009, Equilibrium shoreline response-Observations and modeling: Journal of Geophysical Research, Oceans, v. 114, no. C9, accessed August 7, 2020, at https://doi. org/10.1029/2009JC005359.

Yates, M.L., Guza, R.T., O'Reilly, W.C., Hansen, J.E., and Barnard, P.L., 2011, Equilibrium shoreline response of a high wave energy beach: Journal of Geophysical Research, Oceans, v. 116, no. C4, accessed August 7, 2020, at https:// doi.org/10.1029/2010JC006681.

Yoshida, J., Udo, K., Takeda, Y., and Mano, A., 2014, Framework for proper beach nourishment as adaptation to beach erosion due to sea level rise: Journal of Coastal Research, Special issue no. 70, p. 467-472, accessed September 1, 2020, at https://doi.org/10.2112/SI70-079.1.
Young, R.S., Pilkey, O.H., Bush, D.M., and Thieler, E.R., 1995, A discussion of the generalized model for simulating shoreline change (GENESIS): Journal of Coastal Research, v. 11 , no. 3, p. 875-886, accessed August 07, 2020, at https://www.jstor.org/stable/4298387.

Zajac, R.N., and Whitlatch, R.B., 1991, Demographic aspects of marine, soft sediment patch dynamics: Integrative \& Comparative Biology, v. 31 , no. 6, p. 808-820, accessed July 13, 2020, at https://doi.org/10.1093/icb/31.6.808.

Zarillo, G.A., Zarillo, K.A., and Finnegan, C.R., 2009, Physical characterization of nearshore and offshore borrow sites on the inner continental shelf of northeast and west Florida: Journal of Coastal Research, Special issue no. 56, p. 10951099, accessed June 23, 2020, at https://www.proquest.com/ openview/8e3bafe4d5f0f2006b5463f9bdb19a0b/1?cbl=426 28\&pq-origsite $=$ gscholar.

Zeigler, S.L., Gutierrez, B.T., Hecht, A., Plant, N.G., and Sturdivant, E.J., 2021, Piping plovers demonstrate regional differences in nesting habitat selection patterns along the U.S. Atlantic Coast: Ecosphere, v. 12, no. 3, art. e03418, 21 p., accessed March 11, 2021, at https://doi.org/10.1002/ ecs2.3418.

Zeigler, S.L., Gutierrez, B.T., Sturdivant, E.J., Catlin, D.H., Fraser, J.D., Hecht, A., Karpanty, S.M., Plant, N.G., and Thieler, E.R., 2019, Using a Bayesian network to understand the importance of coastal storms and undeveloped landscapes for the creation and maintenance of early successional habitat: PLoS One, v. 14, no. 7, art. e0209986, 30 p., accessed August 21, 2020, at https://doi.org/10.1371/journal.pone.0209986.

Zimmermann, N., Trouw, K., De Maerschalck, B., Toro, F., Delgado, R., Verwaest, T., and Mostaert, F., 2015, Scientific support regarding hydrodynamics and sand transport in the coastal zone-Evaluation of XBeach for long term cross-shore modeling, ver. 3.0: Antwerp, Belgium, Flanders Hydraulics Research and IMDC, 58 p., accessed August 7, 2020, at http://documentatiecentrum.watlab.be/imis. php? module $=$ ref\&refid $=251995$.

Zinnert, J.C., Stallins, J.A., Brantley, S.T., and Young, D.R., 2017, Crossing scales-The complexity of barrier-island processes for predicting future change: Bioscience, v. 67, no. 1, p. 39-52, accessed June 15, 2020, at https://doi. org/10.1093/biosci/biw154. 
Appendix 1 


\section{Appendix 1. Sediment Management Impact Monitoring Data and Availability}

Assessing the system-wide response of barrier islands to sediment management actions (for example, removal or placement) requires quantifying physical and biological changes to the area where the action took place. Areas adjacent to the action, particularly those downdrift, can also be affected and should be included in the monitoring plan so that the physical and biological effects of alterations to barrier island sediment supplies can be quantified. Though the scope and frequency of the impact monitoring program will vary by location and with the scale of the project itself, standard data types and metrics can be used to quantify effects at any scale. Based on the expertise of the report authors and an extensive review of the literature, we identify foundational data and derived metrics that would allow for the assessment of barrier systemwide impacts from sediment management. For the purposes of this report, "foundational data" refers to what is actually measured, whereas "derived metrics" refers to a value that is derived from the foundational data and is the means by which changes can be assessed. For example, terrestrial elevation would be considered foundational data, whereas an example of a metric derived from that data source would be the position of the mean high-water shoreline. This metric would be used to determine whether the sediment removal or placement action altered the position of the shoreline. An example of biological foundational data would be species abundance and distribution, and the monitoring metric derived from those data would be community composition. This metric would be used to determine whether the sediment removal or placement action has affected the physical habitat to the extent that it alters the composition of barrier ecosystems.

The distinction between foundational data and derived metrics is made for several reasons. First, in some cases, multiple metrics might be derived from one kind of foundational data. For example, in addition to deriving shoreline positions from terrestrial elevations, those data could possibly be used to derive the height and extent of a dune, thereby allowing the monitoring of the shoreline and dune line from just one survey of terrestrial elevation. Second, by focusing on what is measured and the derived metrics, we eliminate the need to specify a particular methodology for acquiring that information, presuming variations in accuracy and associated uncertainties can be tracked. This ensures that critical monitoring data and metrics are collected even if changes in technology and (or) data resolution occur. As an example, it would not matter if submerged elevations were collected using airborne light detection and ranging or acoustic boat-based techniques as long as the areas of interest could be monitored at a temporal and spatial resolution that would allow for effects to be quantified. Lastly, the distinction allows us to account for derived products that might merge several different data types. Seamless topo-bathy digital elevation models (derived product) are the foundation of numerical models and rely on terrestrial and submerged elevations (foundational data). Numerical modeling is an important tool for monitoring and assessment because it integrates various monitoring data types to predict the impact of sediment management on barrier island systems. Furthermore, modeling can provide decision support to help prioritize coastal management actions and subsequent adaptive management procedures after nourishment or restoration actions. With this reasoning in mind, table 1.1 lists multidisciplinary foundational data types required for physical and ecological impact monitoring. Tables 1.2, 1.3, and 1.4 list the derived physical, biological, and biogeochemical metrics that can be used to assess whether the sediment management effects are beneficial or detrimental through comparison to historical (or pre-action) metrics and could also help to validate numerical models. Table 1.5 lists model types and inputs that would be used to predict barrier system changes during and beyond the monitoring period. In any of the tables, a round dot in the cell indicates that a U.S. Geological Survey (USGS) data resource is available for that location and data type/ metric. If use of another source of data outside the USGS is standard practice, that source is indicated in the cell.

Though not a replacement for a project-specific on site and remote-sensing monitoring program at a particular location, USGS work in other areas could serve as analogs to the Coastal Barrier Resource System areas of interest and provide useful information about potential expected behaviors to sediment removal/placement. Locations where the USGS has made relevant and significant research investments include Fire Island, New York; Little Egg Inlet, New Jersey; Assateague Island, Maryland/Virginia; and the Outer Banks, North Carolina, along the Atlantic coast; and the Chandeleur Islands, Louisiana; Ship Island, Mississippi; and Dauphin Island, Alabama, along the Gulf coast. Available foundational data and derived metrics for these locations can be provided by request. 
Table 1.1. Foundational data types and availability at Coastal Barrier Resource System areas of interest.

[A round $\operatorname{dot}(\bullet)$ in the cell indicates that a U.S. Geological Survey data resource is available for that location and data type. If use of another source of data outside the U.S. Geological Survey is standard practice, that source is indicated in the cell. N/A, not available; NOAA, National Oceanic and Atmospheric Administration; USGS, U.S. Geological Survey; NEAMAP, Northeast Area Monitoring and Assessment Program; SEAMAP, Southeast Area Monitoring and Assessment Program]

\begin{tabular}{|c|c|c|c|c|c|}
\hline \multirow[b]{2}{*}{ Foundational data } & \multicolumn{5}{|c|}{ Coastal Barrier Resource System area of interest } \\
\hline & $\begin{array}{l}\text { Hereford Inlet, } \\
\text { New Jersey }\end{array}$ & $\begin{array}{l}\text { Carolina Beach, } \\
\text { North Carolina }\end{array}$ & $\begin{array}{l}\text { Masonboro Inlet, } \\
\text { North Carolina }\end{array}$ & $\begin{array}{l}\text { New River Inlet, } \\
\text { North Carolina }\end{array}$ & $\begin{array}{l}\text { Folly Beach, } \\
\text { South Carolina }\end{array}$ \\
\hline Terrestrial elevations & • & • & • & • & • \\
\hline Submerged elevations & $\mathrm{N} / \mathrm{A}$ & N/A & $\mathrm{N} / \mathrm{A}$ & • & • \\
\hline Beach/dune sediment characteristics & $\mathrm{N} / \mathrm{A}$ & $\mathrm{N} / \mathrm{A}$ & N/A & • & $\mathrm{N} / \mathrm{A}$ \\
\hline $\begin{array}{l}\text { Subsurface beach/dune sediment char- } \\
\text { acteristics }\end{array}$ & N/A & N/A & N/A & N/A & N/A \\
\hline Marsh sediment characteristics & N/A & N/A & N/A & N/A & N/A \\
\hline Submarsh sediment characteristics & N/A & N/A & N/A & N/A & N/A \\
\hline Seafloor sediment/rock characteristics & $\mathrm{N} / \mathrm{A}$ & $\mathrm{N} / \mathrm{A}$ & $\mathrm{N} / \mathrm{A}$ & $\mathrm{N} / \mathrm{A}$ & • \\
\hline $\begin{array}{l}\text { Subseafloor sediment/rock character- } \\
\text { istics }\end{array}$ & N/A & N/A & N/A & N/A & • \\
\hline $\begin{array}{l}\text { Hydrodynamic characteristics (for } \\
\text { example, waves and currents) }\end{array}$ & NOAA waves & NOAA waves & NOAA waves & NOAA waves & NOAA waves \\
\hline Water level & $\begin{array}{l}\text { NOAA tides/ } \\
\text { surge, USGS } \\
\text { runup }\end{array}$ & $\begin{array}{l}\text { NOAA tides/ } \\
\text { surge, USGS } \\
\text { runup }\end{array}$ & $\begin{array}{l}\text { NOAA tides/ } \\
\text { surge, USGS } \\
\text { runup }\end{array}$ & $\begin{array}{l}\text { NOAA tides/ } \\
\text { surge, USGS } \\
\text { runup }\end{array}$ & $\begin{array}{l}\text { NOAA tides/ } \\
\text { surge, USGS } \\
\text { runup }\end{array}$ \\
\hline $\begin{array}{l}\text { Shellfish, finfish, and marine trust spe- } \\
\text { cies distribution and abundance }\end{array}$ & $\begin{array}{l}\text { NEAMAP plus } \\
\text { nearshore } \\
\text { New Jersey } \\
\text { State agency } \\
\text { and academic } \\
\text { surveys }\end{array}$ & $\begin{array}{l}\text { SEAMAP plus } \\
\text { nearshore } \\
\text { North Carolina } \\
\text { State and aca- } \\
\text { demic surveys }\end{array}$ & $\begin{array}{l}\text { SEAMAP plus } \\
\text { nearshore } \\
\text { North Carolina } \\
\text { State and aca- } \\
\text { demic surveys }\end{array}$ & $\begin{array}{l}\text { SEAMAP plus } \\
\text { nearshore } \\
\text { North Carolina } \\
\text { State and aca- } \\
\text { demic surveys }\end{array}$ & $\begin{array}{l}\text { SEAMAP plus } \\
\text { nearshore } \\
\text { South Carolina } \\
\text { State and aca- } \\
\text { demic surveys }\end{array}$ \\
\hline $\begin{array}{l}\text { Land cover (for example, orthopho- } \\
\text { tos, satellite, and unmanned aerial } \\
\text { systems) }\end{array}$ & N/A & N/A & N/A & N/A & N/A \\
\hline $\begin{array}{l}\text { Records of engineering/anthropogenic } \\
\text { modifications (for example, naviga- } \\
\text { tion channel maintenance, location// } \\
\text { timing/extent/volume of removal/ } \\
\text { placement) }\end{array}$ & N/A & N/A & N/A & N/A & N/A \\
\hline $\begin{array}{l}\text { Water quality (for example, tempera- } \\
\text { ture, salinity, turbidity, freshwater } \\
\text { discharge) }\end{array}$ & N/A & N/A & N/A & N/A & N/A \\
\hline $\begin{array}{l}\text { Indicator species nest surveys (for ex- } \\
\text { ample, sea turtles, Charadrius melo- } \\
\text { dus [Ord, 1824] [piping plovers], and } \\
\text { other shorebirds) }\end{array}$ & N/A & N/A & N/A & N/A & N/A \\
\hline Coastal vegetation characteristics & N/A & N/A & N/A & N/A & N/A \\
\hline $\begin{array}{l}\text { Marsh characteristics (for example, } \\
\text { elevation) }\end{array}$ & $\mathrm{N} / \mathrm{A}$ & N/A & N/A & N/A & N/A \\
\hline $\begin{array}{l}\text { Sediment biogeochemical characteris- } \\
\text { tics (for example, groundwater salin- } \\
\text { ity, nitrogen/phosphorus availability) }\end{array}$ & N/A & N/A & N/A & N/A & N/A \\
\hline Contaminant concentrations & N/A & N/A & N/A & N/A & N/A \\
\hline
\end{tabular}


Table 1.2. Derived physical metrics and availability at Coastal Barrier Resource System areas of interest.

[A round $\operatorname{dot}(\bullet)$ in the cell indicates that a U.S. Geological Survey data resource is available for that location and data type. If use of another source of data outside the U.S. Geological Survey is standard practice, that source is indicated in the cell. N/A, not available]

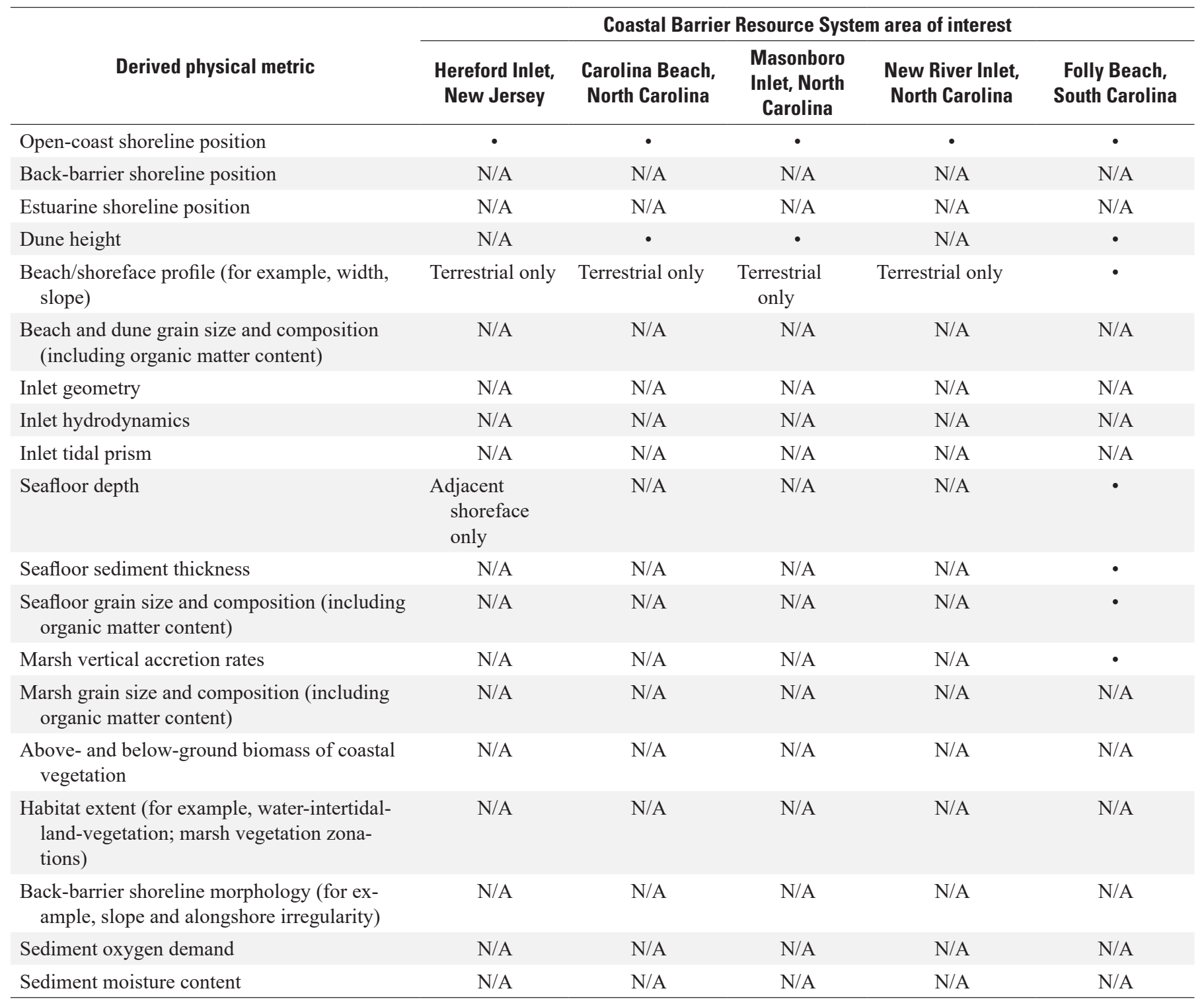


Table 1.3. Derived biological metrics and availability at Coastal Barrier Resource System areas of interest.

[A round dot $(\bullet)$ in the cell indicates that a U.S. Geological Survey data resource is available for that location and data type. If use of another source of data outside the U.S. Geological Survey is standard practice, that source is indicated in the cell. N/A, not available; USFWS, U.S. Fish and Wildlife Service]

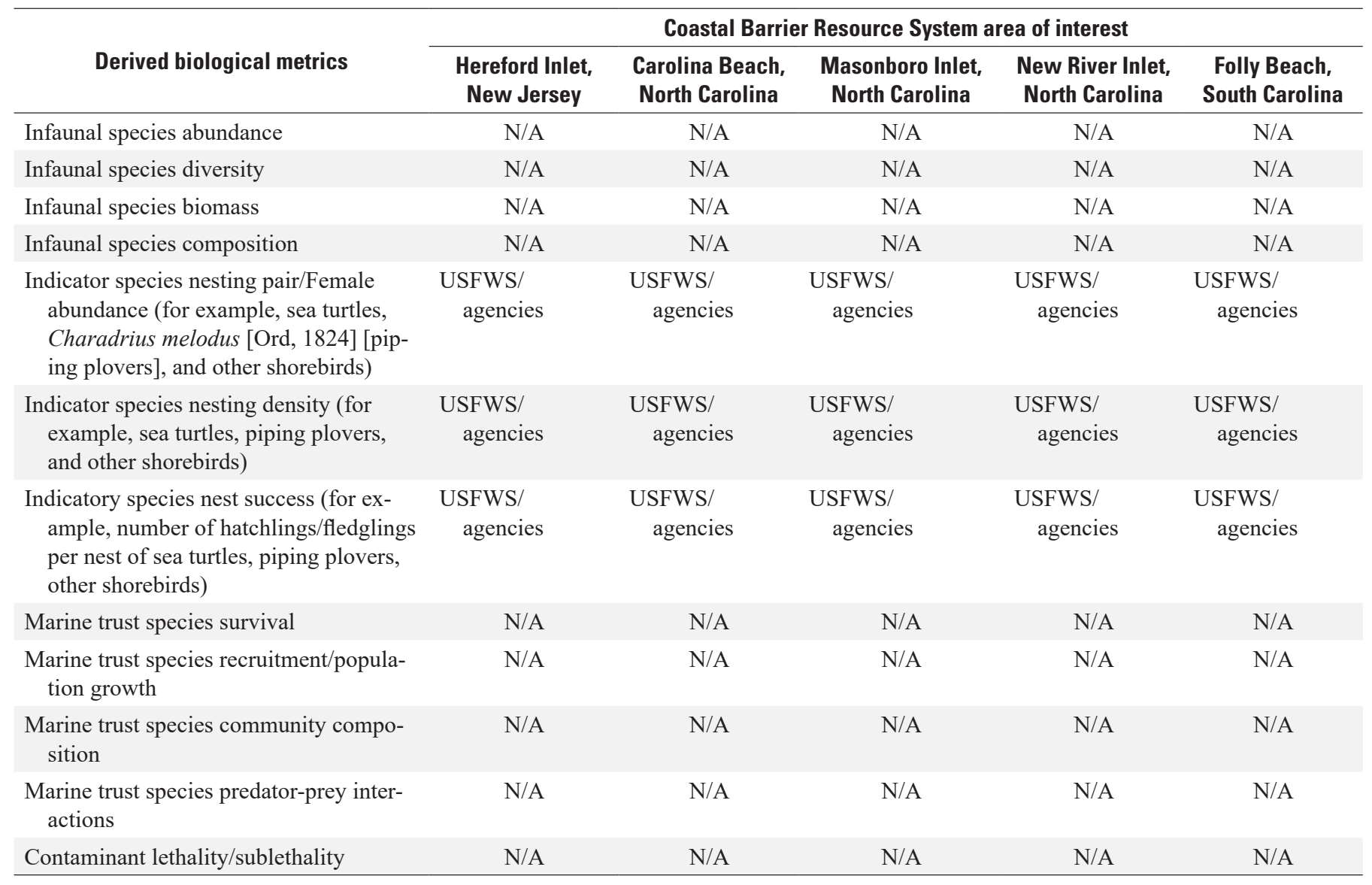


Table 1.4. Derived biogeochemical metrics and availability at Coastal Barrier Resource System areas of interest.

[A round dot $(\bullet)$ in the cell indicates that a U.S. Geological Survey data resource is available for that location and data type. If use of another source of data outside the U.S. Geological Survey is standard practice, that source is indicated in the cell. N/A, not available]

\begin{tabular}{|c|c|c|c|c|c|}
\hline \multirow[b]{2}{*}{ Derived biogeochemical metrics } & \multicolumn{5}{|c|}{ Coastal Barrier Resource System area of interest } \\
\hline & $\begin{array}{l}\text { Hereford } \\
\text { Inlet, New } \\
\text { Jersey }\end{array}$ & $\begin{array}{l}\text { Carolina Beach, } \\
\text { North Carolina }\end{array}$ & $\begin{array}{l}\text { Masonboro } \\
\text { Inlet, North } \\
\text { Carolina }\end{array}$ & $\begin{array}{l}\text { New River } \\
\text { Inlet, North } \\
\text { Carolina }\end{array}$ & $\begin{array}{l}\text { Folly Beach, } \\
\text { South Carolina }\end{array}$ \\
\hline $\begin{array}{l}\text { Hydraulic properties of subsurface (for example, } \\
\text { Carmen-Kozeny permeability, porosity, water } \\
\text { content, saturation) }\end{array}$ & N/A & N/A & N/A & N/A & N/A \\
\hline $\begin{array}{l}\text { Groundwater/porewater physical properties (for } \\
\text { example, salinity, temperature, dissolved oxygen, } \\
\text { pH, and reduction-oxidation potential) }\end{array}$ & N/A & N/A & N/A & N/A & N/A \\
\hline $\begin{array}{l}\text { Water-table elevation (potentiometric maps), dynam- } \\
\text { ics (tidal versus static), and type (freshwater or } \\
\text { saltwater) }\end{array}$ & N/A & N/A & N/A & N/A & N/A \\
\hline $\begin{array}{l}\text { Surface-water properties (for example, salinity, } \\
\text { temperature, dissolved oxygen, } \mathrm{pH} \text {, and reduction- } \\
\text { oxidation potential) }\end{array}$ & N/A & N/A & N/A & N/A & $\mathrm{N} / \mathrm{A}$ \\
\hline Groundwater models & N/A & N/A & N/A & N/A & N/A \\
\hline Flood frequency and duration & N/A & N/A & N/A & N/A & N/A \\
\hline
\end{tabular}

Table 1.5. Models and model inputs and availability at Coastal Barrier Resource System areas of interest.

[A round dot $(\bullet)$ in the cell indicates that a U.S. Geological Survey data resource is available for that location and data type. If use of another source of data outside the U.S. Geological Survey is standard practice, that source is indicated in the cell. N/A, not available]

\begin{tabular}{|c|c|c|c|c|c|}
\hline \multirow[b]{2}{*}{ Models and model inputs } & \multicolumn{5}{|c|}{ Coastal Barrier Resource System area of interest } \\
\hline & $\begin{array}{l}\text { Hereford } \\
\text { Inlet, New } \\
\text { Jersey }\end{array}$ & $\begin{array}{l}\text { Carolina Beach, } \\
\text { North Carolina }\end{array}$ & $\begin{array}{l}\text { Masonboro } \\
\text { Inlet, North } \\
\text { Carolina }\end{array}$ & $\begin{array}{l}\text { New River } \\
\text { Inlet, North } \\
\text { Carolina }\end{array}$ & $\begin{array}{l}\text { Folly Beach, } \\
\text { South Carolina }\end{array}$ \\
\hline Models & N/A & N/A & N/A & N/A & N/A \\
\hline Beach and dune change & $\mathrm{N} / \mathrm{A}$ & • & N/A & N/A & • \\
\hline Inlet evolution & $\mathrm{N} / \mathrm{A}$ & $\mathrm{N} / \mathrm{A}$ & $\mathrm{N} / \mathrm{A}$ & $\mathrm{N} / \mathrm{A}$ & $\mathrm{N} / \mathrm{A}$ \\
\hline Barrier island evolution & $\mathrm{N} / \mathrm{A}$ & $\mathrm{N} / \mathrm{A}$ & $\mathrm{N} / \mathrm{A}$ & N/A & $\mathrm{N} / \mathrm{A}$ \\
\hline Modeling inputs & N/A & $\mathrm{N} / \mathrm{A}$ & N/A & N/A & N/A \\
\hline Seamless topobathy digital elevation models & $\mathrm{N} / \mathrm{A}$ & $\mathrm{N} / \mathrm{A}$ & N/A & N/A & N/A \\
\hline Bedform dimensions & N/A & N/A & N/A & N/A & N/A \\
\hline $\begin{array}{l}\text { Model fore/hindcasts of meteorological, hydrody- } \\
\text { namic, and atmospheric conditions }\end{array}$ & N/A & N/A & N/A & N/A & N/A \\
\hline River discharge (where applicable) & $\mathrm{N} / \mathrm{A}$ & $\mathrm{N} / \mathrm{A}$ & $\mathrm{N} / \mathrm{A}$ & N/A & $\mathrm{N} / \mathrm{A}$ \\
\hline
\end{tabular}


For more information about this publication, contact:

Program Coordinator, USGS Coastal and Marine Hazards and Resources Program

12201 Sunrise Valley Drive

Reston, VA 20192

703-648-5953

For additional information, visit: https://www.usgs.gov/cmhrp

Publishing support provided by the

Reston and Rolla Publishing Service Centers 
